\title{
ANÁLISE CLADÍSTICA DOS BOUCHARDIINAE ALLAN, 1940 (BRACHIOPODA, TEREBRATELLIDAE): IMPLICAÇÕES SISTEMÁTICAS E PALEOZOOGEOGRÁFICAS
}

\author{
LUIZ HENRIQUE CRUZ DE MELLO
}

Orientador: Prof. Dr. Marcello Guimarães Simões

TESE DE DOUTORAMENTO

COMISSÃO JULGADORA

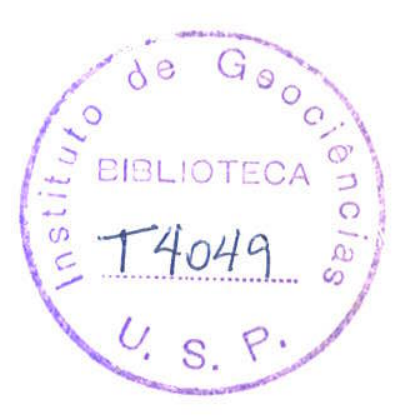

Nome

Presidente Prof. Dr. Marcello Guimarães Simões

Examinadores: Prof. Dr. Fernando Portella de Luna Marques

Prof. Dr. Setembrino Petri

Prof. Dr. Thomas Rich Fairchild

Assifatura

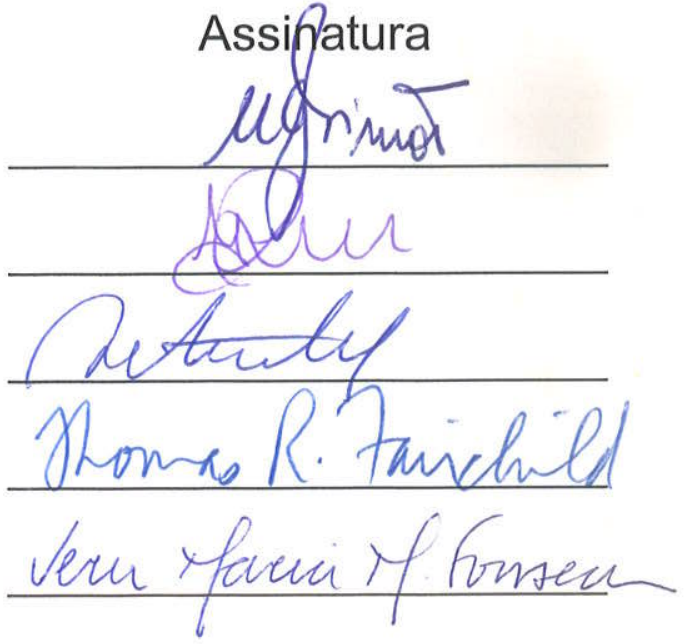

Prof $^{a}$. Dra . Vera Maria Medina da Fonseca

$$
\begin{aligned}
& \text { SÃO PAULO } \\
& 2004
\end{aligned}
$$




\title{
UNIVERSIDADE DE SÃO PAULO \\ INSTITUTO DE GEOCIÊNCIAS
}

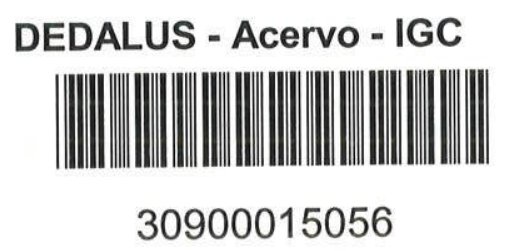

\section{ANÁLISE CLADÍSTICA DOS BOUCHARDIINAE ALLAN, 1940 (BRACHIOPODA, TEREBRATELLIDAE): IMPLICAÇÕES SISTEMÁTICAS E PALEOZOOGEOGRÁFICAS.}

Luiz Henrique Cruz de Mello

Orientador: Prof. Dr. Marcello Guimarães Simões

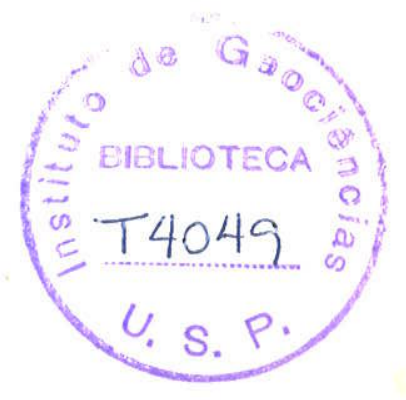

TESE DE DOUTORAMENTO

Programa de Pós-Graduação: Geologia Sedimentar

\author{
SÃO PAULO \\ 2004
}




\section{Mello, Luiz Henrique Cruz de}

Análise Cladística dos Bouchardiinae Allan, 1940 (Brachiopoda, Terebratellidae): implicações sistemáticas e paleozoogeográficas / Luiz Henrique Cruz de Mello.-- São Paulo, 2004.

$$
\text { xii + 181p.: il. }
$$

Tese (Doutorado): IGc/USP

Orient.: Simões, Marcello Guimarães

1. Brachiopoda. 2. Paleontologia. 3. Filogenia: Cladística. 4. Paleogeografia. 5. Cenozóico. I. Título

DOACAO IGC USP

Secióo Pós. Grad.

Data: $25 / 08 / 104$ 


\section{AGRADECIMENTOS}

Ao Prof. Dr. Marcello Guimarães Simöes pela correta orientação e atenção dispensadas durante a elaboração deste trabalho;

Ao Curso de Pós-Graduação do Instituto de Geociências da Universidade de São Paulo por toda infraestrutura colocada à disposição;

À Fundação de Amparo à Pesquisa do Estado de São Paulo FAPESP, pelo valioso auxilio financeiro (Processo n. 99/11431-3);

Ao Departamento de Zoologia da Universidade Estadual Paulista Campus de Botucatu, seus docentes e funcionários, por toda infraestrutura e colaboração proporcionadas;

Aos professores Dr. Luiz Eduardo Anelli (IGc/USP) e Dr. Fernando Portella de Luna Marques (IB/USP), pela atenção e valorosas contribuições prestadas no exame de qualificaçã̀o;

Às Instituições de Pesquisa e seus representantes, pelo acesso ao material indispensável à realização deste trabalho, a saber: Deparłamento de Geologia Sedimentar e Ambiental (IGc/USP), Prof. Dr. Luiz Eduardo Anelli; Museu Nacional do Rio de Janeiro, Prof. Dr. Antonio Carlos S. Fernandes e Profa. Dra. Vera Maria M. da Fonseca; Museo Argentino de Ciencias Naturales de Buenos Aires (Argentina), Dr. Horácio H. Camacho; Museo de Ciencias Naturales de La Plata (Argentina), Dr. Miguel O. Manceñido; Otago University (Nova Zelândia), Dra. Daphne E. Lee; South Australian Museum (Austrália), Dr. Thierry Laperousaz;

Aos profissionais dos laboratórios de Microscopia Eletrônica e de Petrografia Sedimentar (IGc/USP) pelos serviços prestados e ajuda, sempre que necessária; 
Aos professores do IBIUSP, Dr. Antonio Carlos Marques e Dr. Fernando Portella de Luna Marques, pelo valioso auxilio durante a análise cladística realizada;

À Fernanda Torello de Mello pelo inestimável auxílio atenção, em todos os momentos da realização deste trabalho:

As eficientes, atenciosas e dedicadas Ana Paula Cabanal e Magali Poli Fernandes Rizzo, funcionárias da seção de Pós-Graduação do Instituto de Geociências da Universidade de São Paulo pelo valoroso auxílio no decorrer dos anos;

A todas as demais pessoas que, direta ou indiretamente, contribuiram de alguma maneira para que este trabalho fosse concluido. 


\section{SUMÁRIO}

AGRADECIMENTOS

LISTA DE FIGURAS

RESUMO

ABSTRACT

1. INTRODUÇÃ̃O

2. OBJETIVOS

3. REVISÃO DOS CONHECIMENTOS

3.1. ESTADO ATUAL DO CONHECIMENTO SOBRE O GRUPO

3.1.1. Sobre a espécie Bouchardia rosea

3.1.2. Sobre os Bouchardiinae

3.1.3. Sobre a Familia Terebratellidae

3.2. A APLICAÇÃO DA METODOLOGIA CLADISTICA NA INVESTIGAÇÃO DAS RELAÇÖES DE PARENTESCO

ENTRE GRUPOS DE BRAQUIOPODES FOSSEIS E VIVENTES

3.2.1. A integração entre Cladística e Paleontologia

3.2.2. Panorama cladístico do Filo Brachiopoda 16

4. MATERIAIS E MÉTODOS

4.1. OBTENÇÃO E ORGANIZAC̣ÃO DO MATERIAL ANALISADO

4.1.1. Ob́tenção de espécimes no litoral brasileiro 19

4.1.2. Exame de coleçöes científicas _ 21

4.1.3. Contexto geológico das ocorrências fossiliferas dos Bouchardiinae analisados _ 21

4.1.4. Preparação do material ______ 25

4.1.5. Recuperação e registro das feiçôes morfológica 26

4.2. A METODOLOGIA CLADISTICA

4.3. ESTRUTURAÇÃO DO UNIVERSO DA ANALLISE _ 28

4.4. FASE PRÉ-MATRIZ: ANÁLISE MORFOLÓGICA _ 32

5. RESULTADOS 33

5.1. MATRIZ DE CARACTERES 33

5.2. DEFINIÇĀO E TRATAMENTO DOS CARACTERES __ 37

5.3. ANÁLISE NUMÉRICA _ 64

5.4. INTERPRETAÇÃO DA HIPÓTESE ESCOLHIDA 69

6. DISCUSSÃO

6.1. A HIPÓTESE DE TRABALHO _ 70

6.2. SOBRE O MONOFILETISMO DOS BOUCHARDIINAE ___ 74

6.3. CARACTERIZAÇÃO MORFOLÓGICA DO GÊNERO BOUCHARDIA 77

6.3.1. Aspectos ontogenéticos: desenvolvimento de estruturas morfológicas _ 77

6.3.2. Diferenciação morfológica das espécies______ 79

6.4. COMENTÁRIOS SOBRE A TAXONOMIA E SISTEMÁTICA DOS BOUCHARDIINAE___________ 83

6.5. CONSIDERAÇŌES SOBRE A EVOLUÇẢO E (PALEO)BIOGEOGRAFIA DOS BOUCMARDIDAE ___ 86

6.5.1. Aspectos gerais da (paleo)biogeografia dos braquiópodes Rhynchonelliformea 86

6.5.2. Influência do ambiente nos processos evolutivos 90

6.5.3. Evolução do oceano Atlântico ao longo do Cenozóico 93

6.5.4. Bouchardiinae e a evolução do Oceano Atlântico _ـ_ 115

7. CONCLUSÖES 132

8. SUGESTÕES DE INVESTIGAÇÕES FUTURAS ___ 136

ANEXOS

REFEREN NCIA BIBLIOGRAFICAS — 144

ESTAMPAS 


\section{Lista de Figuras}

Figura 1- Localização dos pontos de coleta de Bouchardia rosea no litoral dos estados de São Paulo (A) e Rio de Janeiro (B). Em A, pontos de coleta na regiáo de Ubatuba (pontos II e IV, segundo MANTELLATO \& FRANSOZO, 1999); em 8 , na região de llha Grande onde, segundo TOMMASI (1970), conchas de Bouchardia rosea são freqüentes. O ponto mais ao sul, a parit da itha, corresponde à estação 304 de Tommasi (1970) 20

Figura 2- Localização das principais ocorrências de Bouchardiinae e Anakineticinae (fósseis e viventes), grupos tipicos do hemisfério sul. Fonte: IHERing (1897), DOELLO-JURAdO (1922), ALlan (1940a, 1940b), FuRQUE \& CAMACHO (1949), ELLIOTT (1952), MARTINS (1952), LEVY (1964), RICHARDSON (1973b, 1987, 1991, 1994), MANCENIDO \& GRIFFIN (1988), MALUMIÁN (1990), CONCHEYRo (1991), MACKINNON ot al. (1993), MARTINEz (1994), CRAig (1999), CAMACHO ot al. (2000), KOWALEWSKI et al. (2002) e SiMÖES et al. (2004).

Figura 3- A-F, alguns exemplos de dobras alternadas, observados na comissura anterior das conchas de braquiópodes (em vista frontal e dorsal); A: rectimarginada, B: unisulcada, $C$ : parasulcada, D: uniplicada, E: plicosulcada, F: sulciplicada (segundo WiLliams ef al., 1997). 40

Figura 4 Tipos de bico (representados na horizontal) e pediculos (representados na vertical), e suas combinações observadas entre os táxons analisados (Caracteres 10 e 12).

Figura 5- A.F, Posicionamento do forame em relação ao bico e placas deltidiais em valvas ventrais de braquiópodes (caráter 11); A: anfitírido, B: submesotírido, C: permesotírido, D: hipotírido, E: mesotírido, F: epitírido; G: exemplo de braquiópode articulado com forame apical tendo a ancoragem como modo de vida inferido; H: exemplo de braquiópode articulado com forame ventral tendo a fixação como modo de vida inferido (segundo WILLIAMs et al., 1997) ........ 43

Figura 6- Septo na superfície interna da valva ventral (Caracteres 14 e15). Pode apresentar -se como uma estrutura de largura constante, como em Bouchardia zittelf (A), ou estrutura com extremidade anterior diferenciada, como observado em Bouchardia rosea (B), para acomodar, por exemplo, a extremidade elevada do septo mediano que se ergue a partir da valva dorsal

Figura 7- Visåo interna das valvas dorsais de Bouchardia rosea (A) e Australiarcula artesiana (B) ilustrando os dois padrões de relevo do assoalho das conchas (caráter 16). Explicaçäo: $B R_{-}$ braquidio; EP- espessamento posterior; PC- plataforma cardinal; PP. processo cardinal; Rec- relevo circular; Rer- relevo em forma de linhas inclinadas. Fonte- ElLLotT (1960).... 49

Figura 8- Tipos de septos medianos (caracteres 17 a 19) observados entre os táxons analisados. Em A, Anakinetica cumingi em posição de vida inferida, com algumas feiçôes morfológicas destacadas, tais como a forma do septo (anteriomente elevado, em azul) e sua posiçâo na concha, parte da musculatura (amarelo) e pediculo (marrom). Notar as diferenças entre os demais perfis observados: B) Magadinella woodsiana (septo medianamente elevado); C) Ausiraliarcula artesiana (septo anteriomente estendido); D) Aliquantula insolita (septo anteriormente rebaixado). Fonte- RICHARDSON (1994).

Figura 9- Esquema mostrando parte da anatomia interna de Rhynchonelliformea, ilustrando as bases dos septos medianos (em azul; caráter 21) com largura constante (em A) e septos que se estreitam anteriormente $(B$ e $C)$. Estão representados, também, os tipos de encontro da extremidade posterior do septo mediano com a plataforma cardinal (caráter 21), sendo bifido (em C) ou não (B). Fonte- WILLLAMS et al. (1997c)......

Figura 10- Caracterização dos braquídios observados entre os táxons analisados (Caracteres 24 a 29). Em A, braquidios representando padröes encontrados em Anakinetica cumingi (A3), em forma de laço, e Australiarcula artesiana (A1) e Bouchardia rosea (A2), ambas com braquídio simples, sem formar laço. Em $B$, ramos ascendentes dos braquídios com a região posterior livre (B1), como encontrado nos Bouchardinae, ou regiäo posterior unida, formando laço (B2), como em Anakinetica cumingi. Em $\mathrm{C}$, ramos descendentes dos braquídios, que podem estar fixados apenas ao septo mediano, como em Malleia portlandica (C2), ou estar fixados ao septo e a plataforma cardinal (crura), como em 
Australiarcula artesiana (C1) e Anakinetica cumingi (C3). Em D, tipos de fixaçăo dos ramos ascendentes ao septo mediano onde podem estar fixados à sua extremidade, como em Bouchardia rosea (D2) e Anakinetica cumingi (D3), ou em uma posição intermediária entre o topo e a base do septo, como observado em Australiarcula artesiana (D1). Explicaça: BR- braquídio; EP- espessamento posterior; PC- plataforma cardinal; PR- processo cardinal; $\mathrm{RA}$ - ramo ascendente; $\mathrm{RD}$ - ramo descendente; $\mathrm{SM}$ - septo mediano.

Figura 11. Representação esquemática da estrutura da cardinália dos Rhynchonelliformea, com seus elementos individualizados (caráter 30). Fonte. WLLLIAMs et al. (1997).

Figura 12. Vista parcial das regiöes posteriores de conchas de braquiópodes: estrófica (A) e astrófica (B) (caráter 31). Fonte- WiLkiams et al. (1997).

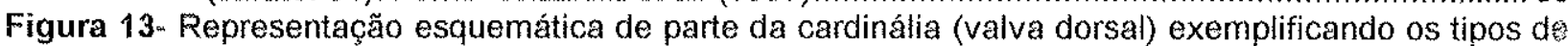
processo cardinal (caráter 32); A: bilobado (boucardineos), B: bilobado com sulcos em forma de ' $V$ ' invertido (Bouchardinae), $C$ : trífido (Anakineticinae), $D$ : transverso (Terebratellinae). Fonte- RICHAROSON (1991).

Figura 14: Interacóes entre estruturas da charneira (caráter 34) de Bouchardia rosea. Em A e C, visão interna das valvas ventral (VV) e dorsal (VD) (respectivamente), com representação das principais estruturas da charneira e que participam da articulação entre as valvas. Notar que, além de dentes e fossetas, a região conta com sulcos (S1,S2, S3, S4) e cristas (C1, C2, C3, C4) que interagem, reforçando a união entre as valvas. Essa interação pode ser meihor observada em $B$, representando um corte transversal $\left(X-Z\right.$ e $\left.X^{\prime}-Z^{\prime}\right)$ na região posterior de um especime articulado fechado

Figura 15- Esquema simplificado ilustrando parte da anatomia interna dos Rhynchonelliformea, com destaque para o número e posicionamento das cavidades na parede anterior da cardinália (caracteres 37 e 38 ) e a relação dessas feições com outras estruturas morfológicas (e.g., septo, cardinália).

Figura 16. Diagrama exemplificando o crescimento do lofóforo de braquiópodes atuais (caráter 39); cada representação mostra uma visão, em perspectiva, do eixo braquial; as setas ao longo dos eixos braquiais indicam o sentido de transporte de partículas de comida até a boca, indicada em vermelho. Abaixo, detalhes da anatomia de um lofoforo plectolofo e seu braquidio. Fonte- WILLAAMs et al. (1997).

Figura 17- Conchas, pediculos e modo de vida (caracteres 40 ao 42) atribuidos a Terebratella (A; para comparação), Magadinella (B) e Anakinetica (C). De cima para baixo estão representadas as conchas em vista dorsal $(A, B, C)$, o pedículo em relação ao bico $(D, E, F$, ) e o sistema pedicutar e modo de vida (i.e., fixo ou livre; $G, H, 1$ ) dos táxons. Os músculos adjustores (ventrais e dorsais) e pediculares médios unem as duas valvas aos pediculos, sejam eles transitivos $(G)$ ou inertes $(H, I)$. Setas maiores indicam a movimentação geral das conchas proporcionadas pela contração dos músculos (setas menores). Fonte- RicHARDSON (1981b)

Figura 18- Espessamento de parte do assoalho da valva dorsal, margeando a cicatriz do músculo didutor em Australiarcula artesiana (caráter 43). Em A, visăo interna da valva dorsal, onde se nota a posição do reforço da cicatriz muscular em relação ao septo mediano. Em B, corte transversal evidenciando, a partir da margem $(m)$ em direção ao centro da concha, a posiçăo do reforço (r), da cicatriz do músculo didutor (c) e do septo mediano (s). FonteELLIOTT (1960)

Figura 19- Cladogramas de consenso estrito $(A)$ e semi-estrito $(B) \quad(L=98 ; C l=0,490 ; R l=0,745 ; R C=$ $0,365)$, com diferentes topologias, obtidos a partir da análise de máxima parcimónia para caracteres não ordenados (veja detalhes da análise no texto). Cores indicam táxons do grupo interno (verde) e externo (laranja).... .68

Figura 20- Cladogramas de consenso estrito $(A)$ e semi-estrito $(B) \quad(L=98 ; C l=0,741 ; R I=0,889 ; R C=$ 0,635 ), com diferentes topologias, obtidos a partir da análise de pesagem sucessiva para caracieres näo ordenados (veja detalhes da análise no texto). Cores indicam táxons do grupo interno (verde) e externo (laranja)... 66 
Figura 21- Cladograma de consenso semi-estrito obtido a partir de análise de pesagem sucessiva (veja explicação no texto) de caracteres não ordenados, por algoritmo exato ('branchmand. bound'), mostrando a distribuição dos caracteres e seus estados. Em azul estão indicados os números dos nos dos diferentes ramos (veja Anexo 2)

Figura 22- Cladogramas de consenso de maioria (A) obtido após análise de "bootstrap", com os valores dos clados indicados em vermelho; cladograma de consenso semi-estrito (B), com indicação dos valores do índice de decaimento de Bremer indicados em azul. 68

Figura 23. Esquema mostrando combinação de informações filogenéticas (cladograma), temporal e paleogeográfica, para os 22 táxons envolvidos na análise...

Figura 24- Distribuição dos Bouchardinae e Anakineticinae durante o Cretáceo inferior e superior, com base em indicações de literatura, e incluindo informações sobre as condiçôes climáticas dominantes em cada área. Com reforco tracejado (azul e vermetho) os limites das zonas temperadas frias e quentes no hemisfério sul. Mapas e legenda modificados do original de "Paleomap Project" (SCOTESE, 2000; www.scotese.com); setas laranja indicam sugestăo de deslocamento do Bouchardinae primitivos a partir do registro inicial na Austrália.

Figura 25- Distribuiçăo dos Bouchardiinae e Anakineticinae durante o Paleoceno e Eoceno inicial, com base em indicações de literatura, e incluindo informações sobre as condições climáticas dominantes em cada área. Com reforço tracejado (azul e vermeho) os timites das zonas temperadas frias e quentes no hemisfério sul. Mapas e legenda modificados do original de "Paleomap Project" (SCOTESE, 2000; www.scotese.com); setas verde e vermelha indicam deslocamento das espécies de Bouchardia para o norte e para o sul, respectivamente, a partir das espécies que habitaram a região da Patagônia no Paleoceno; setas amareias indicam que Bouchardia antarctica ficou restrita à Península Antártica.

Figura 26- Distribuição dos Bouchardiinae e Anakineticinae durante o Eoceno médiolfinal e Mioceno, com base em indicações de literatura, e incluindo informações sobre as condiçōes climáticas dominantes em cada área. O intervalo total de duração das espécies pode ser obtido nos Quadros 1 e 2 . As espécies representadas no Mioceno teriam vivido durante $o$ intervalo Oligoceno-Mioceno. Com reforço tracejado (azul e vermelho) os limites das zonas temperadas frias e quentes no hemisfério sul. Mapas e legenda modificados do original de "Paleomap Project" (SCOTESE, 2000; www.scotese,com); seta verde indica deslocamento das especies de Bouchardia para o norte; setas amarelas indicam que Bouchardia antarctica ficou restrita à Peninsula Antártica.

Figura 27- Distribuição espacial de elementos do gênero Bouchardia (em amarelo), em 3 momentos ao longo do Cenozóico (a- Paleógeno, b- Neógeno, c- Recente). As setas vermelhas indicam a migraçăo rumo ao norte, como sugerido por MANCENIDO \& GRIFFIN (1988); setas negras indicam a movimentaçăo para norte e sul dos táxons, representando passos intermediários dentro do padrão geral; interrogação representa a ausência de registro de Bouchardiinae na Antártica após o desaparecimento de Bouchardia antarctica. 124

Figura 28- Reconstrução paleogeográfica de parte da América do Sul mostrando a distribuição espacial de 4 espécies de Bouchardia no início do Eoceno. Notar a presença de uma grande região emersa (sedimentação não marinha), pode ter influenciado na distribuição desses táxons. Veja comentários no texto. Legenda: Areas escuras sedimentação não marinha; áreas brancas $=$ terras emersas; áreas cinza-claro= sedimentaçẵo marinha; Fonte: ULIANA \& BIDDLE (1988) 


\section{RESUMO}

Foi realizada a investigação cladística dos Bouchardinae (Brachiopoda, Terebratellidae), braquiópodes comuns no registro fóssil cenozóico da Argentina, Uruguai, Antántica, Nova Zelândia e Austrália, bem como, atualmente, na plataforma brasileira. A história geológica do grupo remete ao limite Cretáceo/Terciário. O estudo teve como objetivo central demonstrar que a análise das feições morfológicas internas e externas de conchas fósseis e atuais de braquiópodes possibilita a realização de estudos cladísticos. Para atingir esse objetivo foram avaliadas as relações de parentesco e a sistemática dos Bouchardinae (Família Terebratellidae), bem como o escopo de seus gêneros. A análise envolveu os gêneros Bouchardia, Bouchardiella, Neobouchardia e Malleia, tendo como grupo externo Adnatida, Aliquantula, Anakinetica, Australiarcula, Elderra, Magadina, Magadinella, Parakinetica, Pilkena, Pirothyris e Rhizothyris. A análise contou com 22 táxons (grupo interno e externo) e 43 caracteres. O cladograma $(C l=0,714 ; \mathrm{Rl}=0,889 ; \mathrm{RC}=0,635)$ escolhido como proposta de trabalho apresentou topologia bem resolvida, com dois clados bem distintos. Um deles, reúne todos os Bouchardiinae, tendo Malleia portlandica como táxon basal, o outro agrupa os Anakineticinae, incluindo Australiarcula artesiana. Entre os Bouchardiinae, a única indefinição ficou por conta das espécies Bouchardia rosea e Bouchardia transplatina, o que reforça a suspeita de serem sinônimos. Entre os táxons do grupo externo destaca-se a posição basal de Australiarcula artesiana.

Os resultados obtidos permitiram considerar que: a) a análise morfológica interna e externa de conchas de braquiópodes fósseis e viventes fornece dados morfológicos adequados à análise cladistica; b) existem 2 clados distintos no cladograma escolhido como hipótese de trabalho, um representativo dos Bouchardinae e outro dos Anakineticinae, incluindo Australiarcula artesiana, o que esclarece, de momento, a dúvida quanto a posição desse gênero; c) a condição dos táxons enquanto gêneros válidos e distintos foi reavaliada e foi proposta a sinonímia entre Bouchardiella e Neobouchardia, em favor da primeira; d) Bouchardia rosea e Bouchardia transplatina não apresentaram diferenças morfológicas significativas e, somando-se a isso, sua posição na topologia obtida sugere sinonímia entre os táxons, em favor de Bouchardia rosea (Mawe), 1823; e) o monofiletismo dos Bouchardinae foi corroborado; f) foram confirmadas as 3 sinapomorfias já sugeridas pela literatura, isto é, espessamento 
posterior, processo cardinal em forma de ' $V$ ' e braquidio incompleto; $\mathbf{g}$ ) a topologia obtida suporta a sugestão de que Bouchardia rosea e Anakinetica cumingi apresentam morfologia semelhante por compartilharem modos de vida similares e não por parentesco próximo; h) a proposta de classificação mais adequada para os Bouchardinae parece combinar opiniões de RICHARDSON (1994) e BRUNTON (1996), tornando válida a Subtamilia Bouchardinae, composta por Bouchardia, Bouchardiella e Malleia; i) a despeito da falta do registro estratigráfico de parte da história evolutiva dos Bouchardinae, foi identificada a evolução em paralelo de dois grupos, um deles, de duração mais curta e restrito à Austrália e Nova Zelândia, formado por Bouchardiella cretacea, Bouchardiella (Neobouchardia) minima e Malleia portlandica, e outro, formado por Bouchardiella patagonica, Bouchardiella jorgensis e as espécies de Bouchardia, persistindo até o Recente, tendo se desenvolvido entre a Península Antártica e a costa leste da América do Sul; j) além do padrão geral de migração das espécies de Bouchardia para o norte, foram identificados alguns passos intermediários nesse modelo, principalmente quanto à migração de Bouchardia da Terra do Fogo (Argentina) para a Península Antártica; assim, o modelo de "contínua migração das espécies para o norte, sem retenção de suas localidades prévias" estaria parcialmente descartado, não invalidando, contudo, o padrão geral de migração para o norte. 


\begin{abstract}
A cladistic investigation of Bouchardinae (Brachiopoda, Terebratellidae) was carried out. These brachiopods are common in the Cenozoic fossil record of Argentina, Uruguay, Antarctica, New Zealand, Australia, as well as in the Brazilian shelf. The geological history of the group can be tracked back until de Cretaceous/Tertiary boundary. The main goal of present study was to verify the hypothesis that morphological analysis on internal/external features of extinct/extant brachiopod shells allow us to proceed a cladistic analysis for the group. In order to achieve this goal, the relationships and systematic of the Bouchardiinae (Family Terebratellidae) were evaluated, as well as the scope of their genera. The cladistic analysis involved the ingroup taxa Bouchardia, Bouchardiella, Neobouchardia, Malleia, having Adnatida, Aliquantula, Anakinetica, Australiarcula, Elderra, Magadina, Magadinella, Parakinetica, Pilkena, Pirothyris, Rhizothyris, as the out-group. A total of 22 taxa and 43 characters were evaluated. The cladogram used as work hypothesis $(\mathrm{Cl}=0,714 ; \mathrm{RI}=0,889 ; \mathrm{RC}=$ $0,635)$ presented a well resolved topology with 2 distinct clades; one with all Bouchardinae, being Malleia portlandica the basal taxon; the other presented all Anakineticinae, including Australiarcula artesiana. The only unresolved relationship was between Bouchardia rosea and Bouchardia transplatina, suggesting that both taxa are synonymous. Among the out-group taxa the basal position of Australiarcula artesiana is worthy to mention.
\end{abstract}

The results allow us to consider that: a) the morphological analysis of internal/external features of extinct/extant brachiopod shells supply important morphological data for cladistic analysis; b) there are 2 distinct clades that are representative of the Bouchardiinae and Anakineticinae, the later including Australiarcula artesiana, bringing some new evidences on their systematic position; $c$ ) the status of the genera, while valid and distinct taxa was re-evaluated, and resulted on the proposition of the synonymy between Bouchardiella and Neobouchardia, favoring the former; d) Bouchardia rosea and Bouchardia transplatina did not share significant morphological differences to keep them as distinct taxa. Thus the synonymy in favor of Bouchardia rosea (Mawe), 1823 is proposed; e) the monophyletic status of Bouchardiinae was corroborated; f) 3 synapomorphies ever suggested by the literature were confirmed, as follow: posterior thickening of the shell, "V" shaped cardinal process, 
and incomplete brachidia; g) based on the topology the condition of Bouchardia rosea and Anakinetica cumingi as distinct taxa is reinforced. Thus, their morphological similarities are much more due to similar ecological pressures (or mode of life) than to their close relationships; $\boldsymbol{h}$ ) the classification of bouchardiid brachiopods seems to combine the suggestions of RICHARDSON (1994) and BRUNTON (1996), validating the Subfamily Bouchardinae, with Bouchardia, Bouchardiella, and Malleia; i) despite of the lack of stratigraphic record of part of bouchardiid history, the parallel evolution of 2 groups was identified; one presenting a short interval, restricted to Australia e New Zealand, and corresponding to Bouchardiella cretacea, Bouchardiella (Neobouchardia) minima e Malleia portlandica, and the other group corresponding to Bouchardiella patagonica, Bouchardiella jorgensis, and species of Bouchardia, with an almost continuous record since the Cretaceous. This group evolved around the Antarctic Peninsula and east coast of southern South America; $\mathbf{j}$ ) in spite the general north migration pattern presented by species of Bouchardia, some intermediate steps could be recognized, specially the migration of Bouchardia toward the Tierra del Fuego coast (Argentina) and Antarctic Peninsula. Consequently, the previous pattern of continuous northward migration of bouchardiid species without the retention of previous locations is only partially supported by the current data. 


\section{INTRODUÇÃO}

Os braquiópodes do subfilo Rhynchonelliformea' são invertebrados marinhos com abundante registro fóssil fanerozóico consistindo, muitas vezes, exemplo típicos de fósseis-vivos (Williams et al., 1997c; BRENCHLEY \& HARPER, 1998). A literatura mostra que, pelo menos desde o século 19, esses organismos têm sido objeto de estudo de paleontólogos e neontólogos, embora as investigações tenham se intensificado a partir da década de 1970 (WILLIAMS et al., 1997c). Como resultado, uma ampla gama de informações morfológicas, fisiológicas e moleculares está disponível (e.g., RUDWICK, 1970; DUtRo \& BOARDMAN, 1981; MACKINNon et al., 1991; COOPER \& JIN, 1996; WILliams et al., 1997c; SAVAZZI, 1999). Aspectos ecológicos e embriológicos têm sido, no entanto, pouco explorados (e.g., WILLIAMS et al., 1997c).

Os táxons atribuídos à Subfamília Bouchardiinae (Família Terebratellidae), como definido por RICHARDSON (1994), constituem o foco central das investigações aqui tratadas e, embora a história geológica desse grupo possa ser resgatada desde o limite Cretáceo-Paleoceno (MANCEÑIDO \& GRIFFIN, 1988; RICHARDSON, 1994), pouco se conhece sobre sua (paleo)biologia e evolução, quando comparado a outros grupos de braquiópodes (e.g., Lingulidae, Terebratellinae; WILLIAMS et al., 1997c). A despeito disso, sua presença em concentrações fossiliferas ricas em conchas de braquiópodes do Terciário do Uruguai (e.g., MARTínez \& VERDE, 1992; MARTínez, 1994) e Argentina (e.g., MANCEÑIDO \& GRIFFIN, 1988; CAMACHO et al., 2000), e a ocorrência comum de Bouchardia rosea nos sedimentos de fundo da plataforma continental e talude das regiões sul e sudeste do Brasil (TOMMASI, 1969, 1970a; KoWALEWSKI et al., 2000a, 2000b, 2000c; Mello \& SiMÕES, 2000; SimÕES \& KoWALEWSKI, 2000; SIMÕEs et al., 2000b, 2000c, 2004), constituem importantes fontes de dados tafonômicos, (paleo)biológicos, (paleo)ecológicos e evolutivos para o grupo.

$\mathrm{Em}$ estudos com organismos viventes fica evidente a vantagem decorrente da possibilidade de utilização de uma ampla variedade de informações (e.g., morfológicas, embriológicas), embora os espécimes e suas características estejam sendo observados em uma estreita fatia de tempo (CARLSON, 1995). Esse quadro pode ser complementado através dos fósseis que, a despeito da inerente limitação de dados

\footnotetext{
1 Ao longo do texto, o termo Rhynchonellifomea será utilizado como sinònimo de braturiojodes atticularlos, aceitando se a sugestão de KOWALEWSKI et al. (2002)
} 
(e.g., embriológicos, fisiológicos), contribuem para uma visão mais ampla das modificações, especialmente morfológicas, que ocorreram através do tempo. Desta forma, abordagens integrando essas informações, como desenvolvido no presente estudo, fornecem uma idéia mais precisa sobre a evolução de um dado grupo (CARLSON, 1995). De fato, os Bouchardinae (sensu RICHARDSON, 1994) e prováveis formas afins (e.g., Terebratellinae, Anakineticinae), que contam com representantes fósseis e viventes, apresentam uma ampla base de informações morfológicas, ecológicas e biogeográficas (WILLIAMS et al., 1997c), superando, em muito, os dados existentes para qualquer outro grupo de Rhynchonelliformea vivente (veja revisão em RICHARDSON, 1997a, 1997b).

O exame atento das informações disponiveis sobre os Bouchardiinae e, de maneira geral, sobre os demais Terebratellidae, permite a identificação de diversos aspectos da biologia e evolução de seus membros que demandam investigações adicionais. Faz parte dessa relação, por exemplo, a ausência de embasamento cladístico nas classificações propostas, até o momento, para o grupo (veja RICHARDSON, 1991, 1994; WILLIAMS et al., 2000b), mesmo transcorridos mais de 50 anos da proposição e desenvolvimento da metodologia cladística (HENNIG, 1950, além de atualizações e complementos posteriores). Tendo ciência do quadro exposto até aqui, a presente pesquisa pretende contribuir para uma caracterização morfológica mais precisa dos gêneros e espécies de Bouchardinae, servindo de base para a determinação das relações de parentesco entre seus membros, bem como deste grupo com os demais táxons da Familia Terebratellidae (sensu RichARDSON, 1994), fundamentada na metodologia cladística. A partir dos resultados obtidos serão avaliados aspectos evolutivos, paleoambientais e paleozoogeográficos que envolvem o grupo em questão, tendo como cenário o Oceano Atlântico Sul, durante o Cenozóico. 


\section{OBJETIVOS}

A presente pesquisa visa contribuir para o esclarecimento de diversos aspectos nos campos da sistemática, evolução e (paleo)zoogeografia dos braquiópodes Bouchardiinae, ao longo do Cenozóico, tendo como objetivo geral o estudo cladístico desse grupo de organismos (Terebratellidae, Bouchardiinae) de ocorrência comum, sobretudo, no Cenozóico do Brasil, Uruguai e Argentina. Para cumpri-lo, os seguintes objetivos específicos foram estabelecidos;

a) avaliação do escopo dos gêneros atribuídos aos Bouchardiinae;

b) avaliação da consistência da Subfamília Bouchardiinae;

c) avaliação do "status" da Subfamília Bouchardiinae;

d) confronto dos esquemas de classificação existentes para o grupo (e.g., RicHARDSON, 1973b, 1991, 1994; WILLIAMS et al., 2000b; MACKINNON \& LEE, no prelo) com os resultados obtidos;

O cumprimento dos objetivos acima implica, por sua vez, na verificação da hipótese de que, mesmo com a perda das partes moles, uma regra no registro paleontológico, o exame da morfologia interna e externa das conchas de braquiópodes permite a obtenção de dados morfológicos adequados à análise cladística, sendo, portanto, de grande interesse para a análise do registro fóssil, inclusive Paleozóico. 


\section{REVISÃO DOS CONHECIMENTOS}

\subsection{ESTADO ATUAL DO CONHECIMENTO SOBRE O GRUPO}

\subsubsection{Sobre a espécie Bouchardia rosea}

Bouchardia rosea é um pequeno braquiópode articulado (cerca de $20 \mathrm{~mm}$ de comprimento) (Estampa 2), de coloração rósea, algumas vezes delicadamente listrado de branco, de ocorrência comum na costa brasileira, entre o litoral do Espírito Santo e Paraná (Tomması, 1969, 1970a, 1970b; NonAto \& PetTI, 1996; NonAto, 1999; KOWALEWSKI et al, 2000a, 2000b, 2000c; MELlo \& SiMÖEs, 2000; SiMÕES \& KOWALEWSKI, 2000; SIMÕEs et al, 2000b, 2000c, 2004). Membros desse gênero têm um registro quase contínuo desde o Eoterciário. De fato, segundo MANCEÑIDO \& GRIFFIN (1988), que estudaram a distribuição temporal de Bouchardia, a espécie mais antiga é Bouchardia conspicua, encontrada em sedimentos do Cretáceo (Maastrinchiano)Paleoceno da Argentina.

Referências taxonômicas mais recentes para o gênero Bouchardia podem ser encontradas no trabalho de MANCEÑIDO \& GRIFFIN (1988), sintetizando as informações até então dispersas na literatura. De caráter bastante geral, os autores não promoveram uma revisão taxonômica, limitando-se a aceitar, ou não, sinonímias previamente sugeridas e atribuindo 6 espécies ao gênero. Importante, ainda, é o fato de que, desde o trabalho de LEVY (1964), nenhuma revisão taxonômica foi realizada para o gênero e, portanto, as sinonímias adotadas por MANCEÑIDO \& GRIFFIN (1988) necessitam ser avaliadas. Mais detalhes sobre a taxonomia e sistemática de Bouchardia serão apresentados adiante (Item 3.1.2.).

A despeito de sua óbvia importância biológica e geológica, estudos com Bouchardia rosea têm sido claramente negligenciados, a não ser pelas investigações tafonômicas que tiveram, recentemente, reconhecido avanço (e.g., TORELLo et al, 2000, 2001, 2002a, 2002b, 2003a, 2003b; SIMÕEs et al., 2001; SIMÕES \& KOWALEWSKI, 2002, 2003; KOWALEWSKI et al., 2002; RODLAND et al., 2002, 2003; TORELLO \& SIMÕES, 2003; BARBOUR WOOD et al., 2003; CARROLL et al, 2003). Embora conhecida desde 1846-1847 com o estudo de G. B. Sowerby, uma descrição detalhada da morfologia, tanto das partes duras quanto moles, e da anatomia funcional da espécie foram apresentadas apenas na metade da década de 1990, principalmente através do estudo 
de BRUNTON (1996) (mas veja também RICHARDSON, 1994, 1997b; BRUNTON et al, 1996; WILliams et al., 1997c). No entanto, merece destaque o fato de que tais estudos foram realizados com base em um número reduzido de exemplares (menos de 5) sendo que, a despeito da reconhecida importância, séries ontogenéticas completas não estavam disponiveis (BRUNTON, 1996).

No campo da ecologia, o conhecimento existente para o grupo, até o início deste projeto, esteve mormente fundamentado nos estudos realizados por TOMMASI (1969, 1970a, 1970b) para Bouchardia rosea. Contudo, de acordo com investigações mais recentes (veja KOWALEWSKI et al., 2000c, 2002) o trabalho de TOMMASI (1970a) encontra-se desatualizado, principalmente, por trazer observações pontuais no espaço e no tempo. É interessante notar que MANCENIDO \& GRIFFIN (1988) assumiram que os atributos ecológicos propostos por TOMMASi (1970a), mantiveram-se aproximadamente os mesmos através do Cenozóico, para as espécies do mesmo gênero e, apoiados nesse ponto de vista, realizaram importantes conclusões sobre a evolução do oceano Atlântico Sul (e.g., rearranjo dos padrões de circulação oceânica), nesse período.

Pelo exposto acima, parece óbvio que a taxonomia, sistemática, morfologia, história evolutiva e, em parte, ecologia de Bouchardia rosea, constituem temas ainda inadequadamente investigados. Ao mesmo tempo, o estudo da origem, evolução e relações de parentesco de Bouchardia rosea com outros Terebratellidae constitui parte importante do entendimento da evolução e paleobiogeografia do Atlântico Sul, durante o Cenozóico. Os constantes achados de exemplares (vivos ou não) dessa espécie, nos sedimentos de fundo na plataforma continental do sudeste brasileiro, forneceram material para o estudo morfológico realizado no presente trabalho, envolvendo comparação com as demais espécies do gênero.

\subsubsection{Sobre os Bouchardinae}

Embora Anomia rosea fosse conhecida desde 1823, a descrição de Bouchardia, e a conseqüente designação dessa espécie como tipo do gênero (Bouchardia rosea), foi feita em 1850 por T. Davidson. A partir do trabalho de IHERING (1897), até a metade do século $X X$, muitas espécies foram atribuídas ao gênero (veja resumo no Quadro 1). De acordo com a síntese apresentada por MANCEÑIDO \& GRIFFIN (1988), apenas 6 são consideradas válidas (veja Quadro 1). 
QUADRO 1- RELAÇÃO DAS ESPÉCIES PROPOSTAS PARA O GÊNERO BOUCHARDIA, COM DESTAQUE PARA AS 6 ESPÉCIES CONSIDERADAS COMO VÁLIDAS $\left(^{*}\right)$, E AS SINONÍMIAS PROPOSTAS

\begin{tabular}{|c|c|c|c|c|}
\hline Autor & Espécie & Localidade Tipo & Idade & Designação Atual \\
\hline DAVIDSON, 1850 & B. rosea & Brasil & Recente & Bouchardia rosea* \\
\hline REEVE, 1861 & $\begin{array}{l}\text { B. cumingi } \\
\text { B. fibula } \\
\text { B. tulipa }\end{array}$ & $\begin{array}{l}\text { Nova Zelândia } \\
\text { Austrália } \\
\text { Austrália }\end{array}$ & $\begin{array}{l}\text { Eoceno } \\
\text { Eoceno } \\
\text { Eoceno }\end{array}$ & $\begin{array}{l}\text { Anakinetica cumingi } \\
\text { Anakinetica cumingi }\end{array}$ \\
\hline IHERING, 1897 & B. zitteli & Patagônia Argentina & Plioceno-Mioceno & Bouchardia zitteli* \\
\hline IHERING, 1903 & $\begin{array}{l}\text { B. patagonica } \\
\text { B. jorgensis }\end{array}$ & $\begin{array}{l}\text { Patagônia Argentina } \\
\text { Argentina }\end{array}$ & $\begin{array}{l}\text { Paleoceno } \\
\text { Paleoceno }\end{array}$ & $\begin{array}{l}\text { Bouchardiella patagonica } \\
\text { Bouchardiella jorgensis }\end{array}$ \\
\hline Hutton, 1905 & $\begin{array}{l}\text { B. rhizoida } \\
\text { B. tapirina }\end{array}$ & $\begin{array}{l}\text { Nova Zelândia } \\
\text { Nova Zelândia }\end{array}$ & $\begin{array}{l}\text { Mioceno } \\
\text { Mioceno }\end{array}$ & $\begin{array}{l}\text { Rhizothyris rhizoida } \\
\text { Aliquantula tapirina }\end{array}$ \\
\hline IHERING, 1907 & B. transplatina & Argentina & Miocene & Bouchardia transplatina* \\
\hline BUCKMAN, 1910 & $\begin{array}{l}\text { B. angusta } \\
\text { B. antarctica } \\
\text { B. attenuata } \\
\text { B. elliptica } \\
\text { B. ovalis } \\
\end{array}$ & $\begin{array}{l}\text { Antártica } \\
\text { Antártica } \\
\text { Antártica } \\
\text { Antártica } \\
\text { Antártica }\end{array}$ & $\begin{array}{l}\text { Plioceno-Mioceno } \\
\text { Plioceno-Mioceno } \\
\text { Plioceno-Mioceno } \\
\text { Plioceno-Mioceno } \\
\text { Plioceno-Mioceno } \\
\end{array}$ & $\begin{array}{l}\text { Bouchardia antarctica* } \\
\text { Bouchardia antarctica } \\
\text { Bouchardia antarctica } \\
\text { Bouchardia antarctica } \\
\text { Bouchardia antarctica }\end{array}$ \\
\hline Thomson, 1918 & B. minima & Nova Zelândia & Mioceno & Neobouchardia minima \\
\hline FERUGLIO, 1935 & B. conspicua & Argentina & Paleoceno & Bouchardia conspicua* \\
\hline $\begin{array}{l}\text { FURQUE \& } \\
\text { CAMACHO, } 1949\end{array}$ & B. exigua & Argentina & Paleoceno & Boucharcia exigua* \\
\hline
\end{tabular}

FONTE- THOMSON (1918), LEVY (1964), OWEN (1980), RICHARDSON (1987), MANCEÑIDO \& GRIFFIN (1988), CRAIG (2001)

Chama a atenção o fato das espécies Bouchardia tapirina, Bouchardia tulipa e Bouchardia rhizoida (Quadro 1) não terem sido consideradas por MANCEÑIDO \& GRIFFIN (1988). Na literatura consultada não foi constatada nenhuma proposta de sinonímia para Bouchardia tulipa, e artigos mais recentes sobre o gênero (RICHARDSON, 1973b, 1991, 1994; MANCEÑIDO \& GRIFFIN, 1988) sequer mencionam a espécie. Do mesmo modo, nas coleções investigadas no Brasil e no exterior, exemplares dessa espécie não foram verificados. Por sua vez, Bouchardia rhizoida foi considerada espécie-tipo do gênero Rhyzothyris, eregido por THOMSON (1915), portanto, Rhyzothyris rhizoida. Já Bouchardia tapirina, descrita como Waldheimia tapirina, por HUTTON (1873), e atribuída a Bouchardia por HUTTON (1905), foi referida ao gênero Stethothyris, por ALLAN (1960). Mais recentemente, foi transferida para o gênero Aliquantula (CRAIG, 2001). O exame atento das descrições presentes na literatura (ALLAN, 1960; CRAIG, 2001), para as duas últimas espécies citadas, sobretudo no que tange a morfologia de sua cardinália e braquídio, parece não deixar dúvidas de que pertencem a gêneros outros, que não Bouchardia ou qualquer Bouchardiinae. Vale lembrar que desde o trabalho de LEVY (1964), sobre os gêneros Bouchardia e Bouchardiella do Terciário da Argentina, 
nenhuma revisão taxonômica formal foi realizada para o gênero. Entretanto, sua composição, tal qual sugerida por MANCEÑIDO \& GRIFFIN (1988), embora necessite ser avaliada, foi adotada na presente análise.

De acordo com a designação original de ALLAN (1940b), a Subfamilia Bouchardiinae seria composta por Bouchardia, Bouchardiella e Neobouchardia, idéia esta compartilhada por LEVY $(1961,1964)$ e Williams et al. (1965). Por sua vez, Malleia, até então atribuída à Subfamília Neothyridinae (Família Terebratellidae), foi considerada um Bouchardiinae, na reinterpretação realizada por RICHARDSON (1973b), posição mantida em estudos posteriores (RICHARDSON, 1991, 1994; BRUNTON, 1996). O Quadro 4 (Item 4.3.) traz as espécies atribuídas aos gêneros Bouchardiella e Neobouchardia, ao passo que a única espécie relacionada ao gênero Malleia é Malleia portlandica (RICHARDSON, 1994).

De acordo com Williams et al. (1965), a Familia Terebratellidae, inclui as subfamilias Terebratellinae e Bouchardiinae. No estudo dos Terebratellidae, realizado por RICHARDSON (1994), foi discutida a posição das subfamílias Anakineticinae e Magadinae nesse grupo. As relações entre as 4 subfamilias permanecem, contudo, indefinidas. Conforme comentado por BRUNTON (1996), Bouchardinae não se acomoda satisfatoriamente em Terebratellidae (sensu Williams et al., 1965), o que se deve, sobretudo, à morfologia interna incomum de Bouchardia rosea (veja BRUNTON, 1996; BRUNTON et al., 1996), e à dificuldade na determinação das homologias primárias entre as estruturas da cardinália da valva dorsal de Bouchardia e os demais braquiópodes Terebratellidae (veja BRUNTON et al., 1996).

Adicionalmente, parece claro que o reconhecimento de homoplasia entre eles é o principal desafio na sistemática dos Terebratellidae, situação similar àquela enfrentada no início dos estudos cladísticos com bivalves fósseis do Paleozóico da Bacia do Paraná (Simões et al., 1997, 2000a; Mello et al., 1998, 1999; Mello, 1999). Isto ocorre pois, espécies de diferentes grupos podem responder de maneira semelhante a pressões ambientais semelhantes (veja RICHARDSON, 1981b, 1981c).

A evolução da Subfamília Bouchardiinae, foi rapidamente discutida por LEVY (1964). Segundo a autora, a descoberta de Australiarcula, do Albiano da Austrália, tornou mais clara a evolução da subfamilia. Além de ser o Terebratellidae mais antigo, apresenta a cardinália idêntica à de Bouchardiella, sendo excluído do grupo apenas pela presença de ramos descendentes no braquidio, ausente entre os Bouchardiinae. 
Desta forma, segundo a autora, parece clara a origem de Bouchardiella a partir de Australiarcula, provavelmente por regressão dos ramos descendentes do braquídio (LEVY, 1964). Modificações sucessivas na charneira (e.g., transformação dos dentes anteriores em sulcos em forma de 'V') caracterizariam Bouchardia (LEVY, 1964).

\subsubsection{Sobre a Familia Terebratellidae \\ - Sistemática}

As relações entre Bouchardiinae, Terebratellinae, Anakineticinae e Magadinae (Família Terebratellidae, sensu RICHARDSON, 1994) permanecem, ainda, carentes de uma abordagem rigorosamente cladistica. Portanto, o presente estudo constitui um passo importante na compreensão das relações de parentesco entre esses grupos.

Até recentemente, a visão que se tinha da classificação dos Terebratellidae era a fornecida por RICHARDSON (1994), sintetizando o conhecimento acumulado sobre o grupo (e.g., ALLAN, 1940a; ElLIOTT, 1965; COOPER, 1970, 1973, 1981, 1982; RUDWICK, 1970; MCCAMMON, 1973; Foster, 1974, 1989; RICHARDSON, 1973b, 1975a, 1975b, 1980, 1981a, 1981b, 1981c, 1987, 1991) na tentativa de definir seu escopo. Segundo RICHARDSON (1991, 1994), fariam parte as subfamílias Anakineticinae, Bouchardinae e Terebratellinae, no Hemisfério Sul, (veja composição genérica no Quadro 2), e Magadinae na Europa.

Esta visão começou a mudar com o artigo de WILLIAMS et al. (1996), revisando a classificação supra-ordinal e suplantando as propostas anteriores de Collins et al. (1988, 1991), CARLSON (1990, 1994, 1995), HOLMER (1991), CuRRY et al. (1991), COHEN (1992, 1994), POPOV et al. (1993), BASSET et al. (1994), HOLMER et al. (1995), entre outros, (veja também MACKINNON et al, 1991; RICHARDSON, 1994; BRUNTON et al., 1995 , 1996; BRUNTON, 1996; COOPER \& JIN, 1996; WILliams et al., 1997a, 1997b, 2000a, 2000 b para um histórico dos debates sobre a classificação dentro do filo). De acordo com WILLIAMS et al. (2000a), as limitações que governam a proposição de uma classificação filogenética săo evidentes e dificilmente superadas. Considerou, adicionalmente, que a classificação proposta por WILLIAMS et al. (1996) foi capaz de acomodar todos os táxons de braquiópodes atualmente reconhecidos, sendo flexivel o bastante para incorporar futuras mudanças, tanto no que diz respeito aos grupos externos (e.g., demais lofoforados), quanto a novos caracteres fornecidos, 
principalmente, por pesquisas embriológicas e genéticas em espécies viventes. Contudo, desde então, nenhum artigo tratando especificamente de aspectos da sistemática dos Terebratellidae foi registrado.

\section{QUADRO 2- COMPOSIÇÃO DAS 3 SUBFAMILIAS DA \\ FAMÍLIA TEREBRATELLIDAE COM REPRESENTANTES NO HEMISFÉRIO SUL}

\begin{tabular}{|l|}
\hline Superfamilia Terebratelloidea King, 1850 \\
Família Terebratellidae King, 1850 \\
Subfamilia Bouchardiinae Allan, 1940 \\
Gênero Bouchardia Davidson, 1850 \\
Gênero Bouchardiella Doello-Jurado, 1922 \\
Gênero Malleia Thomson, 1927 \\
Gênero Neobouchardia Thomson, 1927 \\
Subfamília Anakineticinae Richardson, 1991 \\
Gênero Anakinetica Richardson, 1987 \\
Gênero Adnatida Richardson, 1991 \\
Gênero Aliquantula Richardson, 1991 \\
Gênero Australiarcula Elliott, 1959 \\
Gênero Elderra Richardson, 1991 \\
Gênero Magadina Thomson, 1915 \\
Gênero Magadinella Thomson, 1915 \\
Gênero Parakinetica Richardson, 1987 \\
Gênero Pilkena Richardson, 1991 \\
Gênero Pirothyris Thomson, 1927 \\
Gênero Rhizothyris Thomson, 1915 \\
Subfamilia Terebratellinae King, 1850 \\
Gênero Aerothyris Allan, 1939 \\
Gênero Aneboconcha Cooper, 1973 \\
Gênero Austrothyris Allan, 1939 \\
Gênero Calloria Cooper \& Lee, 1993 \\
Gênero Diedrothyris Richardson, 1980 \\
Gênero Dyscritosia Cooper, 1982 \\
Gênero Fosteria Zezina, 1980 \\
Gênero Gyrothyris Thomson, 1918 \\
Gênero Jaffaia Thomson, 1927 \\
Genero Magasella Dall, 1870 \\
Gênero Magella Thomson, 1915 \\
Gênero Magellania Bayle, 1880 \\
Gênero Neothyris Douvillé, 1879 \\
Gênero Pachymagas Ihering, 1903 \\
Gênero Stethothyris Thomson, 1918 \\
Gênero Syntomaria Cooper, 1982 \\
Gênero Terebratella d'Orbigny, 1847 \\
Gênero Victorithyris Allan, 1940 \\
\hline
\end{tabular}

FONTE- RICHARDSON (1994)

Neste contexto, um ponto relevante, e que afeta sobremaneira os resultados finais deste projeto, diz respeito à situação atual da sistemática da Família 
Terebratellidae, frente à revisão recentemente apresentada (WILLIAMS et al., 2000b; MACKINNON \& LEE, no prelo), tendo como base os resultados de WILLIAMS et al. (1996).

A publicação do segundo volume de Treatise on Invertebrate Paleontology (Brachiopoda), tornou parcialmente disponivel uma nova classificação para o Filo Brachiopoda, apresentando apenas os táxons acima da categoria de Família. Trouxe como principal novidade, de interesse para o presente trabalho, a proposta da Superfamília Bouchardioidea (veja reprodução parcial no Quadro 3) ao lado de 7 outras superfamílias, dentro da Subordem Terebratellidina (veja também MACKINNON \& LEE, no prelo). De acordo com esses dados, a Subfamília Bouchardiinae foi elevada à categoria de Superfamília Bouchardioidea, e sua composição (Quadro 3) reafirma a presença de Malleia, como proposto por RICHARDSON (1973b), além de incluir Australiarcula, anteriormente um Anakineticinae (Quadro 2; veja também RICHARDSON, 1994).

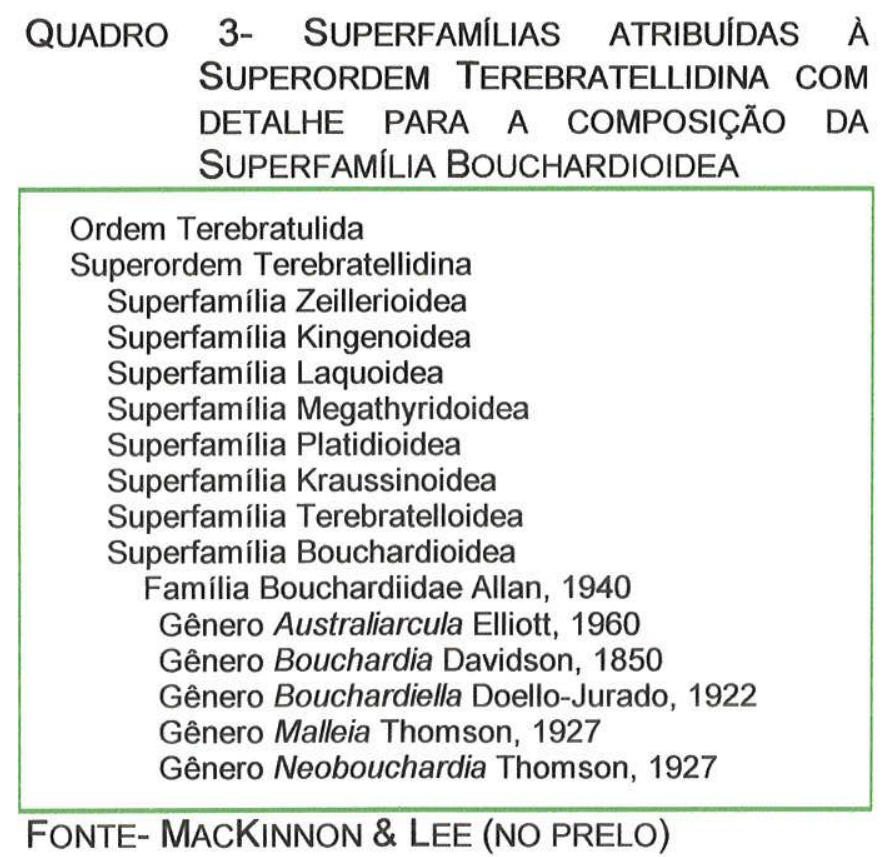

Desta maneira, nota-se claramente um conflito entre a classificação de RICHARDSON (1994), ponto de partida do presente projeto, e a nova proposta de MACKINNON \& LEE (no prelo). No entanto, é importante notar que os procedimentos da 
análise cladística aqui proposta não serão afetados de maneira decisiva por essas mudanças, uma vez que os táxons empregados (táxons terminais) correspondem a gêneros e/ou espécies, e não a categorias taxonômicas mais abrangentes, de maneira que, independentemente da classificação adotada, permanecem válidos. No entanto, ao final da análise os resultados serão interpretados e, ai sim, confrontados com as propostas de classificação existentes. É neste ponto que as recentes modificações, trazidas pela literatura, poderão ter algum efeito. De qualquer forma, informações sobre a composição das demais superfamílias da Subordem Terebratellidina ainda não estão disponiveis, dificultando a escolna de táxons para compor o grupo externo da presente análise, tendo como base esta nova classificação.

\section{- Morfologia}

A origem da Familia Terebratellidae (sensu RICHARDSON, 1994) tem sido objeto de investigação, desde $o$ início do século $X X$, e dados mais recentes (e.g., RICHARDSON, 1973a, 1973b, 1994) sugerem uma origem ainda durante a existência do Gondwana. Por sua vez, inúmeros aspectos da biologia (i.e., morfologia, ecologia, distribuição) dos Brachiopoda encontram-se bem estabelecidos na literatura, estando reunidos, em grande parte, em 8 importantes publicações (WILLIAMS et al., 1965, 1997c; RUDWICK, 1970; DUTRO \& BOARDMAN, 1981; MACKINNON et al, 1991; JAMEs et al., 1992; COOPER \& JiN, 1996; SAVAZZI, 1999). Muitas vezes, os Terebratellidae são utilizados como modelo em uma série de abordagens (e.g., microestrutura, morfologia funcional, fisiologia) tratando de estruturas particulares da anatomia dos braquiópodes, tais como pediculo (RICHARDSON, 1979; RICHARDSON \& WATSON, 1975a, 1975b; MACKAY \& HEWITT, 1978; RICHARDSON, 1981b, 1981c, 1987), musculatura (RICHARDSON \& WATSON, 1975a, 1975b; THAYER, 1975; RICHARDSON, 1987), pontuações da concha (ThAYeR, 1986; PECK et al., 1986), entre outras. Para o presente projeto, foram de especial interesse as informações morfológicas apresentadas na seqüência de trabalhos realizados por J. R. Richardson, a partir da década de 1970 (e.g., RICHARDSON, 1973a, 1973b, 1975a, 1975b, 1979, 1987, 1991, 1994, 1997a, 1997b).

Por exemplo, alguns estudos morfológicos sobre o pedículo (RICHARDSON \& WATSON, 1975a, 1975b; MACKAY \& HEWITT, 1978; RICHARDSON, 1979, 1981b, 1987) e musculatura associada (RICHARDSON \& WATSON, 1975a, 1975b; THAYER, 1975; 
RICHARDSON, 1987) dos Terebratellidae, procuram estabelecer a correlação entre essas estruturas e o hábito de vida dos organismos. Nesse campo, o estudo de Anakineticinae viventes (veja em RICHARDSON, 1984, 1987, 1991) forneceu uma nova visão sobre a estrutura e sua função, confirmando sua variabilidade e estreita relação com o substrato. No entanto, essa visão contrariava idéias, há muito estabelecidas, de que a presença e dimensão de um forâmen estariam relacionadas, respectivamente, a um pedículo para fixação permanente e ao tamanho e força do pedículo (RICHARDSON, $1979,1981 b, 1981 c)$.

\section{- Ecologia}

Importantes avanços sobre o conhecimento (paleo)ecológico dos Rhynchonelliformea foram registrados, sobretudo nas últimas três décadas, com base no estudo dos Terebratellidae (RICHARDSON, 1975b, 1979, 1981a, 1981b, 1981c, 1984, 1987, 1991, 1994, 1997a; RICHARDSON \& WATSON, 1975a, 1975b). Em geral, o aspecto que recebeu maior atenção dos pesquisadores foi o estabelecimento da correta relação entre a morfologia do pedículo, sua musculatura associada (RICHARDSON \& WATSON, 1975a, 1975b; THAYER, 1975; MACKAY \& HEWITT, 1978; RICHARDSON, 1979, 1981b, 1981c, 1987; Williams et al., 1997c), e o hábito de vida desses organismos (e.g., pedículos musculosos, inertes e transitivos). Nessa abordagem merecem destaque os trabalhos de descrição de gêneros viventes de Anakineticinae (RICHARDSON, 1984, 1987, 1991), evidenciando a ampla variabilidade do pedículo e confirmando sua estreita relação com o substrato, contrapondo-se às idéias predominantes até então (veja RICHARDSON, 1979, 1981b, 1981c). O reconhecimento dessa relação tem importantes implicações nos estudos biogeográficos e paleoecológicos, visto que a distribuição dos táxons é governada pela capacidade particular de cada táxon colonizar os substratos (RICHARDSON, 1981c, 1997a, 1997b).

Outro aspecto decorrente das interações ecológicas entre organismos $\theta$ substrato é a ocorrência de possíveis homeomorfias (RICHARDSON, 1994). Foram investigadas populações de braquiópodes atuais com diferentes graus de especialização em relação ao substrato ou modo de vida, ficando evidente a similaridade da resposta morfológica às pressões ambientais semelhantes (RICHARDSon, 1994, 1997a). Segundo RICHARDSON (1981c), 3 gêneros de 
Bouchardiinae apresentam diferentes hábitos de vida, sendo que Neobouchardia seria de vida livre, Bouchardia de vida livre e móvel, e Malleia uma forma fixada através de pedículo muscular. Já os Anakineticinae são interpretados como sendo de vida livre, especializados para vida em sedimentos grossos ("briozoan sands"), utilizando o pedículo apenas para manter a posição junto ao substrato. Esse grupo apresenta conchas com grande espessamento posterior, originado, provavelmente, em resposta à perda da função fixadora do pedículo, e atuando como um estabilizador da concha no substrato (RICHARDSON, 1994; BRUNTON, 1996). Segundo RICHARDSON (1994), esse modo de vida parece ser compartilhado com alguns Bouchardiinae (veja também BRUNTON, 1996), sendo notável a similaridade morfológica entre este grupo e os Anakineticinae. De outro lado, os Terebratellinae são mais variados morfologicamente, refletindo a adoção de estilos de vida mais diversificados, sobretudo ligados ao hábito fixador (RICHARDSON, 1981C).

Informações (paleo)ecológicas para o gênero Bouchardia são, de maneira geral, escassas. Nos trabalhos realizados com as espécies fósseis nenhuma especulação é feita sobre o modo e ambiente de vida dos táxons, ficando restritos aos aspectos morfológicos (veja, por exemplo, IHERING, 1897, 1903, 1907; LEVY, 1964, RICHARDSON, 1973b; MANCEÑIDO \& GRIFFIN, 1988). A ecologia de Bouchardia rosea foi inicialmente abordada por TOMMASI (1970a), contribuindo para o conhecimento autoecológico da espécie. Segundo esse autor, Bouchardia rosea ocorreria principalmente na plataforma continental e áreas costeiras, em profundidades entre 18 e 26 metros, sobre fundos de areia média a grossa e cascalho bioclástico, além de informações a respeito da salinidade e temperatura. Apesar de ser bastante incompleto e desatualizado (KOWALEWSKI et al., 2002, mais comentários no item 6.5.4.), foi durante quase trinta anos o que existia de informação ecológica para a espécie, influenciando investigações posteriores, como de MANCEÑIDO \& GRIFFIN (1988). Nas recentes contribuições trazidas por KoWALEWSKI et al. (2002) e SIMÖES et al. (2004), o contexto ecológico de Bouchardia rosea foi atualizado e complementado, sobretudo as informações sobre distribuição espacial e batimétrica e possíveis relações com zonas de ressurgência na quebra da plataforma continental (veja Item 6.5.4. para comentários adicionais). 


\subsection{A APLiCAÇÃo dA METOdologia CLAdística NA INVESTIGAÇÃo dAS RELAÇões de PARENTESCO ENTRE GRUPOS DE BRAQUIÓPODES FÓSSEIS E VIVENTES}

\subsubsection{A integração entre Cladística e Paleontologia}

O impacto do método cladístico na sistemática é considerado profundo e benéfico, tendo fornecido as bases racionais para uma classificação, acessando, objetivamente, a distribuição dos caracteres, e afastando as abordagens um tanto subjetivas e autoritárias do passado (FORTEY, 1990). Atualmente, a idéia de que a taxonomia deva ser filogenética, ou seja, os táxons propostos devam pertencer a grupos monofiléticos, é amplamente aceita, seja em nível específico ou supraespecífico (DE QUEIROZ \& GAUTHIER, 1990, 1992, 1994; CANTINO \& DE QUEIROZ, 2000; BROCHU \& SUMRALL, 2001).

Mas qual papel cabe aos fósseis nessa perspectiva, levando-se em conta o caráter, muitas vezes, fragmentário do seu registro? É importante que se tenha em mente que os táxons fósseis, por serem mais antigos, retém muitos estados plesiomórficos não vistos nos táxons viventes (DOYLE \& DONOGHUE, 1987; GAUTHIER et al., 1988; Donoghue et al., 1989; HUELSENBECK, 1991; WiENS, 2003) e, também, porque são freqüentemente incompletos, significando que muitos estados não possam ser determinados para muitos caracteres (WIENS, 2003), o que thes confere uma característica notavelmente incompleta. Por isso, os dados paleontológicos pareciam não desempenhar um papel significativo na reconstrução de filogenias de táxons viventes, apenas conferindo incerteza às reconstruções filogenéticas (HENNIG, 1966; Nelson \& Platnick, 1981; PATterson, 1981, 1982; SMITH, 1984, 1994). Consideram-se as definições de homologia como sendo as bases da análise filogenética mas, contudo, não podem ser avaliadas para partes de organismos que são desconhecidas. De fato, para os cladistas de padrão (sensu FORTEY, 1990), mais interessados nas relações entre organismos vivos, os fósseis contribuiriam, principalmente, na determinação da idade dos grupos, discussões paleobiogeográficas e, quando muito, na polarização dos caracteres (HENNIG, 1966; FORTEY, 1990; SMITH, 1994). Atualmente, esse caráter incompleto dos táxons fósseis traz muita ausência de informações (i.e., missing data) para a análise, sendo amplamente considerado como o obstáculo mais significativo na reconstrução de suas relações (DONOGHUE et al., 1989; HUELSENBECK, 1991; WIENS, 
2003) e fortalecendo as dúvidas sobre a utilidade dos fósseis em análises filogenéticas com outros grupos de táxons viventes (PATTERSON, 1981; AX, 1987; WIENS, 2003).

Por outro lado, novos esforços conceituais e metodológicos (testes empíricos e de simulação) tentaram definir melhor o papel das informações paleontológicas nas abordagens cladisticas, visando sempre a utilização de todas as evidências existentes (SMITH, 1994), tanto para táxons quanto para caracteres, resultando em hipóteses de relações mais fortemente corroboradas (KLUEGE, 1989; NIXON \& CARPENTER, 1996a, 1996b; KEARNEY \& CLARK, 2003). Estudos sobre o problema de como os táxons e caracteres incompletos afetam as análises filogenéticas têm demonstrado que, dependendo das circunstâncias em que são empregados, eles podem melhorar ou piorar a acurácia das análises (e.g., HUELSENBECK, 1991; WIENS \& REEDER, 1995; WIENS, 1998, 2003; KEARNEY \& CLARK, 2003; NORELL \& WHEELER, 2003). Estudos de simulação indicam que aumentando o número de caracteres (HUELSENBECK \& HILLIS, 1993; Hillis et al., 1994; HuelsenBeck, 1995; Wiens \& SerVedio, 1998) ou de táxons (GRAYBEAL, 1998; HiLlis, 1998; RANNAlA et al., 1998; WIENS, 1998), independente de serem completos ou não, pode haver melhora nos resultados filogenéticos (WIENS, 2003).

Como resultado dos esforços, os fósseis revestiram-se de grande importância na determinação acurada das relações de parentesco dos diferentes grupos de organismos e na compreensão da evolução de caracteres (GAUTHER et al., 1988; Donoghue et al., 1989; NOVACEK, 1992a, 1992b; WILSON, 1992; SMITH, 1994), isso porque são portadores de importantes informações sobre caracteres e combinações únicas de caracteres (CRANE, 1985; GAUTHIER et al., 1988; RAMSKÖLD \& WERDELIN, 1991; SIDDALL, 1998; KEARNEY \& CLARK, 2003). São, ainda, essenciais na reconstrução de padrões evolutivos e paleobiogeográficos, embora tais padrões não possam ser obtidos diretamente do registro, muitas vezes imperfeito e incompleto (FORTEY, 1990; SMITH, 1994).

A adição de fósseis aos estudos cladísticos fornece uma amostragem mais densa dos caracteres morfológicos do clado, aumentando as chances de reconhecimento de homoplasias nos ramos terminais e de se chegar a uma topologia correta (SMITH, 1994). De fato, filogenias são testadas, e se tornam mais robustas, com - aumento do número de caracteres filogeneticamente informativos utilizados. O potencial dos fósseis para oferecerem acesso a novos caracteres é reconhecidamente 
limitado quando comparado ao de caracteres bioquímicos e genéticos disponivel para łáxons viventes. Por esse motivo os fósseis sempre terão um papel subordinado na determinação de relações filogenéticas. Contudo, eles têm auxiliado muitos cladistas evolutivos no estabelecimento das relações de parentesco de diversos grupos (sobretudo invertebrados e vertebrados), apresentando boa correlação entre o que é expresso pelo cladograma e o que é expresso pelas rochas, auxiliando na construção de árvores filogenéticas (FORTEY, 1990; SMITH, 1994, 2002; SIDDALL, 1998; ALROY, 2002; FISHER et al., 2002; WAGNER, 2002) e demonstrando que a evolução dos organismos (mesmo os extintos) pode ser, em grande parte, recuperada com sucesso e, portanto, interpretada filogeneticamente através da análise cladística (para a classe Bivalvia veja, por exemplo, HEANEY, 1995; WALLER, 1978, 1998; SCHNEIDER, 1992, 1995, 1998a, 1998b; ROOPNARINE, 1996; SIMÕES et al., 1997; SCHNEIDER \& FOIGHIL, 1998; Mello et al., 1998; ANelli, 1999; Mello, 1999; CAMpbell, 2002; GiRIBet \& WHEELER, 2002).

\subsubsection{Panorama cladístico do Filo Brachiopoda}

Na década de 1950, enquanto a comunidade científica começava a vivenciar e debater os conceitos da sistemática filogenética, apresentados por HENNIG (1950), as classificações existentes para os braquiópodes (e.g., BEECHER, 1891, 1895; THOMSON, 1927) e suas bases morfológicas, eram revistas, sendo complementadas ou substituidas por novas propostas (MUIR-WOOD, 1955; WILLIAMS, 1956). A década seguinte marca o surgimento de novas classificações (SARYTCHEVA et al., 1960; WILLIAMS \& RoWELL, 1965) que, embora sintetizassem todas as recentes considerações, não apresentavam, ainda, qualquer embasamento cladístico (WILLIAMS et al., 2000a). As primeiras investigações para o grupo, valendo-se do método cladístico, foram feitas pelo próprio HENNIG (1966; p. 145-154) para braquiópodes viventes, numa tentativa de integrar a classificação existente, com base na articulação das valvas, com uma que refletisse os amplos caminhos evolutivos dos braquiópodes (WILliams et al., 2000a). Como resultado, os Craniidae (braquiópodes inarticulados de concha calcária) seriam mais próximos dos Rhynchonelliformea do que de outros grupos de inarticulados de concha fosfática (e.g., Linguliformea), concordando com 
proposta anterior de JOPE (1965), feita com base em observações sobre a bioquímica da concha.

De lá para cá, a abordagem cladística tem sido empregada, no estudo das relações de parentesco entre diferentes grupos do Filo Brachiopoda, sobretudo a partir de meados da década de 1980 (e.g., Rowell, 1981a, 1981b, 1982; GoRJANSKY \& Popov, 1986; CARLson, 1990, 1994, 1995; HOLMER, 1991; Nielsen, 1991; Popov et al., 1993; BASSET et al., 1994; HOLMER et al., 1995; WILLIAMS et al., 1996, 1997a, 1997b, 2000a, 2000b; ANELLI, 1999; JAECKS \& CARLSON, 2001; LEIGHTON \& MAPLES, 2002). O problema inicialmente considerado por HENNIG (1966), ou seja, a disputa sobre as afinidades dos Craniidae, com evidentes implicações no monofiletismo do Filo Brachiopoda, constitui, ainda hoje, um desafio à utilização de um único caráter (i.e., articulação da concha) para definir os niveis hierárquicos mais altos dentro de um grupo, que tem uma genealogia bem documentada e que se estende por todo o Fanerozóico (WILliams et al., 2000a).

A despeito de recentes progressos, contudo, incluindo o uso da biologia molecular, a taxonomia e sistemática dos braquiópodes constituem, ainda, matérias de grande debate na literatura (e.g., MACKINNON et al., 1991; RICHARDSON, 1994; BRUNTON et al., 1995, 1996; Holmer et al., 1995; BRUNTON, 1996; COOPER \& JIN, 1996; LOGAN et al., 1997; LÜTER \& BARTOlOMAeUs, 1997; Williams et al., 1997a, 1997b, 1998a, 1998b, 2000b; COHEN et al., 1998a, 1998b; COHEN, 2000a, 2000b; ENDO, 2001; SAITO \& ENDO, 2001; Holmer, 2001; Mallatt \& Winchell, 2002; Nielsen, 2002; Prud'homme et al., 2002). As recorrentes investidas nessa questão, sobretudo a partir dos trabalhos de CARLSON (1990, 1995; veja também POPOV et al., 1993; BASSET et al., 1994; HOLMER et al., 1995), produziram intensos debates sobre o monofiletismo dos Brachiopoda, culminando na sintese apresentada por WILLIAMs et al. (1996), e adotada na mais recente revisão do Treatise on Invertebrate Paleontology (Brachiopoda) (WILLIAMS et al., 2000b).

A análise dos trabalhos com abordagem cladística, realizados para grupos de braquiópodes, permite destacar alguns aspectos, tais como: a) o baixo número de investigações cladísticas com braquiópodes fósseis, b) o caráter amplo das investigações, tratando, na maioria das vezes, do filo ou categorias taxonômicas acima de família, e c) o grande número de caracteres relacionados às partes moles dos táxons, inacessiveis nas análises de exemplares fósseis. $O$ número relativamente baixo 
de estudos cladísticos com braquiópodes fósseis parece encontrar explicação na idéia, largamente difundida na Paleontologia, de que alguns grupos de invertebrados, tais como os bivalves, não apresentam caracteres suficientes para serem investigados sob a ótica cladística (SKELTON et al., 1990; SKELTON \& BENTON, 1993; para opinião contrária veja HEANEY, 1995). No estudo evolutivo da Superfamília Spiriferoidea, ANELLI (1999) identifica tais dificuldades no estudo do grupo, as quais estariam relacionadas, provavelmente, ao alto índice de homoplasia, grande variação intraespecifica e ausência de sinapomorfias, por perda das partes moles. Contudo, estudos rigorosamente cladísticos realizados para a Classe Bivalvia, utilizando apenas dados de exemplares fósseis (e.g., Simões et al., 1997; MEllo et al., 1998; ANELLI, 1999; MELLO, 1999) ou sua combinação com espécimes viventes (e.g., WALLER, 1978, 1998; SCHNEIDER, 1992, 1995; ROOPNARINE, 1996), parecem indicar que tais dificuldades não são, primariamente, decorrentes da perda das partes moles nos diferentes grupos de invertebrados. Esta constatação sugere, particularmente no caso de grupos de Rhynchonelliformea, que as dificuldades na análise estão mais ligadas ao comportamento tafonômico próprio de suas conchas, que permanecem fechadas após a morte do animal e decomposição dos tecidos mole, dificultando o acesso às feições morfológicas internas $e$, conseqüentemente, restringindo o volume de informação disponivel. 


\section{MATERIAIS E MÉTODOS}

\subsection{OBTENÇÃO E ORGANIZAÇÃO do MATERIAL ANALISADO}

O material analisado é representado, sobretudo, pelos espécimes da Coleção de Braquiópodes Cenozóicos do Laboratório de Paleozoologia Evolutiva (IBB/UNESP), que reúne uma grande quantidade de Rhynchonelliformea fósseis, subfósseis e viventes.

\subsubsection{Obtenção de espécimes no litoral brasileiro}

As coletas para obtenção dos espécimes foram coordenadas pelos professores Dr. Adilson Fransozo (Núcleo de Estudos de Biologia, Ecologia e Cultivo de Crustáceos/NEBECC, IBB-UNESP) e Dr. Marcello Guimarães Simões (Laboratório de Paleozoologia Evolutiva, (BB-UNESP), entre os anos de 1998 e 2002, contando com a colaboração de outros pesquisadores e alunos de pós-graduação do Programa de Pósgraduação do Instituto de Geociências, USP. As coletas foram realizadas, primariamente, como parte dos esforços para obtenção de material para estudos tafonômicos, geocronológicos e paleoecológicos, desenvolvidos no Laboratório de Paleozoologia Evolutiva (IBB/UNESP) em colaboração com pesquisadores de Virginia Polytechnic Institute and State University (Blacksburg, USA). Inicialmente, foram amostradas as áreas nas quais os braquiópodes são sabidamente mais freqüentes, no litoral de Ubatuba, SP ('Estação 2' de MANTELATTO \& FRANSOzo, 1999; Figura 1a) e liha Grande, RJ (estações de coleta de Tomması, 1970a, Figura 1b).

Em adição, espécimes de Bouchardia rosea, obtidas durante o Projeto REVIZEE (Programa de Avaliação do Potencial Sustentável dos Recursos Vivos da Zona Econômica Exclusiva Brasileira/Score Sul/Bentos), através de 2 cruzeiros oceanográficos (Navio Oceanográfico Prof. W. Besnard) nas costas dos estados de São Paulo, Espírito Santo, Rio de Janeiro e Paraná, entre 1997 e 1998, foram também examinados. Uma sintese das estações de coleta e a lista taxonômica dos braquiópodes obtidos aparecem em KoWALEWSKI et al. (2002) e SIMÕEs et al. (2004).

Uma lista com informações adicionais sobre os exemplares de Bouchardia rosea examinados é apresentada ao final deste documento (Anexo 1). 

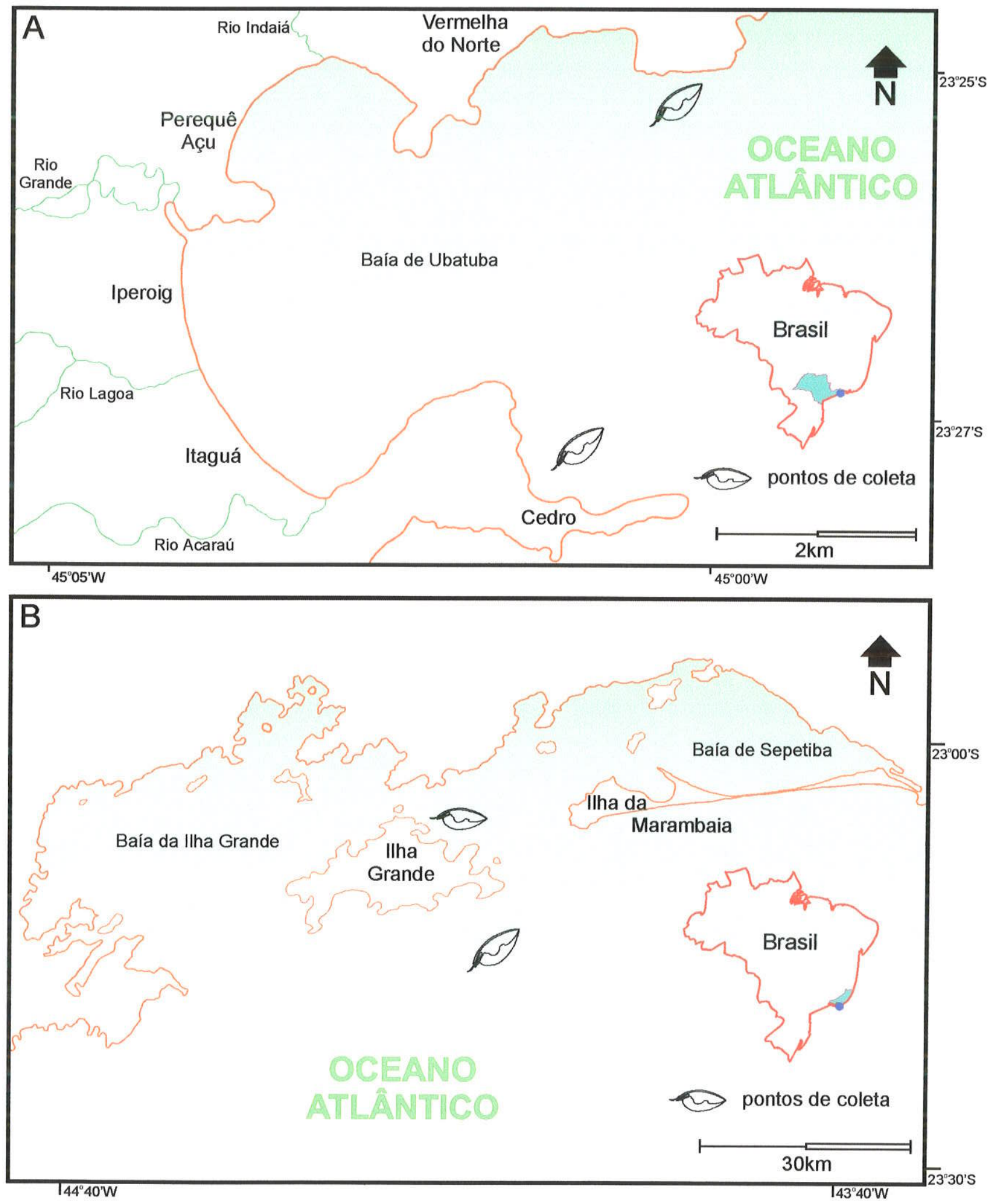

Figura 1- Localização dos pontos de coleta de Bouchardia rosea no litoral dos estados de São Paulo (A) e Rio de Janeiro (B). Em A, pontos de coleta na região de Ubatuba (pontos II e IV, segundo MANTELLATO \& FRANSOZO, 1999); em B, na região de Ilha Grande onde, segundo TOMMASI (1970), conchas de Bouchardia rosea são frequentes. O ponto mais ao sul, a partir da ilha, corresponde à estação 304 de TOMMASI (1970) 


\subsubsection{Exame de coleções cientificas}

Após consulta bibliográfica e contato com pesquisadores para localização dos exemplares de interesse para o presente projeto, foram realizadas visitas a coleções, no Brasil e no exterior, bem como empréstimo de material de coleções do exterior. Foram examinados espécimes das coleções científicas e didáticas do Instituto de Geociências-USP (São Paulo), Museu Nacional (Rio de Janeiro), Museo Argentino de Ciencias Naturales (Buenos Aires, Argentina), Museo de Ciencias Naturales de La Plata (Argentina), Universidade de la República/INGEPA (Montevidéo, Uruguai), Southern Australian Museum (Adelaide, Austrália) e University of Otago (Otago, Nova Zelândia). Uma lista com os exemplares examinados, e informações adicionais, é apresentada no final deste documento (Anexo 1).

\subsubsection{Contexto geológico das ocorrências fossilíferas dos Bouchardiinae analisados}

Com o intuito de complementar as informações fornecidas sobre os Bouchardiinae analisados neste estudo, serão comentados, a seguir, os contextos geológicos de suas ocorrências, embora nem sempre de maneira completa, devido à ausência de tais informações quer sejam no registro do material examinado ou nos artigos científicos, o que denuncia o conhecimento estratigráfico ainda incipiente para o grupo

Espécimes de Bouchardiella patagonica e Bouchardiella jorgensis são provenientes de afloramentos nas proximidades do Golfo de San Jorge (Figura 2), na Argentina, a primeira espécie pouco ao norte do Pico Salamanca, sul da província de Chubut, e a outra em Punta Casa Mayor, norte da província de Santa Cruz. Embora localidades distintas, os sedimentos teriam sido depositados durante o NeocretáceoPaleoceno (Doello-JuRAdo, 1922; ElliotT, 1952; LeVY, 1964). Contudo, não existem informações litológicas e estratigráficas adicionais, na literatura consultada. FURQUE \& CAMACHO (1949) apontam a existência de conchas de Bouchardiella patagonica nos sedimentos da Formação Rio Bueno, a mesma que contém conchas de Bouchardia exigua, na Terra do Fogo, embora em afloramentos distintos. Já Bouchardiella cretacea é encontrada em depósitos, também do Neocretáceo, que afloram no oeste australiano 
(Figura 2) (ElLIOTT, 1952; CRAIG, 1999a). Na Bacia de Perth, ocorre na unidade denominada Gingin Chalk, caracterizada por calcários porosos, de granulação fina, cor branca, friáveis e ricamente fossilíferos (e.g., equinoides, bivalves, braquiópodes) (CRAIG, 1999a, 1999b). Na Bacia de Carnarvon, Bouchardiella cretacea foi encontrada em duas unidades distintas: a) Toolonga Calcilutite, com calcilutitos cinza-claro a verde-claro no topo e calcários finos, mais porosos, na base, e rica em fósseis (e.g., crinóides, bivalves, braquiópodes); e b) Formação Miria, onde predominam calcarenitos de coloração creme, com rica fauna de invertebrados (e.g., braquiópodes, gastrópodes, amonoides) e vertebrados (e.g., terápodes, pterossauros) (CRAIG, 1999a, 2000).

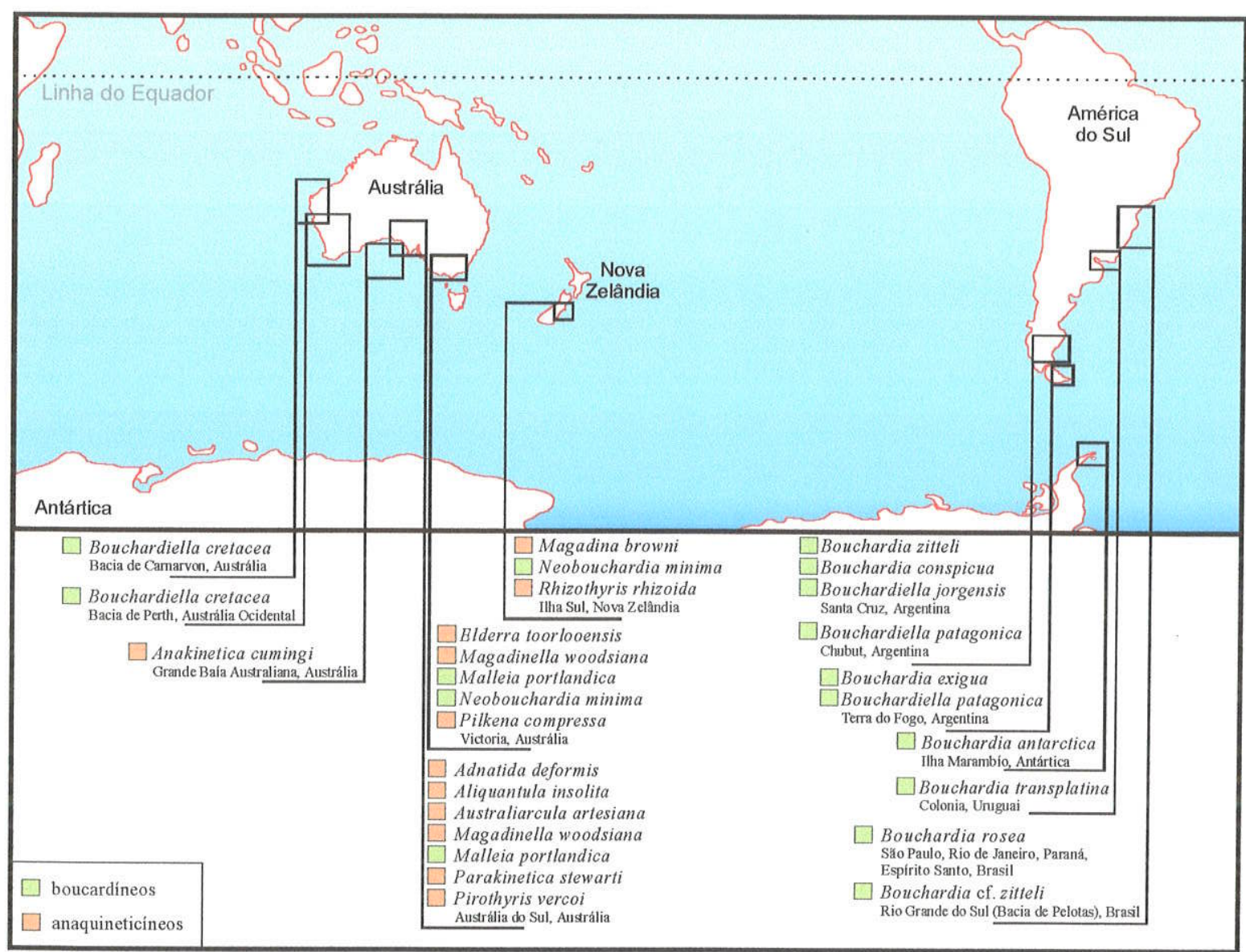

Figura 2- Localização das principais ocorrências de Bouchardiinae e Anakineticinae (fósseis e viventes), grupos típicos do hemisfério sul. Fonte: IHERING (1897), DOELlO-JURADO (1922), ALLAN (1940a, 1940b), FuRQUE \& CAMACHO (1949), ELLIOTT (1952), MARTINS (1952), LEVY (1964), RICHARDSON (1973b, 1987, 1991, 1994), MANCEÑIDO \& GRIFFIN (1988), MALUMIÁN (1990), CONCHEYRO (1991), MACKINNON et al. (1993), MARTINÉZ (1994), CRAIG (1999), CAMACHO et al. (2000), KOWALEWSKI et al. (2002) e SIMÕES et al. (2004) 
Sobre o gênero Bouchardia, a espécie mais antiga, Bouchardia conspicua, é encontrada em afloramentos da parte superior das formações Calafate e Mata Amarilla, depositadas durante o Paleoceno. Seus sedimentos caracterizam-se por uma sucessão de arenitos médios, carbonáticos, levemente friáveis e cinza-esverdeados, aflorantes na província de Santa Cruz, Argentina (Figura 2) (FERUglio, 1949; MANCEÑIDo \& GRIFFIN, 1988; CAMACHO et al., 2000).

Os exemplares de Bouchardia exigua citados pela literatura foram descritos para os estratos da Formação Rio Bueno, do Paleoceno da Terra do Fogo, na Argentina (Figura 2) (Furque \& CAMACHO, 1949; MANCEÑIDO \& GRIFFIN, 1988). Esses sedimentos correspondem a uma intercalação de calcários, por vezes arenosos, brancoamarelados, ricos em fósseis (e.g., equinodermes, braquiópodes, coquinas de bivalves), além de pelitos arenosos, verde-azulados, friáveis e com raros fósseis, e arenitos finos, por vezes argilosos, cinzas, verdes ou azuis, com algumas estratificações, podendo apresentar, dependendo da localização na seção, lentes arenito-argilosas ou concreções (FURQUE \& CAMACHO, 1949).

Os espécimes de Bouchardia zitteli são provenientes das regiões de San Julián e Manantial Salado, província de Santa Cruz, na Argentina (Figura 2), ocorrendo em sedimentos das formações Patagonia (Membro San Julián) e Man Aike (Perfil Cerro Fortaleza e Cerro Castillo), do Eoceno médio/final (IHERING, 1897; MANCEÑIDo \& GRIFFIN, 1988; MALUMIÁN, 1990; CONCHEYRo, 1991; CAMACHO et al., 2000). Litologicamente semelhantes, as duas formações apresentam arenitos de granulometria variável sendo que, nas porções superiores das seções, podem ser encontrados espessos pacotes conglomeráticos, com coquinas intercaladas, de coloração amarelo-esverdeada e estratificações cruzadas. Já nos níveis inferiores são freqüentes as intercalações com argilitos e horizontes glauconíticos. Além de conchas de braquiópodes estão presentes fósseis de outros invertebrados (e.g., gastrópodes, bivalves), restos vegetais e bioturbações. Em particular, as conchas de Bouchardia zitteli são encontradas nas partes médias e inferiores das seções, em arenitos médios a grossos, friáveis, levemente carbonáticos e com estratificações plano-paralelas a levernente cruzadas (IHERING, 1897; MANCEÑIDo \& GRIFFIN, 1988; CAMACHo et al., 2000). Por sua vez, MARTINs (1952) atribuiu a Bouchardia cf. zitteli a única ocorrência, até onde se pôde constatar, de um Bouchardinae fóssil em território brasileiro. $\mathrm{O}$ testemunho, proveniente de uma sondagem realizada em Pelotas (RS), apresentou 3 
valvas encontradas em apenas uma camada de brechas cimentadas por argila muito sólida, com 1,76m de espessura, localizada dentro de uma seqüencia de arenitos esverdeados e argilitos. Na mesma camada foram encontrados restos de briozoários, bivalves e gastrópodes (MARTINS, 1952). Segundo o autor, a sondagem teria atravessado sedimentos terciários correspondentes às camadas da Formação Patagonia, aflorantes na Argentina.

Conchas de Bouchardia antarctica são encontradas em diversas localidades fossiliferas na região nordeste da Itha Seymour, na Antártica (Figura 2), em afloramentos da Formação La Meseta, da parte superior do Grupo Seymour Island depositadas, provavelmente, durante o Eoceno-Oligoceno inicial. Essa unidade é representada por depósitos marinhos compostos por arenitos médios a grossos, esverdeados a cinzas, pouco consolidados a friáveis, e com intercalações de conglomerados (OWEN, 1980; MANCEÑIDO \& GRIFFIN, 1988).

Neobouchardia minima ocorre (Figura 2) em uma série de depósitos oligocênicos na Nova Zelândia (e.g., localidades tipo de Middle Waipara e Weka Pass, em Canterbury) e Austrália (e.g., localidades de Jan Juc e Torquay, em Victoria) (ALLAN, 1940a, 1940b; RICHARDSON, 1973b). A presença dessa espécie foi indicada por MACKInNON et al. (1993) para a Nova Zelândia (Ilha Sul), ocorrendo em uma unidade chamada Kokoamu Greensand, formada por arenito glauconitico, com calcários de granulação fina a média, localmente seixosos, friáveis, incluindo horizontes ricos em conchas de braquiópodes, além de rica variedade de outros fósseis (e.g., moluscos, equinóides, peixes, pingüins, cetáceos). Por fim, Malleia portlandica também é conhecida para uma série de localidades na Austrália (Figura 2) (e.g., Austrália do Sul, Victoria), onde afloram sedimentos depositados do Oligoceno ao Plioceno (ALLAN, 1940a; RICHARDSON, 1973b), embora detalhes sobre a litologia e estratigrafia dos locais não constem na literatura consultada.

Exemplares de Bouchardia transplatina (10 espécimes) são provenientes de concentrações fossiliferas densamente empacotadas, a moda de coquinas (as chamadas "Bouchardia beds"), com cerca de $20 \mathrm{~cm}$ de espessura, atribuídas ao Membro Cerro Bautista da Formação Camacho, do Plioceno do Uruguai (Departamento de Colônia, Figura 2) (Figueiras \& Broggi, 1972; DE SANTA AnA et al., 1988; Martinez; 1994). Essa unidade caracteriza-se por uma sucessão de arenitos finos (predominantes) a grossos, por vezes conglomeráticos ou carbonáticos, e com raras 
estruturas sedimentares (e.g., estratificação espinha de peixe, marcas onduladas) (DE SANTA ANA et al., 1988; MARTinez, 1994). Além de conchas de braquiópodes são encontrados fósseis de outros invertebrados (e.g., gastrópodes, bivalves, briozoários) e vertebrados (e.g., condríctios), concentrados em camadas específicas ao longo da seção (MARTíNEZ, 1994). Na interpretação feita por MARTínez (1994), esses sedimentos são considerados como um depósito formado por areias móveis, fornecidas por um sistema de dunas costeiras, águas quentes, subtropicais, sendo que os horizontes fossiliferos, apenas formados por restos de organismos epibentônicos e nectônicos, representariam a colonização temporária do fundo, durante períodos de estabilidade do substrato. Contudo, a análise realizada por MARTínez \& VERDE (1992) considera que as conchas de Bouchardia transplatina foram depositadas abruptamente.

\subsubsection{Preparação do material}

Para que pudessem ser obtidas informações morfológicas com maior nitidez, o material obtido para estudo, quer por coleta, doação ou empréstimo, foi submetido a procedimentos de triagem e preparação, indicados a seguir e, sempre que necessário, respeitando-se as recomendações das instituições mantenedoras dos exemplares.

\section{A) Triagem}

O material coletado no litoral de São Paulo e Rio de Janeiro (veja Item 4.1.1.), correspondendo a sedimento fino, ricamente bioclástico, foi lavado e triado com a ajuda de peneiras granulométricas, com malhas de diferentes medidas (de 0,062 $\mathrm{mm}$ a $8 \mathrm{~mm}$ ), para a eliminação dos clastos (argila, silte e areia). Os bioclastos foram separados com auxílio de estereomicroscópio, pinças, pincéis e estiletes, sendo formados por grande quantidade de conchas de Bouchardia rosea, entre outros restos esqueléticos (e.g., espinhos de equinóides, conchas de gastrópodes e bivalves). Esses espécimes, sempre mortos, variaram entre $1 \mathrm{~mm}$ e $20 \mathrm{~mm}$ de comprimento, e suas conchas, articuladas ou não, se apresentavam em bom estado de preservação incluindo, algumas vezes, a presença de estruturas frágeis como o braquídio. Após a triagem, os exemplares foram medidos (comprimento, largura e espessura), numerados e devidamente acondicionados (potes plásticos ou lâminas secas), compondo, assim, 
parte da referida coleção científica (veja Item 4.1.). Por sua vez, o material proveniente das coletas do Projeto REVIZEE (veja ltem 4.1.1.) foi recebido já fixado em álcool $70 \%$ e acondicionado em frascos e já se encontrava triado quando do início desse estudo.

\section{B) Preparação física e química}

Tais procedimentos estão, em grande parte, embasados em técnicas paleontológicas rotineiras (e.g., MENDES, 1988; FELDMAN et al, 1989; SIMÕES \& FITTIPALDI, 1992), envolvendo:

a) Preparação Física: usada para a remoção de sedimento que preenche/recobre parcialmente as valvas e estruturas morfológicas especificas (e.g., charneira, dentes), de exemplares fósseis ou atuais. Foram empregados estiletes, de tamanhos variados, pincéis, pinças e estereomicroscópio, sempre que necessários.

b) Preparacão Quimica: um dos procedimentos foi a imersão dos espécimes em água oxigenada 10 volumes, pura, para os fósseis, e diluída $(20 \%)$, para os espécimes atuais por, pelo menos, duas semanas, tendo como finalidade a retirada da matéria orgânica restante (exemplares atuais) e do sedimento menos consolidado (fósseis e atuais). Além disso, foi utilizada uma solução de ácido clorídrico 10\%, para auxiliar a retirada do sedimento carbonático de alguns espécimes fósseis (e.g., Bouchardia transplatina).

\subsubsection{Recuperação e registro das feições morfológicas}

As informações morfológicas recuperadas dizem respeito àquelas observadas nas faces interna e externa de ambas as valvas dos braquiópodes. Embora existam, na literatura, informações sobre as partes moles de alguns táxons analisados (e.g., Anakinetica cumingi, Bouchardia rosea) e, ainda, alguns dos exemplares examinados tivessem seus tecidos e órgãos preservados (e.g., Anakinetica cumingi, Bouchardia rosea), a maioria dos táxons correspondia a espécimes fósseis. Assim, visando a) uma melhor comparação morfológica, b) o estabelecimento de homologias primárias e, sobretudo, c) a verificação da hipótese apresentada (veja ltem 2), a grande maioria das feições morfológicas analisadas e empregadas refere 
organismos. As feições morfológicas de interesse foram recuperadas e registradas, de acordo com os seguintes procedimentos:

A) Confeccãa de moldes e réplicas: procedimento empregado para a cópia de espécimes das coleções visitadas, no Brasil e no exterior, e do material obtido por empréstimo, facilitando a manipulação das informações e eliminando o risco de danos aos exemplares originais. Além disso, os moldes/réplicas podem ser coloridos, maximizando a visualização das feições morfológicas e seu registro em desenhos, fotografias ou imagens digitais. Nesta etapa, foram empregados diversos materiais visando sempre a melhor resolução das feições morfológicas nos produtos finais. Para a confecção de moldes foram utilizados: a) argila, que após a secagem foi pintada com tinta nanquim; b) massa para porcelana fria, na cor preta; c) 'Jeltrate ${ }^{(M)}$ (Material Elástico para Impressão, Tipo II Presa Normal); d) 'Duplicador VIPI' (Gelatina Duplicadora Elástica de Alta Precisão, Extra Dura, para Fundições de Cromo Cobalto). Para as réplicas, feitas a partir dos moldes em 'Jeltrate ${ }^{\circledR,}$ e 'Duplicador $\mathrm{VIPI}{ }^{\circledR}$;, foi utilizado gesso pedra que, após a secagem, foi pintado com tinta nanquim.

B) Reqistro das feicões morfológicas: os espécimes e seus moldes/réplicas tiveram suas feições morfológicas gerais (e.g., contornos, superfícies internas e externas das valvas, estruturas morfológicas particulares, classes de tamanho) registradas através de câmeras fotográficas convencionais, acopladas ou não ao estereomicroscópio, e câmera digital acoplada ao microcomputador e ao estereomicroscópio (disponível no Laboratório de Petrografia Sedimentar, IGc/USP).

C) Emprego de Microscopia Eletrónica de Varredura: foram realizadas sessões de Microscopia Eletrônica de Varredura (disponível no Centro de Microscopia Eletrônica, IBB/UNESP, e Laboratório de Microscopia Eletrônica, IGc/USP), para observação, em detalhe, de características morfológicas externas (e.g. linhas de crescimento, forâmen) e internas (e.g., braquídio, cardinália) de espécimes de Bouchardia transplatina e Bouchardia rosea, nesta última, incluindo exemplares em diferentes estágios ontogenéticos. O objetivo principal foi identificar as modificações sofridas por estruturas morfológicas específicas (e.g., braquidio, cardinália) ao longo do desenvolvimento ontogenético de Bouchardia rosea, além de caracterizar mais detalhadamente a espécie Bouchardia transplatina. As imagens obtidas foram armazenadas como arquivos de imagens digitais. 


\subsection{A METODOLOGIA CLADÍSTICA}

No presente estudo a metodologia cladística (HENNIG, 1950, 1966) é utilizada como ferramenta na investigação das relações de parentesco entre braquiópodes Bouchardinae (Familia Terebratellidae, sensu RICHARDSON, 1994). Contudo, descrições e comentários sobre os conceitos e métodos empregados fogem dos objetivos principais aqui propostos, além de já estarem amplamente registrados na literatura científica (e.g., HENNIG, 1966; ELDREDGE \& CRACRAFT, 1980; NELSON \& PLATNICK, 1981; WILEY, 1981; BROOKS et al., 1984; AX, 1987; Forey et al., 1992; NIXON \& CARPENTER, 1993). O presente documento restringe-se a indicar, quando conveniente, os parâmetros e decisões adotados ao longo da análise. Quaisquer dúvidas sobre o tema poderão ser esclarecidas através de literatura pertinente (e.g., AMORIM, 1997, 2002, além de inúmeras referências bibliográficas contidas nessas obras).

\subsection{ESTRUTURAÇÃO DO UNIVERSO DA ANÁLISE}

A análise cladística aqui apresentada visa, principalmente, a definição das relações de parentesco entre os táxons atribuidos à Subfamília Bouchardiinae (sensu RICHARDSON, 1994; veja, também, comentários nos itens 3.1.2. e 3.1.3., deste documento). Em tempo, tendo ciência a) das modificações recentemente propostas na classificação dos Terebratellidae e, especialmente, dos Bouchardiinae, b) dos seus efeitos imediatos e futuros na análise cladística proposta, e c) dos possiveis ajustes sistemáticos a serem realizados, optou-se por não adotar, de momento, a nova classificação trazida por WILLIAMS et al. (2000a), continuando a utilizar a proposta de RICHARDSON (1994), pelo menos até que se tenha o conhecimento completo sobre a composição genérica e específica das demais familias da Subordem Terebratellidina. $O$ Quadro 4 traz as espécies atualmente atribuídas a esses gêneros e que foram adotadas como unidades taxonômicas operacionais do grupo interno da análise, segundo o método indireto de polarização dos caracteres (NELSON, 1978; MADDISON et al., 1984; NIXON \& CARPENTER, 1993; veja também AMORIM, 1997, 2002, para mais detalhes). 


\section{QUADRO 4- ESPÉCIES ATRIBUÍDAS AOS GÊNEROS DA SUBFAMÍLIA BOUCHARDIINAE, ESCOLHIDAS PARA COMPOR O GRUPO INTERNO DA ANÁLISE, COM SUAS RESPECTIVAS IDADES}

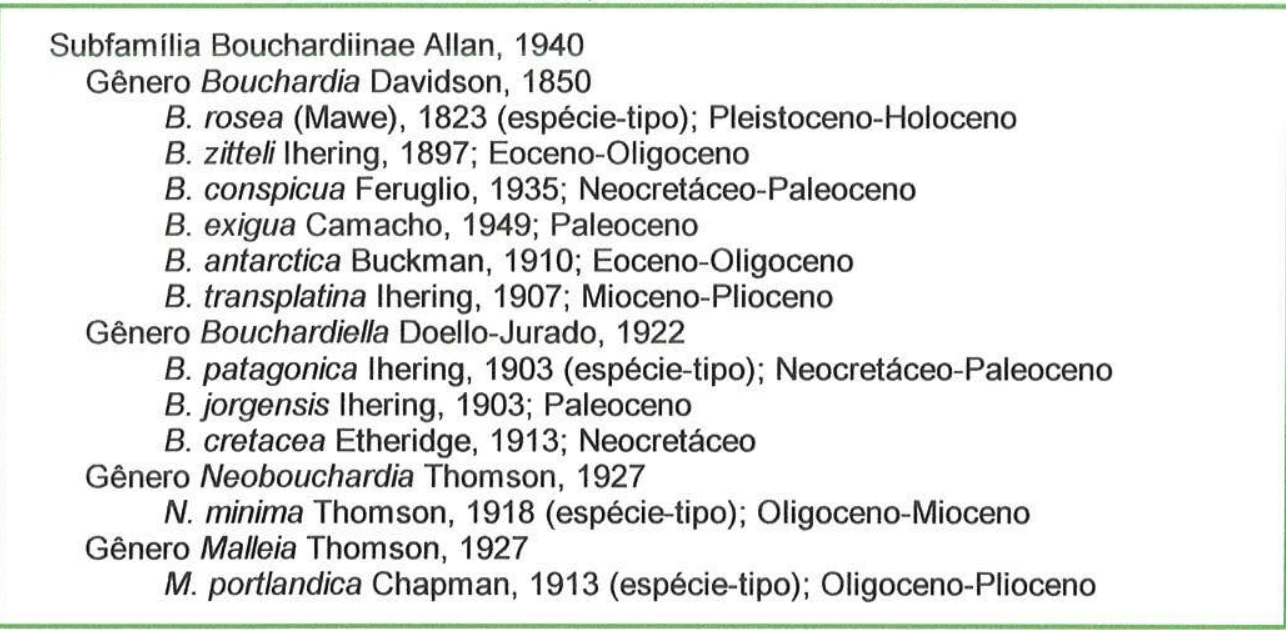

FONTE- RICHARDSON (1994)

O exame da literatura cladística que trata da utilização e definição de grupos externos revela um intenso debate sobre o tema (veja, por exemplo, STEVENS, 1980; WHEELER, 1981a, 1981b, 1990; WATROUS \& WHEELER, 1981; FARRIS, 1982; DONOGHUE \& Cantino, 1984; Maddison et al., 1984; Clark \& CuRran, 1986; Mool, 1989; Smith, 1992; Hanken, 1993; Nixon \& Carpenter, 1993; Trueman, 1996; Milinkovitch et al., 1996; BRYANT, 2001; WAGNER, 2001). A escolha de um grupo externo não se dá de maneira aleatória e sua composição influenciará a polarização dos caracteres e enraizamento do cladograma (NIXON \& CARPENTER, 1993). Esses autores sugerem que seja selecionado um ou mais táxons tendo como critério o compartilhamento de sinapomorfias mais inclusivas com o grupo interno sendo que, quanto mais grupos externos, melhores serão as inferências cladísticas. Contudo, não há garantia que um grupo externo em particular, ou um determinado número de táxons, irá assegurar a inferência mais correta. De qualquer forma, se não for possível identificar sinapomorfias mais inclusivas, classificações prévias ou mesmo semelhança entre os táxons podem ser usados na seleção (NIXON \& CARPENTER, 1993).

Sobre a escolha de táxons para compor o grupo externo, MACKINNON (informação pessoal, 2001) comentou que: "...Choosing an outgroup for cladistic analysis of the Bouchardioidea (aqui já utilizando a classificação mais recente de MACKINNON \& LEE, no prelo) will not be easy... In my view the most likely outgroup is the 
Laqueoidea... My reason for this is that early in ontogeny many Laqueoidea are characterized by the development of septal flanges which also occur in at least some Bouchardioidea. One problem, however, is that all Laqueoidea have dental plates whereas, as far as I can establish, dental plates are absent from Bouchardioidea." Contudo, informações ontogenéticas obtidas para Bouchardia rosea (veja Item 6.3.) e dados adicionais de literatura (e.g., RICHARDSON, 1973b, 1991, 1994; BRUNTON, 1996) não confirmam essas suspeitas. Dessa forma, optou-se por selecionar como grupo externo da presente análise a Subfamília Anakineticinae, como definida por RICHARDSON (1994) (Quadro 5).

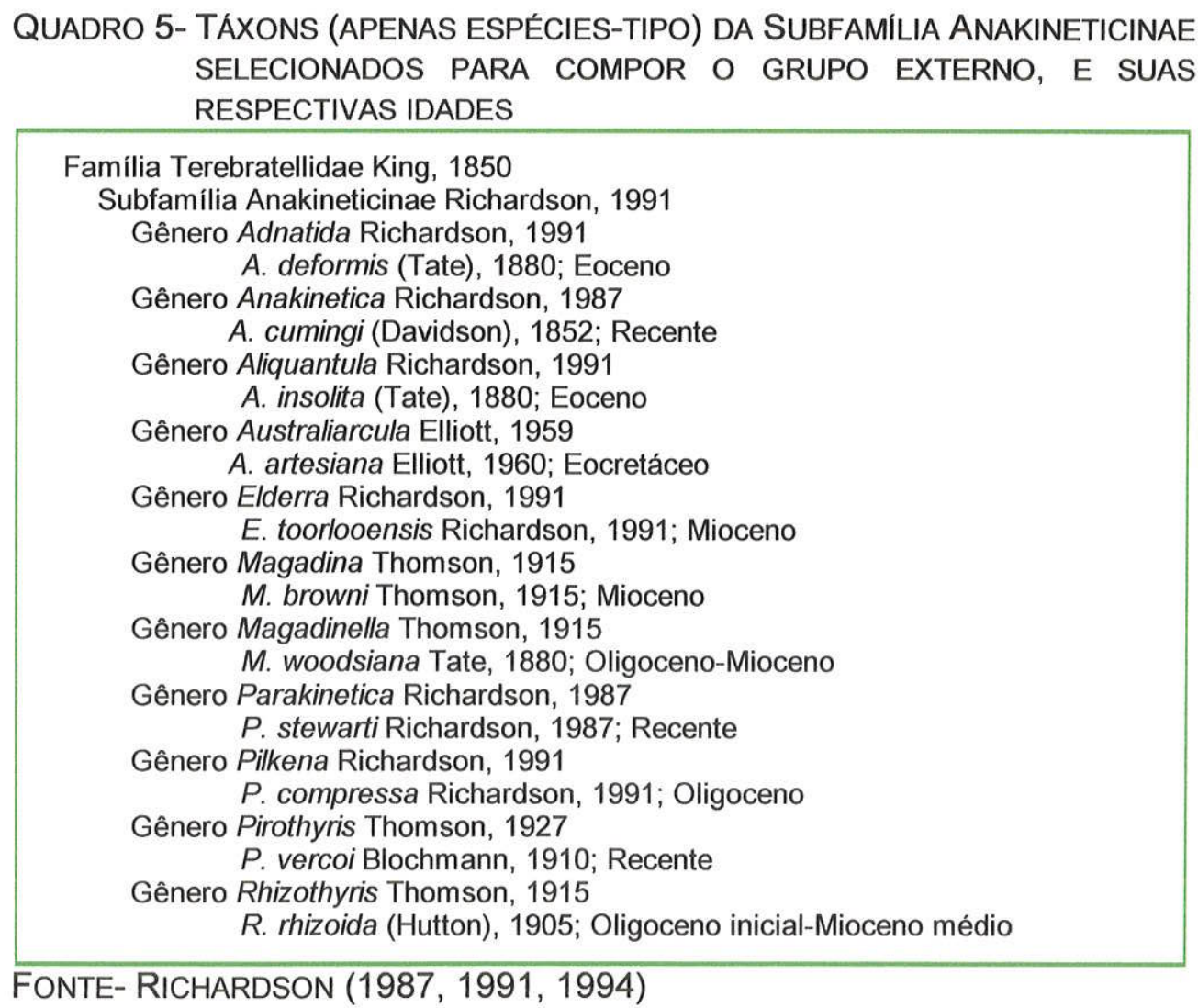

Para isso levou-se em conta a) uma possível proximidade filogenética com o grupo interno, sugerida por esquemas de classificação prévios (RICHARDSON, 1973b, 1991, 1994), embora sem qualquer embasamento cladístico (veja comentários no Item 
3.1.3.), b) o fato de que alguns dos táxons selecionados (e.g., Anakinetica cumingi) terem sido relacionados a gêneros/espécies de Bouchardiinae, como comentado a seguir, c) a dúvida no posicionamento de Australiarcula entre Bouchardinae e Anakineticinae, como apontada pelas classificações existentes (i.e., RICHARDSON, 1991, 1994; MACKINNON \& LEE, no prelo), e d) a melhor representatividade morfológica desses táxons na literatura, quando comparados com outros grupos inicialmente cogitados (e.g. Terebratellinae). Vale ressaltar, ainda, que foram utilizados todos os gêneros atribuídos à subfamília (RICHARDSON, 1991, 1994), representados por suas espécies-tipo.

A presença de algumas características morfológicas (e.g., bico, septo e braquídio) indicaria, segundo THOMSON $(1918,1927)$, um possivel estoque ancestral comum a Magellania, Bouchardia e dois Anakineticinae, Magadina e Rhizothyris. A espécie Bouchardiella cretacea foi comparada a Anakinetica cumingi por ETHERIDGE (1913), mas sua confirmação no gênero Bouchardiella foi feita por ELLIOTT (1952). Desde então, comparações entre Anakinetica e Bouchardia têm sido constantes (RICHARDSON \& WATSON, 1975a, 1975b; MACKINNON, 1987; RICHARDSON, 1987, 1991, 1994; BRUNTON, 1996) devido, sobretudo, às características morfológicas compartilhadas (e.g., espessamento posterior da concha, forâmen, musculatura, pedículo) por suas espécies-tipo, Anakinetica cumingi e Bouchardia rosea, respectivamente. ELLIOTT (1960), com base em algumas características morfológicas (e.g., forma externa da concha, do sinfítio, bico, braquídio), demonstrou haver grande semelhança entre Australiarcula e Magadina, além de importantes diferenças em relação a Bouchardia. O autor considerou, ainda, Australiarcula como o melhor candidato a ancestral de Magadina e, provavelmente, também de Bouchardia. Conforme mencionado anteriormente, LEVY (1964) havia considerado Australiarcula importante para a compreensão da evolução dos Bouchardiinae, parecendo clara a origem de Bouchardiella a partir de Australiarcula. Essas informaçōes contribuíram para a escolha de Australiarcula artesiana como elemento para compor o grupo externo. 


\subsection{FASE PRÉ-MATRIZ: ANÁLISE MORFOLÓGICA}

A análise morfológica é uma das etapas mais importantes de um estudo cladístico (AMORIM, 1997), e seu resultado serviu de base para a elaboração da matriz de caracteres. Visando cumprir os objetivos propostos, foi realizada a análise morfológica dos táxons envolvidos, o que contribuiu, inclusive, para uma melhor caracterização morfológica das espécies atribuídas ao gênero Bouchardia (sensu MANCEÑIDO \& GRIFFIN, 1988) e avaliação do escopo do gênero. Os procedimentos empregados foram indicados no liem 4.1.5. deste documento. 


\section{RESULTADOS}

\subsection{MATRIZ DE CARACTERES}

Os 43 caracteres obtidos a partir da análise morfológica, com seus estados e ordenação, são apresentados, de forma resumida, no Quadro 6. Já a distribuição dos caracteres pelos diferentes táxons envolvidos na análise encontra-se organizada e sintetizada na matriz de caracteres da Tabela 1. 
QUADRO 6- LISTA DOS CARACTERES UTILIZADOS NA ANÁLISE, SEUS RESPECTIVOS ESTADOS, CONDIÇÕES DE ORDENAÇÄO E UTILIZAÇŐES DOS CARACTERES POR AUTORES PRÉVIOS

\begin{tabular}{|c|c|c|c|}
\hline CARÁTER & ESTADOS & ORDENAÇÄO & DEFINIÇĀO DO CARÁTER \\
\hline 1 Forma da concha & $\begin{array}{l}0: \text { curvilínea } \\
\text { 1: poligonal }\end{array}$ & - & $\begin{array}{c}\text { CARLSON (1995) } \\
\text { WILLIAMS et al. (1996, 1997a, } \\
1997 \mathrm{~b}) \\
\text { ANELLI (1999) } \\
\text { WILLIAMS \& HARPER (2000) }\end{array}$ \\
\hline 2 Posicionamento da maior largura da concha & $\begin{array}{l}0: \text { anterior } \\
1: \text { centro }\end{array}$ & - & ANELLI (1999) \\
\hline 3 Dobras na comissura anterior da concha & $\begin{array}{l}0: \text { uniplicadas } \\
1: \text { rectimarginadas }\end{array}$ & -- & $\begin{array}{l}\text { CARLSON (1995) } \\
\text { WILLIAMS et al. (1997a) } \\
\text { ANELLI (1999) }\end{array}$ \\
\hline 4 Carena na valva ventral & $\begin{array}{l}0: \text { ausente } \\
1 \text { : presente }\end{array}$ & - & $\begin{array}{l}\text { presente } \\
\text { estudo }\end{array}$ \\
\hline 5 Sulco na superfície da valva dorsal & $\begin{array}{l}0: \text { ausente } \\
1: \text { presente }\end{array}$ & - & $\begin{array}{l}\text { presente } \\
\text { estudo }\end{array}$ \\
\hline 6 Linhas concêntricas evidentes & $\begin{array}{l}0: \text { ausente } \\
1 \text { : presentes }\end{array}$ & - & $\begin{array}{c}\text { CARLSON (1995) } \\
\text { WILLIAMS et al. (1996, 1997a) } \\
\text { WILLIMAS \& HARPER (2000) }\end{array}$ \\
\hline 7 Convexidade relativa das valvas & $\begin{array}{l}0 \text { : valvas convexas } \\
1: \text { valva dorsal plana }\end{array}$ & - & $\begin{array}{c}\text { CARLSON (1995) } \\
\text { HOLMER \& POPOV (1997) }\end{array}$ \\
\hline 8 Fusão dorsal de placas deltidiais & $\begin{array}{l}0: \text { deltídio } \\
1: \text { sinfítio }\end{array}$ & - & $\begin{array}{l}\text { presente } \\
\text { estudo }\end{array}$ \\
\hline 9 Comportamento das placas deltidiais & $\begin{array}{l}0: \text { plano } \\
1 \text { : côncavo }\end{array}$ & - & $\begin{array}{l}\text { presente } \\
\text { estudo }\end{array}$ \\
\hline 10 Comportamento do bico & $\begin{array}{l}0: \text { reto } \\
1: \text { inclinado } \\
2: \text { curvo }\end{array}$ & $\mathrm{O}$ & $\begin{array}{l}\text { presente } \\
\text { estudo }\end{array}$ \\
\hline 11 Tipo de forâmen & $\begin{array}{l}\text { 0: hipotírido } \\
\text { 1: mesotírido } \\
\text { 2: permesotírido } \\
\text { 3: epitírido }\end{array}$ & NO & $\begin{array}{l}\text { presente } \\
\text { estudo }\end{array}$ \\
\hline 12 Posicionamento do forâmen & $\begin{array}{l}0: \text { apical } \\
1: \text { ventral }\end{array}$ & - & $\begin{array}{l}\text { WILLIAMS et al. }(1996,1997 a) \\
\text { WILLIAMS \& HARPER }(2000)\end{array}$ \\
\hline 13 Pregas na margem interna da concha & $\begin{array}{l}0: \text { ausente } \\
1 \text { : presente }\end{array}$ & - & ANELLI (1999) \\
\hline 14 Septo na superfície interna da valva ventral & $\begin{array}{l}0: \text { ausente } \\
1 \text { : presente }\end{array}$ & - & $\begin{array}{c}\text { presente } \\
\text { estudo }\end{array}$ \\
\hline $\begin{array}{l}15 \text { Extremidade do septo na superfície interna } \\
\text { da valva ventral }\end{array}$ & $\begin{array}{l}0: \text { livre } \\
1: \text { em seta }\end{array}$ & - & $\begin{array}{l}\text { presente } \\
\text { estudo }\end{array}$ \\
\hline 16 Relevo do assoalho da valva dorsal & $\begin{array}{l}0: \text { ausente } \\
\text { 1: retas inclinadas } \\
\text { 2: círculos }\end{array}$ & NO & $\begin{array}{l}\text { presente } \\
\text { estudo }\end{array}$ \\
\hline 17 Perfil do septo mediano & $\begin{array}{l}\text { 0: elevado } \\
\text { 1: estendido } \\
\text { 2: rebaixado }\end{array}$ & NO & CARLSON (1995) \\
\hline 18 Extremidade anterior do septo & $\begin{array}{l}\text { 0: não ultrapassa a metade } \\
\text { da valva ventral } \\
\text { 1: ultrapassa a metade da } \\
\text { valva ventral }\end{array}$ & - & $\begin{array}{l}\text { presente } \\
\text { estudo }\end{array}$ \\
\hline 19 Elevação do septo & $\begin{array}{l}0: \text { anterior } \\
1: \text { mediana }\end{array}$ & - & $\begin{array}{l}\text { presente } \\
\text { estudo }\end{array}$ \\
\hline $\begin{array}{l}20 \text { Contato da extremidade anterior do septo } \\
\text { com a valva ventral }\end{array}$ & $\begin{array}{l}0: \text { ausente } \\
1: \text { presente }\end{array}$ & - & $\begin{array}{l}\text { presente } \\
\text { estudo }\end{array}$ \\
\hline 21 Base do septo mediano & $\begin{array}{l}0: \text { largura constante } \\
\text { 1: estreita anteriormente }\end{array}$ & - & $\begin{array}{l}\text { presente } \\
\text { estudo }\end{array}$ \\
\hline $\begin{array}{l}22 \text { Encontro do septo com a plataforma } \\
\text { cardinal }\end{array}$ & $\begin{array}{l}0: \text { não bífido } \\
1: \text { bífido }\end{array}$ & - & $\begin{array}{l}\text { presente } \\
\text { estudo }\end{array}$ \\
\hline 23 Braquídio fixado ao septo mediano & $\begin{array}{l}0: \text { ausente } \\
\text { 1: presente }\end{array}$ & - & $\begin{array}{l}\text { presente } \\
\text { estudo }\end{array}$ \\
\hline 24 Braquídio em forma de laço ('loop') & $\begin{array}{l}0: \text { ausente } \\
1 \text { : presente }\end{array}$ & - & $\begin{array}{l}\text { presente } \\
\text { estudo }\end{array}$ \\
\hline 25 Fixação dos ramos descendentes no septo & $\begin{array}{l}0: \text { ausente } \\
\text { 1: presente }\end{array}$ & - & $\begin{array}{l}\text { presente } \\
\text { estudo }\end{array}$ \\
\hline $\begin{array}{l}26 \text { Fixação dos ramos descendentes na } \\
\text { cardinália }\end{array}$ & $\begin{array}{l}0: \text { ausente } \\
\text { 1: presente }\end{array}$ & - & $\begin{array}{l}\text { presente } \\
\text { estudo }\end{array}$ \\
\hline
\end{tabular}


conclusão

QUADRO 6- LISTA DOS CARACTERES UTILIZADOS NA ANÁLISE, SEUS RESPECTIVOS ESTADOS, CONDIÇÖES DE ORDENAÇÃO E UTILIZAÇÖES DOS CARACTERES POR AUTORES PRÉVIOS

\begin{tabular}{|c|c|c|c|}
\hline CARÁTER & ESTADOS & ORDENAÇĀO & DEFINIÇÃO DO CARÁTER \\
\hline 27 Ramos ascendentes & $\begin{array}{l}0: \text { ausente } \\
\text { 1: presentes }\end{array}$ & - & $\begin{array}{l}\text { presente } \\
\text { estudo }\end{array}$ \\
\hline 28 Fixação posterior dos ramos ascendentes & $\begin{array}{l}0: \text { ramos livres } \\
\text { 1: formando laço }\end{array}$ & - & $\begin{array}{l}\text { presente } \\
\text { estudo }\end{array}$ \\
\hline 29 Encaixe do braquídio no septo & $\begin{array}{l}\text { 0: na extremidade } \\
\text { 1: posição intermediária }\end{array}$ & - & $\begin{array}{l}\text { presente } \\
\text { estudo }\end{array}$ \\
\hline 30 Diferenciação dos elementos da charneira & $\begin{array}{l}\text { 0: fundidos identificáveis } \\
\text { 1: fundidos não identificáveis }\end{array}$ & - & $\begin{array}{l}\text { presente } \\
\text { estudo }\end{array}$ \\
\hline 31 Relação entre a linha e o eixo da charneira & $\begin{array}{l}0: \text { estrófico } \\
\text { 1: astrófico }\end{array}$ & -- & $\begin{array}{c}\text { CARLSON (1995) } \\
\text { WILLIAMS et al. (1996) }\end{array}$ \\
\hline 32 Configuração do processo cardinal & $\begin{array}{l}\text { 0: bilobado } \\
\text { 1: trífido }\end{array}$ & - & $\begin{array}{c}\text { CARLSON (1995) } \\
\text { WiLLIAMS et al. (1996, 1997a, } \\
\text { 1997b) } \\
\text { ANELLI (1999) }\end{array}$ \\
\hline 33 Processo cardinal bilobado em forma de "V" & $\begin{array}{l}0: \text { ausente } \\
1 \text { : presente }\end{array}$ & -- & $\begin{array}{l}\text { presente } \\
\text { estudo }\end{array}$ \\
\hline 34 Reforço da articulação por cristas e sulcos & $\begin{array}{l}0: \text { ausente } \\
\text { 1: presente }\end{array}$ & - & $\begin{array}{l}\text { presente } \\
\text { estudo }\end{array}$ \\
\hline 35 Crura & $\begin{array}{l}0: \text { ausente } \\
\text { 1: presente }\end{array}$ & - & WILLIAMS et al. (1996) \\
\hline 36 Depressão na charneira ("hinge trough") & $\begin{array}{l}0: \text { ausente } \\
\text { 1: presente }\end{array}$ & - & $\begin{array}{l}\text { presente } \\
\text { estudo }\end{array}$ \\
\hline $\begin{array}{l}37 \text { Cavidades na parede anterior da plataforma } \\
\text { cardinal }\end{array}$ & $\begin{array}{l}0: \text { ausentes } \\
1: \text { presentes }\end{array}$ & - & $\begin{array}{l}\text { presente } \\
\text { estudo }\end{array}$ \\
\hline $\begin{array}{l}38 \text { Número de cavidades na parede anterior da } \\
\text { plataforma cardinal }\end{array}$ & $\begin{array}{l}0: 2 \text { cavidades } \\
1: 3 \text { cavidades }\end{array}$ & - & $\begin{array}{l}\text { presente } \\
\text { estudo }\end{array}$ \\
\hline 39 Tipo de lofóforo & $\begin{array}{l}0: \text { zigolofo } \\
\text { 1: plectolofo }\end{array}$ & - & $\begin{array}{l}\text { presente } \\
\text { estudo }\end{array}$ \\
\hline 40 Tipo de pedículo & $\begin{array}{l}0: \text { fixador } \\
1: \text { móvel }\end{array}$ & - & $\begin{array}{l}\text { presente } \\
\text { estudo }\end{array}$ \\
\hline 41 Tipo de extremidade do pedículo & $\begin{array}{l}0: \text { inerte } \\
1: \text { transicional }\end{array}$ & -- & $\begin{array}{l}\text { presente } \\
\text { estudo }\end{array}$ \\
\hline 42 Tipo de extremidade inerte do pedículo & $\begin{array}{l}0: \text { sem aderência } \\
\text { 1: aderente }\end{array}$ & - & $\begin{array}{l}\text { presente } \\
\text { estudo }\end{array}$ \\
\hline 43 Reforço da cicatriz do músculo adutor dorsal & $\begin{array}{l}0: \text { ausente } \\
\text { 1: presente }\end{array}$ & -- & $\begin{array}{l}\text { presente } \\
\text { estudo }\end{array}$ \\
\hline
\end{tabular}

EXPLICAÇÃO- O= ORDENADO; NO= NÃO ORDENADO; CARACTERES BINÁRIOS SÃO ORDENADOS POR DEFINIÇÃO E, PORTANTO, ESTÃO INDICADOS COMO "--" 
TABELA 1- MATRIZ DE CARACTERES UTILIZADOS NA ANÁLISE CLADÍSTICA

$\begin{array}{lllllllllllllllllllllllllllllllllllllllllllll}\text { Táxons / Caracteres } & 0 & 0 & 0 & 0 & 0 & 0 & 0 & 0 & 0 & 1 & 1 & 1 & 1 & 1 & 1 & 1 & 1 & 1 & 1 & 2 & 2 & 2 & 2 & 2 & 2 & 2 & 2 & 2 & 2 & 3 & 3 & 3 & 3 & 3 & 3 & 3 & 3 & 3 & 3 & 4 & 4 & 4 & 4 \\ & 1 & 2 & 3 & 4 & 5 & 6 & 7 & 8 & 9 & 0 & 1 & 2 & 3 & 4 & 5 & 6 & 7 & 8 & 9 & 0 & 1 & 2 & 3 & 4 & 5 & 6 & 7 & 8 & 9 & 0 & 1 & 2 & 3 & 4 & 5 & 6 & 7 & 8 & 9 & 0 & 1 & 2 & 3\end{array}$

Anakinetica cumingi

Adnatida deformis

Aliquantula insolita

Australiarcula artesiana

Elderra toorlooensis

Magadina browni

Magadinella woodsiana

Parakinetica stewarti

Pilkena compressa

Pirothyris vercoi

Rhizothyris rhizoida

Bouchardia antarctica

Bouchardia conspicua

Bouchardia exigua

Bouchardia rosea

Bouchardia transplatina

Bouchardia zitteli

Neobouchardia minima

Bouchardiella cretacea

Bouchardiella jorgensis

Bouchardiella patagonica

Malleia portlandica $\begin{array}{llllllllllllllllllllllllllllllllllllllllllll}0 & 1 & 0 & 1 & 0 & 0 & 0 & 1 & 0 & 1 & 2 & 0 & 1 & 0 & ? & 0 & 0 & 1 & 0 & 0 & 1 & 0 & 1 & 1 & 1 & 1 & 1 & 1 & 0 & 1 & 1 & 1 & ? & 0 & 1 & 0 & 0 & ? & 0 & 1 & 0 & 0 & 1\end{array}$

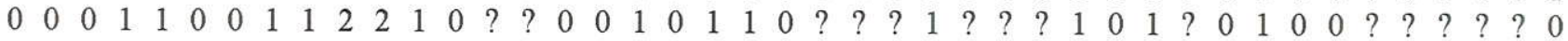
$\begin{array}{llllllllllllllllllllllllllllllllllllllllllll}0 & 1 & 1 & 0 & 0 & 0 & 1 & 1 & 0 & 1 & 1 & 0 & 0 & ? & ? & 0 & 2 & 0 & ? & ? & 1 & 1 & 0 & 1 & 0 & 1 & 1 & 1 & ? & 1 & 0 & 1 & ? & 1 & 1 & 1 & 0 & ? & 1 & ? & ? & ? & 0\end{array}$ $\begin{array}{llllllllllllllllllllllllllllllllllllllllllll}0 & 1 & 0 & 1 & 1 & 1 & 1 & 0 & 1 & 1 & 2 & 0 & 0 & ? & ? & 2 & 1 & 1 & ? & ? & 1 & 0 & 1 & 0 & 1 & 1 & 0 & ? & 0 & 1 & 1 & 1 & \text { ? } & 1 & 1 & 0 & 1 & 0 & 0 & 1 & \text { ? } & \text { ? } & 1\end{array}$

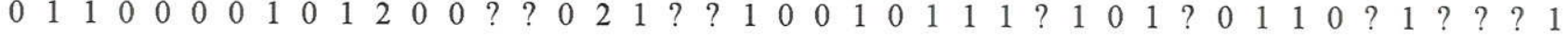

$\begin{array}{lllllllllllllllllllllllllllllllllllllllllll}0 & 1 & 0 & 1 & 0 & 0 & 1 & 0 & 1 & 1 & 2 & 0 & 0 & \text { ? } & \text { ? } & 0 & 0 & 1 & 0 & 1 & \text { ? } & 0 & 1 & 1 & 1 & 1 & 1 & 1 & 0 & 0 & 0 & 1 & ? & 0 & 1 & 1 & 0 & ? & 1\end{array}$ ? ? $\begin{array}{llllllllllllllllllllllllllllllllllllllllllll}0 & 1 & 0 & 1 & 0 & 0 & 0 & 1 & 1 & 2 & 2 & 0 & 0 & 0 & ? & 0 & 0 & 1 & 1 & ? & 1 & 0 & 1 & 1 & 1 & 1 & 1 & 1 & 0 & 1 & 0 & 1 & ? & 0 & 1 & 1 & 0 & ? & 1 & 0 & 1 & ? & 1\end{array}$ $\begin{array}{lllllllllllllllllllllllllllllllllllllllllllll}0 & 1 & 0 & 1 & 1 & 0 & 1 & 0 & 0 & 0 & 2 & 0 & 0 & 1 & 0 & 0 & 0 & 1 & 0 & 0 & 0 & 0 & 1 & 1 & 1 & ? & 1 & 1 & 0 & 0 & 0 & 1 & ? & 0 & 1 & 0 & 0 & ? & 1 & 1 & 0 & 0 & 0\end{array}$

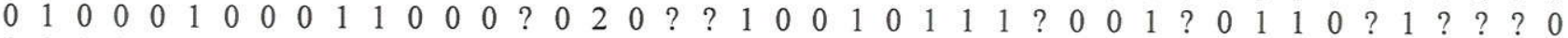
$\begin{array}{llllllllllllllllllllllllllllllllllllllllllll}0 & 0 & 1 & 0 & 0 & 0 & 0 & 1 & 1 & 1 & \text { ? } & 0 & 0 & 0 & ? & 0 & 0 & 0 & 0 & 1 & 1 & 0 & 1 & 1 & 1 & 1 & 1 & 1 & 0 & 1 & 0 & 1 & ? & 0 & 1 & 1 & 0 & ? & 1 & 0 & 0 & 1 & 0\end{array}$ $\begin{array}{llllllllllllllllllllllllllllllllllllllllllll}0 & 1 & 0 & 0 & 0 & 0 & 0 & 1 & 0 & 1 & 2 & 0 & 0 & \text { ? } & \text { ? } & \text { ? } & 2 & 0 & \text { ? } & \text { ? } & 1 & 0 & 0 & 1 & 0 & 1 & 1 & 1 & \text { ? } & 1 & 1 & 1 & \text { ? } & 0 & 1 & 0 & 0 & \text { ? } & 1 & 1 & 0 & 0 & 0\end{array}$ $\begin{array}{lllllllllllllllllllllllllllllllllllllllllllll}0 & 1 & 1 & 1 & 0 & 1 & 0 & 0 & 1 & 0 & 3 & 0 & 0 & 1 & 0 & 1 & 0 & 1 & 0 & 0 & 1 & 0 & 1 & 0 & 0 & 0 & 1 & 0 & 0 & 1 & 1 & 0 & 1 & 1 & 0 & 0 & 1 & 0 & 0 & 1 & 0 & 0 & 0\end{array}$ $\begin{array}{llllllllllllllllllllllllllllllllllllllllllll}0 & 1 & 1 & 0 & 0 & 0 & 0 & 0 & 1 & 0 & 3 & 0 & 0 & ? & ? & 1 & 0 & ? & 0 & 0 & 1 & 0 & 1 & 0 & 0 & 0 & 1 & 0 & 0 & 1 & 1 & 0 & 1 & 1 & 0 & 0 & 1 & 0 & 0 & 1 & 0 & 0 & 0\end{array}$ $\begin{array}{lllllllllllllllllllllllllllllllllllllllllll}0 & 1 & 1 & 0 & 0 & 0 & 0 & \text { ? } & 1 & 0 & 3 & 0 & 0 & \text { ? } & \text { ? } & \text { ? } & \text { ? } & ? & \text { ? } & ? & \text { ? } & 0 & 1 & 0 & 0 & 0 & 1 & 0 & 0 & 1 & 1 & 0 & 1 & 1 & 0 & 0 & \text { ? } & \text { ? } & 0 & 1 & 0 & 0 & \text { ? }\end{array}$ $\begin{array}{llllllllllllllllllllllllllllllllllllllllllll}0 & 1 & 0 & 1 & 1 & 0 & 0 & 0 & 1 & 0 & 3 & 0 & 0 & 1 & 1 & 1 & 0 & 1 & 0 & 0 & 1 & 0 & 1 & 0 & 0 & 0 & 1 & 0 & 0 & 1 & 1 & 0 & 1 & 1 & 0 & 0 & 1 & 0 & 0 & 1 & 0 & 0 & 0\end{array}$ $\begin{array}{llllllllllllllllllllllllllllllllllllllllllll}0 & 1 & 0 & 1 & 1 & 0 & 0 & 0 & 1 & 0 & 3 & 0 & 0 & 1 & 1 & 1 & 0 & 1 & 0 & 0 & 1 & 0 & 1 & 0 & 0 & 0 & 1 & 0 & 0 & 1 & 0 & 0 & 1 & 1 & 0 & 0 & 1 & 0 & 0 & 1 & 0 & 0 & 0\end{array}$ $\begin{array}{llllllllllllllllllllllllllllllllllllllllllll}1 & 1 & 1 & 0 & 0 & 1 & 1 & 0 & 1 & 0 & 3 & 0 & 0 & 1 & 0 & 1 & 0 & 1 & 0 & 0 & 1 & 0 & 1 & 0 & 0 & 0 & 1 & 0 & 0 & 1 & 0 & 0 & 1 & 1 & 0 & 0 & 1 & 0 & 0 & 1 & 0 & 0 & 0\end{array}$ $\begin{array}{llllllllllllllllllllllllllllllllllllllllllll}0 & 1 & 1 & 1 & 0 & 0 & 0 & 0 & 1 & 1 & 3 & 0 & 0 & 1 & 1 & 0 & 0 & 1 & 0 & 0 & 0 & 0 & 1 & 0 & 0 & 0 & 1 & 0 & 0 & 1 & 1 & 0 & 0 & 1 & 1 & 0 & 1 & 1 & 0 & 1 & ? & ? & 0\end{array}$

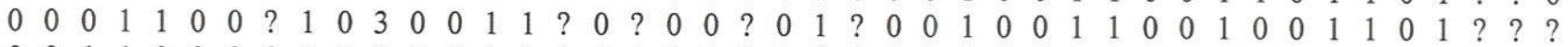

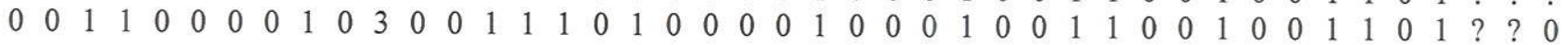
$\begin{array}{llllllllllllllllllllllllllllllllllllllllllll}0 & 1 & 1 & 1 & 0 & 0 & 0 & 0 & 1 & 0 & 2 & 0 & 0 & 1 & 1 & 1 & 0 & 1 & 0 & 0 & 0 & 0 & 1 & 0 & 0 & 0 & 1 & 0 & 0 & 1 & 1 & 0 & 0 & 1 & 0 & 0 & 1 & 1 & 0 & 1 & ? & ? & 0\end{array}$ $\begin{array}{llllllllllllllllllllllllllllllllllllllllllll}0 & 1 & 0 & 1 & 1 & 0 & 1 & 1 & 1 & 0 & 0 & 1 & 0 & 1 & 1 & 1 & 0 & 1 & 0 & 0 & 0 & 1 & 1 & ? & 1 & 0 & 1 & 0 & 1 & 1 & 1 & 0 & 0 & 1 & 0 & 0 & 0 & ? & 0 & 0 & ? & ?\end{array}$ 


\subsection{DEFINIÇÃo E TRATAMENTO dOS CARACTERES}

Inicialmente, foi realizado um levantamento na literatura (Popov et al., 1993; CARLSON, 1995; HOLMER et al., 1995; WILLIAMS et al., 1996, 1997a, 1997b, 2000b; HOLMER \& POPOV, 1997; ANELLI, 1999; WILLIAMS \& HARPER, 2000) para verificar quais caracteres morfológicos são mais empregados nas investigações cladísticas de Rhynchonelliformea. A seguir, foi estabelecida uma lista de caracteres potencialmente utilizáveis, que pôde ser devidamente testada e modificada com o desenvolvimento da análise morfológica aqui relatada.

Os procedimentos para a análise morfológica dos 22 táxons terminais foram descritos e considerados no Item 4.1.5. deste documento, tendo como resultado o estabelecimento de 43 caracteres (binários e multi-estado), arranjados em dois agrupamentos: a) Caracteres externos da concha (Caráter 1 até 12); b) Caracteres internos da concha (Caráter 13 até 43). Os caracteres escolhidos e analisados estão listados a seguir e, quando conveniente, brevemente comentados. O Quadro 6, como já citado, resume a lista dos caracteres e seus estados.

É interessante notar que o uso de caracteres morfométricos (ou contínuos) é comum em investigações cladísticas dos mais variados grupos de organismos (veja, por exemplo, BRUNTON et al., 1995; SIMÕEs et al., 1997; WILLIAMS et al., 1997a, 1997b; SCHNEIDER, 1998a, 1998b; ANELLI, 1999; WILLIAMS \& HARPER, 2000, entre outros). Contudo, tais dados, invariavelmente, refletem aspectos ecológicos dos organismos sendo que indivíduos não aparentados mas com, por exemplo, modos de vida semelhantes podem sofrer as mesmas pressões ecológicas, resultando em morfologias muito próximas evidenciadas por seus dados biométricos (STANLEY, 1970; SAVAZZI, 1999). Portanto, o uso desses caracteres em estudos cladísticos pode aproximar formas não aparentadas, mascarando sinapomorfias e homoplasias, o que demanda cuidado e bom senso por parte do sistemata. As ressalvas quanto a sua utilização estão fundamentadas em dois pontos principais: a) questões sobre os princípios dos dados quantitativos, e b) questões sobre os métodos (e.g., "segment coding" e "gap coding") de derivação de estados de caracteres a partir dessas informações, sobretudo pela sua arbitrariedade (RAE, 1998). Nesse contexto, os métodos para estabelecer estados de caracteres a partir de dados quantitativos, bem como sua aplicação na cladística, têm sido motivo de intensos debates (e.g., ARCHIE, 1985; PIMENTEL \& 
Riggins, 1987; Cranston \& Humphries, 1988; Chappil, 1989; THIELE, 1993; RaE, 1998). Dessa forma, os dados morfométricos obtidos inicialmente no presente estudo não foram considerados para a confeç̧ão da matriz, evitando a utilização de estados de caracteres definidos arbitrariamente o que traria inconsistência para a análise.

Por fim, os termos descritivos aqui empregados representam um consenso das nomenclaturas sugeridas por WILLIAMS et al. (1997c), FonsECA (2000) e trabalhos morfológicos mais específicos de reconhecida relevância para o conhecimento do grupo, como RICHARDSON (1975a, 1975b, 1979, 1981b) e BRUNTON et al. (1996), entre outros. O mesmo ocorre para a denominação de 'valva ventral' e 'valva dorsal' em lugar de 'valva pedicular' e 'valva braquial', respectivamente, seguindo orientação do Treatise on Invertebate Paleontology (Brachiopoda) (WILLIAMS et al., 1997c). Quando necessário, e possivel, os caracteres foram ilustrados por figuras e esquemas. Nas estampas apresentadas (Estampas 1 a 7) podem ser vistos grande parte dos caracteres utilizados.

\section{A) CARACTERES Externos DA Concha (caráter 1 ao 12) CARÁTER 1 - Forma da concha}

\section{Estado $\quad 0$ (curvilínea); 1 (poligonal)}

A forma da concha é de fácil diferenciação entre as diversas espécies de braquiópodes existentes, inclusive aquelas envolvidas na análise (Estampas 2 a 7 ). Talvez, por esse motivo, seja bastante empregada como caráter nas análises cladísticas (e.g., CARLSON, 1995; WILLIAMS et al., 1996, 1997a, 1997b; ANELLI, 1999; WILLIAMS \& HARPER, 2000). Contudo, a definição e determinação de seus estados, geralmente através de caracterizações imprecisas (e.g., subcircular, subquadrado, ovalado), é muito freqüente. Foi observado que valvas ventrais pouco alongadas antero-posteriormente (e.g., Bouchardiella patagonica, Malleia portlandica) apresentavam contorno bastante curvilíneo, quase circular. Por outro lado, um alongamento um pouco mais evidente esteve associado a contornos curvilíneos (e.g., Bouchardia rosea) e poligonais (e.g., Bouchardia zitteli, Anakinetica breva) sendo, este último, caracterizado por paredes laterais aproximadamente retas (paralelas ou não) nas conchas. Desta maneira, o caráter aqui proposto reuniu sob a designação 'curvilinea' (estado ' $O$ ') aquelas conchas circulares ou alongadas, desde que com 
paredes curvas (e.g., Bouchardia rosea), enquanto conchas alongadas com paredes retas (e.g., Bouchardia zitteli) foram consideradas 'poligonais' (estado '1').

\section{CARÁTER 2 - Posicionamento da maior largura da concha na valva ventral}

\section{Estado $\quad 0$ (anterior); 1 (centro)}

A diferença na localização da maior largura da concha é evidente (Estampas 2 a 7). Pode estar localizada em seu comprimento médio (estado '2') ou região anterior (estado '1').

\section{CARÁTER 3 - Dobras na comissura anterior da concha}

\section{Estado $\quad 0$ (uniplicada); 1 (rectimarginada)}

O comportamento da linha de comissura em conchas de braquiópodes é facilmente reconhecivel (e.g., rectimarginada, uniplicada, sulcada). Essa feição, assim como a intensidade da dobra formada, têm sido empregados como estados do caráter em estudos cladísticos (e.g., CARLSON, 1995; WILLIAMs et al., 1997a; ANELLI, 1999). De uma maneira geral, todas as espécies aqui analisadas apresentaram algum vestígio de dobra na comissura anterior de suas conchas, ainda que algumas se mostrassem quase rectimarginadas (e.g., Bouchardia conspicua). Medidas do comprimento e altura dos sulcos de conchas uniplicadas, assim como relações entre esses valores, foram utilizadas por COOPER \& DOHERTY (1993), na tentativa de diferenciar populações de Calloria inconspicua e Calloria variegata. No entanto, a utilização de tais informações no presente estudo implicaria na adoção de caracteres e estados baseados em dados contínuos, o que foi evitado como comentado anteriormente. Dessa forma, a definição dos 2 estados do caráter foi feita apenas pela observação das conchas, diferenciando as rectimarginadas das uniplicadas (Figura 3 ).

\section{CARÁTER 4 - Carena na valva ventral}

\section{Estado 0 (ausente); 1 (presente)}

A carena é uma notável elevação angular da superficie da valva ventral, que se estende antero-posteriormente junto à linha média, conferindo convexidade à valva $\Theta$ marcando o início da inclinação da valva, em direção às suas margens laterais. 


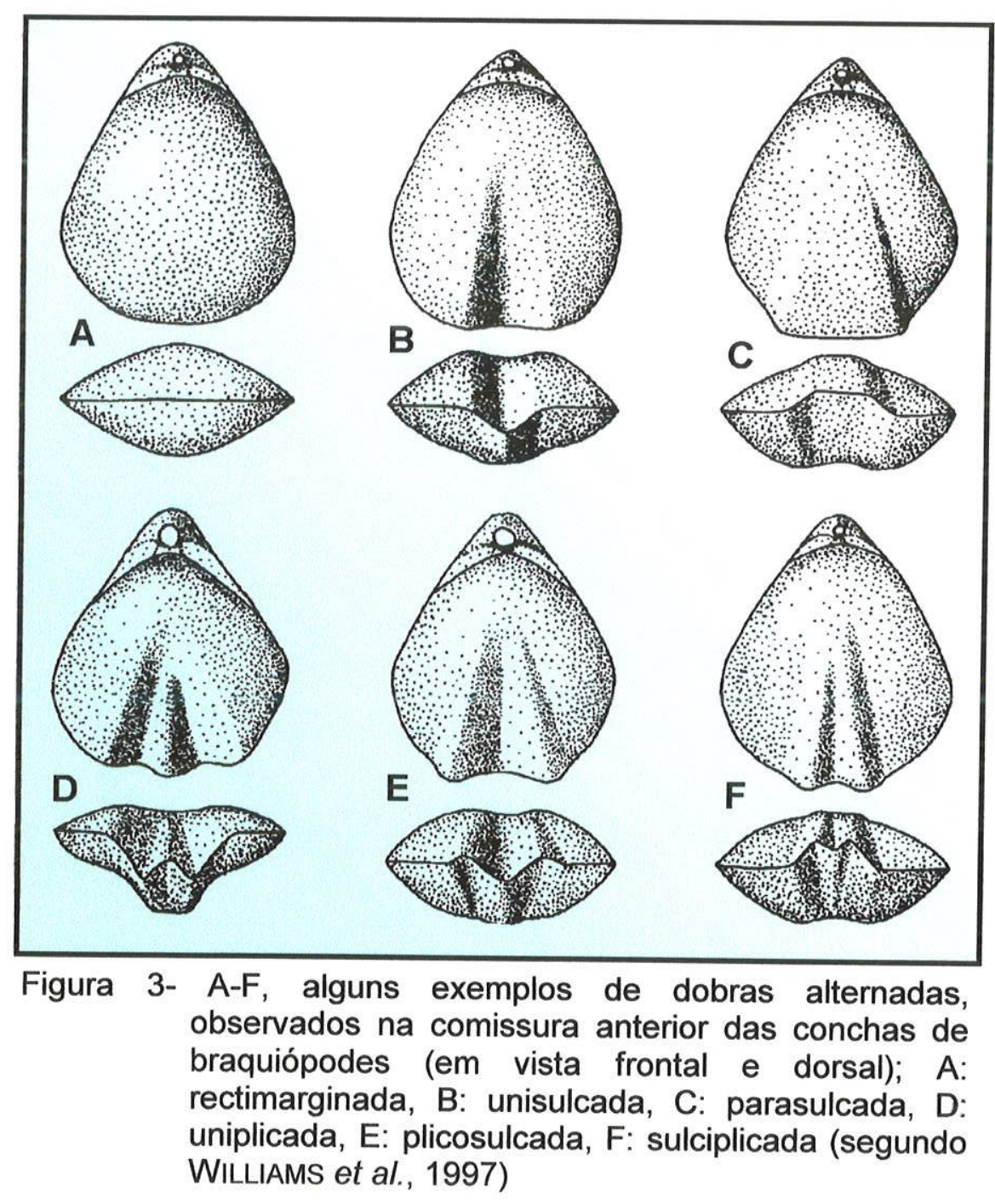

\section{CARÁTER 5 - Sulco na superfície da valva dorsal}

\section{Estado $\quad 0$ (ausente); 1 (presente)}

Depressão alongada antero-posteriormente, que se inicia, normalmente, a partir da região mediana da valva dorsal, larga na margem anterior, estreitando-se posteriormente. Algumas vezes está associado à dobra na comissura anterior da concha (Figura 3).

\section{CARÁTER 6 - Linhas concêntricas proeminentes}

\section{Estado $\quad 0$ (ausente); 1 (presente)}

Os diferentes tipos de ornamentação existentes nas conchas de braquiópodes, amplamente ilustrados na literatura (e.g., WILLIAMS et al., 1965, 1997c; RUDWICK, 1970), 
freqüentemente fazem parte das listas de caracteres dos estudos cladísticos para o grupo (e.g., CARLSON, 1995; HOLMER \& POPOV, 1997; WILliams et al., 1996, 1997b; WILLIAMS \& HARPER, 2000). Os braquiópodes exibem desde conchas totalmente lisas até aquelas ornamentadas com longos espinhos. Entre os táxons examinados no presente estudo foram encontradas conchas exibindo apenas linhas de crescimento levemente marcadas, consideradas sem ornamentação (estado ' $O$ ') e algumas com estruturas concêntricas (estado ' 1 ') bem evidentes, que se intercalavam às linhas de crescimento e se destacavam em relação a estas, repetindo-se de 3 a 5 vezes ao longo da concha (e.g., Bouchardia zitteli) (Estampas 2 a 7). Linhas de crescimento são definidas como linhas concêntricas na superfície externa da concha, formadas quando o crescimento anterior e lateral da concha está temporariamente suspenso, sendo que aquelas linhas mais proeminentes tendem a ser mais regularmente espaçadas e, até, mais pigmentadas (RUDWICK, 1962; HILLER, 1988). Neste contexto, a ornamentação identificada nos exemplares examinados no presente estudo corresponde a um dos três tipos identificados na literatura especializada (HILLER, 1988), a saber: a) inconspícuas ou discretas, que representam incrementos à concha, sendo difíceis de distinguir nos fósseis e organismos viventes de conchas delicadas, b) proeminentes, facilmente identificáveis em exemplares fósseis e viventes, representariam um retardo ou parada, periódico ou sazonal, no crescimento, podendo ocorrer em intervalos mais ou menos regulares nas conchas, e c) anel de distúrbio, formados em ocasiōes de traumas ocorridos durante a vida do indivíduo.

\section{CARÁTER 7 - Convexidade relativa das valvas}

Estado $\quad 0$ (valvas convexas); 1 (valva dorsal plana)

Este caráter foi já empregado por CARLSON (1995). A análise das valvas, em espécimes articulados ou não, sobretudo em vista lateral, permite a avaliação de sua convexidade. Nos táxons examinados as duas valvas poderiam ser convexas (ou biconvexas; estado ' $O$ '), ainda que com intensidades diferentes, ou a valva dorsal poderia ser plana (estado ' 1 '). 


\section{CARÁTER 8 - Fusão dorsal de placas deltidiais}

\section{Estado 0 (deltídio); 1 (sinfítio)}

De acordo com Williams et al. (1997c), tanto o deltídio quanto o sinfítio são formados pela fusão dorsal ou anterior de placas deltidiais, ambos sendo diferenciados justamente pela presença de uma linha na junção dessas placas, mais marcada nos deltídios.

\section{CARÁTER 9 - Comportamento das placas deltidiais}

Estado 0 (plano); 1 (côncavo)

A região formada pela fusão das placas deltidiais pode ser plana ou levemente deprimida, como observado em Bouchardia rosea.

\section{CARÁTER 10 - Comportamento do bico}

Estado 0 (reto); 1 (inclinado); 2 (curvo)

Caráter exemplificado na Figura 4.

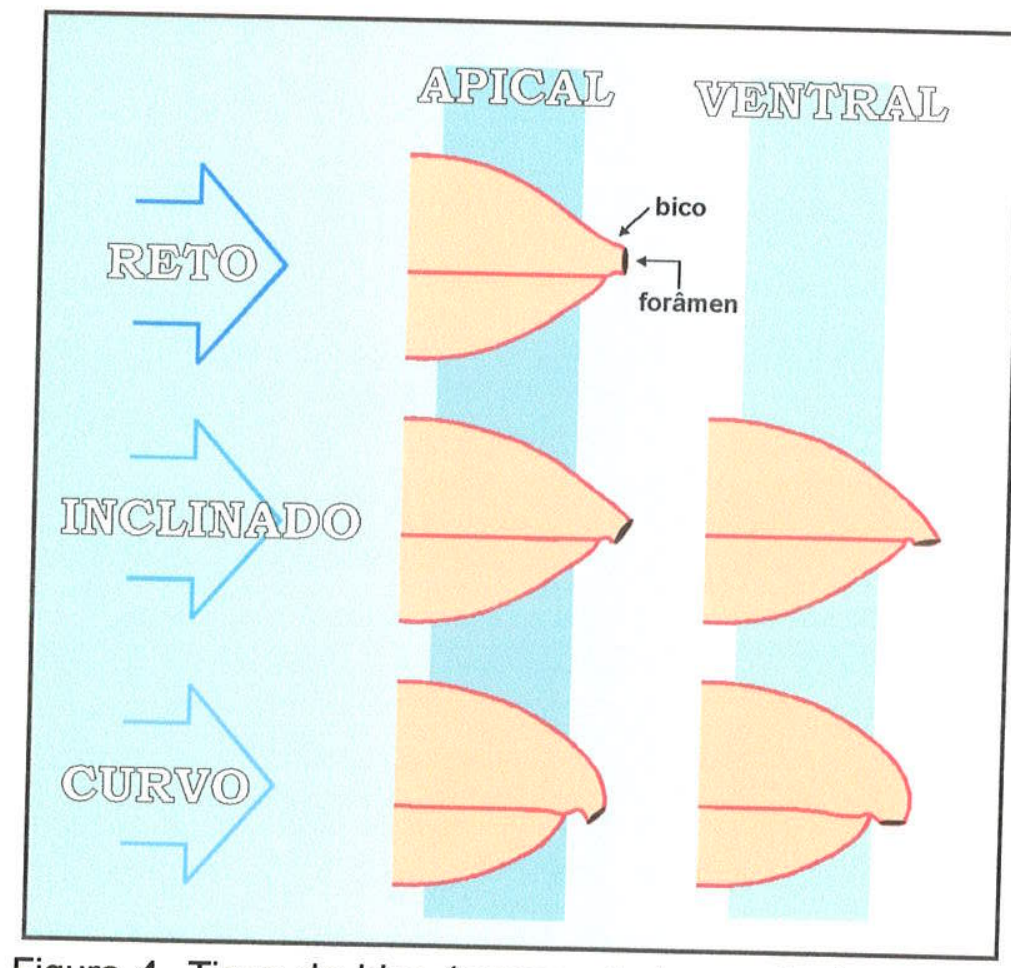

Figura 4- Tipos de bico (representados na horizontal) e pedículos (representados na vertical), e suas combinações observadas entre os táxons analisados (Caracteres 10 e 12) 


\section{CARÁTER 11 - Tipo de forâmen}

Estado 0 (hipotírido); 1 (mesotírido); 2 (permesotírido); 3 (epitírido)

A forma e localização do forâmen estão diretamente associadas aos componentes da concha que estão ao seu redor (e.g., placas deltidiais, cristas do bico), resultando em diferentes denominações, como proposto por WILLIAMS et al. (1997c) (Figura 5). Contudo, apesar desta classificação, não há, na literatura, qualquer referência sobre a evolução destas feições, o que poderia fornecer alguma idéia sobre a contigüidade de seus estados. Independentemente disso, a adoção de critérios lógicos para ordenação, como sugerido por AMORIM (1997), permitiria ordenar os estados desse caráter de várias maneiras, uma vez que a contigüidade do estado ' 0 ' (hipotírido) com os demais estados é ignorada. Dessa forma, optou-se por considerar o caráter como não ordenado.

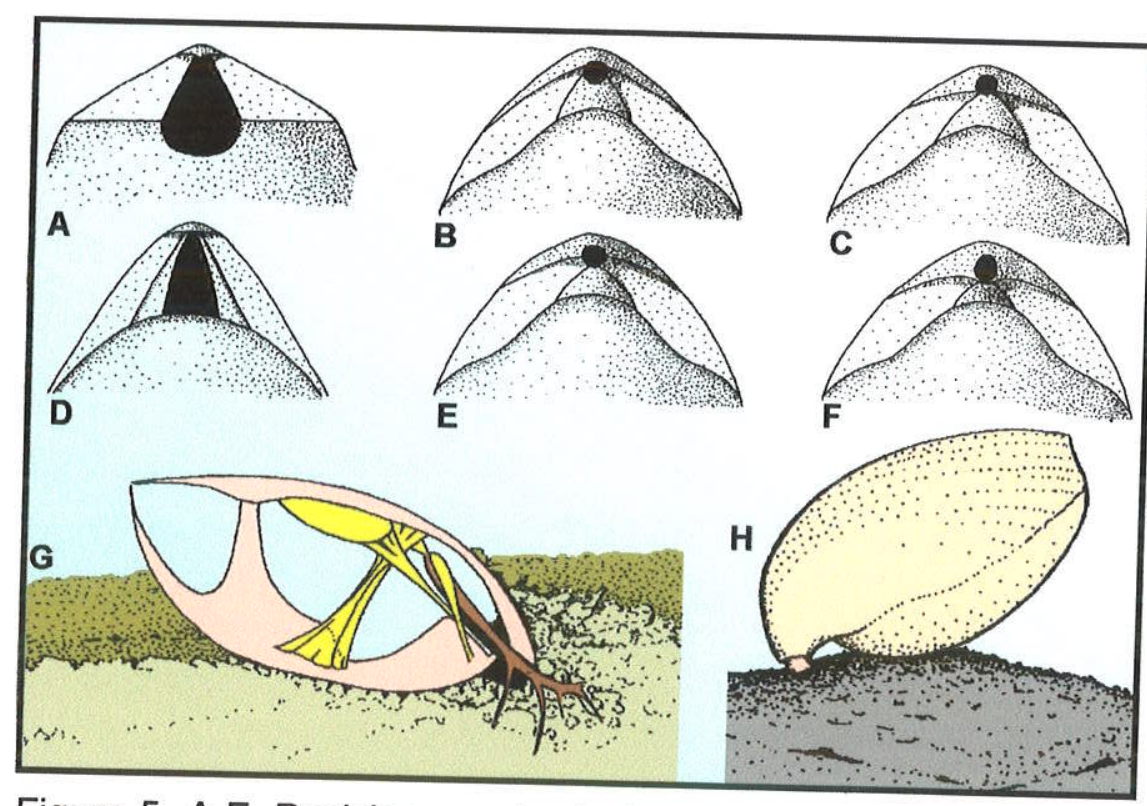

Figura 5- A-F, Posicionamento do forame em relação ao bico e placas deltidiais em valvas ventrais de braquiópodes (caráter 11); A: anfitírido, B: submesotírido, C: permesotírido, D: hipotírido, E: mesotírido, F: epitírido; G: exemplo de braquiópode articulado com forame apical tendo a ancoragem como modo de vida inferido; $\mathrm{H}$ : exemplo de braquiópode articulado com forame ventral tendo a fixação como modo de vida inferido (segundo WILLIAMS et al., 1997) 


\section{CARÁTER 12 - Posicionamento do forâmen}

\section{Estado 0 (apical); 1 (ventral)}

A posição do forâmen, em relação ao bico da concha, já foi utilizada como caráter em estudos cladísticos anteriores (e.g., WILLIAMS et al., 1996, 1997b; WILLIAMS \& HARPER, 2000). Sua posição e a relação com a inclinação do bico, refletem, também, variações de acordo com o modo de vida dos braquiópodes (Figura 5), assumindo uma posição apical quando o pedículo tem função de ancoragem (e.g., Bouchardia rosea), e posição mais ventral quando o pedículo é fixador (e.g., Malleia portlandica) (RICHARDSON, 1979, 1981a, 1981b, 1987; RICHARDSON \& WATSON, 1975a, 1975b; MINUER \& RICHARDSON, 1984).

\section{B) Caracteres Internos da Concha (caráter 13 ao 43)}

Assim como ocorre com os caracteres relacionados à estrutura e evolução da charneira (e.g., dentes, fossetas, crura) (JAANUSSON, 1971; JOHNSON \& WESTBROEK, 1971; RICHARDSON, 1973b, 1975a; CARLSON, 1992; BRUNTON, 1996; BRUNTON et al. 1996; WILLIAMs et al., 1997c), o desenvolvimento e estrutura do braquídio e do lofóforo, também têm sido, freqüentemente, empregados na identificação de táxons, no estabelecimento de relações de parentesco e nas classificações para os diferentes grupos de braquiópodes (JAANusson, 1971; RiCHARDSON, 1975a; BRUNTON, 1996; BRUNTON et al., 1996). Todas essas estruturas têm sido alvo de inúmeros estudos morfo-funcionais e fisiológicos desde o final do século 19 (BEECHER, 1897; ATKINS, 1959a, 1959b; ElLIOTT, 1948, 1953, 1976; WILLIAMS, 1960; WILLIAMS \& WRIGHT, 1961; RICHARDSON, 1973a, 1975a, 1975b; EMIG, 1976, 1992; GILMOUR, 1978; COPPER, 1986; LABARBERA, 1986; GUNJI, 1987, 1990; MACKINNON, 1993; Williams et al., 1997c).

RICHARDSON (1975a) discute o desenvolvimento do braquídio e suas estruturas associadas (e.g., septo mediano, crura). Braquídios longos, dominantes durante o Cenozóico (e.g., Terebratellidae), são resultantes do crescimento e fusão dos ramos descendentes e ascendentes (em forma de laço) que podem, ou não, ser sustentados pelo septo mediano durante o desenvolvimento (RICHARDSON, 1975a). Sua forma final é atingida após uma sucessão de modificações, envolvendo fusão e reabsorção, em partes específicas (e.g., crura, septo), gerando padrões distintos e morfologicamente bem definidos (e.g., Dallinidae, Laqueidae, Terebratellidae; sensu RICHARDSON, 1975a). A fim de sintetizar o conhecimento obtido com esses processos e solucionar o conflito 
nomenclatural existente (veja BEECHER, 1895; ELLIOTT, 1947; ATKINS, 1959a, 1959b; RICHARDSON, 1973a), RICHARDSON (1975a) propôs uma nova terminologia, com base nos representantes das famílias Dallinidae, Laqueidae e Terebratellidae. Os Terebratellidae caracterizam-se pelas etapas axial, anular, haptoide, bilacunar, trabecular e teloforme. Segundo esta nomenclatura, o desenvolvimento do braquidio dos gêneros Bouchardia, Neobouchardia e Bouchardiella apresenta apenas o estágio axial. De fato, Bouchardia possui apenas um braquídio incompleto com ramos ascendentes fixados à porção anterior do septo mediano (RICHARDSON, 1973b, 1975a, 1994; BRUNTON, 1996), informação esta confirmada pela análise morfológica desenvolvida no presente estudo.

Além do braquídio, o lofóforo tem sido estudado em diferentes aspectos como estrutura e função (e.g., WILLIAMS, 1960; ROWELL, 1961; EMIG, 1976, 1992; GILMOUR, 1978; COPPER, 1986; LABARBERA, 1986; RACHEBOEUF \& COPPER, 1990). Sua disposição nos adultos está intimamente relacionada à ontogenia, constituindo importante fonte de dados morfológicos e cladísticos, pois seus estágios de desenvolvimento estão devidamente identificados e caracterizados (veja caráter 39 adiante). De acordo com EMIG (1992), o primeiro estágio de desenvolvimento do lofóforo é denominado taxolofo, comum a todos os braquiópodes em fase larval e caracterizado por uma estrutura simples e crescente. O acréscimo de novos tentáculos e surgimento de lóbulos marcam os estágios trocolofo e esquizolofo, ainda larvais, embora retidos pelas formas adultas de alguns gêneros atuais (EMIG, 1992). A partir do estágio esquizolofo, desenvolvem-se os tipos espirolofo, pticolofo e plectolofo. Por sua vez, o estágio mesolofo foi identificado e descrito apenas para fósseis (Chonetidae; RACHEBOEUF \& COOPER, 1990). Vale a pena destacar que, em muitos casos, as caracterizações dos lofóforos são originalmente propostas sem uma descrição dessa estruturas, sendo inferidas a partir da forma do braquidio. Apesar desta feição não ficar preservada no registro fóssil, o tipo zigolofo, intermediário entre o esquizolofo e o plectolofo, é atribuído aos gêneros Bouchardia e Anakinetica, ao passo que os outros 18 gêneros (40 espécies, sensu RICHARDSON, 1994) de Terebratellidae apresentariamo tipo plectolofo (EMIG, 1992).

A vasta literatura paleontológica disponivel sobre a charneira dos braquiópodes teve profundo efeito nas recentes abordagens e classificações dos braquiópodes, resultando em uma terminologia extensa e conflitante. A identificação deste problema 
levou BRUNTON et al. (1996) a realizarem uma ampla revisão dos termos descritivos utilizados, identificando sinonímias e homologias, e propondo nova nomenclatura, visando a resolução dos conflitos. Essa discussão é de especial interesse para o presente projeto, uma vez que termos conflitantes introduzem erros nos trabalhos de morfologia comparada, base para as investigações cladísticas, podendo acarretar problemas na construção dos cladogramas (BRUNTON et al., 1996; AMORIM, 1998). Além disso, as feições morfológicas incomuns da charneira de Bouchardia geram problemas de interpretação, dificultando muito a comparação e o estabelecimento de homologias primárias com outros táxons (BRUNTON, 1996; BRUNTON et al., 1996).

$O$ desenvolvimento ontogenético e diferenças marcantes (e.g., origem, forma, dimensão, estrutura, função, natureza da superfície de fixação e músculos pediculares associados) entre os pedículos de Rhynchonelliformea e Linguliformea, os define como estruturas não homólogas (RICHARDSON, 1979, 1981b, 1981c; WILLIAMs et al., 1965, 1997c). Estudos sobre o pedículo e musculatura associada (RICHARDSON \& WATSON, 1975a, 1975b; THAYER, 1975; MACKAY \& HEWITT, 1978; RICHARDSON, 1979, 1981b, 1981c, 1987), principalmente para Terebratellidae, têm procurado estabelecer a correlação entre a morfologia e hábito de vida dos organismos. Por sua vez, os Anakineticinae viventes (veja em RICHARDSON, 1984, 1987, 1991) têm dado importante contribuição para a compreensão da variabilidade do órgão e sua estreita relação com o substrato, combatendo idéias, há muito estabelecidas, como presença e dimensão do forâmen indicando a existência de um pedículo fixador (RICHARDSON, 1979, 1981b, 1981c).

Como é sabido, a relação entre o organismo e o substrato de vida influencia o estilo de vida do organismo e, por conseguinte, a distribuição da espécie. Como resultado, entretanto, é freqüente a ocorrência de homeomorfia entre os Rhynchonelliformea (RICHARDSON, 1994, 1997a), como observado em populações de braquiópodes atuais com vários graus de especialização, com relação ao habitat (e.g., tipo específico de substrato ou de modo de vida) e estruturas morfológicas similares em espécies de grupos pouco aparentados (RICHARDSon, 1994, 1997a). Dessa forma, o conhecimento morfológico detalhado dos diferentes tipos de pedículos e estruturas associadas (e.g., musculatura) pode auxiliar em interpretações paleoautoecológica (e.g., modo de vida, substrato, habitat) (RICHARDSON, 1981a, 1981b, 1981c). Contudo, o tipo de pedículo não pode ser acessado diretamente, na maioria das espécies fósseis e 
sua forma e tipo são inferidos, geralmente, com base em estudos de morfologia funcional das conchas, principalmente de estruturas como o bico, as cicatrizes musculares e a charneira (RICHARDSON, 1981b),

A musculatura dos Rhynchonelliformea é tema importante e amplamente investigado nos estudos morfo-funcionais, sobretudo os músculos (ou cicatrizes) relacionados à abertura/fechamento da concha e ao pedículo (e.g., RICHARDSON, 1975b, 1979, 1981b, 1981c, 1987, 1994; RICHARDSON \& WATSON, 1975a; MINUER \& RICHARDSON, 1984; BRUNTON, 1996; WILLIAMS et al., 1997c). Para os Terebratellidae, destacam-se os músculos didutores e adutores (músculos da concha), além dos adjustores e retratores (músculos do pedículo). De acordo com sua especialização, forma, atuação, modo e local de inserção, etc., resultando em uma grande variedade de cicatrizes nas superfícies internas das valvas dos braquiópodes. No entanto, como observado no material consultado para o presente estudo, tais feições nem sempre são mencionadas nas descrições das espécies, e, quando presentes, contam com termos imprecisos, interpretações contraditórias e são pobremente ilustrados. Esse fato, aliado à dificuldade de acesso a espécimes depositados em coleções e ao estado de preservação desfavorável do material efetivamente examinado, tornou evidente a dificuldade no tratamento dessas feições o que, em parte, tornam compreensiveis as falhas notadas na literatura consultada e justificam a ínfima abordagem desse grupo de caracteres (exceção feita ao caráter 43) no presente estudo, frente ao seu grande potencial de fornecer dados para uma investigação cladística.

\section{CARÁTER 13 - Pregas na margem interna da concha}

\section{Estado 0 (ausente); 1 (presente)}

São ondulações na comissura da concha que se refletem nas margens internas, na forma de pequenas pregas (cristas), notada, entre os táxons analisados, apenas em Anakinetica cumingi.

\section{CARÁTER 14 - Septo na valva ventral}

\section{Estado 0 (ausente); 1 (presente)}

Os Bouchardinae podem apresentar um baixo e discreto espessamento da concha (septo) ao longo da linha antero-posterior média da valva ventral, sempre alongado (Figura 6). Alguns táxons apresentam essa estrutura como uma linha 
discreta, uniforme ao longo de toda a extensão (e.g., Bouchardia zittell), enquanto outros têm a extremidade anterior diferenciada (e.g., ponta de seta em Bouchardia rosea e Bouchardia transplatina). Essa diferenciação corresponde ao local onde a porção anterior e mais elevada do septo mediano toca a valva ventral, chegando a apresentar uma pequena depressão central para acomodar a extremidade do septo (e.g., Bouchardia rosea).

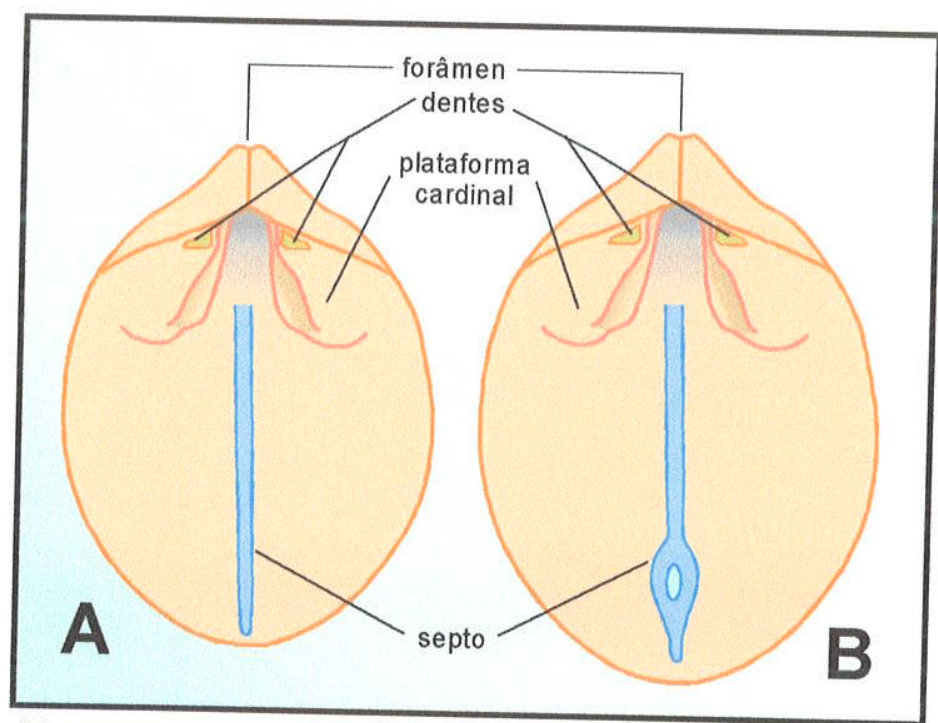

Figura 6- Septo na superfície interna da valva ventral (Caracteres 14 e15). Pode apresentar-se como uma estrutura de largura constante, como em Bouchardia zitteli (A), ou estrutura com extremidade anterior diferenciada, como observado em Bouchardia rosea (B), para acomodar, por exemplo, a extremidade elevada do septo mediano que se ergue a partir da valva dorsal

\section{CARÁTER 15 - Extremidade anterior do septo da valva ventral}

Estado 0 (livre); 1 (em seta)

Segue os comentários feitos no caráter 14 (Figura 6). 


\section{CARÁTER 16 - Relevo do assoalho da valva dorsal}

Estado $\quad 0$ (ausente); 1 (retas inclinadas); 2 (círculos)

Foram observadas diferentes conformações da superfície interna da valva dorsal, nos lados e na frente do septo mediano (Figura 7). Este relevo está, provavelmente, associado aos canais do manto (e.g., "vascula genitália", "vascula media") e à fixação da parede do manto ao assoalho da concha (WILLIAMS et al., 1997c).

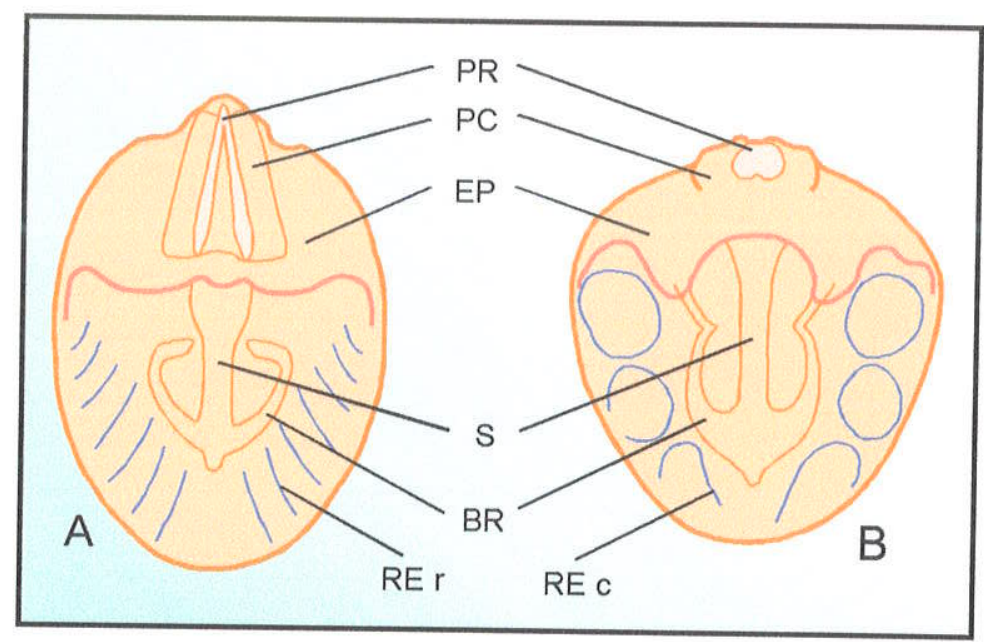

Figura 7- Visão interna das valvas dorsais de Bouchardia rosea (A) e Australiarcula artesiana (B) ilustrando os dois padrões de relevo do assoalho das conchas (caráter 16). Explicação: BR- braquídio; EPespessamento posterior; PC- plataforma cardinal; PP- processo cardinal; Rec- relevo circular; Rer- relevo em forma de linhas inclinadas. Fonte- ELLIOTT (1960)

\section{CARÁTER 17 - Perfil do septo mediano}

Estado 0 (elevado); 1 (estendido); 2 (rebaixado)

O septo mediano é uma elevação delgada fundida ao assoalho da valva dorsal, alongada antero-posteriormente e, geralmente, achatada lateralmente. Tem a função de sustentar o braquídio por toda a vida ou, pelo menos, na fase inicial do desenvolvimento. CARLSON (1995) utilizou esta feição como caráter em sua análise, considerando apenas a ausência e presença nos táxons analisados. O exame, em vista 
lateral, dos septos medianos dos táxons analisados permitiu identificar os 3 estados ilustrados na Figura 8.

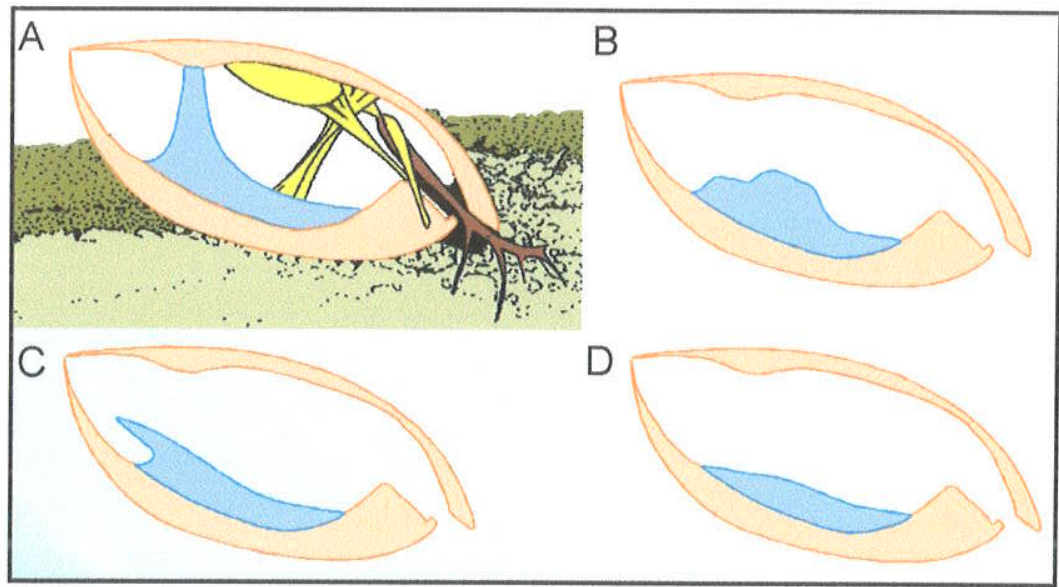

Figura 8- Tipos de septos medianos (caracteres 17 a 19) observados entre os táxons analisados. Em A, Anakinetica cumingi em posição de vida inferida, com algumas feições morfológicas destacadas, tais como a forma do septo (anteriomente elevado, em azul) e sua posição na concha, parte da musculatura (amarelo) e pedículo (marrom). Notar as diferenças entre os demais perfis observados: B) Magadinella woodsiana (septo medianamente elevado); C) Australiarcula artesiana (septo anteriormente estendido); D) Aliquantula insolita (septo anteriormente rebaixado). FonteRICHARDSON (1994)

\section{CARÁTER 18 - Comportamento da extremidade anterior do septo mediano}

Estado $\quad 0$ (não ultrapassa a metade do comprimento da valva ventral);

1 (ultrapassa a metade do comprimento da valva ventral)

Foi observado que o final da extremidade anterior do septo pode chegar até a metade do comprimento da valva ventral ou se estender mais à frente (Figura 8).

\section{CARÁTER 19 - Elevação do septo mediano}

\section{Estado 0 (anterior); 1 (mediana)}

Como observado anteriormente (caráter 17), alguns táxons possuem o septo mediano com perfil elevado e essa característica pode estar localizada na porção anterior (e.g., Bouchardia rosea) ou mediana (e.g., Magellania woodsiana) da estrutura (Figura 8). 
CARÁTER 20 - Elevação anterior do septo mediano toca a superfície interna da valva ventral

Estado 0 (não); 1 (sim)

A elevação anterior do septo mediano pode chegar a tocar a superfície interna da valva ventral e, como visto no caráter 15, a esse comportamento do septo pode, ou não, corresponder uma extremidade diferenciada no septo da valva ventral (Figura 6).

\section{CARÁTER 21 - Base do septo mediano}

Estado 0 (largura constante); 1 (estreita anteriormente)

A união do septo com o assoalho, ou seja, sua base, pode apresentar-se de duas diferentes maneiras, tendo largura constante por toda a extensão, ou sendo larga posteriormente, junto da plataforma cardinal, e estreita na porção antero-mediana (Figura 9).

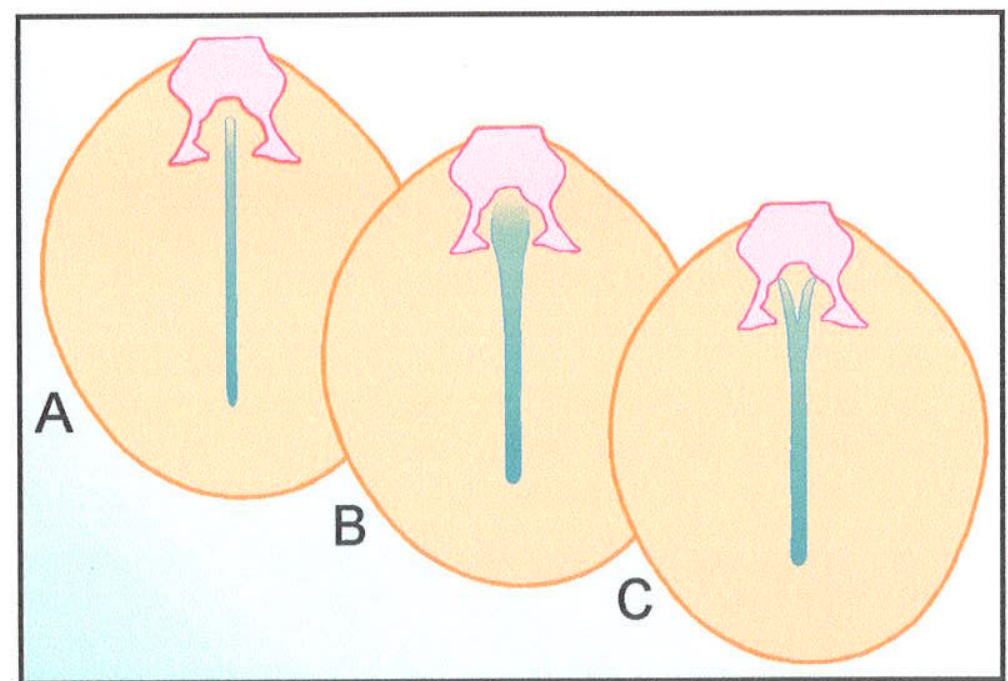

Figura 9- Esquema mostrando parte da anatomia interna de Rhynchonelliformea, ilustrando as bases dos septos medianos (em azul; caráter 21) com largura constante (em A) e septos que se estreitam anteriormente (B e $\quad$ ). Estão representados, também, os tipos de encontro da extremidade posterior do septo mediano com a plataforma cardinal (caráter 21), sendo bífido (em C) ou não (B). Fonte- WILLIAMS et al. (1997c) 


\section{CARÁTER 22 - Encontro do septo com a plataforma cardinal}

\section{Estado 0 (não bífido); 1 (bífido)}

Por sua posição na concha, a porção posterior de septo encontra a plataforma cardinal. No entanto, a extremidade posterior da base do septo, pode apresentar-se bifurcada ou não, antes de se aproximar da plataforma cardinal (Figura 9). Na discussão sobre Malleia, RICHARDSON (1973b) considera a possibilidade de tal bifurcação corresponder ao limite posterior dos músculos adutores que aparecem bem desenvolvidos em alguns exemplares.

\section{CARÁTER 23 - Braquídio fixo ao septo mediano \\ Estado 0 (ausente); 1 (presente)}

A forma final de um braquidio, geralmente, envolve processos de fusão $e$ reabsorção de material conchoso que forma o próprio braquídio ou, ainda, estruturas como o septo e a crura (RICHARDSON, 1975a). Dessa maneira, o braquídio pode ou não estar fixado ao septo mediano.

\section{CARÁTER 24 - Braquídio em forma de laço ('loop')}

\section{Estado 0 (ausente); 1 (presente)}

Conforme discutido anteriormente, o braquídio encontrado em Bouchardia $\dot{e}$ pequeno, incompleto (Figura 10; Estampas 2 e 3) e classificado como axial por RICHARDSON (1975a), com caráter imaturo, encontrando correspondente nos estágios iniciais do desenvolvimento dos braquídios de outros Terebratellidae (RICHARDSON, 1973b; BRUNTON, 1996). O padrão apresentado pelo braquídio está diretamente relacionado ao espaço disponível na cavidade do manto $e$, portanto, quanto mais extenso o espessamento posterior da concha, menor a cavidade do manto $e$, conseqüentemente, braquidios menores (RICHARDSON, 1991). Seguindo esse raciocínio, a presença de ramos ascendentes fixos ao septo mediano, em adultos de Bouchardia rosea, Bouchardia zitteli e, provavelmente, nas demais espécies do gênero e na Subfamília Bouchardiinae, representa a retenção de condições juvenis pelos indivíduos adultos.

Para as demais espécies do gênero não existe confirmação de tais condições, mas apenas indícios. Com exceção de Bouchardia antarctica, as demais espécies do gênero encontram-se brevemente descritas em LEVY (1964), e para todas é registrada 
a presença de restos de ramos ascendentes, sem a existência de ramos descendentes, o que não confirma, entretanto, o caráter incompleto do braquídio. Contudo, OWEN (1980) apresenta uma ilustração de Bouchardia antarctica na qual está visivel um braquídio incompleto. Como já mencionado, a análise morfológica de espécimes de Bouchardia zitteli revelou a presença de um braquídio incompleto (Estampa 3), tal qual aquele observado para Bouchardia rosea. A natureza frágil dessa estrutura, evidente em espécimes de Bouchardia rosea (Estampas 1 e 2), parece exigir condições bioestratinômicas especiais para sua preservação, haja vista que sua presença nas 3 espécies citadas acima só foi observada em espécimes articulados fechados.

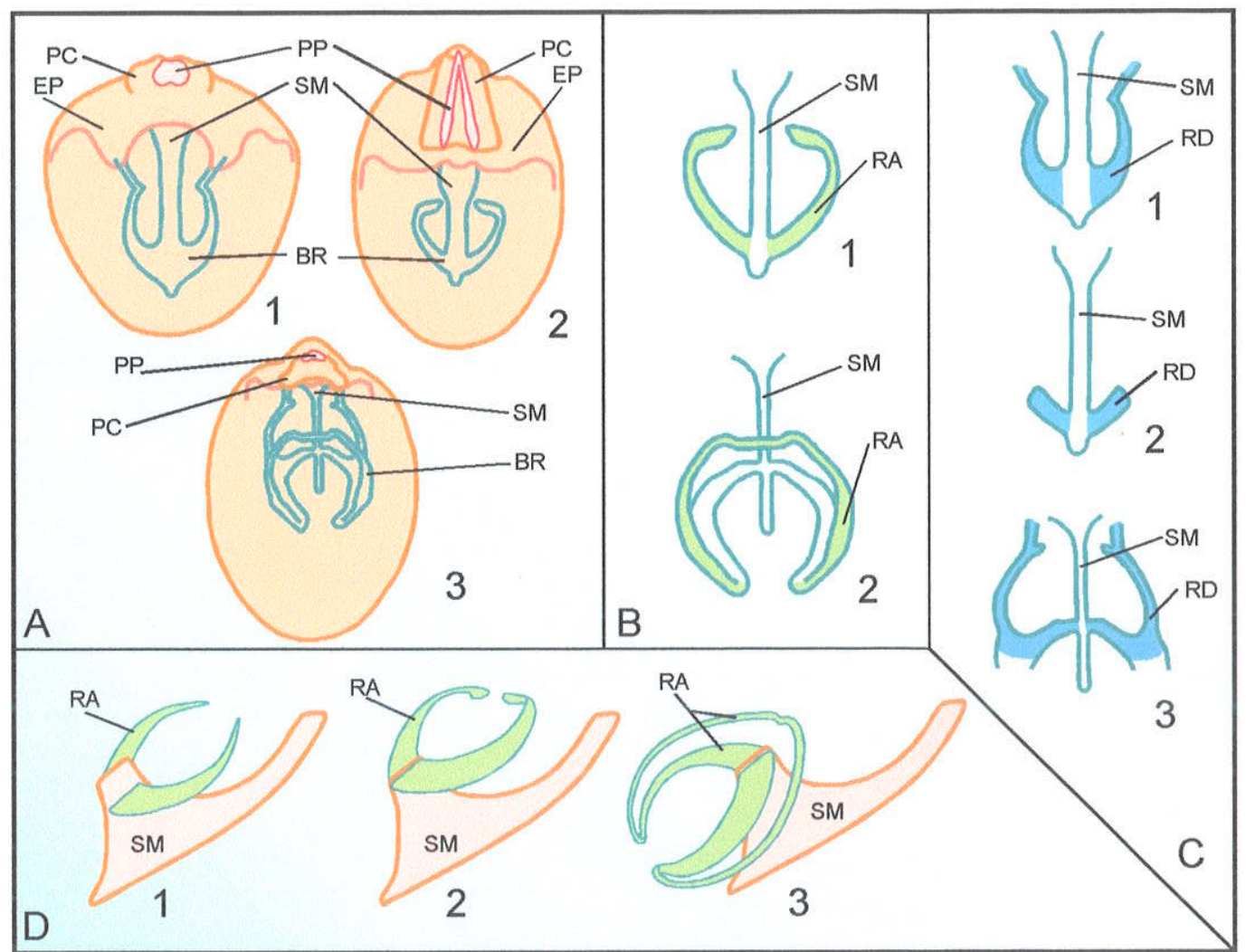

Figura 10- Caracterização dos braquídios observados entre os táxons analisados (Caracteres 24 a 29). Em A, braquídios representando padrões encontrados em Anakinetica cumingi (A3), em forma de laço, e Australiarcula artesiana (A1) e Bouchardia rosea (A2), ambas com braquídio simples, sem formar laço. $\mathrm{Em} \mathrm{B}$, ramos ascendentes dos braquídios com a região posterior livre (B1), como encontrado nos Bouchardiinae, ou região posterior unida, formando laço (B2), como em Anakinetica cumingi. Em C, ramos descendentes dos braquídios, que podem estar fixados apenas ao septo mediano, como em Malleia portlandica (C2), ou estar fixados ao septo e a plataforma cardinal (crura), como em Australiarcula artesiana (C1) e Anakinetica cumingi (C3). Em D, tipos de fixação dos ramos ascendentes ao septo mediano onde podem estar fixados à sua extremidade, como em Bouchardia rosea (D2) e Anakinetica cumingi (D3), ou em uma posição intermediária entre o topo e a base do septo, como observado em Australiarcula artesiana (D1). Explicação: BR- braquídio; EP- espessamento posterior; PC- plataforma cardinal; PR- processo cardinal; RA- ramo ascendente; RD- ramo descendente; SM- septo mediano 
Por fim, parece haver relação entre a extensão do septo e a largura das bandas conectantes presentes em braquídios completos em forma de laço (RICHARDSON, 1991). No entanto, a análise dessas características e verificação de sua inter-relação, para os táxons envolvidos na presente análise, seria útil apenas para discutir a topologia obtida para o grupo externo, uma vez que os Bouchardinae e o gênero Australiarcula não apresentam este tipo de braquídio. Portanto, tal relação não foj levada em conta na presente análise.

\section{CARÁTER 25 - Fixação dos ramos descendentes no septo mediano}

\section{Estado 0 (ausente); 1 (presente)}

Nos táxons com braquídio completo, geralmente em forma de laço, observam-se ramos descendentes fixados à crura (extremidade posterior) e ao septo (extremidade anterior) (Figura 10). Conforme referido anteriormente, a classificação proposta por RICHARDSON (1975a) para os braquídios dos Terebratellidae, considera que os Bouchardinae, em geral, não apresentam ramos descendentes no braquídio (estágio axial). No entanto, Malleia portlandica é citada como possuindo rudimentos ou vestígios triangulares de ramos descendentes, abaixo das inserções dos ramos ascendentes, no septo mediano (RICHARDSON, 1973b). Estes poderiam ser vestígios de ramos destruídos por algum processo tafonômico ou mesmo resquícios de uma reabsorção ocorrida durante o desenvolvimento do braquídio. Somando-se a esse fato a reconhecida ausência de quaisquer vestígios crurais na cardinália desse táxon, considera-se que os ramos descendentes estiveram fixados apenas ao septo mediano. Pelo referido acima, parece razoável considerar o estabelecimento do estágio axial, a partir da ausência de ramos descendentes na plataforma cardinal e no septo mediano, em um momento mais avançado do desenvolvimento ontogenético (RICHARDSON, 1975a).

CARÁTER 26 - Fixação dos ramos descendentes na plataforma cardinal Estado 0 (ausente); 1 (presente)

Segue os comentários do caráter 25. 


\section{CARÁTER 27 - Ramos ascendentes}

\section{Estado 0 (ausente); 1 (presentes)}

Os ramos ascendentes do braquídio, tanto nos incompletos quanto naqueles em forma de laço, têm a extremidade anterior ligada à porção elevada do septo, no seu topo ou em alturas intermediárias. Contudo, conforme esses ramos seguem para a região posterior da cavidade do manto podem apresentar 3 atitudes (Figura 10): a) permanecerem livres, como em Bouchardia rosea, b) estarem ausentes, como em Australiarcula artesiana e c) unirem-se um ao outro, formando um laço, como em Anakinetica cumingi.

\section{CARÁTER 28 - Fixação posterior dos ramos ascendentes \\ Estado $\quad 0$ (livres); 1 (formando laço)}

Segue os comentários para o caráter 27.

\section{CARÁTER 29 - Encaixe do braquídio no septo mediano}

\section{Estado $\quad 0$ (na extremidade); 1 (posição intermediária)}

Conforme já mencionado (CARÁTER 27), os ramos ascendentes dos braquídios estão ligados à porção elevada do septo, em seu topo ou em alturas intermediárias (Figura 10), como ocorre em Malleia portlandica.

\section{CARÁTER 30 - Diferenciação dos elementos da charneira}

Estado $\quad 0$ (parcialmente fundidos); 1 (fundidos não identificáveis)

A presença de espessamento posterior nas conchas de braquiópodes (e.g., Bouchardiinae e alguns Anakineticinae), torna difícil a diferenciação dos componentes da charneira, uma vez que ocorre a fusão de seus diferentes elementos (Figura 11) (RICHARDSON, 1991, 1994; BRUNTON, 1996; BRUNTON et al, 1996). Foram observadas conchas onde esses elementos estavam parcialmente fundidos, mas ainda identificáveis, ou totalmente fundidos e não distintos (RICHARDSON, 1991).

\section{CARÁTER 31 - Relação entre linha e eixo da charneira}

Estado 0 (estrófico); 1 (astrófico)

A margem da charneira, composta em grande parte pelas bordas anteriores das placas deltidiais, pode apresentar fusão de placas deltidiais retas horizontais ou de 
placas deltidiais retas, inclinadas, formando ângulo, geralmente, superior a $90^{\circ} \mathrm{e} \mathrm{com}$ vértice posterior. Muitas vezes, ocorre uma discordância entre a linha da charneira, reta ou arcada, e seu eixo de movimentação. De acordo com WILLIAMS et al. (1997c), esta particularidade permite diferenciar e classificar as conchas em estróficas, quando a linha e o eixo da charneira coincidem, e astrófica ou não-estrófica, quando a linha da charneira é arcada e não coincide com o eixo reto da charneira (Figura 12). Essa relação foi empregada nas análises cladísticas realizadas por CARLSON (1995) e WILLIAMS et al. (1996).

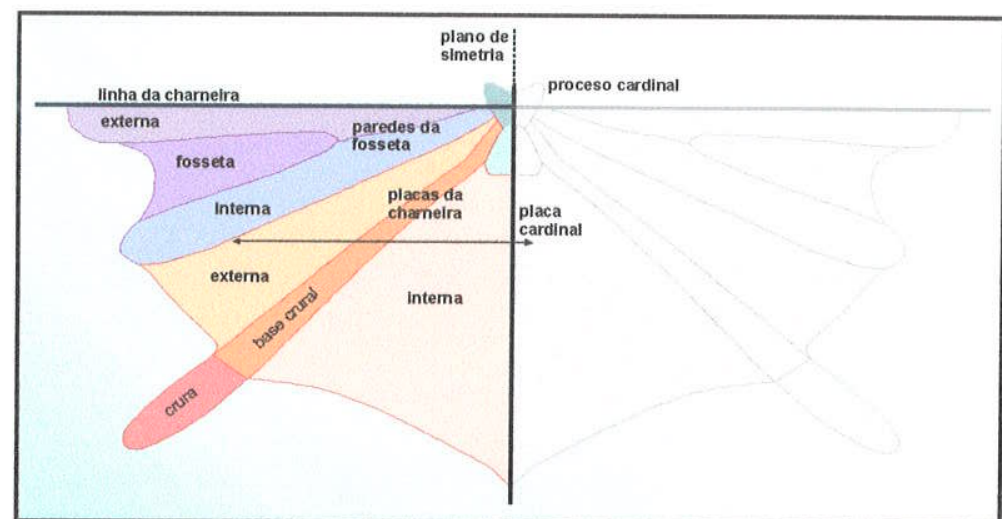

Figura 11- Representação esquemática da estrutura da cardinália dos Rhynchonelliformea, com seus elementos individualizados (caráter 30). Fonte- WILLIAMS et al. (1997)

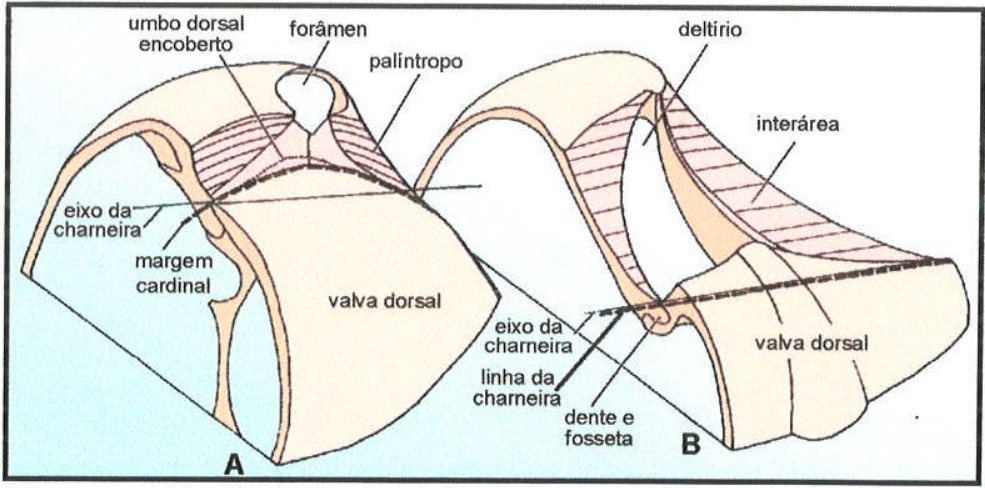

Figura 12- Vista parcial das regiões posteriores de conchas de braquiópodes: estrófica (A) e astrófica (B) (caráter 31). Fonte- WILLIAMS et al. (1997) 


\section{CARÁTER 32 - Configuração do processo cardinal}

\section{Estado $\quad 0$ (bilobado); 1 (trífido)}

O processo cardinal corresponde a um espessamento de formato variável, localizado na extremidade posterior da valva dorsal, e relacionado à separação das áreas de fixação dos músculos didutores (WiLliams et al., 1997c). Sua utilização em estudos cladísticos tem sido observada (CARLSON, 1995; WILLIAMS et al., 1996, 1997a, 1997b; ANELLI, 1999). Em sua revisão das subfamílias de Terebratellidae, RICHARDSON (1994) reconhece 3 variações principais nos processos cardinais (Figura 13): a) bífido em sua extremidade posterior e com os sulcos em forma de ' $V$ ' invertido (que, de acordo com o autor corresponderia às cicatrizes dos ramos dos músculos didutores; RICHARDSON, 1991, 1994; BRUNTON, 1996; BRUNTON et al., 1996), para a Subfamília Bouchardinae, b) com superfície posterior trífida, para a Subfamília Anakineticinae, e c) transverso, para a Subfamilia Terebratellinae. É importante notar, entretanto, que alguns Bouchardiinae (e.g., Malleia, Bouchardiella) apresentam um processo cardinal com sulcos em forma de ' $V$ ' invertido, não tão característicos quanto os de Bouchardia (Figura 13).

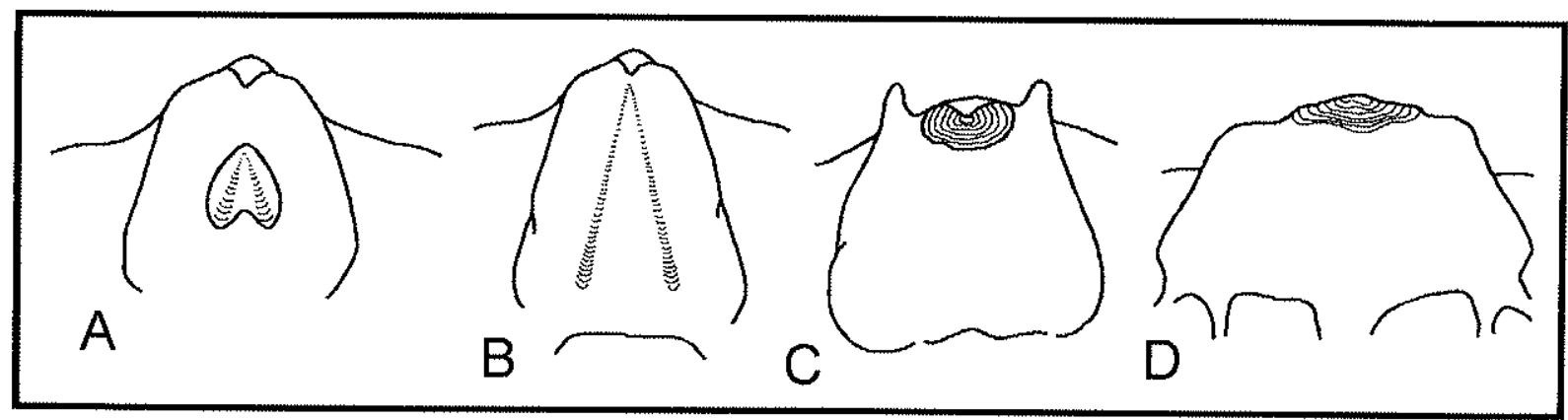

Figura 13- Representação esquemática de parte da cardinália (valva dorsal) exemplificando os tipos de processo cardinal (caráter 32); A: bilobado (boucardíneos), B: bilobado com sulcos em forma de ' $V$ ' invertido (Bouchardiinae), C: trífido (Anakineticinae), D: transverso (Terebratellinae), Fonte- RICHARDSON (1991)

\section{CARÁTER 33 - Processo cardinal bilobado em forma de "V" invertido}

Estado $\quad 0$ (ausente); 1 (presente)

Segue os comentários para o caráter 32. 


\section{CARÁTER 34 - Reforço da articulação por cristas e sulcos}

\section{Estado 0 (ausente); 1 (presente)}

O espessamento posterior das valvas proporciona o aparecimento de estruturas adicionais, tais como cristas e sulcos nas laterais da plataforma cardinal que se encaixam a estruturas complementares na valva ventral (Figura 14) (RICHARDSON, 1994; BRUNTON, 1996; BRUNTON et al., 1996). Essas estruturas aumentam a articulação entre as duas valvas, dificultando a sua separação e restringindo seu ângulo de abertura (RICHARDSON, 1994; BRUNTON, 1996; BRUNTON et al., 1996).

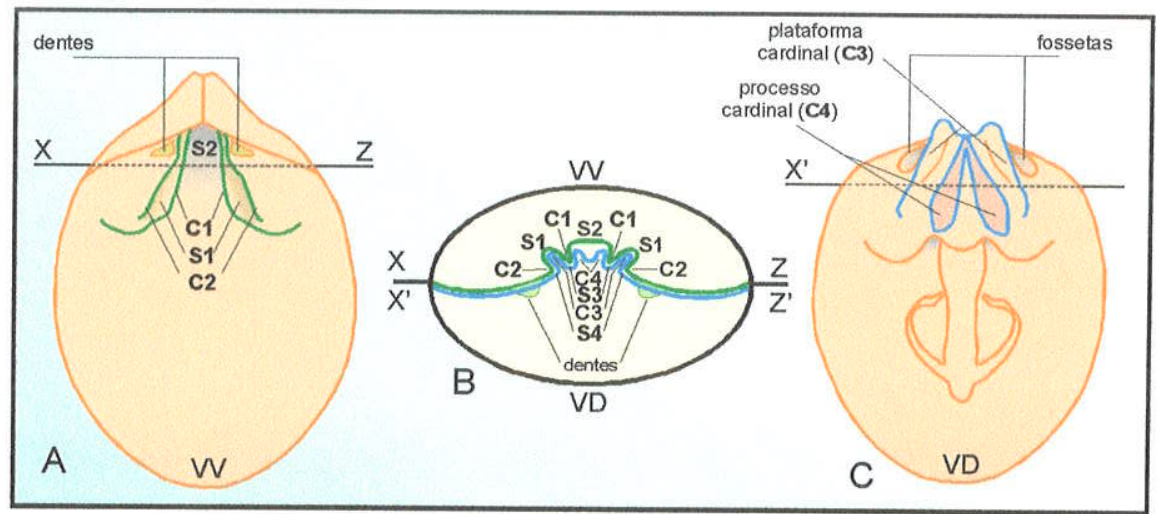

Figura 14- Interações entre estruturas da charneira (caráter 34) de Bouchardia rosea. Em A e C, visão interna das valvas ventral (VV) e dorsal (VD) (respectivamente), com representação das principais estruturas da charneira e que participam da articulação entre as valvas. Notar que, além de dentes e fossetas, a região conta com sulcos $(\mathrm{S} 1, \mathrm{~S} 2, \mathrm{~S} 3, \mathrm{~S} 4)$ e cristas $(\mathrm{C} 1, \mathrm{C} 2, \mathrm{C} 3, \mathrm{C} 4)$ que interagem, reforçando a união entre as valvas. Essa interação pode ser melhor observada em $B$, representando um corte transversal (X - Z e X' - Z') na região posterior de um espécime articulado fechado

\section{CARATER 35 - Crura}

\section{Estado 0 (ausente); 1 (presente)}

Corresponde a um par de processos que se estendem, geralmente, a partir da superfície anterior da plataforma cardinal, em direção à cavidade do manto e são suportados por bases crurais (Figura 11), pouco visiveis em conchas com espessamento posterior (Estampas 2 a 7) (BRUNTON et al., 1996; WILLIAMS et al., 1997c). Tanto a crura quanto as bases crurais foram utilizadas no estudo cladístico de 
braquiópodes cambro-ordovicianos, desenvolvido por WILLIAMs et al. (1996). Presente em muitos Terebratellidae, costuma ligar-se aos ramos descendentes do braquídio, dando suporte à parte posterior do lofóforo e à massa visceral, sobretudo aquela diretamente relacionada à boca, e que está localizada próximo da plataforma cardinal. Alguns autores (RICHARDSON, 1994; BRUNTON, 1996), analisando a morfologia dos Bouchardinae, consideraram que as extremidades anteriores do sulco em forma de ' $V$ ' no processo cardinal, que ultrapassam a margem da plataforma cardinal em direção à cavidade do manto, desempenham função semelhante à da crura, ou seja, sustentam a parede do corpo na região do lofóforo, onde está presente a boca.

Vale a pena comentar que, segundo RICHARDSON (1973b), nem a base crural nem a crura estão presentes nos gêneros de Bouchardiinae, sendo possivel, no entanto, que as bases crurais estejam tão intimamente fundidas aos elementos da cardinália, devido ao espessamento posterior das valvas, que se tornaram irreconheciveis. A autora considera, ainda, que o estudo do desenvolvimento da cardinália em séries ontogenéticas nas diferentes espécies de Bouchardiinae pode identificar a presença dessa estrutura. Uma discussão sobre essa proposta, com incorporação de novos dados, é apresentada mais adiante (Item 6.3.).

\section{CARÁTER 36 - Septalium}

\section{Estado 0 (ausente); 1 (presente)}

Há na literatura uma considerável confusão sobre os termos que tratam das estruturas de conexão das paredes internas da fosseta, e das placas medianas a elas com o assoalho das valvas (BRUNTON et al., 1996). A situação mais comum, observada em braquiópodes fósseis e viventes, diz respeito às placas cardinais internas (veja Figura 11) que acomodam os músculos adjustores dorsais (músculos pediculares), formando uma depressão suportada pelo septo mediano, e chamada septalium (BRUNTON et al., 1996; WILliams et al., 1997c). A mesma estrutura é tratada apenas como depressão na charneira nas descrições de Terebratellidae apresentadas por RICHARDSON (1991, 1994). 


\section{CARÁTER 37 - Cavidades na parede anterior da plataforma cardinal}

\section{Estado 0 (ausentes); 1 (presente)}

Alguns Terebratellidae apresentam cavidades na parede anterior da plataforma cardinal, adentrando o espessamento posterior, nas proximidades da união com a base do septo mediano (Figura 15). Essas cavidades abaixo da cardinália são características de Bouchardia, abrigando as extremidades dos músculos adutores e músculos ligados à sustentação do lofóforo (BRUNTON, 1996), e sua extensão é governada pela quantidade de espessamento secundário da valva dorsal. Nas espécies analisadas foram notadas cavidades nas laterais da base do septo, assim como logo acima da base, quando o septo se une à plataforma cardinal. Em Malleia o processo cardinal não se funde ao assoalho e a cavidade abaixo dele é delimitada posteriormente pela região dorsal do umbo, lateralmente pelas paredes das fossetas e ventralmente pela superfície dorsal do processo cardinal.

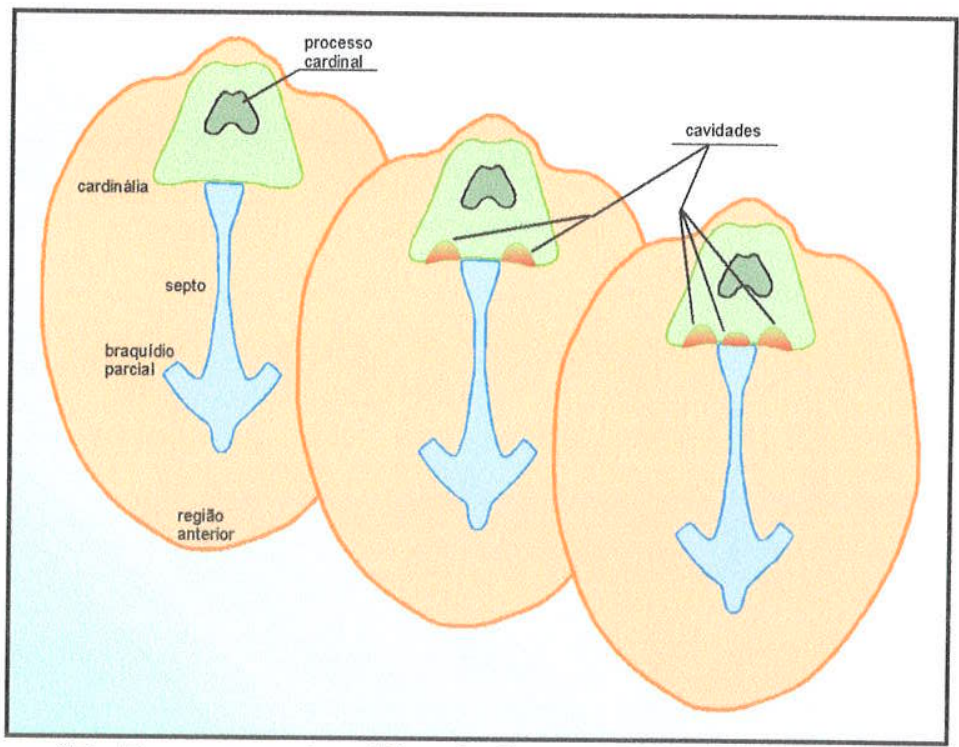

Figura 15- Esquema simplificado ilustrando parte da anatomia interna dos Rhynchonelliformea, com destaque para - número e posicionamento das cavidades na parede anterior da cardinália (caracteres 37 e 38) e a relação dessas feições com outras estruturas morfológicas (e.g., septo, cardinália) 


\section{CARÁTER 38 - Número de cavidades na parede anterior da plataforma cardinal}

Estado 0 (2 cavidades); 1 (3 cavidades)

Enquanto Neobouchardia e Bouchardiella apresentam 3 cavidades na superfície anterior da plataforma cardinal (veja caráter 37), Bouchardia e Australiarcula apresentam apenas 2. (Figura 15).

\section{CARÁTER 39 - Tipo de lofóforo}

\section{Estado $\quad 0$ (zigolofo); 1 (plectolofo)}

Como comentado inicialmente, os estágios de desenvolvimento do lofóforo encontram-se totalmente identificados e caracterizados (Figura 16) (EMIG, 1992). O tipo zigolofo é atribuído a Bouchardia e Anakinetica, ao passo que os demais Terebratellidae apresentariam o tipo plectolofo (EMIG, 1992). Embora correspondam, mesmo que em parte, a inferências sobre a ocorrência de tipos particulares de lofóforos em espécies fósseis, as generalizações acima foram aceitas, levando-se em conta, ainda, que constituem as únicas informações existentes, até o momento, sobre o caráter, para a maioria dos táxons analisados.

\section{CARÁTER 40 - Tipo de pedículo}

\section{Estado 0 (fixador); 1 (móvel)}

De acordo com a classificação proposta por RICHARDSON (1981b), os pedículos dos Rhynchonelliformea podem ser reunidos em (Figura 17): a) musculares: unidade contrátil, com fibras musculares (músculos adjustores) contínuas à estrutura do pedículo, sendo a fixação realizada por curtas papilas; b) inertes: apresentam evidente diferenciação entre as fibras musculares e a estrutura do pedículo, servindo como um eixo ao redor do qual a concha se move por contrações musculares, sendo que a ancoragem se dá pela extremidade ramificada (não fixadora) ou por longas papilas (fixadoras); e c) transitivos: com fibras musculares diferenciadas da estrutura do pedículo, apresentam fixação por curtas papilas. Entretanto, a ausência dos pedículos nos fósseis não impede que sua inferência seja feita a partir de características do bico, cicatrizes musculares e charneira. A associação destas observações com informações disponiveis na literatura (e.g., RICHARDSON, 1979, 1981b, 1981c), sobre o pedículo de espécies viventes e pertencentes aos mesmos grupos (e.g., Anakineticinae) utilizados 
no presente estudo, possibilitou avaliação deste caráter para os táxons do grupo interno e externo.

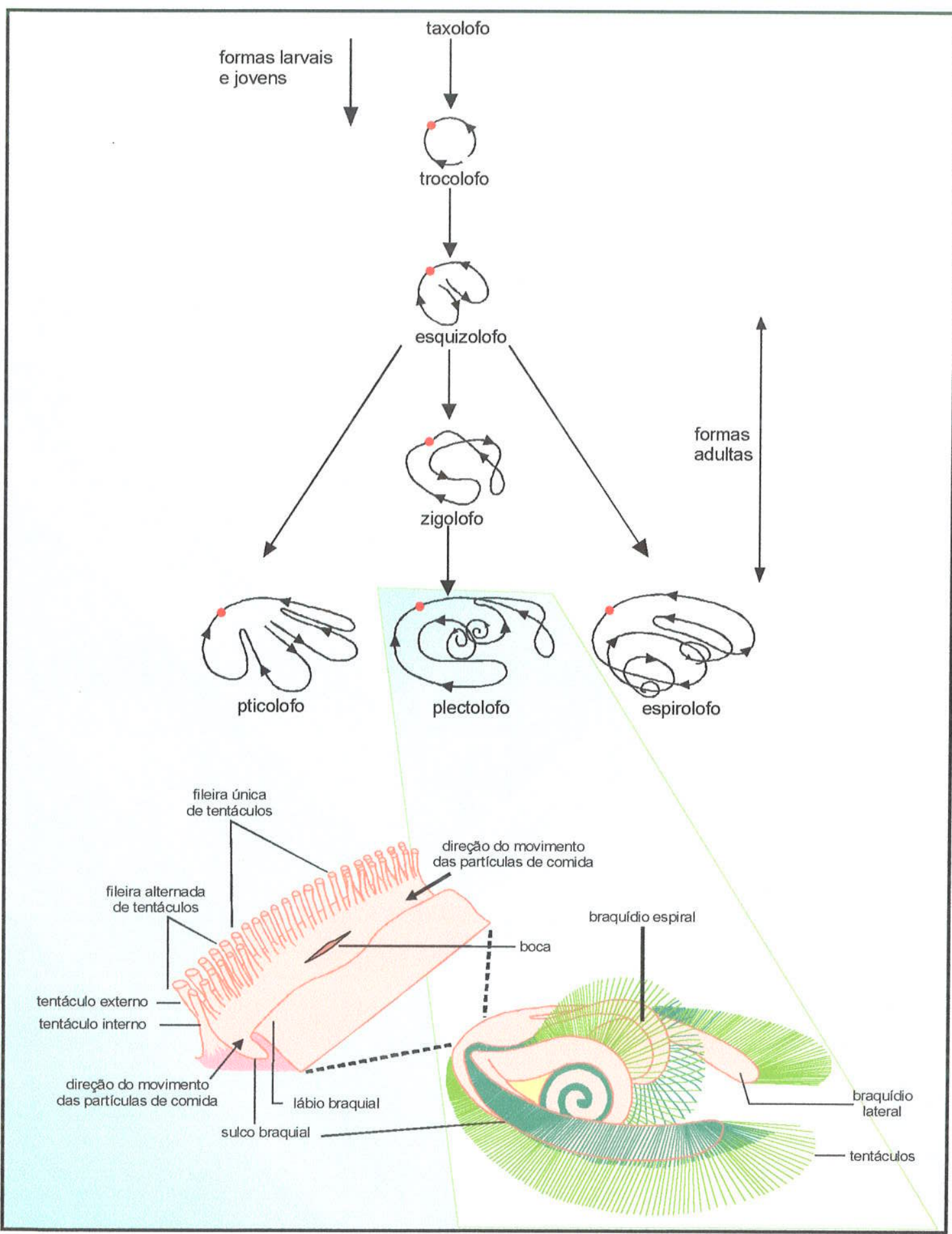

Figura 16- Diagrama exemplificando o crescimento do lofóforo de braquiópodes atuais (caráter 39); cada representação mostra uma visão, em perspectiva, do eixo braquial; as setas ao longo dos eixos braquiais indicam o sentido de transporte de partículas de comida até a boca, indicada em vermelho. Abaixo, detalhes da anatomia de um lofóforo plectolofo e seu braquídio. Fonte- WILLIAMS et al. (1997) 


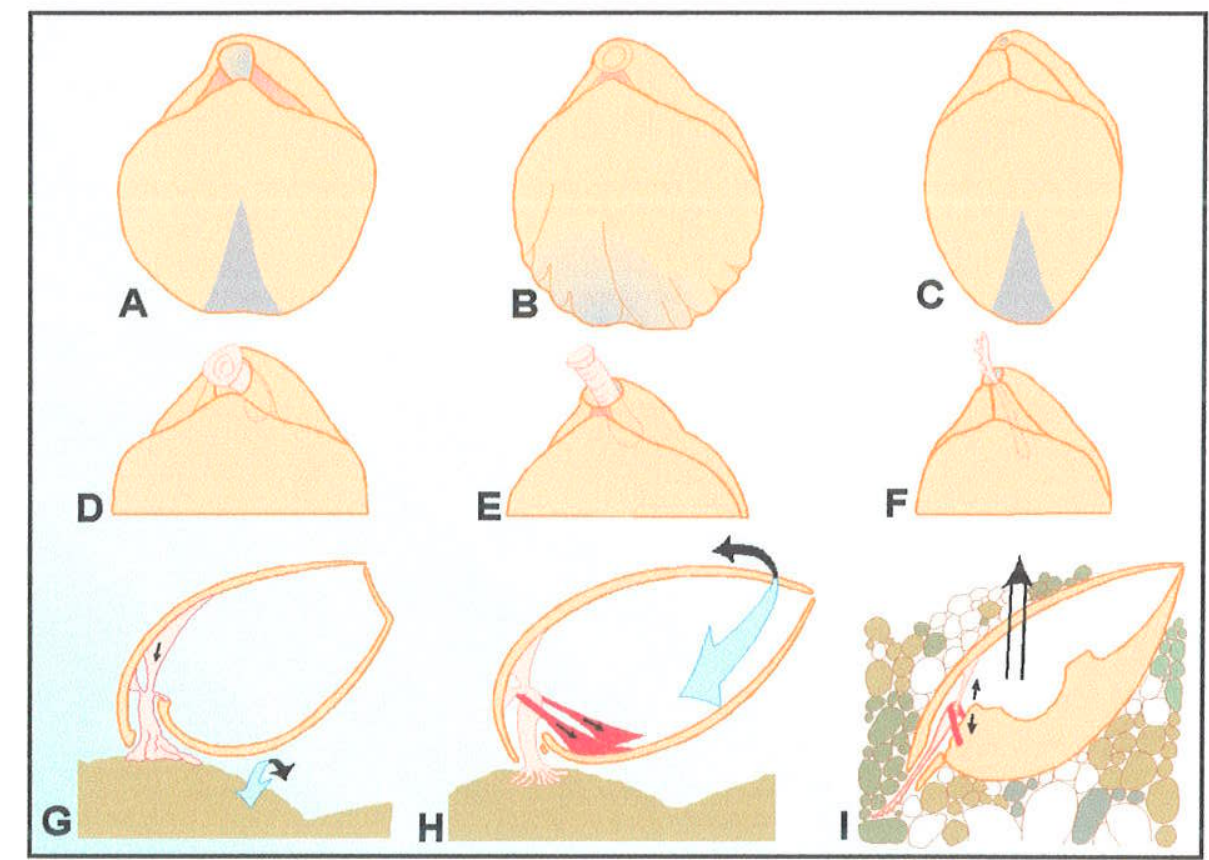

Figura 17- Conchas, pedículos e modo de vida (caracteres 40 ao 42) atribuídos a Terebratella (A; para comparação), Magadinella (B) e Anakinetica (C). De cima para baixo estão representadas as conchas em vista dorsal $(A, B, C)$, o pedículo em relação ao bico $(D, E, F$, ) e o sistema pedicular e modo de vida (i.e., fixo ou livre; $\mathrm{G}, \mathrm{H}, \mathrm{I})$ dos táxons. Os músculos adjustores (ventrais e dorsais) e pediculares médios unem as duas valvas aos pedículos, sejam eles transitivos $(G)$ ou inertes $(H, I)$. Setas maiores indicam a movimentação geral das conchas proporcionadas pela contração dos músculos (setas menores). Fonte- RICHARDSON (1981b)

\section{CARÁTER 41 - Tipo de extremidade do pedículo}

\section{Estado 0 (inerte); 1 (transitiva)}

Segue os comentários para o CARÁTER 40 (Figura 17).

\section{CARÁTER 42 - Tipo de extremidade inerte dos pedículos}

Estado $\quad 0$ (sem aderência); 1 (aderente)

Segue comentários para o caráter 40.

\section{CARÁTER 43 - Reforço da cicatriz do músculo adutor dorsal}

\section{Estado 0 (ausente); 1 (presente)}

O músculo adutor apresenta cicatrizes ( 2 ou 4 pares) bastante evidentes no assoalho da valva dorsal, próximo à região mediana e posterior do septo, e mostrou 
grande variedade de forma e intensidade de impressão. Os táxons foram avaliados quanto à presença ou ausência de um reforço existente nas margens laterais externas (contrárias ao septo) e posteriores dessas cicatrizes, consistindo em uma elevação pronunciada do assoalho, nessas regiões (Figura 18).

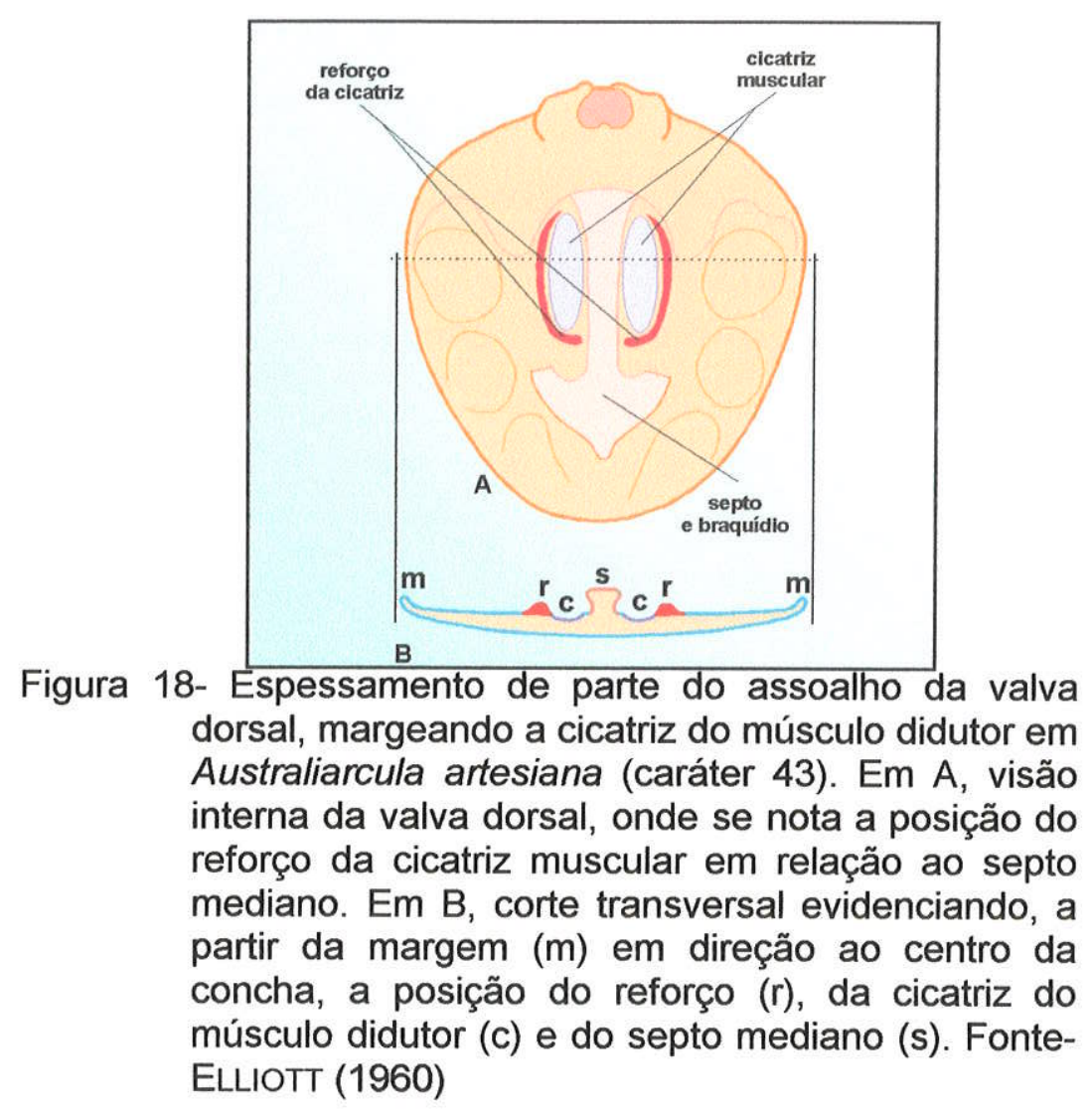

\subsection{ANÁLISE NUMÉRICA}

As informações contidas na matriz de caracteres (Tabela 1) foram convertidas em arquivo eletrônico através do programa MacClade 4 (MADDISON \& MADDISON, 1998), para que pudessem ser analisadas pelos programas adequados. Foi realizada a análise cladística dos 22 táxons (grupos interno e externo) com 43 caracteres (binários e multi estado, incluindo 91 estados). Os dados ausentes foram representados por "?".

A análise dessas informações foi realizada pelo programa PAUP* 4.0 v.8 (SWOFFORD, 1998), sendo utilizada a opção de transformação acelerada (ACCTRAN). Foram conduzidas duas análises paralelas, uma delas considerando todos os 
caracteres como "não-ordenados" e outra atribuindo ordenação aos caracteres sobre os quais havia alguma indicação de contigüidades entre seus estados (veja Quadro 6), permitindo a comparação e avaliação dos resultados obtidos. Tal decisão foi tomada pela dificuldade de se avaliar a ordenação de muitos dos caracteres, uma vez que as homologias primárias entre seus estados não puderam ser traçadas. Sabe-se que a ordenação aleatória de caracteres confere uma pesagem indireta à análise e, segundo AMORIM (1997), parece não haver vantagem da "ordenação" em relação à "nãoordenação", e vice-versa. Conforme destacado por FERRAREZZI \& MARQUES (1997), " ... A ordenação impõe certas restrições às possibilidades de transformações de estados fora da ordem codificada, as quais não são proibidas, mas passiveis de ocorrência apenas através de um maior custo em termos de parcimônia...". Importante destacar que os procedimentos empregados (i.e., algoritmos, consensos) foram iguais e repetidos em ambas análises.

As árvores não enraizadas geradas inicialmente foram enraizadas pelo método do grupo externo, considerando o grupo interno monofilético. As análises com os caracteres ordenados (Quadro 6) tiveram resultados idênticos áqueles obtidos a partir dos caracteres não ordenados, submetidos aos mesmos procedimentos e análises. $E$ importante ressaltar que o número de caracteres e de táxons hora empregados inviabilizou a utilização de algoritmos de busca exaustiva das árvores mais parcimoniosas. No entanto, as análises foram realizadas através do algoritmo exato "branch-and-bound", com opção "furthest" de adição.

$\mathrm{Na}$ análise de máxima parcimônia foram obtidos 168 cladogramas mais parcimoniosos $(\mathrm{L}=98 ; \mathrm{Cl}=0,490 ; \mathrm{Rl}=0,745 ; \mathrm{RC}=0,365)$, aqui sintetizados através dos cladogramas de consenso estrito e semi estrito da Figura 19. Observa-se, claramente, uma baixa resolução das relações entre os táxons dos grupos interno e externo. Boa resolução para os dois grupos só foi atingida quando se processou a análise por pesagem sucessiva, resultando em 12 cladogramas mais parcimoniosos $(\mathrm{Cl}=0,714$; $\mathrm{RI}=0,889 ; \mathrm{RC}=0,635$ ), representados pelos cladogramas de consenso estrito e semiestrito da Figura 20. Comparando-se os resultados obtidos (Figuras 19 e 20), nota-se diferenças consideráveis quanto à resolução geral das politomias, como fica evidente, sobretudo, para os táxons do grupo interno. Tendo em vista os resultados alcançados, optou-se por assumir como proposta de trabalho o cladograma da Figura 20b. A distribuição dos caracteres e seus estados pelos diversos ramos está representada na 
Figura 21 e detalhada no Anexo 2, sendo que considerações a esse respeito serão feitas mais adiante.

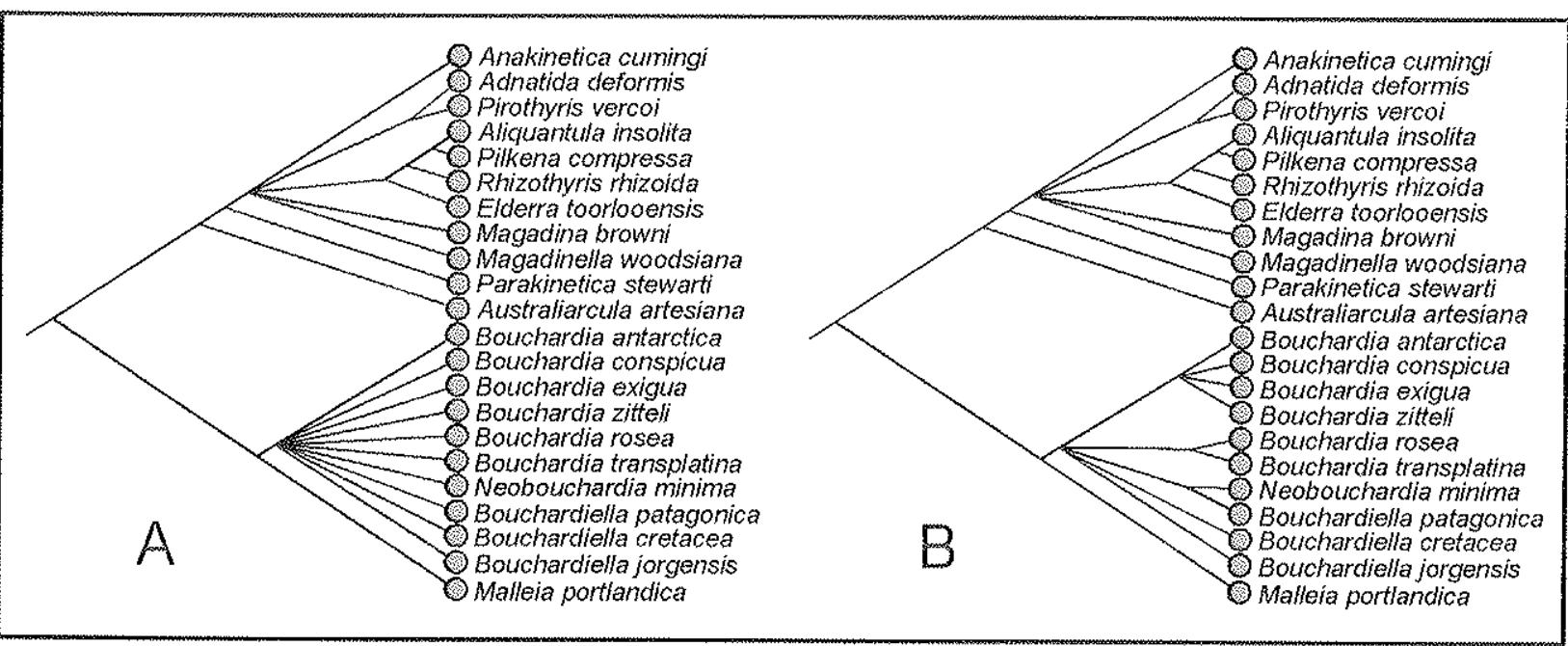

Figura 19- Cladogramas de consenso estrito $(A)$ e semi-estrito $(B)(L=98 ; C l=0,490 ; R l=0,745$; $\mathrm{RC}=0,365)$, com diferentes topologias, obtidos a partir da análise de máxima parcimônia para caracteres não ordenados (veja detalhes da análise no texto). Cores indicam táxons do grupo interno (verde) e externo (laranja)

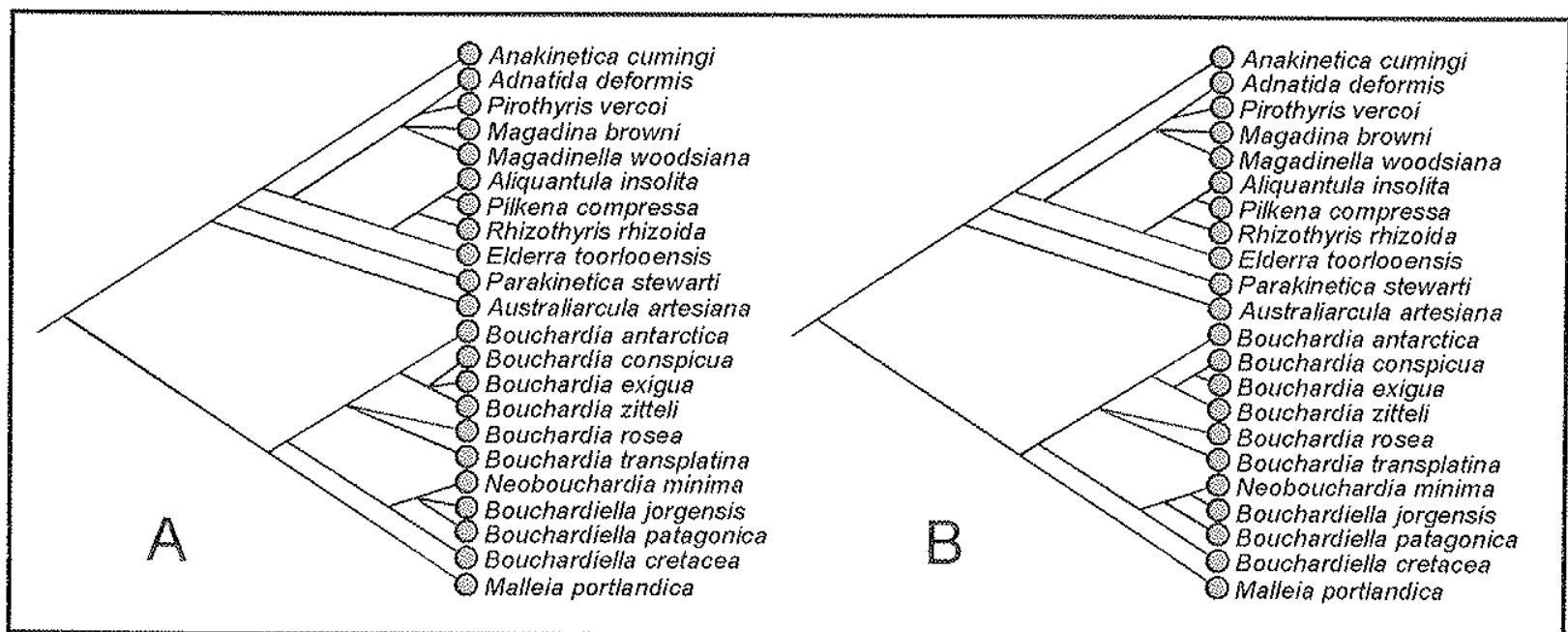

Figura 20-Cladogramas de consenso estrito $(A)$ e semi-estrito $(B)(L=98 ; C l=0,741 ; R l=0,889$; $\mathrm{RC}=0,635$ ), com diferentes topologias, obtidos a partir da análise de pesagem sucessiva para caracteres não ordenados (veja detalhes da análise no texto). Cores indicam táxons do grupo interno (verde) e externo (laranja) 


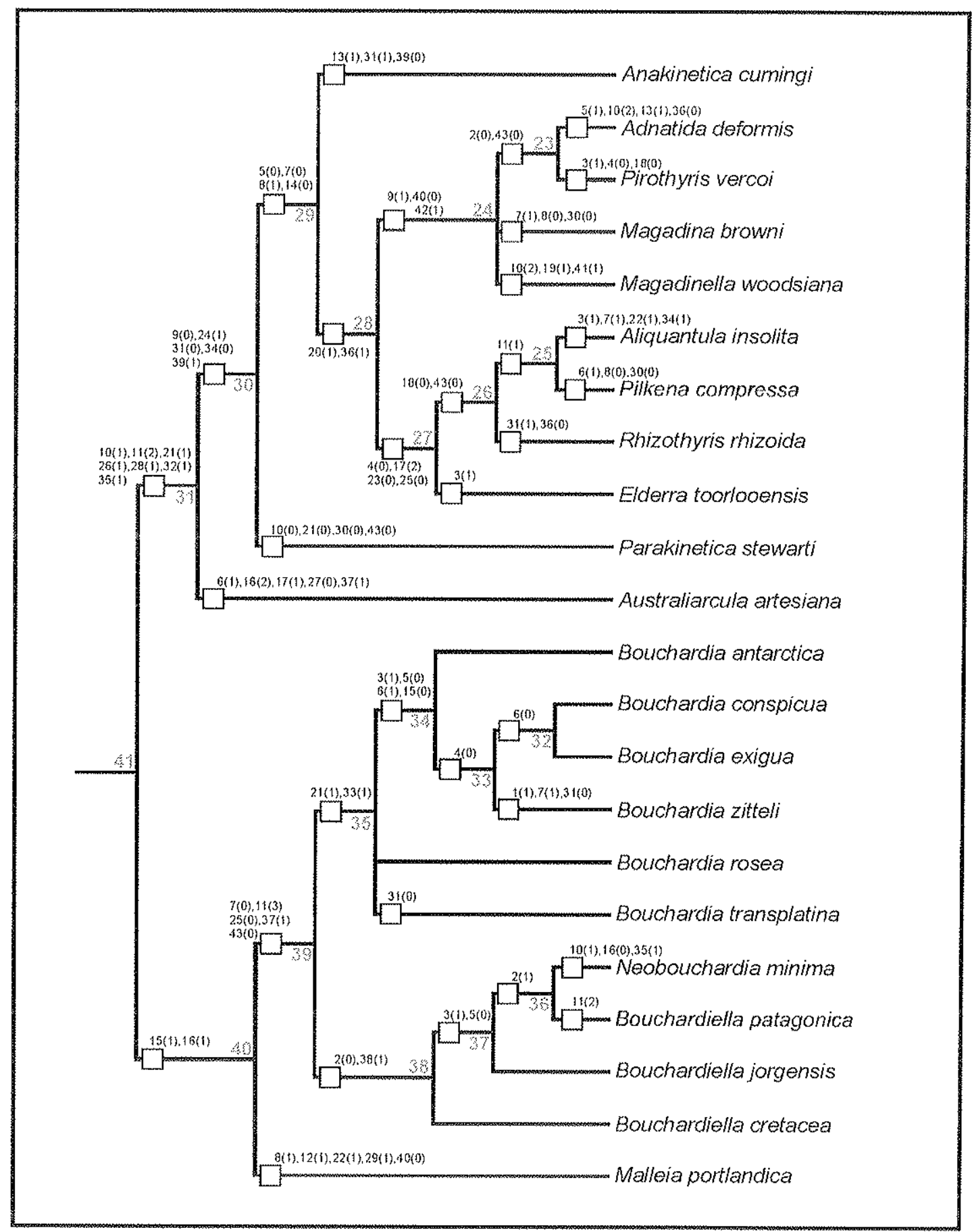

Figura 21- Cladograma de consenso semi-estrito obtido a partir de análise de pesagem sucessiva (veja explicação no texto) de caracteres não ordenados, por algoritmo exato ('branch-and-bound'), mostrando a distribuição dos caracteres e seus estados. Em azul estão indicados os números dos nós dos diferentes ramos (veja Anexo 2) 
Adicionalmente, para complementação dos resultados, foi avaliada a confiabilidade dos clados através dos métodos:

- "Bootstrap": foi utilizada a opção do pacote PAUP*; todos os 43 caracteres foram reamostrados aleatoriamente, com 1000 réplicas, cada uma analisada por "branch-andbound"; resultado final na forma de árvore de consenso de maioria está representado na Figura 22a. Há que se considerar, entretanto, que essa árvore de consenso não é idêntica, nem totalmente comparável, àquela assumida como hipótese de trabalho (Figura 20b), uma vez que resultam de análises diferentes. Contudo, o suporte dos clados obtidos com o teste de "bootstrap" é válido para os mesmos clados que também estejam representados na proposta de trabalho. Por conseguinte, aqueles clados que estão na hipótese de trabalho mas não na árvore de consenso com valores de "bootstrap", são pouco robustos.

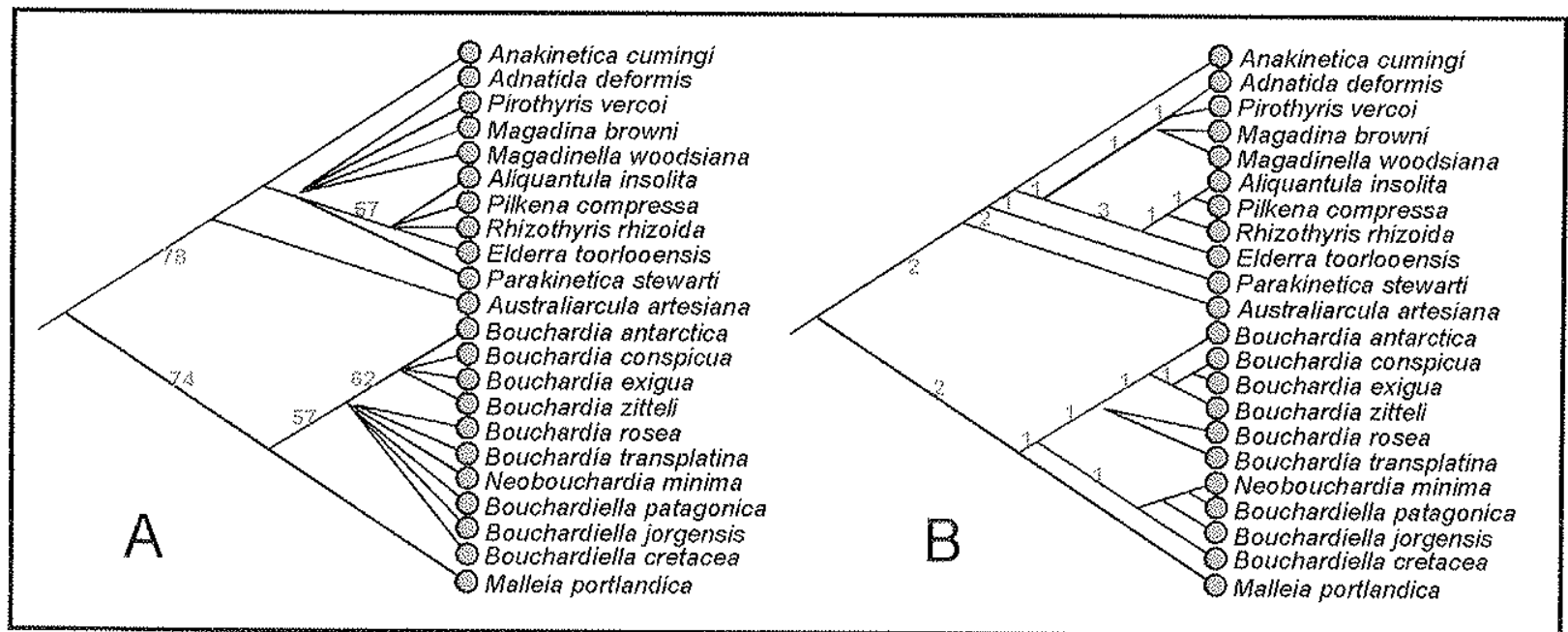

Figura 22- Cladogramas de consenso de maioria (A) obtido após análise de "bootstrap", com os valores dos clados indicados em vermelho; cladograma de consenso semi-estrito (B), com indicação dos valores do índice de decaimento de Bremer indicados em azul

Na literatura há controvérsia quanto aos valores de "bootstrap" que representam um limiar de significância, com porcentagens variando entre $70 \%$ e 95\% (HILLIS \& BULL, 1993; HARAdA et al., 1995; LI, 1997; CHen et al., 2003; SCHNEIDER, 2003). Propostas conciliadoras, no entanto, consideram um clado robusto (significativo) com valores acima de $95 \%$, ou passo que valores moderados ( 70 a $94 \%$ ) ou fracos (51 a $69 \%$ ) 
poderão dar suporte a um clado desde que obtidos a partir de conjuntos de dados diferentes (e.g., caracteres morfológicos, moleculares) (SCHNEIDER, 2003)

- Índice de decaimento de Bremer: foram seguidos os procedimentos indicados pelo programa TreeRot.v2 (SORENSON, 1999) e a árvore de consenso semi-estrito, com os valores de decaimento para os respectivos clados, está representada na Figura 22b. Há na literatura considerações acerca da relação entre os testes de "bootstrap" e de decaimento de Bremer, onde se verifica que arranjos com valores de "bootstrap" moderados apresentam valores baixos de decaimento, e vice-versa.

\subsection{INTERPRETAÇÃO DA HIPÓTESE ESCOL.HIDA}

O cladograma apresentado na Figura $20 \mathrm{~b}$ traz uma topologia bem resolvida. A dicotomia basal sustenta a nítida estrutura de dois clados que correspondem, de um lado aos Bouchardiinae (grupo interno) e, de outro, aos Anakineticinae (grupo externo). Entre os táxons do grupo interno as relações estão, em grande parte, bem estabelecidas. O táxon basal é Malleia portlandica, seguido pelo clado formado por Neobouchardia minima e as 3 espécies de Bouchardiella (veja Figura 20b). A indefinição nas relações fica por conta da politomia envolvendo Bouchardia rosea, Bouchardia transplatina e o clado contendo as outras 4 espécies de Bouchardia. Já o clado formado pelos táxons do grupo externo apresenta, a partir da dicotomia basal, Australiarcula artesiana na base, seguido por Parakinetica stewarti, Anakinetica cumingi, um clado totalmente resolvido formado por Elderra toorlooensis, Rhizothyris rhizoida, Pilkena compressa, Aliquantula insolita e, por fim, a politomia envolvendo Magadina browni, Magadinella woodsiana e o pequeno clado formado por Adnatida deformis e Pirothyris vercoi (Figura 20b). Considerações sobre as relações apontadas acima, e os caracteres que dão suporte a elas, são apresentadas mais adiante. 


\section{DISCUSSÃO}

\subsection{A HIPÓTESE DE TRABALHO}

O que se pode observar na topologia adotada como hipótese de trabalho (Figura 20b) é a nítida presença de 2 clados bem individualizados, representativos dos grupos interno e externo utilizados. Entre os táxons do grupo interno observa-se Malleia portlandica como táxon basal. Segundo RICHARDSON (1973b), apesar das marcantes diferenças morfológicas (i.e., posição do forâmen, tipo de placa deltidial, plataforma cardinal), Malleia deveria ser transferida da Subfamília Neothyrinae para a Subfamília Bouchardiinae, com base no grande número de caracteres exclusivos (sinapomorfias) dos Bouchardiinae, apresentado por esse gênero. De fato, a análise morfológica aqui realizada (veja a Figura 21 e Tabela 2 para informações adicionais sobre a distribuição dos caracteres e seus estados) identificou diferenças em alguns caracteres (e.g., tipo e posição do forâmen, presença de sinfítio) de Malleia em relação aos demais Bouchardiinae. Em contrapartida, muitas características foram compartilhadas entre Malleia e os outros Bouchardinae, inclusive prováveis sinapomorfias desse segundo grupo (e.g., ramos ascendentes livres posteriormente, processo cardinal bilobado, cristas e sulcos na articulação), corroborando a idéia original de RICHARDSON (1973b). Outro clado (Figura 20b) agrupou as três espécies de Bouchardiella junto com Neobouchardia minima de maneira totalmente resolvida, estando Bouchardiella cretacea na base e Neobouchardia minima como táxon mais apical. Mais adiante serão feitas considerações sobre as implicaçōes dessa configuração na sistemática do grupo. O grupo irmão desse clado (Figura 20b) reuniu todas as espécies de Bouchardia. Considerações mais detalhadas sobre este último agrupamento serão feitas mais adiante.

No item 4.3. já havia sido mencionada a dúvida decorrente da literatura, quanto ao posicionamento de Australiarcula artesiana entre os Bouchardinae ou Anakineticinae, de acordo com a proposta de classificação adotada (i.e., RICHARDSON, 1991, 1994; MACKINNON \& LEE, no prelo). Segundo ELLLOTT (1960), apesar de importantes diferenças morfológicas em relação a Bouchardia, Australiarcula seria, provavelmente, o melhor candidato a seu ancestral. 
Tabela 2- Matriz de caracteres empregada na análise. Os números de cada estado do caráter foram substituídos por símbolos para auxiliar na identificação de padrões de distribuição de caracteres. Símbolos para os diferentes estados dos caracteres: $0=\square ; 1=\square ; 2=\square$; $3=$

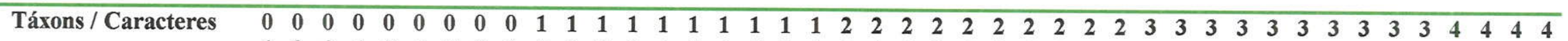
$\begin{array}{lllllllllllllllllllllllllllllllllllllllllll}1 & 2 & 3 & 4 & 5 & 6 & 7 & 8 & 9 & 0 & 1 & 2 & 3 & 4 & 5 & 6 & 7 & 8 & 9 & 0 & 1 & 2 & 3 & 4 & 5 & 6 & 7 & 8 & 9 & 0 & 1 & 2 & 3 & 4 & 5 & 6 & 7 & 8 & 9 & 0 & 1 & 2 & 3\end{array}$

Anakinetica cumingi Adnatida deformis

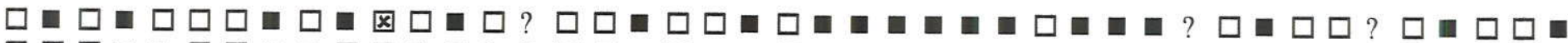
Aliquantula insolita Australiarcula artesiana Elderra toorlooensis

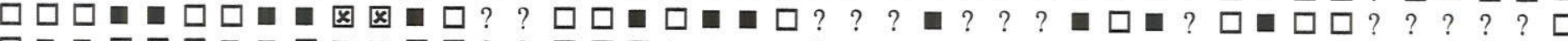

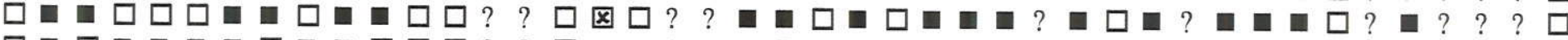

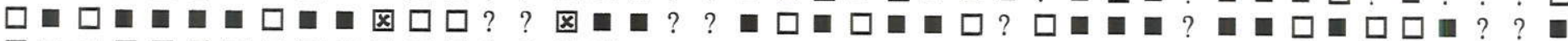

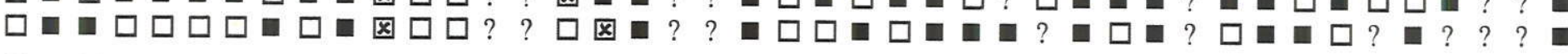

Magadina browni Magadinella woodsiana Parakinetica stewarti Pilkena compressa Pirothyris vercoi

Rhizothyris rhizoida Bouchardia antarctica Bouchardia conspicua Bouchardia exigua Bouchardia rosea

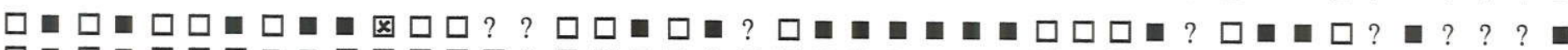

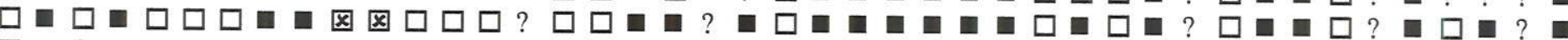

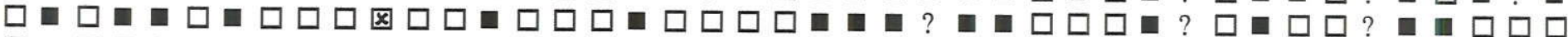

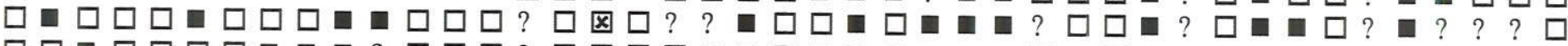

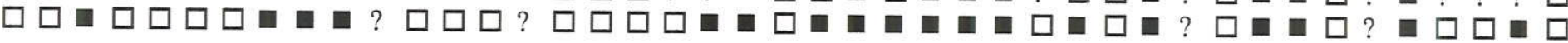

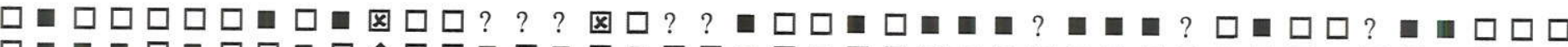

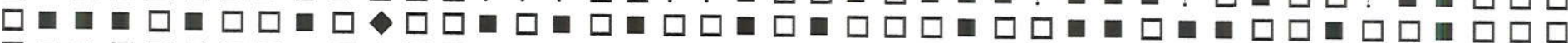

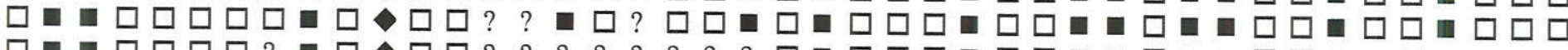

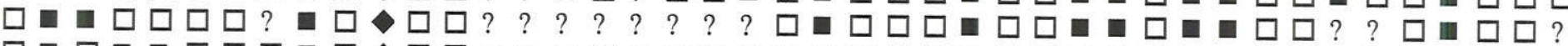

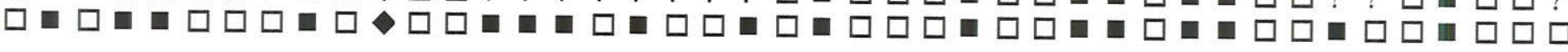

Bouchardia transplatina Bouchardia zitteli

Neobouchardia minima Bouchardiella cretacea Bouchardiella jorgensis

Bouchardiella patagonica Malleia portlandica

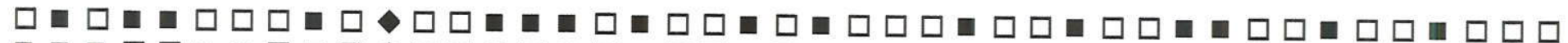

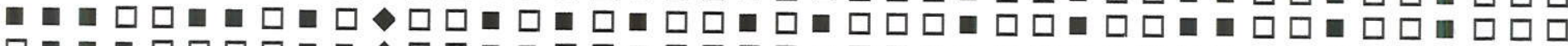

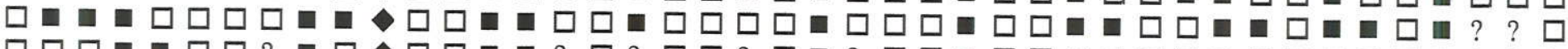

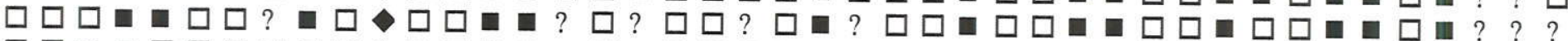

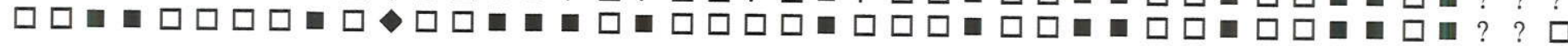

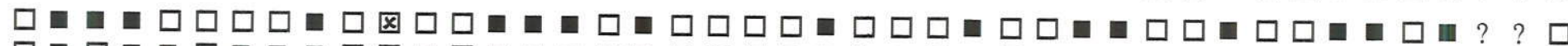

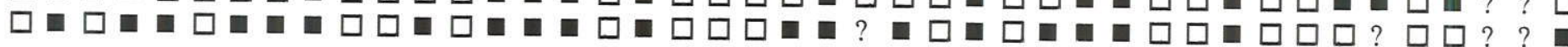


Vale lembrar que, para LEVY (1964), Australiarcula, a despeito da notável semelhança morfológica com Bouchardiinae, seria excluída desse grupo com base na presença de ramos descendentes no braquídio. As informações obtidas da estratigrafia (Figura 23) contribuem para o suporte das idéias de ELLIOTT (1960) uma vez que Australiarcula, do Cretáceo inicial/médio da Austrália, poderia ter dado origem a Bouchardiella cretacea, do Cretáceo médio/final da Austrália, e daí aos demais Bouchardiinae, todos já dentro do Cenozóico. Contudo, as relações obtidas com a presente análise apontam Australiarcula artesiana entre os táxons do grupo externo, como sugerido por LEVY (1964). A análise da distribuição dos caracteres (Figura 21) evidencia que Australiarcula artesiana compartilha com os Bouchardiinae muitas características que dão suporte a esse grupo (e.g., diferenciação dos elementos da charneira, cristas e sulcos na articulação, cavidades na parede anterior da plataforma cardinal), ao mesmo tempo em que compartilha outras características com os demais Anakineticinae (e.g., espessamento posterior da concha, forma do processo cardinal, presença de crura). Dessa forma, o conjunto de dados aqui analisados, resultando no cladograma da Figura 20b, e a posição basal de Australiarcula artesiana dentro do clado, parecem corroborar a posição defendida por LEVY (1964), e sugerir Australiarcula artesiana como um suposto ancestral mais dos Anakineticinae do que dos Bouchardiinae. Embora a definição das relações entre os táxons do grupo externo seja de interesse secundário para o presente estudo, vale a pena destacar o clado completamente resolvido formado por Aliquantula insolita, Pilkena compressa, Rhizothyris rhizoida e Elderra toorlooensis, bem como a reunião em outro clado, embora com resolução menor, de Adnatida deformis, Pirothyris vercoi, Magadina browni e Magadinella woodsiana. Notavelmente, na literatura consultada não há qualquer sugestão de parentesco entre esses táxons que pudesse ser testada com os resultados aqui apresentados, a não ser, obviamente, o fato de que todos pertenceriam aos Anakineticinae.

O espessamento posterior da concha, o forâmen permesotírido e o processo cardinal trífido foram apontados por RICHARDSON (1975a, 1991), como caracteres diagnósticos dos Anakineticinae mas, conforme discutido por MACKINNON et al. (1993), essas não são características exclusivas do grupo, sendo esporadicamente encontradas em muitos outros táxons (e.g., Cancellothyrididae, Neothyrididae). Por fim, valendo-se apenas do jargão filogenético, os autores consideraram o tipo de braquídio 


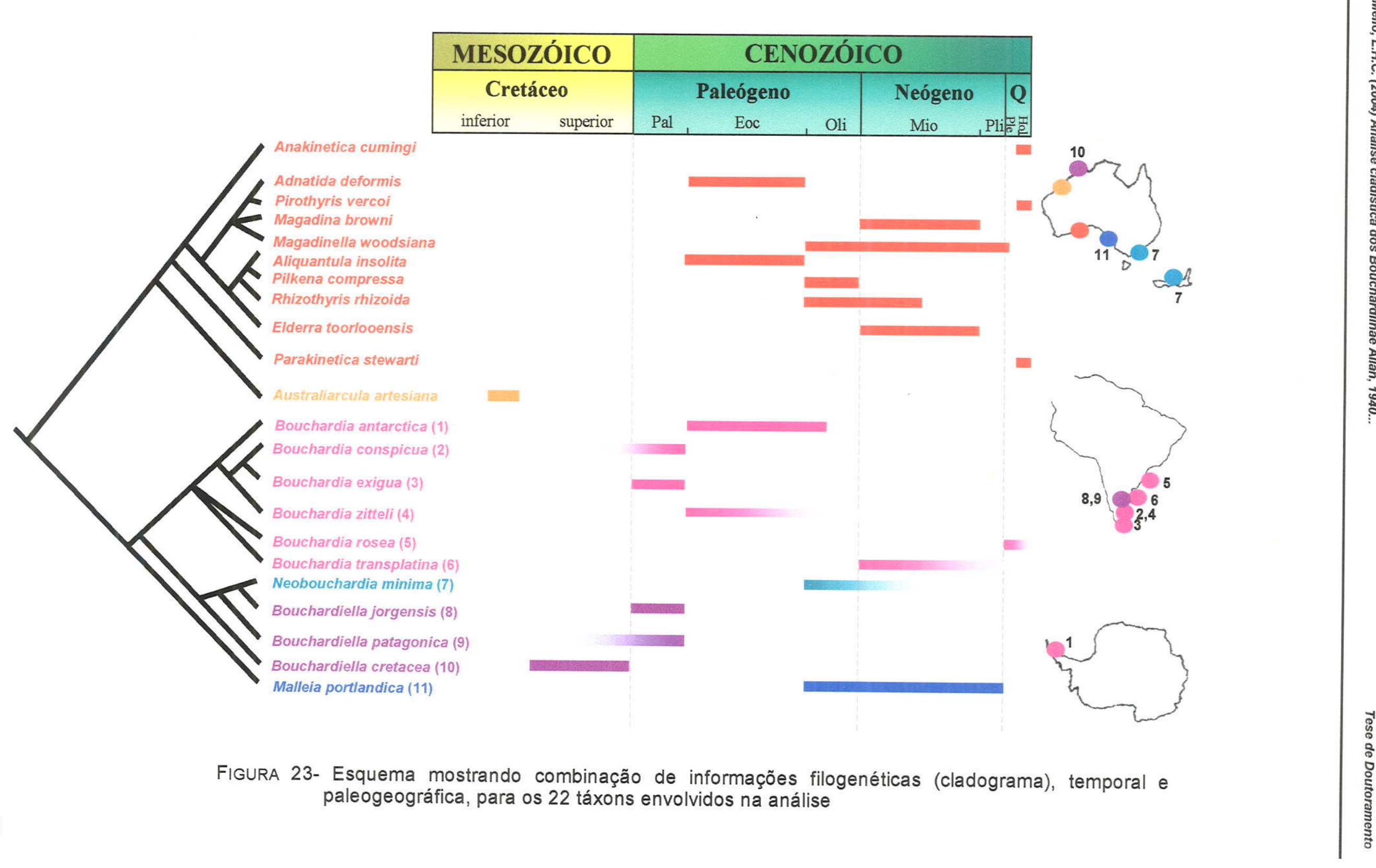


e depressão da charneira como sinapomorfias dos Anakineticinae. Da mesma maneira, no presente estudo, o braquídio incompleto mostrou-se sinapomórfico para os Bouchardinae (veja comentários adiante) e o braquídio completo, em forma de laço, reuniu os táxons do grupo externo. No entanto, análises futuras, com maior representatividade de Anakineticinae e outros braquiópodes (Rhynchonelliformea), devem ser realizadas para avaliar melhor o papel do braquídio na definição das relações entre os táxons desses grupos.

Conforme já mencionado, a Figura 22 traz a representação do suporte dos clados obtidos. Fica evidente, no entanto, que tanto os valores de "bootstrap" quanto os índices de decaimento são muito baixos, sobretudo para os clados envolvendo táxons do grupo externo. Tal fato talvez possa ser decorrente do grau elevado de homoplasia existente entre táxons dos dois grupos, a despeito dos esforços realizados no levantamento, definição e análise dos caracteres. Conforme será comentado mais adiante, a grande similaridade morfológica entre os Bouchardiinae, sobretudo entre as espécies de Bouchardia, dificultou a identificação das apomorfias e pode ter contribuído para conferir indefinição nas relações entre esses táxons,

\subsection{SOBRE O MONOFILETISMO DOS BOUCHARDIINAE}

Os resultados obtidos pela análise morfológica confirmam as sugestões anteriores (LEVY, 1964; RICHARDSON, 1973b, 1994; BRUNTON, 1996; BRUNTON et al, 1996) sobre as 3 características comuns a todos os Bouchardinae, ou seja, a) o espessamento posterior da concha, b) o processo cardinal bilobado, em especial aqueles com forma de ' $\mathrm{V}$ ' invertido, que caracterizam Bouchardia, e c) o braquídio incompleto. O espessamento posterior da concha merece atenção especial por também estar presente, em maior ou menor grau, em táxons do grupo externo (e.g., Anakinetica cumingi, Australiarcula artesiana) e, portanto, não representar uma sinapomorfia exclusiva dos Bouchardinae embora, como já foi comentado, esteja presente em todos os táxons desse grupo. A análise morfológica realizada mostrou que essa feição, embora evidente para ambas as valvas, na maioria dos táxons analisados, é difícil de ser definida como caráter contínuo (veja comentários no Item 5.2.) e, portanto, empregada em análises cladisticas. Dessa maneira, informações sobre essa característica estão diluídas nos estados do caráter 30, através da diferenciação dos 
elementos da charneira, sendo que, via de regra, apresentam uma relação direta (RICHARDSON \& WATSON, 1975a, 1975b; RICHARDSON, 1981a, 1981b, 1981c, 1987; MiNUER \& RICHARDSON, 1984), onde a identificação desses elementos é melhor quanto menor o espessamento posterior das valvas. Essa característica está diretamente relacionada a estabilidade do animal no substrato e, portanto, ao seu modo de vida, refletindo uma resposta às pressões ecológicas. Neste contexto, reveste-se de importância a correlação entre o tipo de substrato, a morfologia da concha (e.g., forâmen, musculatura, charneira) e modo de vida (e.g., ancoragem, fixador) dos braquiópodes, sendo que através da análise dessas características morfológicas, especialmente entre os Rhynchonelliformea, muitas vezes tornam-se evidentes os casos de homeomorfia resultantes desta interação, como já destacado na literatura (e.g., RichARDSON, 1994). A utilização desse tipo de caráter na recuperação das relações de parentesco, a partir de caracteres compartilhados, é potencialmente problemática, visto que pode aproximar, artificialmente, táxons com morfologias semelhantes resultantes de pressões ecológicas similares, mais do que por caracteres derivados herdados (sinapomorfias).

O processo cardinal bilobado e o braquídio incompleto, outras duas características citadas pela literatura como sendo compartilhadas pelos Bouchardiinae correspondem, de fato, a sinapomorfias do grupo, tendo sido identificadas como perda da fixação dos ramos descendentes na plataforma cardinal (caráter 26) e da fixação posterior dos ramos ascendentes (caráter 28) além do processo cardinal bilobado (caráter 32), sendo que o processo bilobado e em forma de ' $V$ ' invertido (caráter 33) é típica do gênero Bouchardia. RICHARDSON (1975a, 1991) enfatizou a importância taxonômica das fases intermediárias do desenvolvimento do braquídio, sendo esse critério especialmente relevante quando envolve extensas seqüências de modificações morfológicas, como ocorre nos Dallinidae e Laqueidae, o que não se observa nos Bouchardiinae e Anakineticinae (MACKINNON et al, 1993). RICHARDSON (1975a) destacou, ainda, a utilização do braquídio, especialmente sua forma, como principal estrutura no agrupamento de Terebratellidae e, conseqüentemente, classificação do grupo. De acordo com a nomenclatura proposta para essa estrutura (RICHARDSON, 1975a), um braquídio axial estaria presente em Bouchardia, Neobouchardia e Bouchardiella (RICHARDSON, 1975a; BRUNTON, 1996). De fato, esta informação pôde ser confirmada pelos resultados obtidos na presente análise, e complementada por sua 
presença em Australiarcula artesiana, embora seus ramos ascendentes não sejam posteriormente livres, como nos Bouchardinae. O braquidio foi identificado para 4 das 6 espécies de Bouchardia, como comentado mais adiante.

Outros dois caracteres merecem destaque. O relevo do assoalho da valva dorsal composto por retas inclinadas (caráter 16) e a perda da crura (caráter 35) estão presentes apenas nos Bouchardinae mas, em ambos os casos, apresentam outro estado de caráter em Neobouchardia minima. Já o forâmen epitírido (caráter 11) foi observado em todos os táxons do grupo interno, exceto Malleia portlandica (hipotírido) e Bouchardiella patagonica (permesotírido), sendo este último compartilhado por muitos táxons do grupo externo.

Outras sinapomorfias foram observadas para os Bouchardiinae (Tabela 2), entre elas as placas deltidiais côncavas (caráter 9), braquídio fixo ao septo (caráter 23), cristas e sulcos reforçando a articulação entre as valvas (caráter 34), perda da depressão na charneira (caráter 36) e lofóforo zigolofo (caráter 39). Contudo, apesar de presentes em todos os táxons do grupo externo, não são exclusivas deles, sendo observadas em pelo menos um táxon do grupo externo. Já para os caracteres 8,10 , $14,15,17,18,20,24,25,31,37,40$ e 43 , determinado estado dos caracteres era compartilhado pela maioria dos táxons do grupo interno, exceção feita a 1 ou 2 táxons representados por outros estados de caráter ou informações ausentes. No entanto, os estados compartilhados estavam também presentes em táxons do grupo externo. Os casos indicados neste parágrafo representam, portanto, possíveis casos de homoplasia.

A partir das considerações feitas até aqui, considera-se que a topologia obtida (Figura 20b) dá suporte à sugestão presente na literatura (RiCHARDSON, 1994; BRUNTON, 1996), sendo que, de fato, Bouchardia rosea e Anakinetica cumingi apresentam morfologia muito semethante, sobretudo externamente, provavelmente por compartilharem modos de vida semelhantes, e não por parentesco próximo. De fato, os Anakineticinae são tidos como sendo de vida livre, especializados em viver em sedimentos grossos, utilizando o pedículo para manter a posição junto ao substrato, e tendo o auxílio do espessamento da região posterior da concha para dar estabilidade (RICHARDSON, 1987, 1991, 1994; BRUNTON, 1996). Esse modo de vida também é atribuído, embora não totalmente comprovado, a Bouchardia rosea justificando a 
semelhança na forma das duas espécies, apesar do espessamento mais acentuado na Guma (BRUNTON, 1996).

\subsection{CARACTERIZAÇÃo MORFOLÓgICA dO GÊNERO BOUCHARDIA}

\subsubsection{Aspectos ontogenéticos: desenvolvimento de estruturas morfológicas}

Ao comparar Laqueoidea e Bouchardiinae, no que tange a morfologia da charneira, MACKINNON (comunicação pessoal, 2001) menciona a aparente ausência de placas dentais no segundo grupo, estrutura essa comum a todos os Laqueoidea. Sugeriu, ainda, que sua presença, pelo menos nos estágios ontogenéticos iniciais, fosse investigada. Contudo, a avaliação de tais características permanece, no momento, inviável para a maioria dos táxons desse grupo (e.g., Bouchardiella, Neobouchardia, Malleia), sobretudo pela falta de espécimes em estágios ontogenéticos iniciais, mas também pela ausência dessas informações na literatura existente sobre o grupo.

De fato, apesar da reconhecida importância dos estudos ontogenéticos para a análise morfológica de grupos de braquiópodes (e.g., WILLIAMS \& WRIGHT, 1961; Foster, 1974; RICHARDSON, 1975a; MACKINNON, 1993; BRUNTON, 1996), não há, até onde foi recuperado, qualquer estudo com essa abordagem para os Bouchardiinae, existindo, quando muito, breves descrições e ilustrações de formas jovens isoladas, mas nunca com séries ontogenéticas completas (e.g., ELLIOTT, 1952; MACKINNON, 1987). Nesse contexto, BRUNTON (1996, p.239) lamenta a falta de séries ontogenéticas, - que, segundo ele, permitiria avaliar a separação desse grupo dos demais Terebratellidae, com base nos estágios iniciais de desenvolvimento do braquidio.

Levando em consideração os comentários acima e contando com o grande número disponível de conchas de Bouchardia rosea em diferentes estágios ontogenéticos, foram feitas investigações, através de microscopia eletrônica de varredura, com o objetivo de complementar a caracterização morfológica de Bouchardia rosea, desde seus estágios mais iniciais de desenvolvimento, bem como investigar a evolução de estruturas particulares (e.g., braquídio, cardinália) (Estampa 1), tentando avaliar a presença das feições morfológicas citadas por MACKINNON (comunicação pessoal, 2001) (i.e., franjas septais e placas dentais). 
De acordo com RICHARDSON (1973b) e BRUNTON (1996), o braquidio adulto de Bouchardia rosea encontra correspondente nos estágios iniciais do desenvolvimento dos braquídios de outros Terebratellidae, tendo sérias implicações para a evolução dessa estrutura dentro do grupo, como discutido mais adiante.

Para investigar essa questão, foram examinadas as valvas dorsais de 10 espécimes articulados fechados, variando entre $1 \mathrm{~mm}$ e $18 \mathrm{~mm}$ de comprimento, na tentativa de se identificar os momentos de surgimento e o desenvolvimento de estruturas como o septo mediano, o braquídio e a cardinália. É necessário salientar, contudo que apesar dos menores exemplares examinados terem apenas $1 \mathrm{~mm}$ de comprimento, eles não foram considerados conchas larvais. O desenvolvimento do braquídio teve inicio apenas nos exemplares entre $1,6 \mathrm{~mm}$ e 2,0 $\mathrm{mm}$, manifestandomse como dois ramos ascendentes, independentes, a partir de cada um dos lados da extremidade anterior do septo mediano (Estampa 1). Ao mesmo tempo, ocorria o desenvolvimento das fossetas e do processo cardinal (Estampa 1), este último, na forma de uma pequena depressão na região posterior da plataforma cardinal. Nesse estágio, o processo cardinal está no início do desenvolvimento, e já lembra a típica forma de ' $V$ ' dos adultos, sendo, contudo, bastante similar àquele apresentado por Bouchardiella e Australiarcula (Estampa 7), embora mais raso em Bouchardia rosea. Até o referido estágio não foram observadas evidências de crura.

Os exemplares com mais de $2 \mathrm{~mm}$, revelaram o gradual desenvolvimento do braquídio, sempre em direção à extremidade posterior da concha, com os ramos ascendentes ainda independentes e sustentados pelo septo mediano. Essa tendência se manteve até alcançar a conformação observada para os exemplares considerados adultos (com aproximadamente $18 \mathrm{~mm}$ de comprimento), com braquídio incompleto e ramos ascendentes separados e suspensos na cavidade do manto (Estampa 1). Notouse, ainda, o desenvolvimento do septo mediano, das fossetas e da cardinália, os quais, de uma maneira geral, não apresentaram grandes mudanças morfológicas entre os estágios ontogenéticos analisados, a não ser o aumento das dimensões. Deve-se considerar que transformações morfológicas mais acentuadas podem ocorrer em estágios ontogenéticos mais primitivos, que não foram analisados até o momento. Talvez as maiores alterações tenham sido observadas no processo cardinal, onde a pequena depressão na região posterior da plataforma cardinal deu origem a um sulco profundo, com bordas elevadas em direção da valva ventral e extremidades anteriores 
bem destacadas da cardinália, livres na cavidade do manto, assumindo a típica forma de ' $V$ ' que caracteriza o gênero (Estampa 1). Destaca-se que, em nenhuma das etapas analisadas foram observadas quaisquer evidencias de crura, bases crurais ou placas dentais.

As informações aqui apresentadas caracterizam o desenvolvimento do braquídio em Bouchardia rosea mostrando ser esse um processo com poucas etapas, quando comparado aos de outros Rhynchonelliformea (veja OWEN, 1980), marcado por sucessivos eventos de fusão e reabsorção de partes do septo e do braquídio. Vale ressaltar que, além de Bouchardia rosea, há registro da presença de braquídios incompletos, em indivíduos considerados adultos, em Bouchardia antarctica, Bouchardia transplatina e Bouchardia zitteli (Estampa 3). Dessa forma, a julgar pela grande semelhança morfológica guardada pelas espécies atribuídas ao gênero Bouchardia, sobretudo no que diz respeito às estruturas referidas acima, seria lícito supor que os mesmos passos observados ao longo do desenvolvimento de Bouchardia rosea marquem, também, o desenvolvimento das demais espécies. Obviamente, a confirmação de tal suposição dependeria do emprego de abordagens semelhantes para as espécies fósseis, o que, de momento, se mostra impossivel pelo reduzido número de exemplares que compõem as coleções examinadas.

Adicionalmente, a analogia entre o braquidio incompleto de Bouchardia rosea e os estágios iniciais do desenvolvimento dessa estrutura em outros Terebratellidae, sugerida por RICHARDSON (1973b) e BRUNTON (1996), deve ser avaliada com mais atenção, podendo favorecer a idéia de retenção dos caracteres juvenis, com importantes implicações para a evolução do grupo. Finalmente, se considerarmos, novamente, o comentário de MACKINNON (comunicação pessoal, 2001), as observações morfológicas feitas para Bouchardia rosea, e que podem, com algum cuidado, ser estendidas a todo o gênero, confirmam as diferenças morfológicas (i.e., franjas septais e placas dentais) apontadas entre os Laqueoidea e os Bouchardiinae.

\subsubsection{Diferenciação morfológica das espécies}

Ficou evidente, após as etapas iniciais do presente estudo, que a literatura, de uma forma geral, apresenta grave deficiencia nas descrições morfológicas das espécies de Bouchardia (e.g., IHERING, 1903, 1907; LEVY, 1964), sobretudo por 
empregar termos pouco precisos e que permitem diferentes interpretações para uma mesma estrutura ou feição. Dificuldade adicional foi notada na utilização das ilustrações presentes na literatura como fonte de informação morfológica, devido, sobretudo, a baixa qualidade de reprodução, mesmo nos originais, muito embora isso esteja relacionado à data de publicação da maioria dos trabalhos sobre o grupo. A despeito dessas dificuldades, foi possivel identificar na literatura (LEVY, 1964; RICHARDSON, 1973b, 1994; BRUNTON, 1996; BRUNTON et al., 1996) três características compartilhadas por todas as espécies de Bouchardia, configurando, a priori, possiveis sinapomorfias para o gênero. Essas características contribuiram sobremaneira para o que BRUNTON (1996) classificou como 'morfologia incomum' de Bouchardia, e correspondem a:

a) espessamento da região posterior das valvas ventrais e dorsais;

b) processo cardinal representado por sulco profundo em forma de ' $V$ ';

c) braquídio incompleto.

Como ficou demonstrado pelos resultados obtidos no presente estudo (Figuras 19-22), essas estruturas correspondem, de fato, a sinapomorfias não só para o gênero mas para os Bouchardiinae (sensu RiCHARDSON, 1994). Adicionalmente, as informações obtidas permitiram a complementação dos dados de literatura, esclarecendo alguns pontos obscuros sobre a morfologia dos Bouchardiinae, tais como:

- o espessamento da região posterior das conchas que está presente, em maior ou menor intensidade, em todos os Bouchardinae e não apenas nas espécies de Bouchardia. Contudo, em comparação com os Anakineticinae, essa característica também é notada para muitos de seus componentes. Já em uma comparação com outros Terebratellidae, essa parece ser uma importante feição diagnóstica para o grupo por ser rara em Terebratellinae. As dificuldades de trabalhar com essa feição na forma de um caráter contínuo e empregá-lo na análise cladística, adia as conclusões sobre uma possivel extensão de espessamento que caracterize Bouchardia ou outro grupo, ficando a sugestão para que estudos ulteriores tratem especificamente dessa questão e avaliem a implicação dessa característica para a definição do grupo;

- o processo cardinal diferenciado, descrito por RICHARDSON (1994) como bilobado, aqui representado pelos caracteres 32 e 33, pode ser encontrado em todos o Bouchardiinae. No entanto, a estrutura em forma de ' $V$ ' é exclusiva dos integrantes do 
gênero Bouchardia. Segundo BRUNTON (1996), estes sulcos corresponderiam a traços de crescimento de uma crura não funcional e, portanto, os elementos normais da cardinália poderiam ser reconhecidos e comparados às estruturas de outros Terebratellidae, tornando possível o estabelecimento de homologias (BRUNTON, 1996; BRUNTON et al., 1996). Entretanto, as investigações ontogenéticas de estruturas morfológicas em Bouchardia rosea, realizadas no presente estudo, não acusaram a presença desta característica. Assim, pelo menos até o momento, não foi possível estabelecer uma homologia entre o sulco em forma de ' $V$ ' e a crura, apesar das funções provavelmente semelhantes;

- apesar de muito frágil e de difícil preservação, o braquídio axial foi identificado para outros Bouchardiinae (RICHARDSON, 1973b; BRUNTON, 1996) e os distingue dos demais Terebratellidae, sendo, portanto, uma sinapomorfia para o grupo;

- pela estrutura observada durante a análise morfológica, e complementada por dados de literatura, o pedículo de Bouchardia rosea é, possivelmente, inerte (RICHARDSON, 1981a, 1981b), consistindo em uma haste rígida com pequenos prolongamentos ramificados na extremidade distal, e com musculatura associada bastante diferenciada. Assemelha-se muito, em estrutura e função, àquele existente em Anakinetica cumingi (RICHARDSON, 1991, 1994; BRUNTON, 1996). Como discutido pela literatura (e.g., RICHARDSON, 1979, 1981b, 1981c), a estrutura de um pedículo, e por conseguinte sua função, podem ser reconstituídos a partir do estudo do bico, das cicatrizes musculares e da charneira dos Rhynchonelliformea, feições essas intimamente ligadas ao hábito de vida dos braquiópodes e, por conseqüencia, ao pedículo. Exceto pelas cicatrizes musculares, muito dificeis de serem analisadas nos Bouchardinae fósseis, as estruturas do bico e da charneira são muito semelhantes entre Bouchardia rosea e as demais espécies do gênero, permitindo extrapolar a característica do pedículo para todas as espécies, com exceção de Bouchardia exigua, para a qual ainda não foi possível examinar o bico e o forâmen, devido ao escasso material existente e à sua preservação;

- já foi discutido que o forte espessamento da região posterior das valvas de Bouchardia dificulta a clara diferenciação dos elementos da cardinália. No entanto, a ausência de crura ou bases crurais nas espécies de Bouchardia não parece ser um artifício causado por tal espessamento. Esta observação encontra suporte nas 
investigações ontogenéticas realizadas para Bouchardia rosea, onde não foi notado Gualquer sinal de desenvolvimento ou presença de crura;

- bases do septo mediano da valva dorsal, posteriormente espessados e estreitando-se anteriormente, é uma sinapomorfia das espécies de Bouchardia quando analisamos a distribuição desse estado de caráter entre os Bouchardiinae. No entanto, o mesmo tipo de base do septo mediano é encontrado na maioria dos táxons do grupo externo;

- com exceção de Malleia portlandica, todos os demais táxons do grupo interno apresentam cavidades na parede anterior da plataforma cardinal (caracteres 37 e 38). Vale mencionar que Australiarcula artesiana, do grupo externo, também as possui. No entanto, entre os Bouchardiinae, as espécies de Bouchardia apresentam 2 cavidades ao passo que os demais táxons apresentam 3 cavidades;

O que se observa, em linhas gerais, é que Bouchardia é um grupo bastante conservativo morfologicamente, sendo que as 6 espécies reconhecidas por MANCEÑIDO \& GRIFFIN (1988) destacam-se pela grande semelhança morfológica interna e externa (Estampas 2 e 3) e sua diferenciação carece de uma definição mais detalhada. Ficou evidente, ainda, a grande semelhança morfológica entre Bouchardia rosea e Bouchardia transplatina como denunciado pelos caracteres analisados (Tabela 2), sendo que, dos 43 caracteres, essas duas espécies diferem apenas quanto à relação entre eixo e linha da charneira (caráter 31). Tal fato se refletiu na posição desses dois táxons em uma politomia com um clado formado pelas demais espécies do gênero (Figura 20b), configurando uma indefinição no estabelecimento das relações de parentesco entre os táxons causada, provavelmente, pela grande quantidade de caracteres compartilhados. Deve-se levar em conta que foram analisados pouco mais de 20 espécimes de Bouchardia transplatina, embora muitos deles em bom estado de preservação sendo que, para Bouchardia rosea, existe um número muito maior de espécimes disponiveis (veja Anexo 1). Disto resulta que grande parte das possíveis singularidades morfológicas apresentadas por Bouchardia transplatina foram também observadas entre os numerosos exemplares de Bouchardia rosea. Como exemplo, algumas das características sugeridas por MELLo \& SIMŐES (2000) como distintivas entre as duas espécies (e.g., base do septo, superfície de união das placas deltidiais) correspondiam, na verdade, a artefatos tafonômicos, tendo sido as mesmas reinterpretadas no presente estudo. 
Dessa forma, levando-se em conta o conjunto de caracteres morfológicos analisados (representando essencialmente as partes duras da concha) bem como as relações de parentesco obtidas para o grupo, a condição de Bouchardia rosea e Bouchardia transplatina, enquanto espécies válidas e distintas, não encontra suporte. Considerações sobre sua taxonomia e implicações para a sistemática do gênero serão feitas mais adiante. Considera-se, ainda, que a diferenciação entre essas duas espécies talvez esteja relacionada às características das partes moles (e.g., lofóforo, musculatura), não disponiveis para Bouchardia transplatina.

\subsection{CoMENTÁRIOS SOBRE A TAXONOMIA E SISTEMÁtICA dos BOUCHARdINAE}

Conforme visto anteriormente, os resultados obtidos (Figura 20b), até o momento, corroboram, fortemente, o monofiletismo dos Bouchardiinae, bem como o escopo de seus gêneros, o que, em parte, vai de encontro à classificação proposta por RICHARDSON (1991, 1994).

Em primeiro lugar, com base nesses resultados, podem ser feitas algumas considerações sobre a validade das espécies atualmente atribuídas a Bouchardia (MANCEÑIDO \& GRIFFIN, 1988). Como já comentado, das 6 espécies consideradas para - gênero, Bouchardia rosea e Bouchardia transplatina não apresentaram diferenças significativas com relação às características morfológicas analisadas. Somando-se a isso, sua posição na topologia obtida (Figura 20b) sugere que os dois táxons correspondem à mesma espécie, devendo, portanto, ser colocadas em sinonímia.

Sinonímia envolvendo Bouchardia transplatina havia sido sugerida por OWEN (1980). Segundo esse autor, THOMSON (1918) considerou Bouchardia angusta e Bouchardia transplatina como indiferenciáveis morfologicamente. Contudo, Bouchardia angusta foi, mais tarde, sinonimizada em favor de Bouchardia antarctica e a sinonimia passou a valer para Bouchardia transplatina e Bouchardia antarctica. No entanto, as diferenças morfológicas entre essas duas espécies, são notáveis (veja Tabelas 1 e 2), levando-se em conta o conservadorismo morfológico do gênero. Portanto, essa sinonímia parece não ter validade. Já a sinonímia entre Bouchardia rosea e Bouchardia transplatina, aqui sugerida, seria feita em favor de Bouchardia rosea (Mawe), 1823, por prioridade na proposição dos nomes. Assumindo-se essa nova posição, são óbvias as implicações no escopo do gênero, que passa a contar com 5 espécies e não mais 6 
COMo proposto por MANCENIDO \& GRIFFIN (1988). Além disso, Bouchardia rosea passa a fer um registro estratigráfico que alcança o limite Plioceno-Mioceno, ampliando muito sua distribuição temporal e espacial.

Outra suspeita de sinonímia recai sobre Neobouchardia que faz parte de um clado completamente resolvido com as demais espécies de Bouchardiella. Assim, desperta-se a suspeita sobre o status do gênero Neobouchardia, enquanto táxon válido e distinto de Bouchardiella e, portanto, sugere-se que esses 2 táxons sejam colocados em sinonímia, em favor de Bouchardiella Doello-Jurado, 1922.

No que tange à sistemática dos Bouchardiinae, o confronto dos modelos de classificação existentes e que competem para expressar, da maneira mais fiel, as relações entre os táxons, dão margem a algumas questões, tais como: Família Bouchardiidae ou Subfamília Bouchardiinae? Se Família Bouchardidae, pertenceria à Superfamilia Bouchardioidea, como proposto por MACKINNON \& LEE (no prelo)? Se subfamília, estaria na Família Terebratellidae, como proposto por RICHARDSON (1994)?

O contexto que cerca essa discussão está amplamente exposto na literatura analisada. Diz respeito a situação atual da sistemática da Família Terebratellidae, como definida por RICHARDSON (1994) (Quadro 7), frente à revisão sistemática trazida por MACKINNON \& LEE (no prelo). De acordo com essa última proposta (Quadro 7), a Superfamilia Bouchardioidea contém a Familia Bouchardiidae, formada por Malleia, Bouchardia, Bouchardiella e Neobouchardia, como proposto por RICHARDSON (1973b). Inclui, também, Australiarcula, anteriormente posicionada entre os Anakineticinae por RICHARDSON (1994). Desta maneira, nota-se claramente um conflito entre a classificação de RICHARDSON (1994) e a nova proposta de MACKINNON \& LEE (no prelo).

Sobre a composição dos Bouchardiinae, sem entrar no mérito classificatório, os resultados alcançados corroboram, em parte, a proposta de RICHARDSON (1994), que considera o grupo como sendo formado por Bouchardia, Bouchardiella, Malleia e Neobouchardia, ao passo que Australiarcula permanece junto dos Anakineticinae. Deve-se levar em conta aqui, a suspeita de sinonímia entre Bouchardiella e Neobouchardia, em favor da primeira, o que altera a composição do grupo. Seu diferencial para a proposta de MACKINNON \& LEE (no prelo) está, justamente, na exclusão de Australiarcula. 
QUADRO 7. COMPARAÇÃO ENTRE DUAS PROPOSTAS DE CLASSIFICACÄO (SUBFAMILIA E
SUPERFAMILIA) INCLUINDO OS BOUCHARDINAE RiCHARDSON, 1994

MACKINNON \& LEE, no prelo

Superfarnilla Terebratelloidea King, 1850

Familia Terebratellidae King, 1850

Subfamília Bouchardinae Allan, 1940

Gênero Bouchardia Davidson, 1850

Gênero Bouchardiella Doello-Jurado, 1922

Gênero Malleia Thomson, 1927

Gênero Neobouchardia Thomson, 1927

Subfamilia Anakineticinae Richardson, 1991

Gênero Anakinetica Richardson, 1987

Gênero Adnatida Richardson, 1991

Gênero Aliquantula Richardson, 1991

Gênero Australiarcula Elliott, 1959

Gênero Elderra Richardson, 1991

Gênero Magadina Thomson, 1915

Gênero Magadinella Thomson, 1915

Gênero Parakinetica Richardson, 1987

Gênero Pilkena Richardson, 1991

Gênero Pirothyris Thomson, 1927

Gênero Rhizothyris Thomson, 1915

Subfamilia Terebratellinae King, 1850

Gênero Aerothyris Allan, 1939

Gênero Aneboconcha Cooper, 1973

Gênero Austrothyris Allan, 1939

Gênero Calloria Cooper \& Lee, 1993

Gênero Diedrothyris Richardson, 1980

Gênero Dyscritosia Cooper, 1982

Gênero Fosteria Zezina, 1980

Gênero Gyrothyris Thomson, 1918

Gênero Jaffaia Thomson, 1927

Genero Magasella Dall, 1870

Gênero Magella Thomson, 1915

Gênero Magellania Bayle, 1880

Gênero Neothyris Douvillé, 1879

Gênero Pachymagas thering, 1903

Genero Stethothyris Thomson, 1918

Gênero Syntomaria Cooper, 1982

Gênero Terebratella d'Orbigny, 1847

Gênero Victorithyris Allan, 1940

Genero Waiparia Thomson, 1920

FONTE-RICHARDSON (1994); MACKINNON \& LEE (no prelo)

* composição do grupo ainda nāo está disponivel na literatura

Em relação à proximidade entre Bouchardiinae, Terebratellinae e Anakineticinae, a análise realizada não permite tecer comentários, uma vez que nenhum Terebratellinae foi utilizado para compor o grupo externo. De qualquer forma, a topologia obtida sustenta os Bouchardinae como grupo monofilético e morfologicamente distinto dos Anakineticinae, corroborando a postura assumida pelas classificações existentes que, a despeito das diferenças, concordam em considerar os 
Bouchardinae como grupo distinto dos demais, quer seja como subfamília (RICHARDSON, 1994) ou superfamília (MACKINNON \& LEE, no prelo).

Dessa forma, não se pode, de momento, optar por um dos esquemas de classificação acima citados, muito embora deva ser levado em consideração o comentário de BRUNTON (1996), segundo o qual a Subfamilia Bouchardiinae não estaria satisfatoriamente posicionada na Familia Terebratellidae, a julgar pela morfologia interna incomum de Bouchardia e dificuldade na determinação de homologias entre as estruturas da sua cardinália (veja BRUNTON et al, 1996). O autor aponta, ainda, a necessidade de investigação da consistência das subfamilias atribuidas a Terebratellidae, assim como do escopo dos gêneros e espécies dentro de Bouchardiinae. Parte dessa sugestão foi conduzida na análise aqui apresentada, tendo sido investigado o escopo das subfamílias Bouchardiinae e Anakineticinae, bem como as relações de parentesco entre seus componentes. De qualquer forma, com relação à composição dos grupos, os resultados aqui apresentados parecem ajustar-se melhor à proposta de RICHARDSON (1994), ao considerar Australiarcula como pertencente aos Anakineticinae

\subsection{Considerações SOBRE A EVOLUÇÃo E (PALEO)BIOGEOGRAFIA dOS BOUCHARdIDAE 6.5.1. Aspectos gerais da (paleo)biogeografia dos braquiópodes Rhynchonelliformea}

O estudo dos padröes de distribuição dos organismos levou ao desenvolvimento de duas escolas de pensamento que defendem processos e filosofias diferentes (i.e. eventos de vicariância e de dispersão) (NELSON \& PLATNICK, 1984; HALLAM, 1988). Entre esses organismos, diferentes grupos de braquiópodes (e.g., Spiriferoidea, Rhynchonellidae), sobretudo os fósseis, têm, há muito, contribuido para a reconstrução paleogeográfica de diferentes regiões, nos mais diversos contextos temporais (e.g., para o Paleozóico HANGER, 1995; SHI \& ARCHBOLD, 1995; BENEDEtTo et al., 1999; Garcia-Alcalde, 1998; Martinez Chacón \& Prins, 1999; ShI \& GRUnt, 2000; Diaz MARTINEz et al., 2000; RoBARDEt et al., 2001; BENEDETTO, 2001; LeEs et al., 2002; ANGIOLINI et al, 2003; para o Mesozóico VöRös, 1977, 1997; AGER \& WALLEY, 1977; SANDY, 1990; COOPER, 1975, 1977; SANDY \& BLODGETT, 2000; para o Cenozóico CuRRY \& ENDO, 1991; HILLER, 1994a, 1994b; BENEDETTO et al., 1995; JIN \& COOPER, 1997; 
BuENing et al., 1998). Contudo, de acordo com ZEZINA (1970), braquiópodes viventes têm sido pouco empregados nesse tipo de abordagem (e.g., DAVIDSON, 1888; THOMSON, 1918, 1927; Allan, 1939, 1940b; Hatal, 1940; Hertlein \& GRant, 1944; BOWEN, 1968), devido, em parte, às poucas coleções existentes, fruto da dificuldade de acesso aos organismos, geralmente, restritos a faixas estreitas, em grandes profundidades (superiores a 600 metros) e distantes das regiões costeiras (RICHARDSON, 1997a). Embora esse padrão exista KOWALEWSKI et al. (2002) e SIMÕES et al. (2004) demonstraram que esse não pode ser adotado como uma regra geral para o grupo, especialmente nas áreas tropicais/subtropicais.

UPCHURCH \& HUNN (2002) consideram perfeitamente possivel o estudo de padrões biogeográficos passados usando informações pontuais no tempo, muito embora, a paleobiogeografia, inevitavelmente, tenha uma dimensão temporal, sendo que a observação de variações na distribuição dos táxons através do tempo é um de seus pilares (ROSEN, 1994). Contudo, um problema que persegue os pesquisadores, e que talvez esteja bem presente na análise paleozoogeográfica para os Brachiopoda, em especial os Bouchardiinae, é a incerteza inerente ao registro fossilifero para refletir, de maneira precisa, a verdadeira distribuição espacial do táxon extinto (UPCHURCH \& HunN, 2002). Foi citado o caso dos Bouchardinae pois, como será detalhado adiante, existe muita dúvida sobre o registro fossilifero bastante incompleto do grupo, que compreende uma área abrangente e um intervalo longo de tempo (cerca de $30 \mathrm{~m} . a$.) sem registro.

Adicionalmente, examinando a discussão levantada por (UPCHURCH \& HUNN, 2002), observa-se que um padrão de distribuição de um táxon é estabelecido com os registros de "presença" e "ausência" do táxon. Nesse ponto, entender o contexto do registro de um grupo fóssil é importantíssimo, ajudando a definir, principalmente, o que significa a "ausência" do táxon. Em rápidas palavras os autores identificam 3 possiveis significados para esse fato: a) o táxon nunca viveu na área, b) viveu em um momento anterior mas se tornou extinto, e c) viveu na área mas ainda não foi encontrado. De maneira complementar, uma quarta alternativa poderia ser incluída nessa lista, ou seja, o táxon viveu ali mas seu registro não foi preservado, quer seja em decorrência de um baixo potencial de preservação, ou intemperismo ou mesmo perda do registro por erosão ou não deposição de sedimentos. Dessa forma, estabelece-se uma forte ligação entre a paleobiogeografia e a tafonomia, a medida que as deficiencias no registro, por 
causas tafonômicas, podem mascarar os padrões paleobiogeográficos observados. Esse cuidado deve ser tomado não apenas no caso da ausência de táxons, mas também na sua presença em determinado local. Isso porque sem analisar as características tafonômicas das concentrações, pode-se estar desprezando importantes assinaturas que indicam eventos de transporte lateral ou retrabalhamento de material mais antigo, proveniente de outros locais ou outros estratos, incorporando informações falsas à análise paleobiogeográfica.

Talvez por conta desses fatos a maneira como a distribuição do táxon fóssil deve ser interpretada e seu valor para a biogeografia histórica ainda são matérias controversas e em discussão, havendo, inclusive, dúvida da utilidade dos fósseis nas análises biogeográficas, especialmente sobre a distribuição de táxons atuais (UPCHURCH \& HUNN, 2002; veja também, por exemplo, CROIZAT, 1964; ROSEN, 1976, 1978, 1994; Nelson \& Platnick, 1981; PATterson, 1981; GRANDE \& BEMIS, 1998). De qualquer maneira, os táxons fósseis têm um papel importante na biogeografia histórica, pois representam a única fonte direta de informações sobre as relações passadas, com determinada área (UPCHURCH \& HUNN, 2002).

Sobre a distribuição de braquiópodes viventes no hemisfério sul, merece destaque as contribuições de FOSTER (1969a, 1969b, 1974, 1989), ZEZINA (1970, 1975, 1980, 1985), Manceñido \& GrifFin (1988), Dawson (1990), Hiller (1994a, 1994b), RichARDSON (1994, 1997b), KoWALEWSKI et al. (2002) e SimÕEs et al. (2004). Além de estabelecer as áreas ocupadas pelos diferentes táxons, esses estudos avaliam a) os modos e padrões de dispersão de acordo com a capacidade de dispersão e colonização das formas larvais e adultos (e.g., NOBLE et al., 1976; WEBB et al., 1976; DOHERTY, 1979; CURRY, 1982), e b) a influência e/ou controle dos fatores abióticos (e.g., tipo de substrato, temperatura, latitude) na dispersão dos táxons (RICHARDSON, 1997a, 1997b; KOWALEWSKI et al., 2002). Sobre esse último aspecto, RICHARDSON (1997a) considera difícil compreender seu papel devido à falta de informações, não havendo evidências diretas de que qualquer fator limite essa distribuição. No entanto, KOWALEWSKI et al. (2002) tentam estabelecer a relação entre distribuiçâo dos táxons e zonas de ressurgência na quebra da plataforma continental da região sudeste brasileira (veja mais comentários abaixo).

A despeito dos comentários e dificuldades apontadas acima, uma importante contribuição ao conhecimento da distribuição espacial dos grupos viventes foi dada por 
ZEZINA (1970). Segundo seu zoneamento global dos mares e oceanos atuais, os braquiópodes estariam distribuídos em 16 principais áreas, sendo as zonas a) "Atlântico-América Central", com espécies de águas quentes, e b) "Sul Americana", considerada região transicional, as zonas mais relacionadas ao presente estudo, por conterem os táxons aqui analisados. Do lado leste, estão ao longo do oceano Atlântico, desde a América do Norte até a extremidade austral da América do Sul. No lado oeste, a partir da latitude $35^{\circ} \mathrm{S}$ do oceano Pacifico, em direção ao sul. No entanto, apenas Discinisca foi atribuído à costa leste da América do Sul pois, segundo ZEZINA (1970), Bouchardia rosea não se encaixava em nenhuma de suas divisões. Em estudo posterior, apesar de analisar a contribuição de diferentes grupos de invertebrados (e.g., bivalves, gastrópodes, crustáceos) para a zoogeografia do litoral sul-sudeste brasileiro, PALACIO (1982), menciona a existência de braquiópodes na área.

De uma maneira geral, o que se observa nos estudos zoogeográficos empregando braquiópodes é que grande parte (e.g., FOSTER, 1969a, 1969b, 1974, 1989; ZEZINA, 1970, 1975, 1980, 1985; MANCEÑIDO \& GRIFFIN, 1988; DAWSON, 1990) apresenta uma relação das espécies existentes na área estudada, com seus intervalos e limites de distribuição, além de algumas considerações sobre os fatores físicos ambientais (e.g., temperatura, profundidade) que regem tais distribuições sem, contudo, propor hipóteses biogeográficas que expliquem as distribuições observadas.

Recentemente, ZEZINA (2003) comentou os aspectos ecológicos e morfológicos relacionados a braquiópodes que habitam ambientes marginais e extremos, tais como áreas litorâneas e cavernas submarinas, considerando que a colonização desses tipos de ambientes teve importantes conseqüências evolutivas para o grupo ligadas, sobretudo, a pedomorfose e neotenia. ZEZINA (2003) considera que os braquiópodes fósseis e recentes que têm sido coletados por todo o mundo, são úteis na procura por soluções para problemas filogenéticos e para participar de generalizações biogeográficas globais bem fundamentadas sendo, ainda, indicadores convenientes e altamente significativos de mudanças temporais e espaciais no ambiente, em uma escala local. 


\subsubsection{Influência do ambiente nos processos evolutivos}

Como será tratado adiante, a evolução e distribuição dos Bouchardiinae estão, ao que tudo indica, intimamente ligadas à evolução do oceano Atlântico, desde o Mesozóico final, época provável de surgimento do grupo. A partir da fragmentação inicial do Gondwana, no Eocretáceo, os continentes do sul foram palco de numerosos e geologicamente rápidos eventos de vicariância e convergência (WooD et al., 1999). Exemplos de relações como essas, entre a distribuição de grupos de braquiópodes e eventos tectônicos são conhecidos da literatura (veja, por exemplo, Vörös, 1977; AGER \& WALLEY, 1977; NAKAMURA et al., 1985; MACKINNON, 1987; SHI \& WATERHOUSE, 1990a, 1990b; SHI \& ARCHBOLD, 1995; SHI \& GRUNT, 2000). Logo, todas e quaisquer alterações físicas e químicas ocorridas no ambiente ao longo do tempo, em decorrência desses eventos, podem ter influenciado a dinâmica do grupo.

HILLER (1994a, 1994b) considera que, provavelmente, a distribuição de espécies de animais marinhos, nos dois lados da costa sul da África, seja fundamentalmente influenciada por fatores abióticos. Seriam condições quimicas e físicas contrastantes entre um lado e outro do continente, formando uma ampla gama de condições ambientais (e.g., sedimento, temperatura, salinidade) controladas pela circulação e sistema de ventos. Com isso, as espécies marinhas, entre elas os braquiópodes, apresentam índices de proliferação e número de espécies maiores nas águas subtropicais do leste do que nas águas mais frias das regiões de ressurgência da costa oeste (HEYDORN et al., 1978; HILLER, 1991; ZEZINA, 1979). No caso dos braquiópodes, essa distribuição pode estar relacionada a maior concentração de fitoplancton nas zonas de ressurgência, o que pode prejudicar os Rhynchonelliformea (veja discussão em KoWALEWSKI et al., 2002), embora seu efeito sobre grupos de braquiópodes inarticulados não pareça tão limitante (ZEZINA, 1979; HILLER, 1991, 1994a).

$E$ freqüente observar que alterações climáticas são tidas como importante fator de influência na história evolutiva dos organismos marinhos (LEE, 1986, 1990; DAMBORENEA, 1993), muitas vezes contribuindo para a extinção dos grupos sobretudo pela diminuição na temperatura das águas do mar (CLARKE, 1993). Especialmente no Cenozóico, as constantes variações climáticas levaram a queda gradual da temperatura desde o Eoceno médio, gerando condições glaciais em grande parte do planeta e alterando as propriedades das águas de superfície e de fundo (veja, por 
exemplo, SchnitKeR, 1974; DOUglas \& SAVIN, 1975; SAVIN et al, 1975; SHACKLETON \& KENNETT, 1975a, 1975b; OBERHÄNSUI et al., 1991).

É preciso enfatizar, entretanto, que variações na temperatura da água alteram muitos outros parâmetros do ambiente (e.g., viscosidade, solubilidade de gases e de carbonatos) $e$, atualmente, parece ser consenso que a extinção de uma espécie marinha raramente é causada apenas pelo impacto fisiológico direto e isolado da temperatura (CLARKE, 1993). Esta afirmação encontra suporte pois, como pode ser facilmente observado, todas as equações que descrevem as propriedades físicas da água do mar têm, como um de seus termos, a temperatura. Dessa forma, fatores ambientais (e.g., viscosidade, solubilidade de gases e de carbonatos) de relevância direta para organismos marinhos (e.g., fatores envolvidos na captura de partículas por invertebrados suspensívoros), também são afetados pelo aquecimento ou resfriamento da água do mar. $\hat{E}$ inegável, entretanto, que a variação da temperatura influencia diretamente a fisiologia dos organismos alterando processos como ionização, estruturação de proteínas, difusão e taxas de reação (CLARKE, 1993),

Assim, as extinções marinhas e a distribuição restrita ou não de grupos de organismos devem estar relacionadas a mudanças em feições particulares da ecologia (ambiente e organismos) da comunidade, e as alterações climáticas são apenas uma das causas dessas mudanças (CLARKE, 1993). Por exemplo, alguns braquiópodes, como Crania, toleram intervalos extremos de temperatura que vão dos trópicos às águas sub-antárticas (COOPER, 1954; FOSTER, 1974; LEE, 1986). Conforme estabelecido na literatura, mudanças climáticas de longa duração levam a adaptações evolutivas que promovem um ajuste fino do metabolismo, o que não é possível, nem apropriado, em mudanças repentinas ou sazonais (CLARKE, 1993). Já os eventos repentinos, como mudança de temperatura, podem causar severos e amplos efeitos sobre os organismos marinhos, influenciando processos como dispersão larval e extinções localizadas (CLARKE, 1993). Ao comparar a influência de eventos de resfriamento em biotas de diferentes partes do planeta (e.g., Atlântico ocidental, Oceano do SUl), CLARKE (1993) destaca que nem todo evento dessa natureza leva à extinção, e o impacto das mudanças climáticas, sofrido pela comunidade, depende de sua história térmica ou ecológica prévia. Parece estar bem estabelecido que as regiões polares, há muito, têm sido o foco de significante diferenciação faunística, com vários táxons sofrendo rápida evolução para só depois dispersar para latitudes mais baixas, 
possivelmente devido ao resfriamento global das águas do mar (CRAME, 1992; CLARKE, 1993).

Conforme comentado acima, é evidente a influência de fatores ambientais em processos evolutivos (e.g., dispersão, extinção). A influência sobre especiação, embora bastante discutida, está pouco definida, em parte pela falta de arcabouços suficientemente explícitos e detalhados que ajudem na análise desses processos (ALLMON, 2001). Na busca por essa definição, é importante a) correlacionar o primeiro aparecimento da espécie com alterações em algumas variáveis ambientais (e.g., temperatura, nível do mar, salinidade, produtividade) e b) partir desses padrões observados para propor hipóteses que testem processos evolutivos particulares. Apenas assim espera-se poder obter as conclusões sobre exatamente quais condições ambientais levam às mudanças evolutivas (ALLMON, 2001). Esforços têm sido feitos (veja ALLMON, 2001) no sentido de tentar criar um arcabouço que relacione, a princípio, mudanças em variáveis particulares do ambiente a processos de extinção e especiação. A partir disso, seria analisada, por exemplo, a resposta biológica a eventos geológicos de grande magnitude (e.g., surgimento do istmo do Panamá, glaciações) deixando evidente, na maioria das vezes, a relação de diferentes variáveis ambientais marinhas (principalmente temperatura e nutrientes) com padrões de extinção e especiação (VERMEIJ, 1978, 1987, 1989, 1990, 1993; StANLEY, 1986; AlLmON, 1992, 1993, 2001; CRONIN \& DOWSETT, 1993; ALLMON et al., 1993, 1996a, 1996b; JACKSON et al., 1993, 1996a, 1996b, 1999; JOHNSON et al., 1995; BUDD et al., 1996; ROOPNARINE, 1996, 1997; BUDd \& JoHNSON, 1999; RoOPNARINE \& BEUSSINK, 1999; Collins \& COATES, 1999; ANDERSON, 2000).

Pelo que se conhece, populações podem se tornar geograficamente isoladas por dispersão ou vicariância (VALENTINE \& JABLONSKI, 1983; STANLEY, 1990; ALLMON, 1992), sendo o primeiro processo governado por fatores intrínsecos dos organismos e o segundo por fenômenos ambientais. Nesse ponto, assumindo-se que o registro fossilifero é incompleto, parece razoável considerar que esses processos dificilmente poderão ser estudados em detalhe para grupos de organismos fósseis, embora existam importantes contribuições fazendo a ligação entre os distúrbios ambientais, vicariância e especiação (e.g., Cronin, 1985; StANLEY, 1986; CRONIN \& IKEDA, 1990; CRONIN \& SCHNEIDER, 1990; JOHNSON et al., 1995). 
Para o presente estudo, foi conduzida uma abordagem semelhante àquela sugerida por ALLMON (2001), sendo indispensável a observação dos aspectos acima mencionados para a compreensão da distribuição e evolução dos Bouchardiinae. Sendo assim, deve-se tentar estabelecer a ligação entre distúrbios marinhos (e.g., tempestades, influências de água doce, estabelecimento de correntes, variação na temperatura ou salinidade da água, eventos de sedimentação, fornecimento de alimento) e a distribuição atualmente conhecida para os Bouchardiinae, na tentativa de se identificar qual(is) fator(es) influenciou(aram) as especiações e distribuições de táxons dentro do grupo. Deve-se considerar, ainda, que os mesmos fatores ambientais (e.g., temperatura, fonte de nutrientes e alimentos, habitat) competem para permitir que as espécies permanecessem isoladas (ALLMON, 2001),

\subsubsection{Evolução do oceano Atlântico ao longo do Cenozóico}

Com base nas considerações feitas no item anterior deste capitulo, a seguir serão examinados alguns dos pontos principais da história biótica e ambiental das águas que cercaram parte do Gondwana, mais especificamente a América do Sul, Antártica, Austrália e Nova Zelândia, nos últimos 65 milhões de anos. Serão apresentadas informações sobre o comportamento de alguns parâmetros abióticos, e como eles podem ter influenciado a evolução do grupo durante a fragmentação do Gondwana. Nesse contexto, as regiões desses continentes que apresentam táxons de interesse estão localizadas nas altas e médias latitudes do Hemisfério Sul, o que é importante para avaliar a influência de importantes eventos geológicos na região, i.e., abertura da Passagem Drake e separação entre Antártica e Austrália, nos padrões paleozoogeográficos e evolutivos dos Bouchardiinae e outros grupos de organismos (para abordagens semelhantes, mas em outras regiões, veja JACKson et al., 1996a, 1996b; VERMEIJ, 1996; COLLINS \& COATES, 1999; ALLMON, 2001),

Todas essas informações servirão de subsídio para uma discussão final sobre o comportamento evolutivo e zoogeográfico dos Bouchardiinae no contexto mais amplo das mudanças ambientais, levando-se em conta, obviamente, os resultados obtidos no presente estudo. De uma maneira geral, todos os comentários feitos a seguir, no que tange a paleogeografia e parâmetros paleoclimáticos, podem ser satisfatoriamente acompanhados com a ajuda dos mapas das figuras 24-26. 


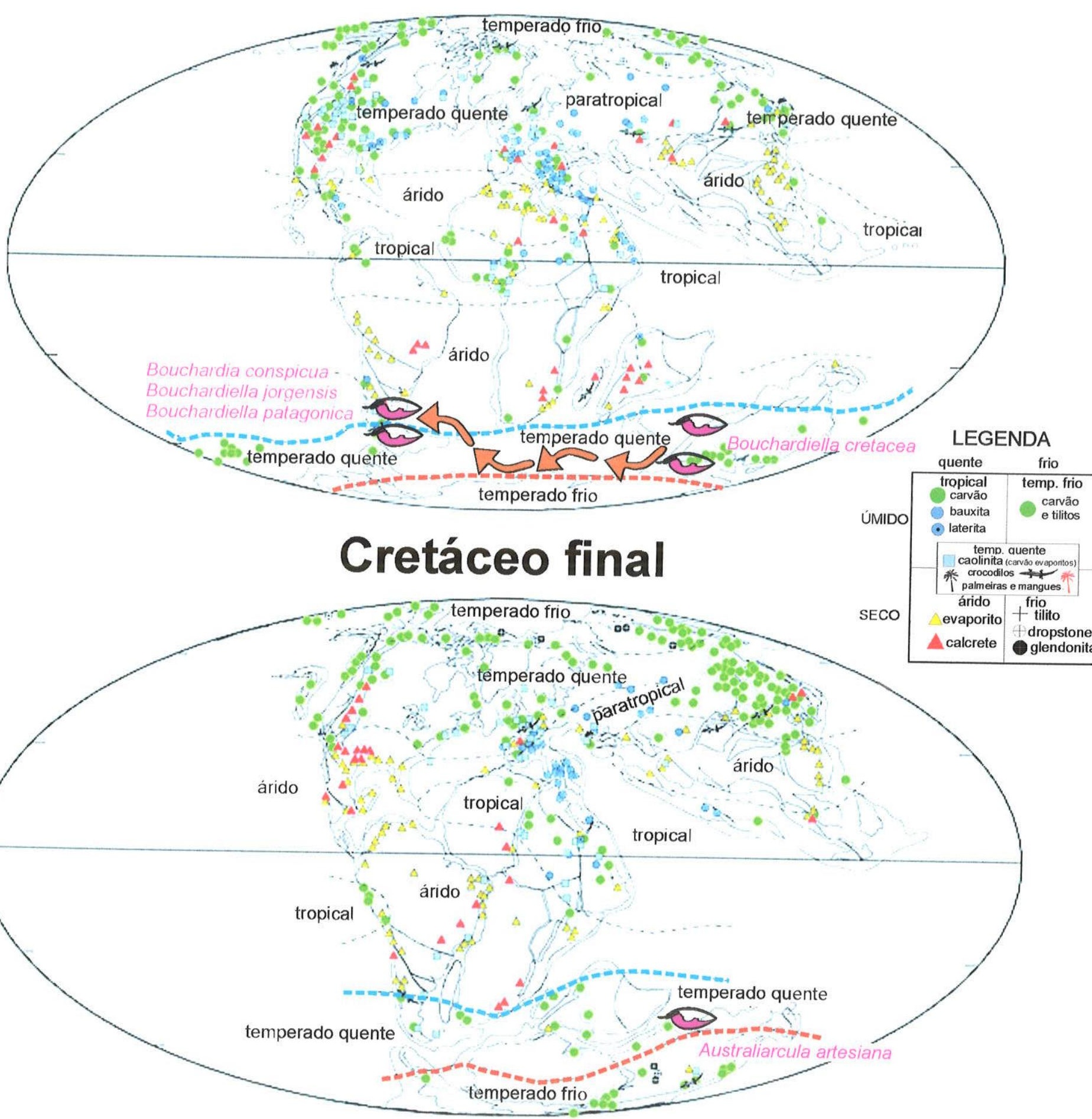

\section{Cretáceo inicial}

Figura 24- Distribuição dos Bouchardiinae e Anakineticinae durante o Cretáceo inferior e superior, com base em indicações de literatura, e incluindo informações sobre as condições climáticas dominantes em cada área. Com reforço tracejado (azul e vermelho) os limites das zonas temperadas frias e quentes no hemisfério sul. Mapas e legenda modificados do original de "Paleomap Project" (SCOTESE, 2000; www.scotese.com); setas laranja indicam sugestão de deslocamento do Bouchardiinae primitivos a partir do registro inicial na Austrália. 


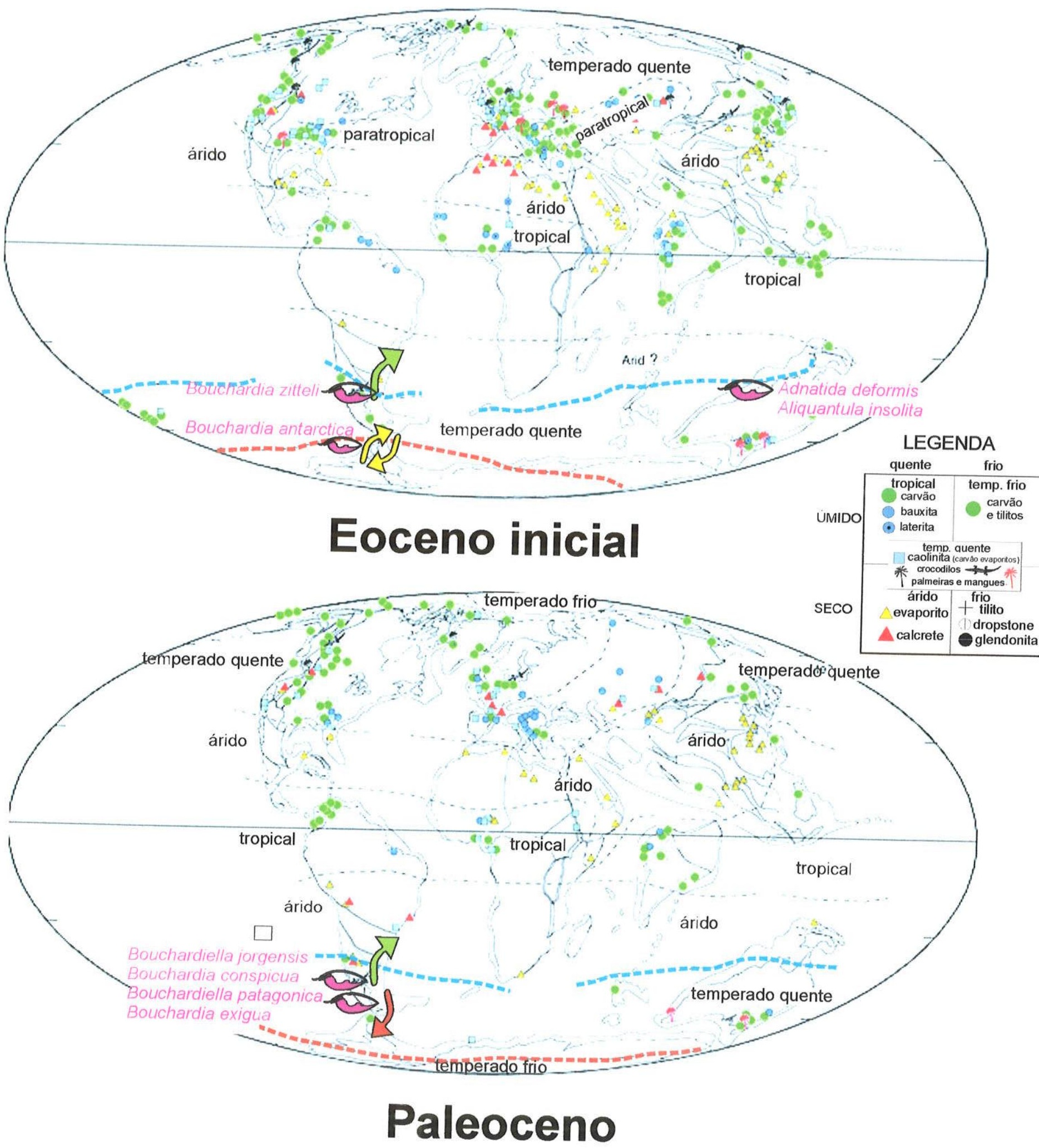

Figura 25- Distribuição dos Bouchardiinae e Anakineticinae durante o Paleoceno e Eoceno inicial, com base em indicações de literatura, e incluindo informações sobre as condições climáticas dominantes em cada área. Com reforço tracejado (azul e vermelho) os limites das zonas temperadas frias e quentes no hemisfério sul. Mapas e legenda modificados do original de "Paleomap Project" (SCOTESE, 2000; www.scotese.com); setas verde e vermelha indicam deslocamento das espécies de Bouchardia para o norte e para o sul, respectivamente, a partir das espécies que habitaram a região da Patagônia no Paleoceno; setas amarelas indicam que Bouchardia antarctica ficou restrita à Península Antártica. 


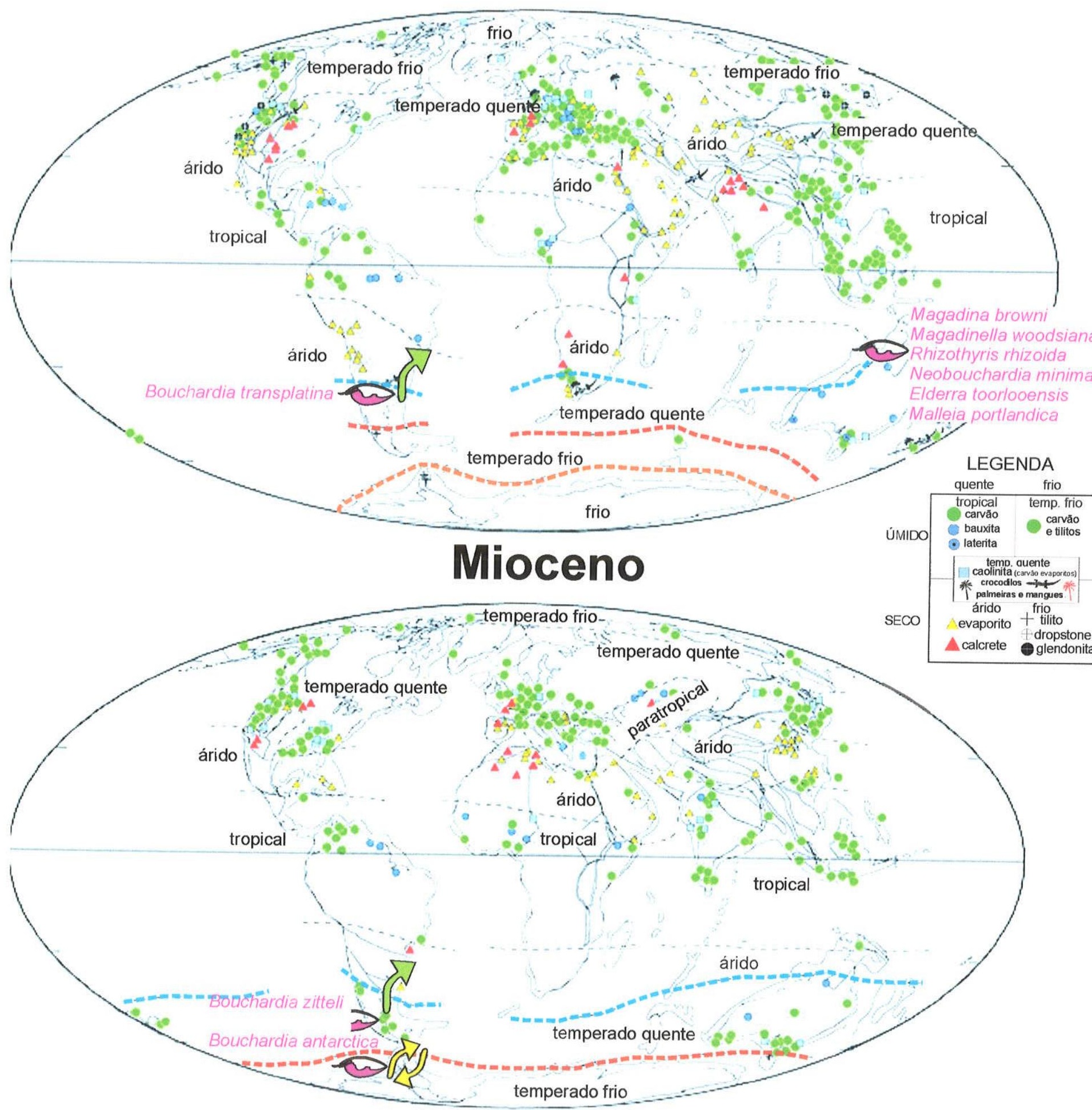

\section{Eoceno médio e final}

Figura 26- Distribuição dos Bouchardiinae e Anakineticinae durante o Eoceno médio/final e Mioceno, com base em indicações de literatura, e incluindo informações sobre as condições climáticas dominantes em cada área. O intervalo total de duração das espécies pode ser obtido nos Quadros 1 e 2. As espécies representadas no Mioceno teriam vivido durante o intervalo Oligoceno-Mioceno. Com reforço tracejado (azul e vermelho) os limites das zonas temperadas frias e quentes no hemisfério sul. Mapas e legenda modificados do original de "Paleomap Project" (SCOTESE, 2000; www.scotese.com); seta verde indica deslocamento das espécies de Bouchardia para o norte; setas amarelas indicam que Bouchardia antarctica ficou restrita à Península Antártica. 


\section{A) INTERVAlo CretÁceo-Terciário}

Há aproximadamente 120 m.a., teve início a fragmentação do Gondwana e dados paleomagnéticos (CREER, 1973; KELLOGG \& REYNOLDS, 1978; STOREY \& Alabaster, 1991; GRUNOW et al., 1991; ElliotT, 1992; LIVERMORE \& WOOLLETT, 1993; DIVENERE et al., 1994, 1995a, 1995b, 1996; STOREY \& KYLE, 1997; LIVERMORE \& REEVES, 1999; MACNIOCAILL et al., 2003) indicam que a parte desse supercontinente correspondente a Austrália, Nova Zelândia, Antártica e América do Sul moveu-se inicialmente para o sul, durante o Mesozóico, sendo que a Antártica teria atingido uma posição próxima à atual ainda no Neocretáceo. A partir daí, a América do Sul moveu-se com uma componente geral de leste para oeste, enquanto na Austrália e Nova Zelândia o movimento foi de sul para norte, e a Antártica ficou praticamente estacionária (DECONTO \& POLLARD, 2003).

Segundo ZINSMEISTER (1982), um aspecto interessante de se notar na história geológica dos continentes do hemisfério sul é a relativa simplicidade da ruptura das massas continentais e que levou à configuração atual, sendo possivel, dessa forma, acompanhar uma fauna ou comunidade quando ela se fragmenta em unidades menores, cada uma com uma história distinta (e.g., climática, geológica).

Como será colocado abaixo, mudanças climáticas se processaram no Cenozóico, passando de uma condição relativamente quente, e certamente não glacial, no Paleoceno para maciças capas de gelo em ambos os hemisférios no final do Plioceno, tendo como diversas causas, entre elas o estabelecimento da circulação marítima ao redor da Antártica e as correntes superficiais e profundas que atuaram na região (LAWVER \& GAHAGAN, 2003). Como destacado por ZAchos et al. (2001) são necessárias muitas variáveis para explicar as mudanças climáticas ao longo do Cenozóico. Adicionalmente, deve-se considerar que durante o Cenozóico ocorreu uma série de eventos tectônicos que alteraram as circulações dos oceanos como, por exemplo, o fechamento do caminho maritimo equatorial do Tethys e a abertura dos caminhos maritimos ao redor da Antártica (LAWVER \& GAHAGAN, 2003). 


\section{- Austrália, Nova Zelândia e leste da Antártica}

No Eocretáceo a Austrália, Nova Zelândia e leste da Antártica estiveram dominadas por um amplo cráton, com baixo relevo e tectonicamente estável. $\mathrm{Na}$ margem australiana banhada pelo oceano índico formaram-se muitas baías rasas (ZINSMEISTER, 1982; CLARKE \& CRAME, 1989) deixando a plataforma continental disponivel para vários organismos criando, provavelmente, locais de intensa especiação (CRAIG, 1999b, 2000). Algumas dessas áreas certamente serviram de habitat para Australiarcula artesiana, espécie atualmente encontrada em sedimentos australianos dessa idade (ELLIOTT, 1952).

A análise de sedimentos marinhos indica que a separação entre Austrália e Antártica teve seus primórdios em algum momento durante o Neocretáceo (LUDBROOK, 1978; ZINSMEISTER, 1982; O'BRIEN \& EXON, 2000; EXON et al., 2000, 2003; ROBERT et al., 2001; WEl, 2002), acabando com a maioria dos mares rasos existentes, os quais ficaram restritos à poucas regiões, uma delas representada pela Bacia Carnarvon, no centro da Austrália Ocidental. Nos sedimentos cretáceos dessa bacia são encontradas as conchas de Bouchardiella cretacea (Toolonga Calcilutite e Formação Miria; CRAIG, 1999a), gênero que está presente também em depósitos cretáceos na América do Sul e oeste australiano (veja comentários a seguir; DoEllo-JURADO, 1922; CRAIG, 2000). De acordo com CRAIG (2000), muitas das espécies de braquiópodes encontradas nos estratos do intervalo Paleoceno-Mioceno da Bacia Carnarvon derivam de evolução in situ na plataforma continental que se estendia da margem oeste australiana, passando pela costa Indo-Atlântica da Antártica até a Península Antártica.

Condições de mares profundos, sobretudo nas partes sul e sudoeste da Austrália, teriam se estabelecido já no Paleoceno (por volta de 56 m.a.), como indicado por dados de anomalias magnéticas, muito embora uma estreita ligação, entre a porção sudeste da Austrália e a Antártica, tenha persistido até, pelo menos, o Oligoceno inicial, com mares rasos ao redor (WEISSEL \& HAYES, 1972; ZINSMEISTER, 1982; BUENING et al., 1998). Foi no Oligoceno médio essa ligação entre Austrália e Antártica desapareceu, ocasionando o isolamento total de Austrália e Antártica, e permitindo o início da formação de correntes oceânicas profundas e intermediárias na região (CRAIG, 2000).

Sobre a temperatura na região, dados isotópicos (MILler et al., 1987) indicam grande aquecimento global durante o Paleoceno, onde a temperatura das águas de 
superfície, ao redor da Antártica, aumentaram cerca de $3^{\circ} \mathrm{C}$, estando próximas dos $20^{\circ} \mathrm{C}$ no final do Paleoceno-inicio do Eoceno (STOTT et al., 1990; HILDEBRAND-HABEL \& STRENG, 2003). Ainda dentro do Paleoceno, as águas ao redor da Austrália e Nova Zelândia experimentavam um aumento gradativo na temperatura, provável reflexo da migração para o norte dessas massas de terra (ZINSMEISTER, 1982), dentro do esquema de separação do Gondwana. No limite Paleoceno-Eoceno houve uma evento de aquecimento global com temperaturas subindo rapidamente, sobretudo nas altas latitudes, sendo que as águas de superficie tiveram um aumento da ordem de 8 a $10^{\circ} \mathrm{C}$, e as águas de fundo da ordem de 4 a $5^{\circ} \mathrm{C}$ (KELLy et al., 1997; THOMAS et al., 1999; SCHELlEMBERG, 2001; WiNG et al., 2003; ZACHOs et al., 2003). No entanto, ainda no Eoceno inicial, tem início um resfriamento global progressivo até o final do período, coincidindo com o início da glaciação na Antártica, iniciada no limite Paleoceno-Eoceno (SHACKLETON \& KENNETT, 1975a, 1975b; FEARY et al., 1991; ABREU \& ANDERSON, 1998; HILDEBRAND-HABEL \& STRENG, 2003). No entanto ainda hoje existe grande debate sobre as variações climáticas desse período (veja HAMBREY et al., 1991; BARRON et al., 1991; BROWNING et al., 1996; ZACHOS et al., 1996; LAWVER \& GAHAGAN, 2003).

Mais adiante, no limite Eoceno-Oligoceno, o resfriamento que já vinha se desenvolvendo no Eoceno, sofre uma intensificação abrupta (i.e., em menos de 500 mil anos), sentida na Austrália e leste da Antártica, sendo que as temperaturas de superficie e de fundo ficaram em torno de $7^{\circ}-5^{\circ} \mathrm{C}$ (SHACKLETON \& KENNETT, 1975a, 1975b). Fenômenos similares, para o mesmo intervalo de tempo, foram, mais tarde, registrados para Nova Zelândia e Península Antártica (ZINSMEISTER, 1982; BERGREEN et al., 1995; BUENING et al., 1998). Talvez esse evento marque o início de condições polares nas altas latitudes, embora as causas exatas desse quadro sejam, ainda, controversas, porém ligadas à mudanças ambientais na Antártica, como a formação das correntes de fundo, da corrente que circunda o continente e o estabelecimento definitivo da glaciação (Kennett et al., 1975; POORE \& Matthews, 1984; KenNetT \& BARKER, 1990; ZACHOS et al., 1992, 1994; BUENING et al., 1998). Dados mostram que durante o final do Eoceno-início do Oligoceno a formação da cobertura de gelo no leste da Antártica foi acelerada pela abertura dos caminhos marítimos ao redor da Antártica, embora essa não seja a única razão (DECONTO \& POLLARD, 2003; LAWVER \& GAHAGAN, 2003). 
Ao longo do Oligoceno teve início um novo aquecimento que fez a cobertura de gelo do leste da Antártica retrair, situação essa que parece ter durado até o Mioceno médio. Se observarmos a situação atual da Antártica veremos que, infelizmente, apenas uma pequena fração do continente está livre do gelo e disponivel para investigações geológicas e paleontológicas diretas, o que dificulta a obtenção de informações sobre a região e torna indispensável a exploração dos registros de subsuperfície (WEBB, 1991). O registro de macrofósseis do Oligoceno inicial dessa sugere condições climáticas mais temperadas do que aquelas que serão observadas ao final do período, embora mais frias do que as que dominavam no Eoceno médiofinal (TAVIANI \& BEU, 2003). Com base em bivalves TAVIANI \& BEU (2003) sugerem o desenvolvimento de uma biota sob condições climáticas relativamente quentes $\mathrm{e}$ úmidas, análogas àquelas encontradas atualmente na Patagônia, o que está de acordo com dados paleontológicos marinhos e terrestres prévios (CANTRILL, 2001; HANNAH et al., 2001; RAINE \& ASKIN, 2001). Por outro lado, o oeste da Antártica manteve-se livre da cobertura permanente de gelo, pelo menos, até o Mioceno final (ANDERSON \& SHIPP, 2001).

Em meio a esses eventos, a temperatura das águas das altas latitudes se mantiveram quase inalteradas durante o Oligoceno, embora na Austrália e Nova Zelândia tenham começado a aumentar novamente, ainda em resposta à migração para o norte. Com base em foraminíferos planctônicos (KENNETT, 1967, 1968; FIELD et al., 2002; DIEKMANN et al., 2003; OHTA et al., 2003) são sugeridas condições de baixa temperatura para as águas ao redor da Nova Zelândia no Oligoceno e Mioceno, chegando mesmo a condições glaciais extremas durante o Mioceno final, por influência direta da Convergência Antártica, já em operação.

De maneira similar, depósitos miocênicos (Mioceno inicial) da Nova Zelândia documentam o que parece ser o início de um dos mais importantes episódios de mudanças ambientais do Cenozóico, conhecido como "Ótimo Climático" do Mioceno médio (entre \pm 17 e 15 m.a.) (BOHME, 2003). Esses sedimentos sugerem temperaturas mais elevadas do que as atuais nas águas de fundo da região, embora um pouco mais frias do que aquelas que predominavam no Oligoceno. Essa constatação é reforçada, em parte, pela presença de bivalves (e.g., Austrochlamys marisrossensis e A. gazdzickii) atualmente desconhecidos em regiões antárticas com condições verdadeiramente polares (JONKERS \& TAVIANI, 1998; TAVIANI et al., 2000; TAVIANI \& BEU, 
2003). Além desse argumento ecológico, análise dos isótopos estáveis de oxigênio dos mesmos bivalves confirmou as condições anteriormente citadas, sendo equivalentes ao que hoje em dia se conhece para os ambientes sub-antárticos, ou seja, água em torno dos $5^{\circ}-7^{\circ} \mathrm{C}$ (TAVIANI \& BEU, 2003). Vale a pena mencionar que os mapas utilizados nas figuras 24-26, obtidos originalmente do Projeto Paleomap (www.scotese.com.br) consideram a região sob influência de clima temperado quente durante o Mioceno. $O$ final do Mioceno teria sido caracterizado por um momento de expansão da glaciação Antártica e intensificação da circulação atmosférica, o que coincidiu com o estabelecimento de um oceano frio e fortemente estratificado (latitudinalmente e verticalmente), como revelam sedimentos dessa idade em território australiano (GALlagher et al., 2001; BöHME, 2003).

Para o Plioceno inicial-médio a estimativa das temperaturas é um tanto controversa, uma vez que amostras de foraminiferos, esporos, pólens e medidas de isótopos de oxigênio, em rochas da Nova Zelândia, apontam a favor das baixas temperaturas (JENKINS, 1968; LEWIS \& JeNKINS, 1969; MILDENHALL \& HARRIS, 1970; DEVEREUX et al., 1970; VELLA \& KENNETT, 1975), enquanto faunas de moluscos dizem o oposto (para o contexto que cerca essa discussão veja BEU, 1974, 1975; VELLA \& KENNETT, 1975). Talvez por essa controvérsia, GALLAGHER et al. (2003) considerem esse período como um tempo de mudanças, pelo menos na Austrália, onde o clima global teria flutuado com a expansão e contração das capas de gelo nos dois hemisférios (veja também, GALLAGHER et al., 2001). Foi nessa época que ocorreram as maiores variações na extensão glacial da Antártica (WARNKE et al., 1992) ocasionadas por diferentes períodos de aquecimento, sobretudo no início do Plioceno (BURCKLE et al., 1996; BOHATY \& HARWOOD, 1998). De acordo com GALLAGHER et al. (2003), a paleoflora indica que o Plioceno na Austrália foi marcado por alternâncias de fases quentes e frias, com as temperaturas chegando a cerca de $2^{\circ}-4^{\circ} \mathrm{C}$ acima da atual (início do Plioceno) até $0^{\circ}-2^{\circ} \mathrm{C}$ abaixo da atual (metade do Plioceno final), isso tudo dentro de uma tendência geral de clima mais frio e seco através do período.

É importante considerar que as variações geográficas e climáticas que ocorreram ao longo do Cenozóico tiveram marcantes reflexos na fauna e flora. Por exemplo, o aumento gradativo da temperatura das águas ao redor de Austrália e Nova Zelândia parecem ter causado um notável aumento na diversidade da fauna em torno da Austrália e Nova Zelândia e, ainda, aparecimento de táxons imigrantes Indo- 
Pacíficos e desaparecimento de táxons locais, previamente estabelecidos e adaptados às condições mais frias anteriores (ZINSMEISTER, 1982). Contudo, o início das condições polares nas altas latitudes do hemisfério sul, intensificado no início do Oligoceno, também acarretaram profundas alterações nessas faunas que antes estavam sob condições amenas, e que passaram a apresentar uma baixa diversidade e pouca influência de imigrantes Indo-Pacíficos (ZINSMEISTER, 1982).

Por fim, foi nas águas ao redor da Nova Zelândia, em maio a essas mudanças climáticas intensas ocorridas durante o Oligoceno e Mioceno, que alguns Anakineticinae (e.g., Magadina browni, Rhizothyris rhizoida) e Bouchardiinae (e.g., Neobouchardia minima) se desenvolveram, o mesmo sendo notado para a costa sudeste australiana (i.e., Elderra toorloensis, Magadinella woodsiana, Pilkena compressa, Malleia portlandica).

\section{- Litoral sul brasileiro até Península Antártica}

O início da abertura do oceano Atlântico Sul resultou no estabelecimento do chamado Sistema Rift do leste brasileiro, formado por 6 bacias marginais (i.e., Pelotas, Santos, Campos, Espirito Santo, Bahia Sul e Sergipe-Alagoas), ocupando a planície costeira, plataforma continental e talude. São banhadas pela porção oeste do oceano Atlântico Sul, tendo como embasamento rochas pré-cambrianas, ou localmente paleozóicas (RICCARDI, 1988), e sendo preenchidas por sedimentos com idade variando do Neojurássico ao Recente (CHANG et al., 1988, 1992; RICCARDI, 1988).

Dentre essas bacias, a de Pelotas é de maior interesse para o presente estudo, uma vez que de seus sedimentos provém os únicos 3 exemplares fósseis de Bouchardia (i.e., Bouchardia zittell) conhecidos para o Brasil, ao menos até o momento (MARTINS, 1952; Closs, 1971; MANCENido \& GRIFFIN, 1988). Aspectos como sua estrutura, composição, formação, tectônica e estratigrafia estão bastante detalhados na literatura (e.g., AsMUS \& PORTO, 1972; Asmus \& PONTE, 1973; HINZ, 1981; MUTTER et al., 1982; FONTANA, 1987, 1990; MORTON \& TAYLOR, 1987; RICCARDI, 1988; CHANG et al., 1992; VILLWOCK \& TOMAZELLI, 1995; CARREÑo et al., 1999).

O conteúdo paleontológico da Bacia de Pelotas é bem conhecido, sobretudo para palinomorfos (DAEMON, 1969) e grupos de invertebrados, como foraminíferos (Closs, 1967, 1970, 1971; Fernandes, 1975; THIESEN, 1977) e ostracodes 
(SANGUINETTI, 1979, 1980; SANGUINETtI et al., 1991, 1992; CARREÑo et al., 1999). GOMIDE (1989) estabeleceu a biocronoestratigrafia da seção marinha da Bacia de Pelotas utilizando como principal ferramenta os nanofósseis calcários (veja, também, GONÇALVES \& DEHNHARDT, 1999). A partir daí tem início uma série de eventos regressivos e transgressivos intercalados, sendo que a última regressão teria ocorrido há 15 mil anos (CARREÑo et al., 1999), já dentro do Quaternário (veja comentários mais adiante).

No Mioceno, a Bacia de Pelotas estaria uniformemente coberta por um mar com profundidade máxima de 200 metros (SANGUINETTl, 1980). Drásticas mudanças na composição da fauna da Bacia de Pelotas (i.e., espécies de água quente substituindo espécies de água temperada), especialmente em assembléias de ostracodes (e.g., zona de Henryhowella evax), foram identificadas em rochas do Mioceno, sugerindo importantes mudanças ambientais a partir do Mioceno final, ligadas, ao que tudo indica, à variações climáticas, flutuações no nível do mar e influências de águas frias vindas da Antártica e Malvinas (Closs, 1970; BERTELS, 1975; BoltovskoY, 1979; CARREÑo et al., 1999). CARREÑo et al. (1999) estabelece para a Bacia de Pelotas, com base em ostracodes, quatro grandes eventos regressivos entre o Plioceno e Pleistoceno e quatro grandes eventos transgressivos entre o Mioceno e Pleistoceno, com provável controle glacio-eustático. O que pode ser sugerido é a influência desses eventos no controle das condições climáticas e ambientais da região, na distribuição das espécies de Bouchardia (e.g., Bouchardia zitteli, Bouchardia transplatina) bem como na preservação do registro fóssil desses táxons pelo intenso retrabalhamento dos bioclastos.

Antes de atingir o litoral brasileiro, a separação do Gondwana deixava suas marcas pelo extremo sul do continente que ainda apresentava-se ligado à Antártica. A geologia da Patagônia e dos Andes, na Terra do Fogo, indicam que a margem ocidental, banhada pelo Pacífico, foi extremamente ativa durante o Cretáceo, sofrendo soerguimento e erosão associados ao fechamento final de uma bacia marginal existente na região, desde o Jurássico médio (DALZIEL et al., 1974; ZINSMEISTER, 1982; ULIANA \& BIDDLE, 1988). A despeito do soerguimento em curso na época, depósitos marinhos em diversas partes da cordilheira indicam a ocorrência de mares rasos conectando o sudeste do Pacífico ao Atlântico Sul (ZINSMEISTER, 1982). 
No entanto, a história tectônica dessa porção da América do Sul, que por um longo periodo esteve em estreita ligação com a Península Antártica, não está totalmente esclarecida (ULIANA \& BIDDLE, 1988). Sabe-se que, durante o Neocretáceo, a América do Sul esteve localizada a leste de sua posição atual e, desde então, tem se movido progressivamente para oeste, com leve componente de rotação. Nessa época uma importante transgressão cobriu diagonalmente boa parte do território argentino, regiões conhecidas como extra-andina e fogo-santacruzina, dando origem a uma bacia que persistiu até o final do Cretáceo sendo, talvez, a primeira bacia atlântica (CAMACHO, 1969). Também nessa época, significantes diferenças entre assembléias de fauna e flora ao longo do Platô Falkland indicam influência de temperatura, sendo que esse platô teria servido como uma barreira entre massas de água na região (CIESIELSKI et al., 1977).

Já a localização, orientação e paleoclimatologia da Península Antártica permanecem em discussão (ZINSMEISTER, 1982; ELLIOT, 1985; WRENN \& HART, 1988; Cocozza \& ClaRKE, 1992; KenNETT \& WARNKE, 1992; STILWELL \& ZINSMEISTER, 1992; Prothero, 1994; Gazdzicki et al., 1992; Berggren et al., 1995; Crame, 1999; LeAr et al., 2000; ARONSON \& BLAKE, 2001). Porções descontínuas de terras emersas e mares rasos teriam existido entre essas duas regiões, até o final do Oligoceno ou Mioceno inicial, mantendo alguma ligação até por volta de 29 m.a. (ELLIOT, 1985; KENNETT \& WARNKE, 1992; CRAME, 1999). Mesmo atualmente, essas regiões continuam apresentando uma via de comunicação com águas mais rasas pelo arco Scotia (PICKEN, 1985). Acredita-se que essa configuração no intervalo Oligoceno-Mioceno inicial teria sido suficiente para permitir o desenvolvimento apenas de uma protocorrente ao redor da Antártica, uma vez que condições de águas profundas $( \pm 3000 \mathrm{~m})$ e contínuas ao redor do continente, essenciais ao desenvolvimento de correntes de fundo, só teriam se instalado com a conclusão da abertura da Passagem Drake, por volta de 29 m.a. atrás (GILL \& BRYAN, 1971; BARKER \& BURRELL, 1977; ZINSMEISTER, 1982; ELLIOT, 1985; FLORINDO et al., 2003; LAWVER \& GAHAGAN, 1998, 2003). De acordo com CrAme (1999) a abertura da Passagem Drake foi um processo de longa duração, ocorrendo entre 37-23,5m.a., ainda dentro do Oligoceno (ELLIOT, 1985; HALLAM, 1994). CARMO \& SANGUINETTI (1999) sugerem que a Corrente das Malvinas já havia se estabelecido no Mioceno, corroborando a idade sugerida para a abertura da Passagem 
Drake que foi no Oligoceno final $( \pm 29$ m.a.) (BARKER \& BURRELL, 1977; RINGUELET, 1978; KENNETT, 1982).

Com base nos dados atuais sobre a Antártica, sabe-se que o gelo exerce grande influência no ambiente (e.g., temperatura da água, nível de luz transmitida, circulação oceânica, salinidade, composição do sedimento) e com reflexos evidentes em organismos pelágicos e bentônicos, de litoral e sub-litoral (PICKEN, 1985). Por sua vez, a separação entre Antártica e Patagônia, e o estabelecimento de um mar efetivo entre Austrália e Antártica, no Mioceno inicial, levaram ao desenvolvimento da corrente ao redor do continente antártico e de seu braço mais ao norte, a Corrente das Malvinas, (WOod et al., 1999). Por sua vez, CAMACHO (1967) e DEL RIO (1990) consideram que a presença de uma associação faunística de água quente na extremidade sul do continente americano, a cerca de $10 \mathrm{~m}$.a. atrás, está ligada ao fato da Corrente das Malvinas ainda não estar completamente operante no começo do Mioceno final e que a proto-corrente do Brasil, de águas quentes, influenciava fortemente essas latitudes. Portanto, embora um gradiente térmico já existisse na época, ele não teria sido tão forte quanto hoje em dia.

A exemplo do que havia ocorrido no Cretáceo (CAMACHO, 1969), um grande evento transgressivo atingiu o extremo sul das Américas, entre o Oligoceno e o Mioceno inicial (CAMACHO, 1966, 1967). Deslocamentos faunisticos foram mais facilitados durante o Plioceno, com o desenvolvimento das correntes do Brasil (águas quentes) e das Malvinas (águas frias), sendo que a primeira teve uma influência muito maior na Patagônia do que aquela exercida atualmente, permitindo que organismos de águas temperadas habitassem essas latitudes maiores. Contudo, aos poucos, a corrente das Malvinas foi se colocando entre a corrente do Brasil e o continente, resfriando as águas e causando a retirada de elementos faunísticos temperados, rumo ao norte, e permitindo a migração de elementos polares (CAMACHO, 1967; RINGUELET, 1978).

Toda a porção austral da América do Sul parece ter sido atingida por distintas transgressões marinhas desde o Neocretáceo (principalmente no Aptiano, Cenomaniano-Maastrichtiano) e em vários momentos no Terciário (e.g., Paleoceno, Eoceno e Mioceno médio; CAMACHO, 1966, 1967, 1969). Informações fornecidas por isótopos de oxigênio e corais fósseis indicam que, durante o Eocretáceo, a Patagônia apresentou clima quente, seguido por um resfriamento no Neocretáceo, deixando as 
águas temperadas (BOWEN, 1963; CAMACHO, 1967). Pouco depois, já no limite Cretáceo-Terciário, o desenvolvimento da cordilheira, ao sul do continente, passou a influenciar fortemente o clima, barrando os ventos vindos do oeste e impedindo que a umidade chegasse à Patagônia, tornando essa região cada vez mais árida e progressivamente fria (SAVIN et al., 1975; FISHER \& ARTHUR, 1977; LORIUS \& DUPLESSY, 1977; CIONE, 1978; CRAME, 1999). Dados paleontológicos (fauna e flora), biogeográficos e geológicos têm mostrado um declinio na temperatura da região ao longo do Cenozóico (e.g., CAMACHO, 1966, 1967; FAIRBRIDGE, 1967; AXELROD \& BAILEY, 1969; ARCHANGELSKY \& ROMERO, 1974; FISHER \& ARTHUR, 1977; BAEZ \& GASPARINI, 1977; CIONE, 1978; ElLIOT, 1985; KenNeTt \& STOT, 1991, entre outros). Argumentos contrários a essa tendência de resfriamento são discutidos e considerados por CIONE (1978) e literatura por ele citada (e.g., WOLFE, 1971; BERTELS, 1973, 1975; MALUMIÁN \& Masiuk, 1973; GasparinI \& BAez, 1975; Petriella \& Archangelsky, 1975; BÁez \& GASPARINI, 1977; FISHER \& ARTHUR, 1977; veja também OBERHÄNSLI et al., 1991).

Dentro do modelo de queda progressiva da temperatura na região austral da América do Sul, as condições climáticas ficaram ainda mais severas durante o Mioceno, com as águas alcançando temperaturas cada vez mais baixas, muito próximas das observadas atualmente, como indica o registro fossilifero de pingüins $\mathrm{e}$ baleias, exceção feita a um curto período no Mioceno médio, de rápido aquecimento (ElLIOT, 1985). BERTELS \& MADEIRA-FALCETTA (1977) baseiam-se no conjunto microfaunístico para considerar temperaturas mais quentes que as atuais para o litoral argentino no Mioceno, ao mesmo tempo em que SPRECHMANN (1978) reconhece o que ele chamou de "subprovíncia Sul-Brasileira" com águas temperadas quentes até cerca de $34^{\circ}-35^{\circ}$ de latitude no litoral atlântico.

Contudo, existe, ainda, muita discussão sobre a história climática da Antártica e seus efeitos nas terras e águas vizinhas, sobretudo no que tange o início, a taxa e a localização da acumulação de gelo (para síntese das discussōes veja ZINSMEISTER, 1982; ELLLOT, 1985; EL-SAYED, 1985; BONNER \& WALTON, 1985; DECONTO \& POLLARD, 2003; FLoRINDO et al., 2003; HILDEBRAND-HABEL \& STRENG, 2003; LAWVER \& GAHAGAN, 2003). Sinais climáticos obtidos a partir da paleoflora, e suportados também por evidências sedimentológicas e geoquímicas, indicam clima frio já no Neocretáceo, estendendo-se até o Paleoceno final-Eoceno inicial, quando houve um período de rápido aquecimento, logo substituído novamente por clima sazonal frio, com início da 
instalação da cobertura de gelo e eliminação da vegetaçăo de grande parte do continente (DUTRA, 1997, 2000; DUTRA \& BATTEN, 2000; FrancIS \& POOLE, 2002). Sobre essa época, DINGLE et al. (1998) sugerem uma deterioração gradual do clima na Península Antártica, passando de uma condição muito quente e úmida, no início do Eoceno médio, para um clima frio e seco ao final do Eoceno.

Como já comentado anteriormente, a porção leste do continente antártico apresenta poucas exposições de rochas quando comparado à porção oeste, com importantes exposições de rochas do intervalo Eoceno-Plioceno ao redor da Península Antártica (THOMSON, 1991; WEBB, 1993; StOLARSKı, 1996; JONKERS, 1998, 2003; TAVIANI \& BEU, 2003). O registro geológico do Eoterciário está melhor representado nas ilhas Seymour, Cockburn e King George, na Península Antártica, formadas por rochas não marinhas (Formação Cross Valley, do Paleoceno) e marinhas (Formação La Meseta, do Eoceno final-Oligoceno; Grupo Moby Dick, Jenny Buttress, Mioceno inicial) (Buckman, 1910; Trautman \& Elliott, 1976; Hall, 1977; Zinsmeister, 1977, 1982; OWEN, 1980; BieRnat et al., 1985; Weidman et al., 1988; Bitner, 1996; MAREnssi et al., 1998; Bitner \& Crame, 2002; Reguero et al., 2002).

A paleoflora do Paleoceno final da Formação Cross Valley, apresenta pteridófitas e outros elementos que sugerem climas muito mais quentes do que nas mesmas latitudes hoje em dia (Reguero et al., 2002). Por sua vez, a paleoflora da Formação La Meseta é singular por apresentar uma predominância de táxons antárticos (e.g., Nothofagus, podocarpos e araucárias) em florestas decíduas e perenes do Eoceno, sugerindo uma tendência de resfriamento durante o Eoceno da Antártica, com climas sazonais, temperados frios e chuvosos além de gradiente latitudinal e de altitude, no Eoceno médio-final (REgUero, et al., 2002). Segundo ClONE (1978; veja também ZiNMEISTER \& CAMACHO, 1978), a fauna de peixes da Formação La Meseta indicaria um mar temperado quente ao redor da Península Antártica, ao final do Eoceno início do Oligoceno, ao passo que os restos de pingüins, encontrados em camadas superiores, indicariam um inicio de condições mais frias.

Dessa forma, os sedimentos da Formação La Meseta parecem indicar um momento importante de mudança de temperatura, fato reconhecido por diversos autores (e.g., DeVereux, 1967, 1968; AdDICot, 1969; MARgolis \& KENNETT, 1970; MENÉNDEZ, 1971; VolKHEIMER, 1971; WolfE, 1971; CIONE, 1978; KENNETT \& WARNKE, 1992; ARONSON \& BLAKE, 2001). Adicionalmente, esses sedimentos não mostram 
qualquer tipo de sinal de depósitos glaciais durante os episódios de resfriamento ocorridos no Paleoceno inicial e Eoceno final (LAWVER \& GAHAGAN, 2003). Acredita-se que a queda da temperatura no hemisfério sul, nessa época, tenha relações com o estabelecimento do tipo de circulação atual nos oceanos do sul em decorrência da separação entre Austrália e Antártica, o que teria permitido o estabelecimento da corrente ao redor de toda a Antártica, no limite Eoceno-Oligoceno (FOSTER, 1974; KENNETT et al., 1974; CIONE, 1978), a partir de quando teve início a formação da glaciação na Antártica levando ao rápido resfriamento das águas profundas e intermediárias e posterior aumento na glaciação (KENNETT, 1978).

Sobre o Oligoceno final, evidências marinhas indicam um pequeno aumento da temperatura nessa época, deixando as águas ao redor da Antártica temperadas frias (Wolfe, 1971; Raven \& AXelrod, 1974; Fisher \& ARThuR, 1977; CIONE, 1978). No entanto, a temperatura das regiões antárticas e subantárticas havia começado a cair lentamente no Oligoceno, como indicado por estudos de assembléias de foraminiferos planctônicos no Atlântico Sul (BOLTOVSKOY, 1979, 1980; FLOWER \& KENNETT, 1994; SPEZZAFERRI, 1995; WoOD et al., 1999), e um desenvolvimento rápido da capa de gelo da Antártica teria ocorrido bem mais tarde, entre 17-14 m.a. (BEU et al., 1997). No entanto, SHACKLETON \& KENNETT (1975a, 1975b) e KENNETT $(1977,1980)$ registraram um aumento abrupto da temperatura das águas antárticas e subantárticas a cerca de 10 m.a., evento este também observado por CAMACHO (1967) e DEL RIO (1990), com base em assembléias de moluscos e fauna associada. Para BERTELS (1984a, 1984b) a presença de correntes frias de superfície no Atlântico Sul teria sido apenas incipiente no Mioceno final.

Segundo FLOWER \& KENNETT (1994), o Mioceno médio representa um período de grande mudança na evolução climática do Cenozóico, seguindo agora para uma tendência de aquecimento no final do período. O estágio inicial dessa transição climática teria começado por volta de 16-14,8 m.a. sendo marcado por importantes variações de curta duração no clima global, no volume da cobertura de gelo da Antártica, no nivel do mar e circulação oceânica profunda (FLOWER \& KENNETT, 1995; CHOW \& BART, 2003). No começo do Mioceno médio o fechamento do mar de Tethys na região do Mediterrâneo interrompeu a circulação equatorial, diminuindo o transporte meridional de calor, o que levou a um resfriamento nas águas o sul e rápido crescimento da cobertura de gelo na Antártica (CHOW \& BART, 2003). Contudo, apesar 
das grandes flutuações seguidas por uma queda global no nivel do mar, importantes mudanças nas circulações oceânicas profundas e aumento na cobertura de gelo do leste da Antártica, a região oeste se manteve praticamente sem gelo até o final do Mioceno (KENNETT \& BARKER, 1990; CHOW \& BART, 2003).

O Plioceno na América do Sul e oeste da Antártica sofreu praticamente as mesmas variações mencionadas para a Austrália e leste da Antártica, ficando evidente, entretanto, que esse foi um periodo de intensas mudanças climáticas, com o clima global flutuando com a expansão e contração das capas de gelo nos dois hemisférios (WARNKE et al., 1992; THOMPSON \& FLEMING, 1996; BURCKLE et al., 1996; BOHATY \& HARWood, 1998; Gallagher et al., 2001, 2003). Segundo Crowley (1996), o Plioceno pode ter sido o último periodo no qual a temperatura global esteve maior que a atual, influenciada por altos niveis de $\mathrm{CO}_{2}$ ou altos níveis de transporte oceânico de calor (veja também DowsETT et al., 1996).

Todos os dados sobre a evolução e distribuição das faunas marinhas ao redor da Antártica, durante o Neocretáceo-Eoterciário, estão fundamentados exclusivamente no conteúdo fossilífero dos depósitos da Península Antártica. Neste contexto, Elliot (1985) sugere a existência de barreiras às trocas faunísticas entre América do Sul e Península Antártica, já no início do Cenozóico, mesmo antes da abertura da Passagem Drake, uma vez que faunas dessas duas localidades não apresentam correspondência em seus elementos, nesse periodo. Esse mesmo autor se refere, ainda, a abruptas mudanças faunísticas na Península Antártica do Eoceno ao Oligoceno, com possiveis ligações com a variação na circulação dos oceanos ou eventos paleoclimáticos (ELLIOT, 1985).

Devido à idade (Eoterciário) e posição, entre a Antártica e América do Sul, essas faunas têm fornecido importantes informações sobre a história geológica e biológica da região (ZINSMEISTER, 1982). Durante todo o processo de resfriamento do clima ao longo do Terciário, as faunas austrais, principalmente os invertebrados marinhos acostumados com as águas temperadas do Paleoceno, foram bastante atingidas, muitas chegando à extinção (veja, por exemplo Prothero, 1989, 1994; ProtHERo \& BERGgREN, 1992; CLARKE, 1993). A deterioração do clima no hemisfério sul, durante esse período, resultou em um progressivo declínio na temperatura ao redor da Antártica, com a correspondente adaptação das faunas às condições mais frias (ZINSMEISTER, 1982; ELLIOT, 1985). Ao contrário do que aconteceu com as faunas ao 
redor de Austrália e Nova Zelândia, que passaram a sofrer influência de temperaturas mais elevadas, decorrente do deslocamento das massas de terra rumo ao norte, as faunas ao redor da Antártica ficaram estacionadas em altas latitudes e tiveram que se adaptar às condições mais frias. Por outro lado, não precisaram competir com as sucessivas invasões de imigrantes, como acredita-se ter ocorrido na Austrália e Nova Zelândia. De uma maneira geral, as faunas do Eoceno final da liha Seymour refletem essas mudanças gradativas para um ambiente frio, mas também indicam que elas foram capazes de se ajustar às novas condições (ZINSMEISTER, 1982). Embora com registro mais incompleto, os macrofósseis de águas rasas apresentam indicações claras desses eventos de extinção, como nas altas latitudes da América do Sul, onde as águas do mar teriam resfriado $10^{\circ} \mathrm{C}$ em 10 m.a., coincidindo com o crescimento do manto de gelo da Antártica e desenvolvimento de águas geladas de profundidade (ZINSMEISTER, 1982; CLARKE, 1993). A ausência de registro fossilifero mais novo que Mioceno inicial torna impossivel a reconstituição da história das faunas antárticas do Neoterciário (ZINSMEISTER, 1982).

Concomitantemente aos eventos geológicos e climáticos no hemisfério sul, houve o aparecimento de um grande número de grupos endêmicos nas faunas de moluscos da passagem Cretáceo-Terciário no Pacífico Sul, o que também foi observado para outros grupos de plantas e animais contemporâneos (ZINSMEISTER, 1982), entre eles os braquiópodes Anakineticinae, através de Australiarcula artesiana (veja comentários anteriores), e os Bouchardiinae, no Neocretáceo, através de Bouchardiella cretacea nos mares do sudoeste australiano, e Bouchardiella patagonica e Bouchardia conspicua nos mares da Argentina (Patagônia e Chubut). Nesse contexto de mudanças ambientais e climáticas, considera-se que 3 fatores tenham sido importantes para a origem e evolução da biota patagônica total, inclusive os Bouchardiinae, ao longo do Cenozóico (CAMACHO, 1967). São eles a) as faunas e floras existentes na região ao final do Cretáceo e início do Terciário, b) a evolução paleogeográfica da região e c) as mudanças paleoecológicas e paleoclimáticas decorrentes. Já no litoral brasileiro, foraminiferos, briozoários (e.g., Discoporella, Cellaria) e braquiópodes (e.g., Bouchardia zitteli) reforçam as idéias de condições marinhas e sem muitas oscilações de temperatura para a Bacia de Pelotas, durante 0 Mioceno-Plioceno inicial (CARREÑo et al., 1999). 
Por sua vez, a história do Pacífico sul durante o Neocretáceo e Terciário apresenta uma oportunidade para observar e comparar as diferentes respostas das faunas de água rasa a uma variedade de crises ambientais provocadas por eventos tectônicos, oceânicos e climáticos, servindo de parâmetro para inferências sobre como eventos similares teriam afetado os Bouchardiinae no Atlântico Sul. Exemplo disso é a influência das correntes oceânicas do Atlântico Sul, sobre a costa da extremidade austral da América do Sul que foi identificada com o estudo de assembléias de moluscos miocênicos. Isso refletiu o deslocamento do gradiente térmico (temperaturas mais elevadas) das águas em direção ao sul, quando comparado com o atual (MARTínez, 1994; MARTínez \& DEL Rio, 2000, 2002) e, portanto, apontam para o desenvolvimento de condições mais quentes do que as atuais na mesma área, com a temperatura das águas oscilando entre 20-24으 (IHERING, 1907; DEL RIO, 1988, 1990; MARTinez, 1988, 1989, 1990, 1994). Essas informações são corroboradas pelos dados obtidos de ostrácodas, foraminiferos e braquiópodes (MALUMIAN, 1970; SPRECHMANN, 1978; Bertels, 1979; Boltovskoy, 1979; Herbst \& ZABERT, 1987; MANCEÑIdo \& GRIFFIN, 1988; FIgUEIRAS \& MARTINEZ, 1995; ZuCOL \& BREA, 2000), e ajudam a compreender 0 tempo de abertura da Passagem Drake e subseqüente desenvolvimento da Corrente das Malvinas na região, após a completa implantação da corrente ao redor da Antártica (MARTínEZ \& DEL RIOO, 2002).

É interessante notar que nos sedimentos da Patagônia são freqüentes camadas extremamente ricas em turritelídeos e briozoários nas facies deposicionais mais profundas da Formação Puerto Madryn (Mioceno final), localizada na Argentina, ao sul da área que teria sido recoberta durante a transgressão Entrerriense (DEL Rio et al., 2001; MARTínez \& Del Rio, 2002). De acordo com AlLmon $(1988,1993)$ e JONES \& ALLMON (1995), concentrações desse tipo são indicadores de altos niveis de nutrientes, de produtividade e de resfriamento das águas, geralmente associado com fenômenos de ressurgência, embora essas concentrações não estejam, necessariamente, na área em que ocorrem esses fenômenos, podendo ter sido transportadas.

Condições análogas a essas podem ser encontradas no litoral da região sudeste do Brasil (e.g., Cabo Frio, São Sebastião), onde as ressurgências são responsáveis por trazer à superficie águas ricas em nutrientes (PIOLA et al., 2000). Se a gênese das concentrações de turritelídeos da Formação Puerto Madryn estiver ligada a áreas de ressurgência durante o Mioceno final da Patagônia, poderia ser um indício da presença 
de uma proto-corrente das Malvinas, operando há 10 m.a. ao longo do litoral argentino. Nesse contexto, mudanças no regime das ressurgências também poderia ter influenciado no desenvolvimento das faunas de moluscos terciárias, como sugerido por AlLMON (2001).

\section{B) Quaternário}

Durante o Quaternário importantes mudanças paleoambientais tiveram curso, sendo de curta ou longa duração, cíclicas ou escalonadas, referindo-se, sobretudo, aos eventos climáticos que resultaram em períodos glaciais e interglaciais, com desenvolvimento de fenômenos característicos desses tipos de condições climáticas, principalmente variação no nivel do mar (BOULTON, 1979; AGUIRRE \& WHATLEY, 1995; LOWE \& WALKER, 1997; SUGUIO, 1999). Por sua vez as mudanças paleogeográficas não foram significativas, ao menos aquelas relacionadas ao deslocamento dos continentes, embora as variações no nível do mar tenham contribuído muito para a modelagem do litoral brasileiro. Ao conjunto de mudanças climáticas é atribuída uma origem complexa (e.g., astronômica, geofísica, geológica), com interação de diferentes fatores (e.g., atividade solar, ciclos de Milankovitch, mudanças na composição da atmosfera da Terra) no tempo e no espaço (Suguio, 1999). Por sua vez, as prováveis causas dos períodos glaciais estariam ligadas ao aumento da precipitação de neve e diminuição da temperatura nas épocas de degelo, que levaram ao aumento das capas glaciais, oscilaçōes no nivel relativo do mar, alterações na circulação atmosférica e oceânica, além de profundas influências na fauna e flora (SUGUIO, 1999).

De acordo com Suguio (1999) os eventos iniciais de resfriamento do ar e das águas oceânicas teria começado ainda no Terciário, por volta do Mioceno-Plioceno. Informações de sedimentos perfurados no leste do continente antártico (veja TAVIANI \& BEU, 2003) informam, com base em macrofósseis e isótopos estáveis, que condições polares extremas, comparáveis às atuais, passaram a predominar na Antártica no início do Pleistoceno, com as águas marinhas de fundo atingindo entre $-2^{\circ}$ e $0^{\circ} \mathrm{C}$ (TAVIANI et al., 1998; TAVIANI \& ZAHN, 1998). As variações no nivel relativo do mar no Quaternário têm sido intensamente investigadas, e representadas por curvas de variações globais (Fairbridge, 1961; Shepard, 1963; Clark et al., 1978; PIRAzZOLI, 1993), regionais e locais (MÖRNER, 1976, 1980, 1986; SUGUIO et al., 1988; GodolPHIM et al., 1989). 
Nesse contexto brevemente descrito para o Quaternário, o Brasil teve seu mais antigo nivel de mar alto há 123 mil anos, entre 20-25 metros acima do nível atual no litoral do Rio Grande do Sul (VILLWock et al., 1986; Suguio et al., 1988; MARTIN et al., 1996; Suguio, 1999). Planícies costeiras nos litorais de Santa Catarina, Paraná e São Paulo apresentam vestígios desses niveis de mar elevado de mesma idade (e.g., Transgressão Cananeiense, sensu SUGUIO \& MARTIN, 1978) ou mais antigas (MARTIN et al., 1988), compostos basicamente por terraços arenosos cujo topo chega até os 10 metros acima do nível de maré alta do mar atual. Após esse período teve início uma gradual regressão marinha que durou até cerca de 7 mil anos atrás, sendo que o nivel do mar sempre esteve abaixo do atual (MARTIN et al., 1996; SUGUIO, 1999).

De acordo com Suguio (1999), a plataforma continental do Rio Grande do Sul apresenta sucessivas posições de estabilização de antigos niveis do mar, tendo sido proposto um nivel de 130 metros abaixo do nivel do mar atual como o limite máximo da regressão pleistocênica, há 17,5 mil anos (SHEPARD \& SUESS, 1956; KoWSSMANN et al., 1977; CORRÊA, 1979, 1990, 1996; SUguio et al., 1988; MARTINS et al., 1996; CORRÉA \& TOLDO JÚNIOR, 1996). A partir daí, durante o Holoceno médio, entre 9-2,5 mil anos atrás (Idade Hipsitérmica sensu SUGUIO, 1999), a temperatura média anual teria sido cerca de $1^{\circ}-2^{\circ}$ superior a atual, considerada em $15^{\circ} \mathrm{C}$ (MATSUSHIMA, 1979). Esse evento teve seu reflexo também em grande parte do litoral brasileiro, principalmente na porção sulsudeste, ocasionando a subida do nível relativo do mar em até 5 metros, com o máximo transgressivo por volta dos 5,1 mil anos (SUGUio et al., 1985, 1988; MARTIN \& Suguio, 1986; Suguio, 1999).

A região costeira do Rio Grande do Sul apresenta atributos que são de interesse para a compreensão da evolução e paleobiogeografia dos Bouchardiinae. Ao mesmo tempo que contém representantes desse grupo nos sedimentos terciários da Bacia de Pelotas, até agora não foi registrada a ocorrência de elementos viventes. Dessa forma, a compreensão da evolução paleogeográfica costeira do Rio Grande do Sul, explorada por diversos autores (e.g., DELANEY, 1965; Closs, 1966, 1970; FORTI-ESTEVES, 1968, 1974; BIANCHI, 1969; JOST, 1971; VILLWOCK \& MARTINS, 1972; SOLIANI, 1973; SOLIANI \& JosT, 1975; ZELTZER, 1976; GODOLPHIM, 1976, 1983, 1985; VILLWOCK, 1984; TOMAZELLI \& VILLWOCK, 1989; GODOLPHIM et al., 1989) pode trazer contribuições importantes para o entendimento da evolução dos Bouchardiinae. 
Como brevemente comentado, essa região apresenta uma série de características geomorfológicas (e.g., linhas de erosão de depósitos quaternários; juzantes de rios em forma de vales com margens inclinadas), sedimentológicas (e.g., seqüência grano-crescente ascendente; argila negra com pequena porção de areia muito fina associada a grandes quantidades de conchas) e paleontológicas (e.g., associações de subfósseis marinhos e estuarinos) que indicam a ocorrência de processos transgressivos e regressivos, durante o Quaternário (Sugulo et al., 1988; GoDOLPHIM et al., 1989).

Dentro dessa fase transgressiva, o nivel do mar atual foi ultrapassado pela primeira vez há 7 mil anos, sendo que há cerca de 5,5 mil anos o mar no Rio Grande do Sul esteve cerca de 5 metros acima do nivel atual, encobrindo barreiras arenosas, lagunas e sistemas fluviais que desembocavam na costa, estabelecendo-se um ambiente marinho raso (GODOLPHIM, 1983; GODOLPHIM et al., 1989). Entre 4 e 2,5 mil anos o nivel do mar oscilou entre 1,5-3,5 metros acima do atual, sendo que dos 2,5 mil anos teve início a fase regressiva (MESQUITA, 1994; MASSAD et al., 1996). No contexto regressivo recente, as condições do litoral do Rio Grande do Sul passaram, de mar raso para estuarino, lagunar e fluvial, deixando, junto à linha de costa atual, várias cristas que formaram uma superfície de cordões regressivos (GODOLPHIM, 1983; GoDOLPHIM et al., 1989).

No que tange as mudanças climáticas do intervalo Pleistoceno final-Holoceno, que atingiram a Província de Buenos Aires houve a transição de um clima quente e úmido, no Pleistoceno médio, para frio e seco no final desse período, voltando às condições quentes e úmidas ao longo do Holoceno (TONNI \& FIDALGO, 1978). Durante a última transgressão pleistocênica, as águas do mar recobriram o nordeste da província de Buenos Aires, chegando a 10 metros acima dos niveis atuais (GoDiGnotTo \& AGUIRRE, 1993). Após a fase de máxima transgressão, terminada por volta de 7 mil anos atrás na América do Sul, as oscilações do nível do mar começaram a diminuir até os niveis atuais (SUGUIO et al., 1986; TURCQ et al., 1986; FASANO et al., 1987; GonZÁLEZ \& Weller, 1988; AguirRe \& WHATLEY, 1995; GoODWIN, 1998; BENTLEY, 1999; MCCULLOCH et al., 2000; HJORT et al., 2001; HuLTON et al., 2002).

Para o Pleistoceno, informações fundamentadas em faunas de moluscos do Uruguai consideram que as temperaturas foram mais elevadas do que as atuais (MARTÍNEZ et al., 2001). Um forte deslocamento para o sul da Corrente do Brasil foi 
sugerido como explicação para essas altas temperaturas, como indicado pelos depósitos de ambientes proximais atualmente encontrados na costa do Uruguai (SCARABINO, 1977; LAYERLE \& SCARABINO, 1984; MARTinez, 1988, 1990) e Argentina (AGUIRRE, 1990, 1993a; GoRdLlo, 1998). Há 4 mil anos, um evento de resfriamento do hemisfério sul (BOLTOVSKOY, 1990; IRIONDO \& GARCIA, 1993) teria provocado uma leve diminuição na temperatura das águas oceânicas superficiais, além do deslocamento da corrente quente do Brasil para o norte e o início da convergência SubtropicalSubantártica (AGUIRRE, 1993b; para informações mais detalhadas consulte CODIGNOTTO \& AGUIRRE, 1993; AgUIRRE \& WHATLEY, 1995). Na Antártica, análises de perfuração do gelo indicam temperaturas consideravelmente mais baixas há 8 mil anos, com níveis extremos (em torno de $5-7^{\circ} \mathrm{C}$ mais baixas do que as médias atuais) tendo ocorrido há 18 mil anos (PHILLPOT, 1985).

Ao contrário do que ocorre com os braquiópodes, grandes acumulações de conchas de bivalves marinhos (e.g., Mactracea, Tellinacea, Myacea) são comuns ao longo do litoral leste da América do Sul, da Guiana a Terra do Fogo (AguiRRE \& WHATLEY, 1995). Análises paleobiogeográficas realizadas por AGUIRRE (1993a, 1993b) demonstram que as comunidades bentônicas dessa área viveram em um oceano mais quente do que o atual, durante o Holoceno médio. Adicionalmente, foram notadas profundas mudanças na composição e distribuição das faunas de moluscos nessa região, concomitantes às grandes alterações ambientais em curso, e situações semelhantes são registradas por observações independentes (e.g., geológicas, palinológicas, microfósseis), para depósitos similares nos dois hemisférios (AGUIRRE \& WHATLEY, 1995). Portanto, integrando os resultados obtidos no presente estudo com o conhecimento atual sobre as circunstâncias paleogeográficas, paleoclimáticas e paleoambientais que atuaram desde o final do Mesozóico, serão feitas algumas considerações sobre a evolução dos Bouchardiinae e, mais especificamente, a relação entre o gênero Bouchardia e a evolução do oceano Atlântico Sul.

\subsubsection{Bouchardiinae e a evolução do Oceano Atlântico}

A partir da observação da distribuição da fauna de Bouchardiinae, no tempo e no espaço (Figuras 24-26), surgem questões sobre sua origem. Seria ela resultado de eventos evolutivos localizados e subseqüentes dispersões de seus elementos ou seria 
um grupo formado por membros não relacionados filogeneticamente e que migraram de diferentes locais? Quando tais processos teriam ocorrido? Sobre o gênero Bouchardia, em particular, o que teria controlado sua atual distribuição? As respostas para estas e outras questões sobre a história evolutiva dos Bouchardiinae serão comentadas a partir de agora. Pelos resultados obtidos no presente estudo os Bouchardiinae representam um grupo monofilético $e$, portanto, seus membros compartilham uma história evolutiva comum, até então sem o detalhamento dos passos dessa trajetória.

Para RICHARDSON (1997b) os esquemas de distribuição existentes para os braquiópodes, de uma forma geral, permitem identificar o predomínio de certos grupos (e.g., familias, superfamilias) em determinadas áreas e, portanto, podem ser identificados diferentes padrões regionais. De acordo com a autora, são as famílias com distribuição restrita (e.g., pela geografia, pela profundidade) que fornecem evidências sobre os caminhos da dispersão. Neste contexto, as investigações sobre a origem e distribuição dos Bouchardiinae passam, necessariamente, pelo hemisfério sul, área exclusiva de ocorrência de dessa subfamília e de outros 2 grupos de interesse para a presente discussão. São eles os Terebratellinae e os Anakineticinae, presentes desde o litoral da Antártica até latitudes de aproximadamente $35^{\circ} \mathrm{S}$, sendo freqüentes em áreas de até 1000 metros de profundidade (RICHARDSON, 1973b, 1991, 1994, 1997a, 1997b).

As informações trazidas pela literatura sugerem o Gondwana como provável área de origem desses grupos, especialmente na região ao redor da Austrália (RICHARDSON, 1994). Obviamente devem ser consideradas possiveis diferenças entre os padrões evolutivos iniciais e aqueles apresentados ao longo do Cenozóico e, segundo RICHARDSON (1994, 1997b), parece seguro sugerir que a distribuição teria ocorrido através de mares rasos ao longo das massas de terra que formavam o Gondwana. No início, os ambientes litorâneos e plataformais teriam sido ocupados por táxons com comportamentos "generalista" e "especialista" para algum parâmetro ambiental (e.g., tipo de substrato; RICHARDSON, 1994, 1997a, 1997b). Posteriormente, a distribuição dessas espécies teria sido limitada pela mudança no tipo dos sedimentos decorrente da separação dos continentes já em franco desenvolvimento (MACKINNON, 1987; RICHARDSON, 1994, 1997a). 
Mesmo com a evidente diferenciação morfológica entre os 2 grupos, a proximidade de parentesco entre Bouchardinae e Terebratellinae tem sido sugerida pela literatura, ainda que sem aplicação da metodologia cladística (e.g., RICHARDSON, 1973, 1991, 1994, 1997; BRUNTON, 1996). Contudo, pela proximidade espacial e temporal entre eles, sendo que seus membros estão distribuídos por quase todo o hemisfério sul, o conhecimento existente sobre a origem e evolução da Subfamília Terebratellinae, advindo das conclusões apresentadas por RICHARDSON (1994), pode servir como um ponto de partida ou termo de comparação, na tentativa de se compreender a evolução dos Bouchardiinae, mas sempre encarados sob uma visão crítica.

Conforme referido anteriormente, a reconstituição da história evolutiva e geológica dos Bouchardiinae remete ao limite Cretáceo-Terciário, inserindo-se, grosso modo, no contexto descrito previamente para os continentes do hemisfério sul e, em parte, investigado por SANDY (1991). Indiscutivelmente esses foram tempos de profundas mudanças no contorno e disposição dos continentes ao sul do Equador e, por conseguinte, na disposição das massas de águas, palco dos primórdios da evolução do grupo, acarretando alteraçōes em seus parâmetros físicos e químicos e padrões de circulação.

\section{- Bouchardiinae na Austrália e Nova Zelândia}

Observando a distribuição dos Bouchardinae desde o limite Cretáceo-Terciário, Bouchardiella cretacea é um dos primeiros elemento do grupo a ficar preservado. Seu registro fossilifero sugere que tenha habitado as águas rasas do sudoeste e oeste australianos, ainda durante o Neocretáceo (Figura 24). Espécimes de Australiarcula artesiana são encontrados na mesma região, em sedimentos datados do Eocretáceo e, a primeira vista, sugerem que as espécies teriam coexistido. No entanto, essa afirmação depende de investigações tafonômicas complementares ligadas, sobretudo, à resolução temporal e espacial das concentrações (veja, por exemplo, CARROLL et al., 2003) Neste ponto podemos levar em conta a opinião de CRAIG (2000), segundo a qual muitas das espécies de braquiópodes encontradas nos estratos do intervalo Paleoceno-Mioceno da Bacia Carnarvon, oeste da Austrália, derivam de evolução in situ nos mares rasos das plataformas costeiras que se estendiam até a Península 
Antártica e litoral Indo-Atlântico da Antártica. Assim, Australiarcula artesiana e Bouchardiella cretacea podem fazer parte dos estoques precursores das duas linhagens que hoje se traduzem nas subfamilias Anakineticinae e Bouchardiinae, respectivamente. Contudo, do Paleoceno até o Oligoceno, portanto cerca de $30 \mathrm{~m}$.a., não houve registro de Bouchardiinae nos sedimentos marinhos da Austrália e Nova Zelândia. Algo semelhante ocorreu com os Anakineticinae, embora com hiato maior (cerca de 40 m.a.) no registro, uma vez que Australiarcula artesiana, primeiro representante do grupo, é limitado ao Eocretáceo.

É interessante notar que, a partir do início do Paleoceno há uma sucessão de alternâncias entre condições climáticas quentes e frias, motivadas por variações na circulação dos oceanos ou na extensão das glaciações (WEISSEL \& HAYES, 1972; ZiNSMEISTER, 1982; StOTt et al., 1990; BuenING et al., 1998; Hildebrand-HABel \& STRENG, 2003), fatores esses que devem ter, de alguma maneira, influenciado na sobrevivência, especiação e distribuição dos braquiópodes das regiões atingidas. Assim, alguns táxons teriam desaparecimento frente as novas condições ambientais dominantes e que se mostravam essencialmente diferentes daquelas que existiam no limite Cretáceo-Paleoceno, diminuindo sua quantidade, diversidade e restringido sua distribuição no litoral australiano àquelas áreas que ainda conservavam condições adequadas à sobrevivência, preservando, assim, um banco genético para dar continuidade às linhagens na Austrália e Nova Zelândia mais tarde, no Oligoceno. Talvez por terem sido áreas bastante restritas, seu pequeno registro fossilifero tenha se perdido ao longo dos tempos, originando o hiato hoje observado. Dessa forma teriamos uma componente estritamente ambiental influenciando diretamente outra componente, que é o potencial de preservação.

No início do Oligoceno começa novamente o registro dos grupos. Os Bouchardiinae Neobouchardia minima e Malleia portlandica duram até o final do Mioceno quando, então, a primeira espécie desapareceu. Como sugerido anteriormente, pela topologia obtida no presente estudo, observamos que Neobouchardia faz parte de um clado totalmente resolvido com as demais espécies de Bouchardiella o que sugere a sinonímia entre esses táxons em favor de Bouchardiella, - que ampliaria a distribuição estratigráfica do gênero até o intervalo OligocenoMioceno. Segundo o registro preservado, a linhagem dos Bouchardiinae, nessa parte do mundo, chega ao fim no Plioceno, com o final do registro de Malleia portlandica. Já 
os próximos representantes dos Anakineticinae, isto é, Adnatida deformis e Aliquantula insolita, surgem apenas no Eoceno.

O que significa essa volta dos táxons ao registro? Talvez a retomada de condições ambientais mais favoráveis e desenvolvimento maior das espécies. $\dot{E}$ no limite Eoceno-Oligoceno que existem indícios de um resfriamento abrupto nos oceano ao redor da Austrália, Nova Zelândia, leste da Antártica e Península Antártica, representando o início de mudanças das altas latitudes para condições polares (ZINSMEISTER, 1982; SHACKLETON \& KENNETT, 1975a, 1975b; BERGREEN et al., 1995; BUENING et al., 1998). Como conseqüência foram registradas profundas alterações nas faunas ao redor dessas localidades, especialmente Austrália e Nova Zelândia, que antes experimentavam águas mais quentes, e passaram a apresentar uma baixa diversidade geral da fauna (ZINSMEISTER, 1982). Essas condições podem ter sido favoráveis às espécies de Anakineticinae e Bouchardiinae que permaneciam na região e poderiam, agora, se distribuir por outras áreas que também apresentassem condições favoráveis ao seu desenvolvimento. Embora haja registro de novo aquecimento ao longo do Oligoceno (ANDERSON \& SHIPP, 2001), afetando sobretudo a Antártica, a temperatura das águas ao redor da Austrália e Nova Zelândia permaneceu quase inalterada durante o Oligoceno. Merece destaque o fato de que no Oligoceno médio a ligação entre Austrália e Antártica desaparece, permitindo o início da formação de correntes oceânicas profundas e intermediárias na região (CRAIG, 2000). São sugeridas condições de baixa temperatura para as águas do mar dessas regiões por todo o Oligoceno e Mioceno, culminando com condições glaciais extremas na Nova Zelândia durante o Mioceno final, por influência direta da Convergência Antártica, já em operação (KENNETT, 1967, 1968; FIELD et al., 2002; DIEKMANN et al., 2003; OHTA et al, 2003).

No entanto, é no Mioceno médio que tem início o "Ótimo Climático" (BÖHME, 2003), levando a temperaturas mais elevadas do que as atuais nas águas de fundo da Antártica e Austrália, embora um pouco mais frias do que aquelas que predominavam no Oligoceno. Já o final do Mioceno teria sido marcado pela expansão da glaciação Antártica, levando a um oceano frio e estratificado, como revelam sedimentos da época em território australiano (GALLAGHER et al., 2001; BöHME, 2003). No Plioceno, as variações nas condições ambientais foram constantes e significativas, resultado da expansão e retração das geleiras nos dois hemisférios (GALLAGHER et al., 2003). 
Como o contexto das mudanças climáticas constantes e intensas descritas acima está ligado primordialmente à variação da temperatura, parece razoável sugerir que este tenha sido um fator importante no desaparecimento dos Bouchardinae da Austrália e Nova Zelândia, ao final do Plioceno. Na contramão, entretanto, os Anakineticinae encontraram, nas mesmas condições adversas aos Bouchardiinae, possibilidades de desenvolvimento o que permitiu ao grupo permanecer até hoje na mesma região. Talvez seja prematuro assumir uma afinidade maior dos Bouchardinae por temperaturas mais amenas, mas parece evidente que a variação da temperatura das águas, sobretudo sua queda acentuada ao final do Mioceno e durante o Plioceno, desempenhou papel importante na evolução do grupo na região.

\section{- Bouchardiinae na América do Sul e Península Antártica}

Durante o Neocretáceo, enquanto Bouchardiella cretacea estava nos mares rasos da plataforma Australiana, Bouchardiella patagonica, Bouchardiella jorgensis e Bouchardia conspicua habitavam as águas da região sul Argentina, entre a Patagônia e a atual província de Santa Cruz. Por sua vez, o registro de rochas sedimentares do Paleoceno, na mesma região, indica a presença de Bouchardia exigua (Figura 24).

Deste pequeno quadro que se formou, alguns fatos são de interesse. No momento em que surgem os primeiros registros dos Bouchardinae (i.e., Neocretáceo), sua distribuição geográfica já é ampla (Figura 24) e, embora os elementos estejam em extremos opostos, ou seja, Austrália e América do Sul, não há registro de sua presença em toda a Antártica. Existem, pelo menos, duas alternativas para explicar essa distribuição. Uma primeira explicação poderia considerar que esses táxons não apresentam parentesco próximo e, portanto, tiveram surgimentos independentes, sofrendo pressões ecológicas semelhantes o que justificaria sua semelhança morfológica. Essa alternativa é descartada pelos resultados obtidos no presente estudo, e que corroboram o monofiletismo dos Bouchardinae. A explicação mais provável é que pelo menos uma espécie de Bouchardiella, com registro fossilífero conhecido ou não, estivera habitando os mares ao longo do continente antártico durante o limite Cretáceo-Terciário, havendo, entretanto, ausência desse registro, quer seja por motivos de preservação ou porque ainda não foram encontrados. Há que se considerar que rochas dessa idade são bem conhecidas apenas na porção oeste do 
continente, próximo da Península Antártica (ELLIOT, 1985), e os táxons estão ausentes nas rochas do Paleoceno.

Por certo que, apoiado no monofiletismo do grupo, esses táxons tiveram um ancestral comum em algum momento anterior. Isso poderia ter ocorrido durante o Eocretáceo, quando os continentes do sul do Gondwana ainda estavam unidos, e as distâncias entre América do Sul e Austrália eram menores (Figura 24). Nessa época, como citado anteriormente, Australiarcula artesiana habitava os mares rasos da região e poderia ser cogitado como um suposto ancestral, embora isso não possa ser confirmado.

Aqui, merece referência o fato de que, pela morfologia semelhante, Australiarcula foi atribuida aos Bouchardiinae (MACKINNON \& LEE, no prelo), apesar de sua posição junto aos Anakineticinae ter sido ratificada no presente estudo. Com a separação dos continentes teria havido também a divisão da população dos primeiros representantes de Bouchardiella, sendo que uma parte continuou pelos litorais da Austrália, como Bouchardiella cretacea, e outra acompanhou o litoral antártico. Deve ser levado em conta que durante o Eocretáceo, um clima temperado quente dominava a região da Austrália habitada por esses elementos, ao passo que em direção ao Paleoceno, e já no Neocretáceo, a Antártica esteve sob condições mais frias do que Austrália e América do Sul (Figura 24). Dessa forma, buscando regiões com condições ambientais mais adequadas, talvez ligadas à temperatura, os Bouchardiinae que seguiram pelo litoral antártico ocuparam latitudes mais baixas, com condições mais temperadas, até atingirem o litoral da Patagônia. Infelizmente, como já mencionado, até - momento não há registro da parte antártica desse deslocamento, sendo que a hipótese sugerida acima tem caráter meramente especulativo.

Outro ponto a ser explorado é a presença das quatro espécies na Patagônia, duas de Bouchardia e duas de Bouchardiella, em um espaço relativamente curto de tempo. Apesar da falta de registro na Antártica, espécies de Bouchardiella são, de momento, as mais prováveis de terem se originado na Austrália e dado início ao deslocamento, uma vez que estão presentes nos dois extremos da distribuição geográfica total desses gêneros. Isso estabelecido, resta saber se as duas espécies da Patagônia, i.e., Bouchardiella patagonica e Bouchardiella jorgensis, se originaram já na região ou realizaram juntas a migração a partir da Antártica, ao que tudo indica em decorrência das baixas temperaturas. A mesma dúvida se apresenta no caso de 
Bouchardia conspicua, do Neocretáceo, e Bouchardia exigua, do Paleoceno. No entanto, deve ser levada em conta a informação de que Bouchardia exigua, mais nova, é encontrada mais ao sul do território argentino, especificamente na Terra do Fogo (MANCEÑIDO \& GRIFFIN, 1988), o que mostra um deslocamento do registro do gênero para o sul, no referido intervalo de tempo.

Neste ponto, cabe uma colocação. Ao observarmos o que o registro dos Bouchardiinae nos mostra vemos que existem dois táxons de gêneros diferentes, pertencentes a um grupo monofilético, representados em locais distantes mas no mesmo intervalo de tempo. Trata-se de Bouchardiella cretacea e Bouchardia conspicua, ambas do Neocretáceo, mas a primeira da Austrália e a segunda da Patagônia. Isso tem implicações diretas nas especulações sobre a origem do grupo, sendo que deve-se esperar, no mínimo, que ela tenha ocorrido no Eocretáceo. No entanto as demais questões sobre os passos seguintes permanecem encobertas, principalmente pela falta de registro. Teria sido realmente Bouchardiella o gênero inicial? Já existia o gênero Bouchardia na época da fragmentação dos continentes, ou ele teria surgido depois, já no litoral da Patagônia?

A literatura aponta porções descontínuas de terras emersas e mares rasos entre a Patagônia e a Península Antártica por todo o Cretáceo (ELLIOT, 1985). Levando isso em conta, seria de se esperar que parte da história dos Bouchardiinae na região ficasse gravada no registro geológico dessas áreas, o que, até o momento, não foi revelado. Tal constatação não esclarece, definitivamente, os passos do estabelecimento de Bouchardiella e Bouchardia na Patagônia, indicando, entretanto, que essas formas não habitaram a região da Península Antártica no Cretáceo. Portanto, para atingir a Patagônia podem ter vindo a) originalmente após a fragmentação dos continentes, ainda no Cretáceo, ou b) a partir da Antártica, levados por alguma corrente que percorria a costa antártica e se afastava dela antes de chegar à península, indo atingir a Patagônia. Vale lembrar que condições de circulação contínua e de águas profundas ao redor da Antártica só se desenvolveram muito tempo depois, por volta dos 29 m.a., com a abertura da Passagem Drake, quadro esse que sugere a existência de correntes mais superficiais e em direção ao norte ao final do Cretáceo (GILL \& BRYAN, 1971; BARKER \& BURRELL, 1977; ZINSMEISTER, 1982; ELLIOT, 1985). 
Por sua vez, a distribuição de Bouchardia conspicua e Bouchardia exigua pode estar associada ao evento regressivo ocorrido no Cretáceo, que fez recuar um mar que cobria grande parte do território argentino, sobretudo sua porção extra-andina e fogosantacruzina (CAMACHO, 1969). Ao final do Cretáceo, essa regressão em associação com as condições áridas e frias na região, em parte decorrentes do soerguimento dos Andes no extremo sul do continente (ULIANA \& BIDDLE, 1988), podem ter influenciado a distribuição e especiação dos táxons na região, suspeita reforçada pelas primeiras ocorrências de Bouchardia exigua.

Essas são as informações que compõem o conhecimento atual sobre a distribuição espacial e temporal iniciais de Bouchardia na América do Sul e Antártica. MANCEÑIDO \& GRIFFIN (1988) investigaram a distribuição espacial e temporal de todas as espécies do gênero, assinalando um longo deslocamento das espécies em direção ao norte, a partir de uma paleolatitude de $75^{\circ} \mathrm{S}$, no Paleógeno, até os atuais $35^{\circ} \mathrm{S}$ ocupados por Bouchardia rosea, e sem a retenção de suas antigas localidades (Figura 27). A principal causa desse evento, segundo os autores, teria sido a diminuição profunda na temperatura das águas do sul do continente, ao longo do tempo, o que teria motivado as espécies a buscarem condições mais amenas ao norte. Vale lembrar que, conforme comentado anteriormente, a busca por temperaturas mais amenas pode ter influenciado na distribuição inicial dos Bouchardiinae ao redor da Austrália.

MANCENIIDO \& GRIFFIN (1988) consideraram, ainda, que os atributos ecológicos (e.g., temperatura, substrato de fundo, profundidade) obtidos por TOMMASI (1970a) para a espécie vivente Bouchardia rosea, mantiveram-se, aproximadamente, os mesmos através do Cenozóico, para as demais espécies do gênero. No entanto, Recentes atualizações mostraram que tais informações encontram-se claramente desatualizadas (KoWAlEWSKI et al., 2000c; SimõEs et al., 2000a, 2000b). Um exemplo disso é a distribuição batimétrica de Bouchardia rosea, que não obedece estritamente os atributos definidos por TOMMASI (1970a), uma vez que exemplares foram encontrados em ambientes de águas rasas até profundidades de 485 metros, o que aumenta em muito o intervalo batimétrico de sua ocorrência (KOWALEWSKI et al., 2000c; SIMÕES et al., 2000a, 2000b). 


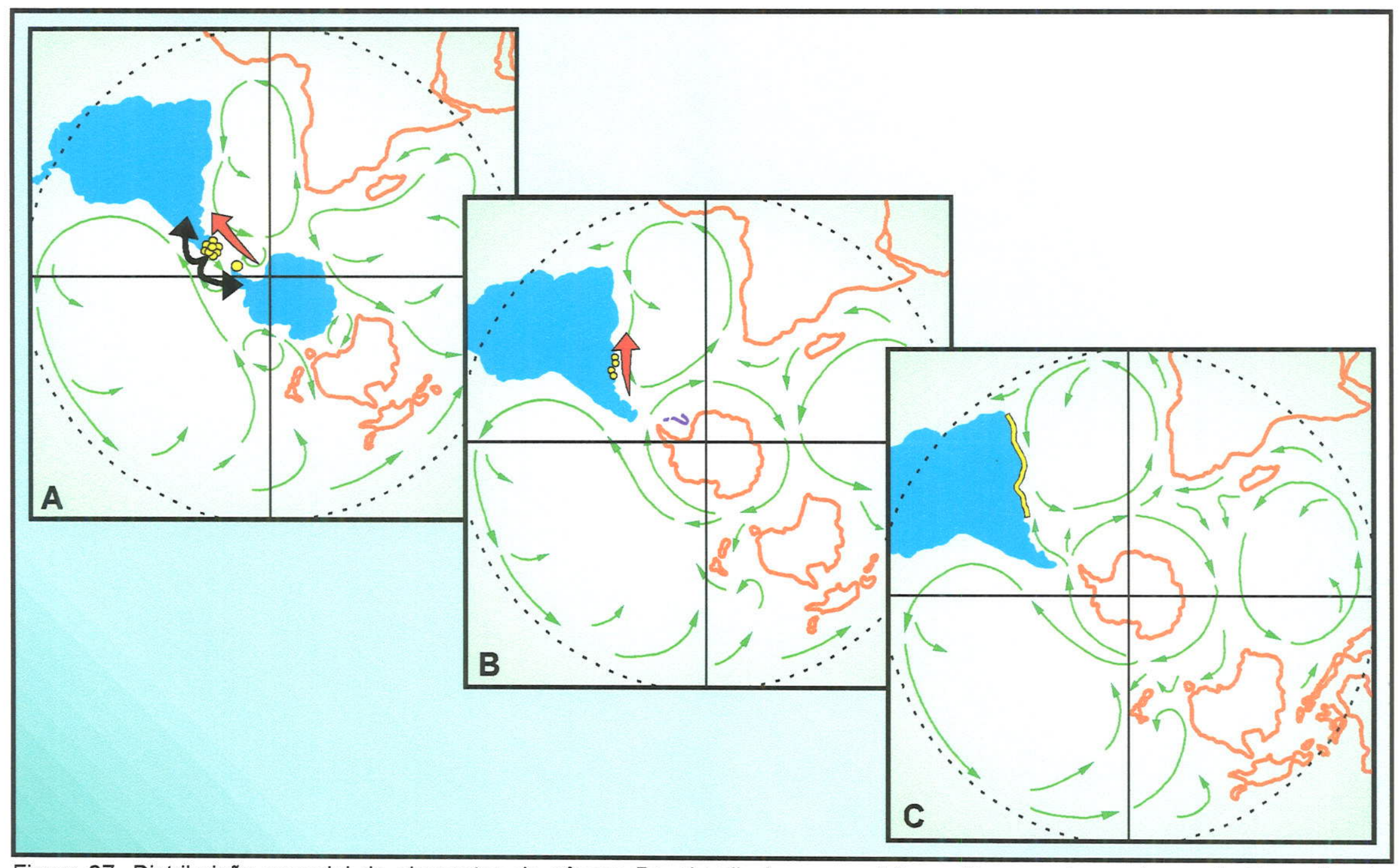

Paléç \& GRIFFIN (1988); setas negras indicam a movimentação para norte e sul dos táxons, representando passos intermediários dentro do padrão geral; interrogação representa a ausencia de registro de Bouchardiinae na Antártica após o desaparecimento de Bouchardia antarctica 
A seguir serão reconsideradas as afirmações de MANCEÑIDO \& GRIFFIN (1988), agregando-se a elas novos dados ecológicos, paleogeográficos e paleoambientais, aceitando a sugestão feita pelos próprios autores, segundo os quais é importante a reunião dos dados paleontológicos, biológicos e geológicos, dispersos na literatura e gerados em laboratório, a fim de fornecer um quadro compreensivo do gênero no espaco e no tempo, visando esclarecer o provável tipo de dispersão ocorrido e sua relevância, se existir alquma, para a evolução do Atlântico Sul, durante o Cenozóico. Para tanto, uma reavaliação do significado biogeográfico de Bouchardia rosea, de acordo com sua distribuição atual, se mostra bastante pertinente.

De fato, recentes contribuições taxonômicas, ecológicas e biogeográficas ao conhecimento dos braquiópodes da plataforma brasileira (KOWALEWSKI et al., 2002; SimÕEs et al., 2004) apresentaram evidências contrárias ao modelo de evolução de Bouchardia, sugerido por MANCEÑIDO \& GRIFFIN (1988), e dos Terebratellidae, como proposto por RICHARDSON (1994). De acordo com SIMÕES et al. (2004), a fauna de Rhynchonelliformea brasileira não é representada apenas por Bouchardia rosea, contando com elementos cosmopolitas (e.g., Argyrotheca, Platidia, Terebratulina) que imigraram, provavelmente, durante o Cenozóico. Todas essas formas compartilham o mesmo espaço e apresentam histórias evolutivas próprias, compondo uma fauna mais diversa, abundante e com um caráter muito mais cosmopolita do que pensado anteriormente. Sua presença em habitats abertos da plataforma tropical das baixas latitudes do leste do Atlântico Sul, contrasta com a visão geral a respeito de sua distribuição latitudinal, sendo que essa ocorrência anômala pode estar associada a áreas de ressurgência na quebra da plataforma (SIMõEs et al., 2004). Desta maneira, a fauna de braquiópodes brasileira, como um todo, pode ser um produto da migração, para o norte, de formas endêmicas e cosmopolitas durante o Cenozóico, facilitada, talvez, por áreas de ressurgência na quebra da plataforma. Esse padrão de migração durante o Cenozóico pode ser, de uma forma geral, extrapolado para o Hemisfério Sul (RICHARDSON, 1997b; CRAIG, 2000).

Contudo, como destaca SimôEs et al. (2004), mesmo levando-se em conta a complexidade da biogeografia por vicariância, em decorrência da associação de processos de longa duração com tectônica de placas, bem como a multifacetada história biogeográfica dos Terebratullidae (RICHARDSON, 1997b), a origem geográfica da fauna de braquiópodes brasileira permanece controversa. A migração das formas 
cosmopolitas (i.e., Argyrotheca, Platidia, Terebratulina) encontra suporte na grande capacidade de dispersão por correntes oceânicas documentada por CURRY \& ENDO (1991) para algumas formas, podendo ter migrado com as correntes oceânicas a partir de regiões distantes. Desta maneira, a história paleozoogeográfica cenozóica dos Bouchardiinae deve ser reconsiderada sob esses novos pontos de vista, mas, entretanto, traçar sua origem, como já destacado, é difícil, considerando a escassez de informações sobre seu registro fóssil (SMÖES et al, 2004).

Após essa breve atualização dos conhecimentos sobre a fauna de braquiópodes da plataforma brasileira, podemos retomar a discussão sobre a evolução das espécies de Bouchardia. De acordo com o modelo proposto por ALLMON (2001), para a evolução das faunas marinhas do Atlântico ocidental, podemos considerar que alterações em parâmetros ambientais, como temperatura e fontes de nutrientes, podem ter afetado a evolução dos Bouchardiinae ao longo de sua história, quer seja na origem, extinção, distribuição ou, mais provavelmente, todos os processos. Sendo assim, a seguir tentarse-á estabelecer as ligações entre os aspectos ambientais e evolutivos do grupo.

Como já comentado acima, os quatro táxons que habitaram o extremo sul do continente americano no Paleoceno, i.e., Bouchardia conspicua, Bouchardia exigua, Bouchardiella patagonica e Bouchardiella jorgensis, desapareceram antes do Eoceno. Nessa transição, Bouchardiella se extinguiu enquanto Bouchardia deu continuidade à evolução do grupo estando agora representado por duas novas espécies. Bouchardia antarctica é encontrada nos sedimentos do intervalo Eoceno-Oligoceno da Formação La Meseta, na Península Antártica (IIha Seymour). Já Bouchardia zitteli é encontrada ainda na Argentina, mas deslocada um pouco mais para o norte (Província de Santa Cruz) em relação às espécies recentemente extintas (MANCEÑIDO \& GRIFFIN, 1988).

Diversos gêneros de braquiópodes (e.g., Liothyrella, Magellania), entre eles Bouchardia (i.e., Bouchardia antarctica), foram descritos para os sedimentos eocênicos da Formação La Meseta (Ilha Seymour, Península Antártica), refletindo, provavelmente, grandes eventos de dispersão para latitudes mais baixas a partir da Antártica (WEIDMAN et al., 1988). No entanto, os dados apresentados por CRAIG (2000) vão contra essa proposta, por suportarem uma migração de oeste para leste, durante a expansão da abertura entre Austrália e Antártica, no Paleógeno. BITNER (1996) já havia discutido a possivel migração desses e outros braquiópodes a partir da Antártica para a Austrália, Nova Zelândia, Japão, sul da África e até América do Sul, sempre com base na 
comparação entre os elementos encontrados nessas localidades. Segundo a autora, entre esses táxons está Bouchardia, proveniente de sedimentos da Nova Zelândia, Austrália, Península Antártica (MANCEÑIdo \& GRIFFIN, 1988; WeIDMAN et al., 1988) e América do Sul (LEVY, 1964; RICHARDSON, 1973; MANCEÑIDO \& GRIFFIN, 1988). É importante salientar que esta é a primeira vez que se menciona a presença de Bouchardia na Austrália e Nova Zelândia, embora não tenha sido detalhada a localidade, unidade estratigráfica ou idade das ocorrências (BITNER, 1996; CRAIG, 2000) e nem os espécimes tenham sido ilustrados, o que faz crer que deve ter havido alguma confusão com relação aos nomes dos gêneros e, na verdade, a autora desejasse se referir a Bouchardiella. Os modelos de distribuição sugeridos por BITNER (1996) e CRAIG (2000) poderiam servir para explicar o início da distribuição dos Bouchardiinae, sendo que a partir da Antártica poderiam ter surgido, de um lado, as linhagens que se desenvolveram na América do Sul, e de outro a linhagem que se desenvolveu na Austrália. Infelizmente, sem o registro inicial do grupo na Antártica não pode-se avaliar essa sugestão.

Agora que foram fornecidas as informações sobre a migração das espécies de Bouchardia até o final do Paleógeno, uma primeira consideração a ser feita é sobre a representação desses acontecimentos por MANCEÑIDO \& GRIFFIN (1988; Figura 1, p. 203; aqui Figura 27). A Figura 29 reproduz as figuras originais de MANCENIIDO \& GRIFFIN (1988), representando as ocorrências de fósseis de Bouchardia em sedimentos paleógenos em comparação o que se observa no Neógeno, permitindo identificar claramente a migração dos elementos em direção ao norte. Para os autores, o início da corrente ao redor da Antártica (águas frias; FRAKES, 1979) teria sido o estímulo para que Bouchardia se deslocasse um pouco para cima buscando águas com temperaturas mais elevadas. HilleER $(1994 a, 1994, b)$ comenta o transporte de formas larvais de braquiópodes (e.g., Aerothyris, Liothyrella) pela corrente circo-polar Antártica, durante o Pleistoceno, provavelmente a partir da extremidade austral da América do Sul e Península Antártica, até duas pequenas ilhas vulcânicas do oceano Índico Sul.

No entanto, pela escala temporal utilizada, parte da informação foi perdida, ou pelo menos ficou restrita ao texto. Isso porque, como já citado anteriormente, na passagem Cretáceo-Paleoceno ocorrem os primeiros registros de Bouchardia exigua na Terra do Fogo, local ao sul da província de Santa Cruz, área de ocorrência de Bouchardia conspicua, mais antiga. Na passagem Paleoceno-Eoceno, os registros 
dessas duas espécies são totalmente substituídos pelo registro de Bouchardia antarctica, na Península Antártica, e Bouchardia zitteli, na província de Santa Cruz. Embora com caráter especulativo, dizer simplesmente que houve uma migração para o norte pode estar encobrindo uma suposta relação de ancestral-descendente entre essas espécies, uma vez que Bouchardia conspicua pode ter dado origem a Bouchardia zitteli, nos limites da província de Santa Cruz, enquanto Bouchardia exigua pode ter originado Bouchardia antarctica, ambas espécies mais adaptadas às condições frias dos mares rasos entre o extremo sul do continente e a Península Antártica.

ULIANA \& BIDDLE (1988) ao descreverem a evolução paleogeográfica e geodinâmica da América do Sul, no Mesozóico-Cenozóico, representam claramente (Figura 6, p. 180, aqui Figura 28) uma extensa área sem sedimentação marinha entre a provincia de Santa Cruz e a Terra do Fogo, isso há 50 m.a., ou seja, limite PaleocenoEoceno. Essa área poderia representar uma barreira geográfica significativa, isolando as espécies existentes, além de influenciar a circulação oceânica local. Infelizmente nenhum dos estudos consultados trouxe qualquer associação entre esses acontecimentos. Vale lembrar que a região passava por um resfriamento cada vez maior ao longo do Cenozóico, decorrente da instalação da glaciação na Antártica, com temperaturas muito baixas ao redor desse continente e tendência de melhoria nas latitudes mais baixas, com a proximidade do Mioceno (BERTELS \& MADEIRA-FALCETTA, 1977; SPRECHMANN, 1978).

Deve ser lembrada, ainda, a ocorrência de espécimes atribuídos a Bouchardia zitteli em sedimentos da Bacia de Pelotas, em território brasileiro (MARTINS, 1952). Apesar desses estratos terem sido correlacionados às camadas da Formação Patagônia, a mesma que contém as conchas de Bouchardia zitteli na Argentina, alguns aspectos devem ser levados em consideração. Closs (1971) ressaltou a importância dessa espécie como fóssil-guia nas correlações de sedimentos entre diferentes regiões da porção austral da América do Sul, o que, de certa forma, corrobora as informações iniciais de MARTINS (1952). No entanto, como ficou constatado nas análises cladística e morfológica conduzias no presente estudo, as espécies atribuidas ao gênero Bouchardia são bastante conservativas morfologicamente, o que poderia trazer alguma confusão em estudos bioestratigráficos realizados com base apenas em Bouchardia zitteli, sobretudo pelo reduzido número de exemplares disponiveis para a Bacia de 


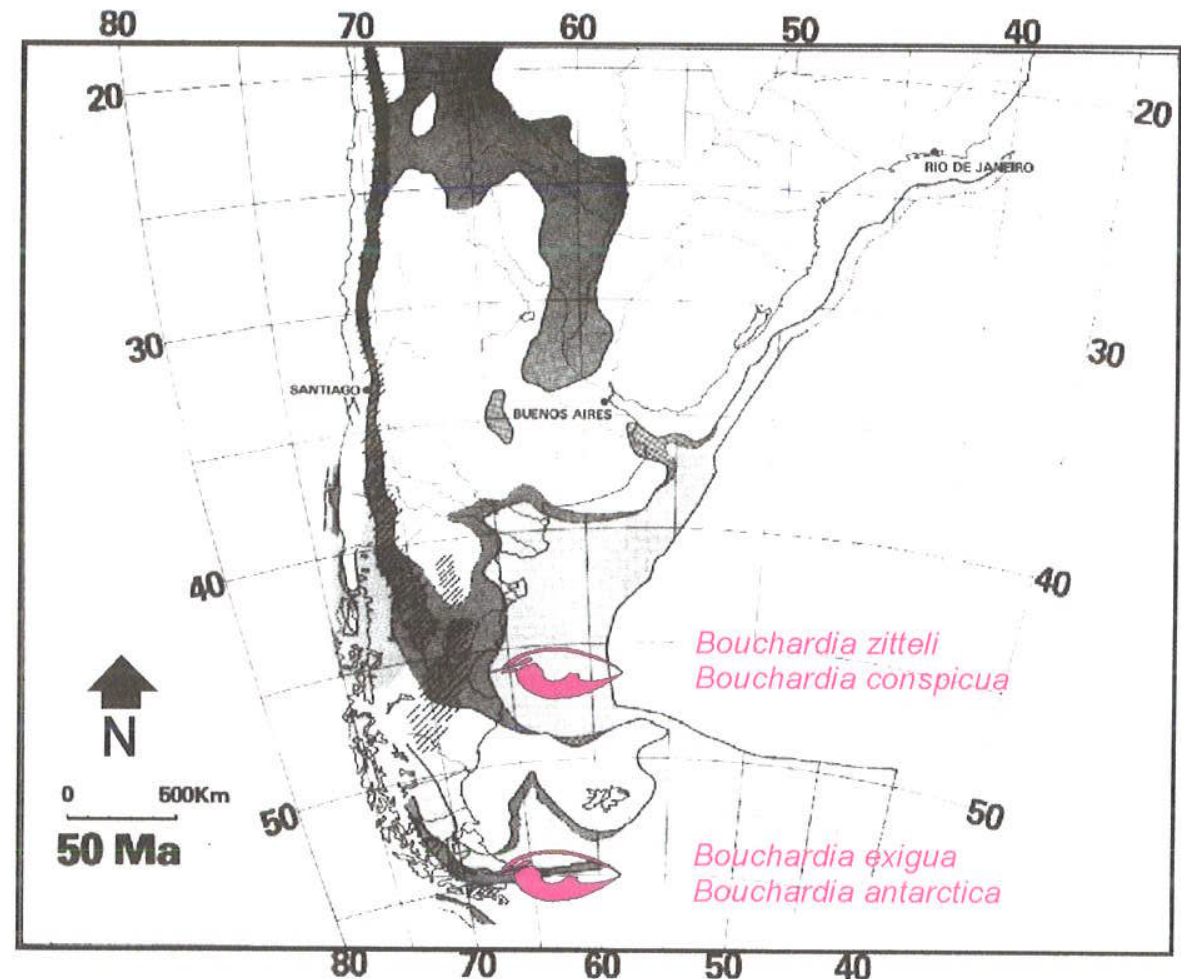

Figura 28- Reconstrução paleogeográfica de parte da América do Sul mostrando a distribuição espacial de 4 espécies de Bouchardia no início do Eoceno. Notar a presença de uma grande região emersa (sedimentação não marinha), pode ter influenciado na distribuição desses táxons. Veja comentários no texto. Legenda: Áreas escuras= sedimentação não marinha; áreas brancas = terras emersas; áreas cinza-claro= sedimentação marinha; Fonte: ULIANA \& BIDDLE (1988)

Pelotas. Entretanto, caso venha a ser confirmada a "identidade" dos exemplares da Bacia de Pelotas, a distribuição espacial da espécie aumenta sobremaneira, revelando, no entanto, uma lacuna em seu registro para grande parte do território argentino e para o Uruguai. E não é só isso. Outro ponto a ser observado diz respeito aos sedimentos argentinos que contém Bouchardia zitteli, datados do intervalo Eoceno-Oligoceno (MANCEÑIDO \& GRIFFIN, 1988). Já os exemplares da Bacia de Pelotas são encontrados em rochas miocênicas (MARTINS, 1952; Closs, 1971; MANCEÑIDO \& GRIFFIN, 1988) havendo, portanto, um impasse temporal entre as ocorrências. Por fim, a despeito da espécie e idade específicas dos exemplares da Bacia de Pelotas, apenas o registro desses elementos terciários em território brasileiro já é importante, pelas implicações diretas para o modelo de migração do gênero, proposto por MANCEÑIDO \& GRIFFIN (1988).

Entre o Oligoceno e o Mioceno inicial teria ocorrido um grande evento regressivo no extremo sul das Américas (CAMACHO, 1966, 1967) combinado com a tendência de 
queda progressiva da temperatura na região austral da América do Sul, durante o Mioceno, com as águas alcançando temperaturas cada vez mais baixas, muito próximas das observadas atualmente, como indica o registro fossilifero de pingüins e baleias, exceção feita a um curto período no Mioceno médio (ElLLIOT, 1985). Foi na passagem Oligoceno-Mioceno que terminou o registro de ambas espécies de Bouchardia zitteli e Bouchardia antarctica. Pelo que se conhece do registro fossilifero terciário da Península Antártica, nenhuma espécie ficou preservada após o final do registro de Bouchardia antarctica, ao passo que o registro do gênero, mais ao norte, até então representado por Bouchardia zitteli, foi substituído pelo de Bouchardia transplatina. Embora em contexto de clima temperado frio, condiçöes mais amenas de temperatura em latitudes um pouco mais elevadas, no litoral nordeste argentino e litoral uruguaio, influenciadas pelo momento de rápida melhoria no Mioceno médio (ELLIOT, 1985), podem ter favorecido o desenvolvimento de Bouchardia transplatina.

Durante o Mioceno final, uma ampla área coberta pelo Mar Entrerriense, deixou depósitos sedimentares na Argentina (Formação Paraná), Uruguai (Formação Camacho) e sul do Brasil (Bacia de Pelotas) (CAMACHO, 1966; Goso \& Bossi, 1966; YRIgoYen, 1969; Closs, 1970; MalumiÁN, 1970; Haller, 1978; MARTinez, 1994). Dentre esses depósitos merece destaque a Formação Camacho, do litoral sul do Uruguai, onde são encontrados, entre outros invertebrados (e.g., moluscos, briozoários, equinóides), as conchas de Bouchardia transplatina, cujo registro mais recente data do Plioceno (MANCEÑIDO \& GRIFFIN, 1988). Os sedimentos da Formação Camacho foram depositados em ambiente intermaré até plataformal (SCASSO \& DEL RIO, 1987; MARTínez, 1994; ACEÑolaza \& AceñolazA, 2000; Del Río et al., 2001; MARTínez \& DEL. Rio, 2002), com águas quentes e salinidade pouco inferior a média atual (ZABERT \& HERBST, 1977; SPRECHMANN, 1978), indicando sensivel melhora nas condições climáticas nessas latitudes, já no final do Mioceno. Assim, levando-se em conta a sugestão feita anteriormente, no presente estudo, segundo a qual Bouchardia transplatina seria sinônimo júnior de Bouchardia rosea, a duração e distribuição geográfica dessa última espécie, até então presente apenas em parte do litoral sulsudeste do Brasil, seriam bastante ampliadas.

Durante muito tempo Bouchardia rosea foi considerada a única espécie atual de Rhynchonelliformea para o litoral do Brasil, idéia esta que só começou a mudar no final da década de 1990, com novas investigações (SIMÕES \& KOWALEWSKI, 2000; SIMÕES et 
al., 2000b, 2000c; KOWALEWSKI et al., 2002). Grande parte do conhecimento inicial sobre sua distribuição e ecologia foi fornecida pelas investigações de TOMMASI (1969, 1970a, 1970b), considerando Bouchardia rosea presente na plataforma continental e áreas costeiras, principalmente, em profundidades entre 18 e 26 metros, sobre fundos de areia média a grossa e cascalho bioclástico, informações essas extrapoladas para outras espécies atribuídas ao gênero (MANCEÑIDO \& GRIFFIN, 1988). Recentemente, KOWALEWSKI et al. (2002) analisaram numerosas e densas populações de braquiópodes de parte da costa sudeste do Brasil, construindo um retrato atual de Bouchardia rosea no litoral brasileiro, sobretudo no que tange as relaçöes com o ambiente, fornecendo informações relevantes ao entendimento da evolução do gênero ao longo do Cenozóico. Foi identificada sua ampla tolerância batimétrica (entre $10 \mathrm{e}$ 500 metros de profundidade; veja TOMMASI, 1970; KoWALEWSKI et al., 2002), além de sugerir que a abundância dessa espécie estaria ligada à presença de sedimentos dominados por carbonatos biogênicos (KoWALEWSKI et al., 2002). Ainda, essa ocorrência foi considerara anômala pelos pesquisadores, uma vez que a espécie é encontrada em uma zona de clima tropical o que pode ser parcialmente explicado pela influência de águas frias na plataforma externa decorrentes de ressurgência (veja CAmpos et al., 1995, 2000; KowALEWSKI et al., 2002).

Fazendo o confronto entre as informações trazidas por MANCENIIDO \& GRIFFIN (1988) e por KoWALEWSKI et al. (2002), pode-se observar que a fauna de braquiópodes brasileira pode ser um produto da migração para o norte de formas endêmicas (e.g., Bouchardia) e cosmopolitas (e.g., Terebratulina) durante o Cenozóico, talvez facilitada pela ocorrência de zonas de ressurgência ao longo da costa (SIMÕES et al., 2004). No entanto, torna-se necessário avaliar a interferência das correntes de ressurgência também nas etapas intermediárias de deslocamento, não descartando a interferência de outros fatores ambientais (e.g., temperatura geral da água, tipos substrato) como mediadores da distribuição. Para tanto há sempre que se considerar a paleogeografia da região, com influência direta nos padrões de circulação atmosférica e oceânica, no clima e condições ambientais locais. Infelizmente, até o momento, com base no material analisado e na literatura examinada, não foi possivel estabelecer uma proposta satisfatória para explicar essa distribuição, sendo relevante o fato de que os dados existentes atualmente para os grupos ainda apresentam lacunas importantes sobre sua distribuição global ou regional. 


\section{CONCLUSÕES}

As principais contribuições gerais do presente estudo dizem respeito a: a) melhoria e ampliação do conhecimento morfológico das espécies atribuídas ao gênero Bouchardia, b) reunião e organização das informações morfológicas disponíveis e dispersas na literatura, sobre os gêneros e espécies de Bouchardiinae e Anakineticinae, c) proposição de uma hipótese filogenética para esse grupo, e d) reavaliação do contexto evolutivo e paleozoogeográfico que os cerca.

Assim, dentro desses contextos gerais as seguintes conclusões puderam ser obtidas:

1- a análise morfológica interna e externa de conchas de braquiópodes fósseis e viventes pode sim fornecer dados morfológicos adequados a uma análise cladística; 2- existem 2 clados distintos na hipótese de trabalho. Um deles reúne todos os táxons atribuídos aos Bouchardiinae (grupo interno). O outro clado reúne as espécies de Anakineticinae, incluindo Australiarcula artesiana, esclarecendo a questão detectada nas propostas de classificação (RICHARDSON, 1994; MACKINNON \& LEE, no prelo) quanto a posição de Australiarcula;

3- a condição dos táxons Australiarcula, Bouchardia, Bouchardiella, Malleia e Neobouchardia, enquanto gêneros válidos e distintos entre si, foi reavaliada, tendo sido proposta a sinonímia entre Bouchardiella e Neobouchardia, em favor da primeira, apoiado na topologia obtida e no registro estratigráfico;

4- Bouchardia rosea e Bouchardia transplatina não apresentaram diferenças significativas com relação às características morfológicas analisadas. Somando-se a isso, sua posição na topologia obtida (Figura 20b) sugere que os dois táxons correspondem à mesma espécie, devendo, portanto, serem colocadas em sinonímia, em favor de Bouchardia rosea (Mawe), 1823;

5- os Bouchardiinae tiveram seu monofiletismo corroborado mas, no entanto, com uma composição diferente daquela proposta por MACKINNON \& LEE (no prelo), confirmando a presença de Australiarcula entre os Anakineticinae, como sugerido por RICHARDSON (1994); 
6- foram confirmadas as 3 sinapomorfias do grupo já sugeridas pela literatura, isto é, o espessamento posterior da concha, o processo cardinal em forma de ' $V$ ' invertido e o braquídio incompleto, além de terem sido apresentadas algumas sinapomorfias novas; 7- a topologia obtida não deixa dúvidas e suporta a sugestão existente na literatura de que Bouchardia rosea e Anakinetica cumingi apresentam morfologia semelhante por compartilharem modos de vida semelhantes (homoplasia) e não por parentesco próximo;

8- os resultados sugerem como proposta de classificação mais adequada para os Bouchardiinae aquela formulada por RICHARDSON (1994) que os considera grupo independente e distinto de outros Terebratellidae, na Subfamília Bouchardiinae. Contudo, deve ser levado em consideração o comentário de BRUNTON (1996), segundo - qual a Subfamília Bouchardiinae não estaria satisfatoriamente posicionada na Família Terebratellidae, a julgar por particularidades morfológicas. Dessa forma poderia constituir uma nova família (i.e., Família Bouchardiidae) concordando, neste ponto, com a classificação proposta por MACKINNON \& LEE (no prelo);

9- houve o resgate de parte da história evolutiva dos Bouchardiinae, a despeito de importantes lacunas temporais e espaciais no registro fossilifero do grupo, sobretudo na Antártica e Austrália, complementada com informações paleoambientais diversas, ligadas às mudanças ambientais que tiveram curso durante o Cenozóico;

10- houve a evolução em paralelo de dois grupos de Bouchardinae, um deles, de duração mais curta e restrito à Austrália e Nova Zelândia, formado por Bouchardiella cretacea, Neobouchardia minima e Malleia portlandica, e outro que persiste até hoje e vem se desenvolvendo entre a Península Antártica e a costa leste da América do Sul, formado por Bouchardiella patagonica, Bouchardiella jorgensis e as espécies de Bouchardia. A separação inicial desses dois grupos está ligada, provavelmente à separação inicial dos continentes do Gondwana no Eocretáceo e alterações ambientais decorrentes dessa separação. No entanto, os motivos que governaram o fracasso da linhagem australiana no final do Plioceno e o sucesso da linhagem sul-americana até os dias atuais ainda permanece indeterminado;

11- especificamente sobre Bouchardia, foi confirmado o padrão geral de migração de suas espécies para o norte, como proposto por MANCEÑIDO \& GRIFFIN (1988). No entanto, informações importantes foram suprimidas quando da proposição daquele modelo. Isso diz respeito, principalmente, à migração de Bouchardia antarctica para o 
sul, indo se instalar no continente antártico (Península Antártica). Antes do surgimento desse táxon, duas espécies existiam no extremo sul do continente americano, sendo Bouchardia conspicua mais ao norte da costa Argentina, e Bouchardia exigua mais ao sul, na Terra do Fogo. Dessa forma, o modelo de "contínua migração das espécies para o norte, sem retenção de suas localidades prévias" estaria, em parte, descartado; 12- conforme ocorre com os braquiópodes do mundo todo, a determinação precisa dos fatores ambientais que governaram ou influenciaram a evolução e dispersão das espécies de Bouchardia, não se dá de maneira fácil. O parâmetro que permite maior especulação, acúmulo de informações e posterior extrapolação para outras espécies é Bouchardia rosea. Isso se dá pelo contexto em que esse táxon se apresenta, a) sendo o único representante vivo do gênero e entre os Bouchardiinae, b) encontrado em concentrações com grande número de indivíduos, chegando, em algumas delas, a dominar a comunidade bentônica em detrimento de bivalves e gastrópodes, c) não estar restrito a faixas estreitas e profundas do litoral, mas sim apresentando um amplo intervalo batimétrico o que permite observar suas respostas às diferentes profundidades e acompanhar seu comportamento e distribuição através de diferentes tipos de substratos. Com base nessas informações, em grande parte reunidas e analisadas pelo estudo completo realizado por KoWALEWSKI et al. (2002), os fatores ambientais mais relevantes na distribuição atual de Bouchardia rosea foram o tipo de substrato, com preferência por sedimento carbonático, e a associação com zonas de ressurgência na quebra da plataforma, fornecendo águas frias, oxigenadas e ricas em nutrientes dissolvidos. Dessa forma, assumindo-se essa preferência para as demais espécies do gênero, a investigação mais aprofundada da variação desses parâmetros ao longo da costa leste do extremo austral da América do Sul poderá ajudar a esclarecer alguns aspectos ainda obscuros da evolução do grupo, tais como, a ausência de registro de Bouchardiinae na Antártica e a extinção, ainda no Plioceno, do grupo na Austrália e Nova Zelândia;

13- esforços adicionais devem ser feitos, no entanto, para adaptar esse conhecimento adquirido com Bouchardia rosea, para os demais elementos do grupo, levando-se em conta as etapas intermediárias de migração identificadas dentro do padrão geral sugerido por MANCENIDO \& GRIFFIN (1988). Para tanto, maior conhecimento do registro fossilífero do grupo é indispensável, embora isso não seja possível de momento. 
Assim, poder-se-á confrontar essas informações com os dados ambientais e paleogeográficos já existentes para a regiäo e o período de tempo correspondente. 


\section{SUGESTÕES DE INVESTIGAÇÕES FUTURAS}

Como já salientado, os comentários que serão apresentados a seguir representam interpretações e sugestões oriundas dos resultados morfológicos e cladísticos obtidos no presente estudo e são apresentados com o intuito maior de melhorar o entendimento evolutivo sobre os Bouchardiinae. No entanto, qualquer que seja a abordagem sugerida ou desenvolvida, deve passar, inicialmente, por uma fase de trabalhos paleontológicos de base, compreendendo a coleta intensa e preparação de conchas. Essa etapa primordial tem a finalidade de ampliar as coleções científicas $e$ melhorar o controle estratigráfico do grupo, no tempo e no espaço. Isto se explica pois, apesar de terem sido examinados exemplares da maioria dos Bouchardiinae, depositados em diferentes coleções científicas (veja itens 4.1.1. e 4.1.2.; Anexo 1), o que se observa é que, com exceção de Bouchardia rosea, as coleções contêm um número reduzido de exemplares, muitos deles em péssimo estado de preservação e, raramente, com todos os estágios ontogenéticos representados. Dessa forma, seria possível uma melhor comparação entre dados biométricos ou morfológicos desses táxons, quer seja entre espécies ou entre gêneros, servindo de base para melhorar a diferenciação morfológica das espécies de Bouchardia além de testar e ampliar a análise cladística do grupo.

No contexto evolutivo, as sugestões de investigaçöes ulteriores ficam por conta dos ajustes entre os dados estratigráficos e as topologias obtidas pela análise cladística dos grupos (para esse contexto veja YoUNG, 1995; SIDDALL, 1998; WILLS, 1998; SMITH, 2000, 2002; POL \& NORELL, 2001; ALROY, 2002; WAGNER, 2002; FISHER et al., 2002). Seria interessante avaliar, por exemplo, a posição apical de espécies mais antigas (e.g., Bouchardia conspicua), bem como a posição basal de espécies mais novas (e.g., Malleia portlandica) e as possiveis correlações dessas ocorrências com a evolução e significado das estruturas morfológicas dentro do grupo. Obviamente, devemos esperar que este fato esteja sendo controlado por algum(ns) processo(s) evolutivo(s). Estaria aberta, assim a possibilidade de investigações sobre ocorrência de heterocronia, ou seja, um padrão evolutivo resultante de mudanças na taxa ou no tempo dos eventos ontogenéticos (FINK, 1982; MCKINNEY \& MCNAMARA, 1991; RACHEBOEUF \& GARCIA, 1996). Adicionalmente, um fato já vinha, há muito, sendo 
descrito na literatura mas nunca havia sido associado a nenhum processo evolutivo, até porque faltava a base cladística para discussão. Como comentado anteriormente, o braquidio axial de Bouchardia, é pequeno, incompleto e considerado imaturo, encontrando correspondente apenas nos estágios iniciais do desenvolvimento dos braquídios de outros Terebratellidae, sendo esta uma característica compartilhada por todos os Bouchardiinae (RICHARDSON, 1973b, 1975a; BRUNTON, 1996). Dessa forma, a evolução do grupo pode contar com eventos de heterocronia, os quais seriam devidamente identificados com abordagens mais completas. Situação semelhante pode estar acontecendo para os demais Terebratellidae mas, contudo, hipóteses filogenéticas mais completas para o grupo deverão ser produzidas para que haja a confirmação.

No campo das mudanças paleoambientais são sugeridas abordagens integradoras como aquelas apresentadas, por exemplo, por BUENING et al. (1998) e BRAND et al. (2003), utilizando ferramentas geoquímicas na análise de conchas das espécies de Bouchardia para avaliar as implicações dos resultados na compreensão da evolução dos parâmetros (paleo)oceanográficos, (paleo)ambientais e (paleo)zoogeográficos das diferentes regiões.

Dessa forma, as sugestôes apresentadas acima mostram possibilidades de interação entre os resultados de uma análise cladística, com bases morfológicas, e a detecção de eventos evolutivos na linhagem estudada. Reforça, dessa forma, a importância da utilização das informações cladísticas em abordagens mais amplas, envolvendo comparações com informações estratigráficas, biogeográficas, etc., avaliando se são consistentes com o conjunto de informações gerais, disponível para o grupo em estudo. A comprovação dessas correlações daria suporte à idéia de Fink (1982) de que as hipóteses filogenéticas têm papel importante na identificação de casos de heterocronia, haja vista que a maioria dos estudos nesse campo tem comparado mudanças na forma e tamanho dos organismos diretamente com os dados estratigráficos, sem um suporte cladístico. 
ANEXOS 
ANEXO 1- RELAÇÃO DOS ESPÉCIMES, FÓSSEIS E RECENTES, DEPOSITADOS EM COLEÇÕES CIENTIFICAS E EXAMINADOS NO PRESENTE ESTUDO, CONFORME DETALHADO NO TEXTO

\begin{tabular}{|c|c|c|c|c|c|}
\hline Instituicsa & Especie & $\begin{array}{l}\text { Numero de } \\
\text { exemplares }\end{array}$ & procedencia & ldade & $\begin{array}{l}\text { Número de } \\
\text { registro }\end{array}$ \\
\hline \multirow[t]{2}{*}{$\begin{array}{l}\text { Coleçäo Científica } \\
\text { DZP, IBB-UNESP }\end{array}$} & Bouchardia rosea & 11390 & $\begin{array}{l}\text { Projeto REVIZEE, } \\
\text { São Paulo, Rio de } \\
\text { Janeiro e Paraná }\end{array}$ & Recente & $\begin{array}{r}\text { DZP } 4000 \text { até } \\
\text { DZP } 15390\end{array}$ \\
\hline & Bouchardia rosea & 3292 & $\begin{array}{l}\text { Uhatuba (SP) e } \\
\text { Itha Grande (RJ) }\end{array}$ & Recente & $\begin{array}{r}\text { DZP } 16735 \text { até } \\
\text { DZP } 20026\end{array}$ \\
\hline \multirow[t]{3}{*}{$\begin{array}{l}\text { Coleção Cientifica, } \\
\text { DGSA, IGc-USP }\end{array}$} & Bouchardia rosea & 50 & $\begin{array}{l}\text { Santos (SP) e } \\
\text { Maricá (RJ) }\end{array}$ & Recente & $\begin{array}{r}190(2599) \\
221(1242), 234\end{array}$ \\
\hline & Bouchardia zitteli & 81 & $\begin{array}{l}\text { San Julián e } \\
\text { Manantial Salado, } \\
\text { Patagônia } \\
\text { Argentina }\end{array}$ & $\begin{array}{l}\text { Eoceno } \\
\text { mediol } \\
\text { superior }\end{array}$ & $\begin{array}{r}115(865), 154, \\
168(855) \\
195(864) \\
199(853) \\
218(851)\end{array}$ \\
\hline & Bouchardiella patagonica & 02 & $\begin{array}{l}\text { Goifo de San } \\
\text { Jorge, Argentina }\end{array}$ & $\begin{array}{l}\text { Cretáceo } \\
\text { superior }\end{array}$ & $204(850\rangle$ \\
\hline $\begin{array}{l}\text { Coleçäo de } \\
\text { Invertebrados } \\
\text { Fósseis, MN (RJ) }\end{array}$ & Bouchardia cf. zitteli & 03 & Pelotas (RS) & Eoceno & $5065-1$ \\
\hline $\begin{array}{l}\text { Coleção de } \\
\text { Invertebrados } \\
\text { Fósseis, }\end{array}$ & Bouchardia conspicua & 15 & $\begin{array}{l}\text { Santa Cruz, } \\
\text { Argentina }\end{array}$ & $\begin{array}{l}\text { Eoceno } \\
\text { médio }\end{array}$ & $\begin{array}{r}\text { CIRGEO, } \mathrm{Pln}^{\circ} \\
2658\end{array}$ \\
\hline \multirow[t]{5}{*}{$\begin{array}{l}\text { MACN (Buenos } \\
\text { Aires), Argentina }\end{array}$} & Bouchardia transplatina & 11 & $\begin{array}{l}\text { Cerro Bautista, } \\
\text { Uruguai }\end{array}$ & Mioceno & $45,46,4949$ \\
\hline & Bouchardia zitteli & 61 & $\begin{array}{l}\text { San Julián, } \\
\text { Argentina }\end{array}$ & Eoceno & $\begin{array}{r}41,42,43,44 \\
4946\end{array}$ \\
\hline & Bouchardia sp & 12 & $\begin{array}{l}\text { Santa Cruz, } \\
\text { Argentina }\end{array}$ & Eoceno & $\begin{array}{r}\text { CIRGEO, } \mathrm{PIn}^{\circ} \\
2270,2302 \\
2319\end{array}$ \\
\hline & Bouchardiella jorgensis & 22 & $\begin{array}{l}\text { Golfo de San } \\
\text { Jorge, Argentina }\end{array}$ & Mioceno & 02,4948 \\
\hline & Bouchardiella patagonica & 29 & $-\cdots$ & $-\ldots$ & $-\cdots-{ }_{-1}$ \\
\hline $\begin{array}{l}\text { Coleção de } \\
\text { Invertebrados } \\
\text { Fósseis, }\end{array}$ & Bouchardia antarctica & 19 & $\begin{array}{l}\text { Isla Marambío, } \\
\text { Antártica }\end{array}$ & $\begin{array}{l}\text { Eoceno } \\
\text { Oligoceno }\end{array}$ & $\begin{array}{r}12914,12949 \mathrm{a}- \\
b\end{array}$ \\
\hline \multirow[t]{4}{*}{$\begin{array}{l}\text { MCN (La Plata), } \\
\text { Argentina }\end{array}$} & Bouchardia conspicua & 01 & $\begin{array}{l}\text { Santa Cruz, } \\
\text { Argentina }\end{array}$ & Paleoceno & CPI-MLP 21109 \\
\hline & Bouchardia zitteli & 09 & $\begin{array}{l}\text { Santa Cruz, } \\
\text { Argentina }\end{array}$ & $\begin{array}{l}\text { Eoceno } \\
\text { Oligoceno }\end{array}$ & $479 a-b$ \\
\hline & Bouchardiella patagonica & 41 & Chubut, Argentina & $\cdots$ & 777 \\
\hline & Magellania patagonica & 01 & Chubut, Argentina & $\begin{array}{l}\text { Terciário } \\
\text { inferior }\end{array}$ & 6369 \\
\hline
\end{tabular}




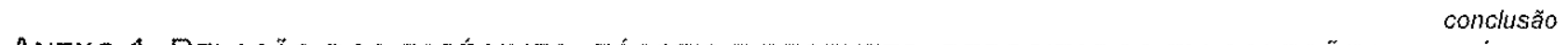

ANEXO 1- RELACAAO DOS ESPÉCIMES, FÓSSEIS E RECENTES, DEPOSITADOS EM COLEÇÓES CIENTIFICAS EEXAMINADOS NO PRESENTE ESTUDO, CONFORME DETALHADO NO TEXTO

\begin{tabular}{|c|c|c|c|c|c|}
\hline Mastangaro & Espocie & $\begin{array}{l}\text { Numaro ke } \\
\text { axemplares }\end{array}$ & Procederacia & dadace & $\begin{array}{l}\text { Numero de } \\
\text { registro }\end{array}$ \\
\hline \multirow[t]{4}{*}{$\begin{array}{l}\text { SAM (Adelaide), } \\
\text { Austrália }\end{array}$} & Australiarcula antesiana & 05 & Austrália do Sul & $\begin{array}{c}\text { Albiano } \\
\text { inferior } \\
\text { (Cretáceo) }\end{array}$ & $F 15276-15280$ \\
\hline & Anakinetica cumingi & 07 & $\begin{array}{l}\text { Grande Baía } \\
\text { Australiana, } \\
\text { Austrália do Sul }\end{array}$ & Recente & PLO136 \\
\hline & Magellania flavescens & 05 & $\begin{array}{l}\text { Babel Island, } \\
\text { Tasmânia }\end{array}$ & Recente & $\ldots$ \\
\hline & Terebratella sanguinea & 02 & Nova Zelândia & Recente & $L 16453$ \\
\hline \multirow[t]{2}{*}{$\begin{array}{l}\text { Otago University, } \\
\text { Nova Zelândia }\end{array}$} & Neobouchardia minima & 11 & $\begin{array}{l}\text { Weka Pass, Nova } \\
\text { Zelândia }\end{array}$ & Mioceno & DL98 \\
\hline & Terebratella sanguinea & 02 & $\begin{array}{l}\text { Oamaru, Nova } \\
\text { Zelândia }\end{array}$ & Recente & - \\
\hline
\end{tabular}

EXPLICAÇÃO-DZP, IBB-UNESP= Departamento de Zoologia, Coleção Paleontológica, Instituto de Biociências, UNESP, Campus de Botucatu; DGSA, IGc-USP= Departamento de Geologia Sedimentar e Ambiental, Instituto de Geociências, USP; MN (RJ)= Museu Nacional, Rio de Janeiro; MACN= Museo Argentino de Ciencias Naturales; MCN= Museo de Ciencias Naturales; CPI-MLP= Colección Paleontológica de Invertebrados, Muso de La Plata; SAM= Southern Australian Museum 
ANEXO 2- LISTA DE MUDANÇAS DOS CARACTERES NOS DIVERSOS CLADOS, RAMOS E TERMINAIS DO CLADOGRAMA ASSUMIDO COMO PROPOSTA DE TRABALHO

\begin{tabular}{|c|c|c|c|}
\hline Carater & $\mathrm{Cl}{ }^{*}$ & $N^{*}$ & Mudanças \\
\hline 1 & 1,000 & 1 & nó 33:0 $\Rightarrow 1:$ Bouchardia zitteli \\
\hline \multirow[t]{3}{*}{2} & 0,333 & 1 & nó $24: 1 \Rightarrow 0:$ nó 23 \\
\hline & & 1 & nó $39: 1 \rightarrow 0:$ nó 38 \\
\hline & & 1 & nó $37: 0 \rightarrow 1:$ nó 36 \\
\hline \multirow[t]{5}{*}{3} & 0,200 & 1 & nó 23:0 $\Rightarrow 1:$ Pirothyris vercoi \\
\hline & & 1 & nó 25: $0 \Rightarrow 1:$ Aliquantula insolita \\
\hline & & 1 & nó 27: $0 \Rightarrow 1:$ Elderra toorlooensis \\
\hline & & 1 & nó 35:0 $\Rightarrow 1:$ nó 34 \\
\hline & & 1 & nó $38: 0 \Rightarrow 1:$ nó 37 \\
\hline \multirow[t]{3}{*}{4} & 0,333 & 1 & nó 23:1 0: Pirothyris vercoi \\
\hline & & 1 & nó $28: 1 \Rightarrow 0:$ nó 27 \\
\hline & & 1 & nó 34: $1 \Rightarrow 0:$ nó 35 \\
\hline \multirow[t]{4}{*}{5} & 0,250 & 1 & nó $30: 1 \Rightarrow 0:$ nó 29 \\
\hline & & 1 & nó 23:0 $\Rightarrow 1:$ Adnatida deformis \\
\hline & & 1 & nó $35 ; 1 \Rightarrow 0:$ nó 34 \\
\hline & & 1 & nó 38: $1 \Rightarrow 0:$ nó 37 \\
\hline \multirow[t]{4}{*}{6} & 0,250 & 1 & nó $25: 0 \Rightarrow 1:$ Pilkena compressa \\
\hline & & 1 & nó 31: $0 \rightarrow 1:$ Australiarcula artesiana \\
\hline & & 1 & nó 35:0 $\rightarrow 1:$ nó 34 \\
\hline & & 1 & nó 33: $1 \rightarrow 0:$ nó 32 \\
\hline \multirow[t]{5}{*}{7} & 0,200 & 1 & nó 30: $1 \Rightarrow 0:$ nó 29 \\
\hline & & 1 & nó 24: $0 \Rightarrow$ 1: Magadina browni \\
\hline & & 1 & nó 25:0 $\Rightarrow 1:$ Aliquantula insolita \\
\hline & & 1 & nó $40: 1 \rightarrow 0:$ nó 30 \\
\hline & & 1 & nó $33: 0 \Rightarrow 1:$ Bonchardia zitteli \\
\hline \multirow[t]{4}{*}{8} & 0,250 & 1 & nó 30:0 $\Rightarrow 1:$ nó 29 \\
\hline & & 1 & nó 24: $1 \Rightarrow 0:$ Magadina browni \\
\hline & & 1 & nó 25: $1 \Rightarrow 0:$ Pilkena compressa \\
\hline & & 1 & nó 40:0 $\Rightarrow 1:$ Malleia portlandica \\
\hline \multirow[t]{2}{*}{9} & 0,500 & 1 & nó $31: 1 \Rightarrow 0:$ nó 30 \\
\hline & & 1 & nó 28:0 $\Rightarrow 1:$ nó 24 \\
\hline \multirow[t]{5}{*}{10} & 0,400 & 1 & nó $41: 0 \rightarrow 1:$ nó 31 \\
\hline & & 1 & nó 23: I $\Rightarrow 2:$ Adnatida deformis \\
\hline & & 1 & nó 24: $1 \Rightarrow 2$ : Magadinella woodsiana \\
\hline & & 1 & nó $30: 1 \rightarrow 0:$ Parakinetica stewarti \\
\hline & & 1 & nó 36:0 $\Rightarrow 1:$ Neobouchardia minima \\
\hline \multirow[t]{4}{*}{11} & 0,750 & 1 & nó $41: 0 \rightarrow 2:$ nó 31 \\
\hline & & 1 & nó $26: 2 \Rightarrow 1:$ nó 25 \\
\hline & & 1 & nó $40: 0 \rightarrow 3:$ nó 39 \\
\hline & & 1 & nó $36: 3 \Rightarrow 2$ : Bouchardiella patagonica \\
\hline \multirow[t]{2}{*}{12} & 0,500 & 1 & nó 23:0 $\Rightarrow 1:$ Adnatida deformis \\
\hline & & 1 & nó 40:0 0 1: Malleia portlandica \\
\hline 13 & 1,000 & 1 & nó 29:0 $\Rightarrow 1:$ Anakinetica cumingi \\
\hline 14 & 1,000 & 1 & nó $30: 1 \Rightarrow 0:$ nó 29 \\
\hline
\end{tabular}


ANEXO 2- LISTA DE MUDANÇAS DOS CARACTERES NOS DIVERSOS CLADOS, RAMOS E TERMINAIS DO CLADOGRAMA ASSUMIDO COMO PROPOSTA DE TRABALHO

\begin{tabular}{|c|c|c|c|}
\hline 15 & 0,500 & $\begin{array}{l}1 \\
1\end{array}$ & $\begin{array}{l}\text { nó } 41: 0 \rightarrow 1: \text { nó } 40 \\
\text { nó } 35: 1 \rightarrow 0: \text { nó } 34\end{array}$ \\
\hline 16 & 0,667 & $\begin{array}{l}1 \\
1 \\
1\end{array}$ & $\begin{array}{l}\text { nó } 31: 0 \rightarrow 2: \text { Australiarcula artesiana } \\
\text { nó } 41: 0 \rightarrow 1: \text { nó } 40 \\
\text { nó } 36: 1 \Rightarrow 0: \text { Neobonchardia minima }\end{array}$ \\
\hline 17 & 1,000 & 1 & $\begin{array}{l}\text { nó } 28: 0 \Rightarrow 2: \text { nó } 27 \\
\text { nó } 31: 0 \gg 1: \text { Australiarcula artesiana }\end{array}$ \\
\hline 18 & 0,500 & 1 & $\begin{array}{l}\text { nó } 23: 1 \Rightarrow 0: \text { Pirolhyris vercoi } \\
\text { nó } 27: 1 \Rightarrow 0: \text { nó } 26\end{array}$ \\
\hline 19 & 1,000 & 1 & nó 24:0 $\Rightarrow 1:$ Magadinella woodsiana \\
\hline 20 & 1,000 & 1 & nó 29:0 $\rightarrow 1:$ nó 28 \\
\hline 21 & 0,333 & $\begin{array}{l}1 \\
1 \\
1\end{array}$ & $\begin{array}{l}\text { nó } 41: 0 \rightarrow 1: \text { nó } 31 \\
\text { nó } 30: 1 \rightarrow 0: \text { Parakinetica stewarti } \\
\text { nó } 39: 0 \rightarrow 1: \text { nó } 35\end{array}$ \\
\hline 22 & 0,500 & 1 & $\begin{array}{l}\text { nó } 25: 0 \Rightarrow 1: \text { Aliquantula insólita } \\
\text { nó } 40: 0 \Rightarrow 1: \text { Malleia portlandica }\end{array}$ \\
\hline 23 & 1,000 & 1 & nó 28: $1 \rightarrow 0:$ nó 27 \\
\hline 24 & 1,000 & 1 & nó 31:0 $\rightarrow 1:$ nó 30 \\
\hline 25 & 0,500 & 1 & $\begin{array}{l}\text { nó } 28: 1 \Rightarrow 0: \text { nó } 27 \\
\text { nó } 40: 1 \Rightarrow 0: \text { nó } 39\end{array}$ \\
\hline 26 & 1,000 & 1 & nó 41:0 $\rightarrow 1:$ nó 31 \\
\hline 27 & 1,000 & 1 & nó 31: $1 \Rightarrow 0:$ Australiarcula artesiana \\
\hline 28 & 1,000 & 1 & nó $41: 0 \rightarrow 1:$ nó 31 \\
\hline 29 & 1,000 & 1 & nó 40:0 $\Rightarrow$ 1: Malleia portlandica \\
\hline 30 & 0,333 & $\begin{array}{l}1 \\
1 \\
1\end{array}$ & $\begin{array}{l}\text { nó } 24: 1 \Rightarrow 0: \text { Magadina browni } \\
\text { nó 25:1 } \Rightarrow 0: \text { Pilkena compressa } \\
\text { nó 30:1 } 1 \text { 0: Parakinetica stewarli }\end{array}$ \\
\hline 31 & 0,200 & $\begin{array}{l}1 \\
1 \\
1 \\
1 \\
1\end{array}$ & $\begin{array}{l}\text { nó 31:1 } \rightarrow 0: \text { nó } 30 \\
\text { nó 29:0 } \rightarrow 1: \text { Anakinetica cumingi } \\
\text { nó 26:0 } \Rightarrow 1: \text { Rhizothyris rhizoida } \\
\text { nó 33:1 } \rightarrow 0: \text { Bouchardia zilteli } \\
\text { nó 35:1 } \Rightarrow 0: \text { Bouchardia transplatina }\end{array}$ \\
\hline 32 & 1,000 & 1 & nó 41:0 $\rightarrow 1:$ nó 31 \\
\hline 33 & 1,000 & 1 & nó 39:0 $\Rightarrow 1:$ nó 35 \\
\hline 34 & 0,500 & $\begin{array}{l}1 \\
1\end{array}$ & $\begin{array}{l}\text { nó } 31: 1 \Rightarrow 0: \text { nó } 30 \\
\text { nó } 25: 0 \Rightarrow 1: \text { Aliquamtula insólita }\end{array}$ \\
\hline 35 & 0,500 & $\begin{array}{l}1 \\
1\end{array}$ & $\begin{array}{l}\text { nó } 41: 0 \rightarrow 1: \text { nó } 31 \\
\text { nó } 36: 0 \gg 1: \text { Neobouchardia minima }\end{array}$ \\
\hline 36 & 0,333 & $\begin{array}{l}1 \\
1 \\
1\end{array}$ & $\begin{array}{l}\text { nó } 29: 0 \Rightarrow 1: \text { nó } 28 \\
\text { nó } 23: 1 \Rightarrow 0: \text { Adnatida deformis } \\
\text { nó } 26: 1 \Rightarrow 0: \text { Rhizothyris rhizoida }\end{array}$ \\
\hline 37 & 0,500 & 1 & $\begin{array}{l}\text { nó 31:0 } \rightarrow 1: \text { Austratiarcula artesiana } \\
\text { nó } 40: 0 \rightarrow 1: \text { nó } 39\end{array}$ \\
\hline 38 & 1,000 & 1 & nó 39:0 0 1: nó 38 \\
\hline
\end{tabular}


ANEXO 2- LISTA DE MUDANÇAS DOS CARACTERES NOS DIVERSOS CLADOS, RAMOS E TERMINAIS DO CLADOGRAMA ASSUMIDO COMO PROPOSTA DE TRABALHO

\begin{tabular}{llll}
39 & 0,500 & 1 & nó $31: 0 \rightarrow 1:$ nó 30 \\
& & 1 & nó $29: 1 \rightarrow 0:$ Anakinetica cumingi \\
40 & 0,500 & 1 & nó $28: 1 \rightarrow 0:$ nó 24 \\
& 1 & nó $40: 1 \rightarrow 0:$ Malleia portlandica \\
\hline 41 & 1,000 & 1 & nó $24: 0 \rightarrow 1:$ Magadinella woodsiana \\
\hline 42 & 1,000 & 1 & nó $28: 0 \rightarrow 1:$ nó 24 \\
\hline 43 & 0,250 & 1 & nó $24: 1 \rightarrow 0:$ nó 23 \\
& & 1 & nó $27: 1 \rightarrow 0:$ nó 26 \\
& 1 & nó $30: 1 \rightarrow 0:$ Parakinetica stewari \\
& 1 & nó $40: 1 \rightarrow 0:$ nó 39
\end{tabular}

Explicação $\rightarrow$ significa incerteza na condição original; $\Rightarrow$ indica certeza quanto à condição original; $\Leftrightarrow$ condição no nó basal correspondente 
REFERENNCIAS BIBLIOGRÁFICAS 
ABREU, V.S.; ANDERSON, J.B. (1998) Glacial eustasy during the Cenozolc; sequence stratighaphic implications. American Association of Petroleum Geology Bulletin, v. 82, p. 1385-1400.

Aceñolaza, F.g.; Aceñolaza, G.F. (2000) Trazas fósiles del Terciario marino de Entre Rios (Formación Paraná, Mioceno Medio), República Argentina. Boletín de la Academia Nacional de Ciencias de Córdoba, v. 64. p. 209-233.

Addicot, W. (1969) Tertiary climatic change in the marginal northeast Pacific Ocean. Science, v. 165, p. $583-$ 586.

AgEr, D.V.; WALLEY, C.D. (1977) Mesozoic brachiopod migrations and the opening of the North Atlantio. Palaeogeography, Palaeoclimatology, Palaeoecology, v. 21, p. 85-99.

AgUIRRE, M.L. (1990) Holocene macrobenthic molluscan associations from northeastern Buenos Aires Province, Argentina. Quaternary of South America and the Antarctic Peninsula, v. 7, p. 161-195.

AgUIRRE, M.L. (1993a) Palaeobiogeography of the Holocene molluscan fauna from northeastern Buenos Aires Province, Argentina: its relation to coastal evolution and sea level changes. Palaeogeography, Palaeoclimatology, Palaeoecology, v. 102, p. 1-26.

AgurRe, M.L. (1993b) Caracterización faunistica del Quatemario marino en el noreste Bonaerense. Revista Asociación Geológica Argentina, v. 47, n. 1, p. 31-54.

AGUIRRE; M.L.; WHATLEY, R.C. (1995) The Mactracea, Telinacea and Myacea (Bivalvia) in the marine Holocene of northeastern Buenos Aires Province (Argentina, South America): indicators of environmental change Alcheringa, v. 19, p. 297.332

ALLAN, R.S. (1939) Studies on the Recent and Tertiary brachiopods of Australia and New Zealand. Part I. Record of the Canterbury Museum, v. 4, p. 231-253.

ALLAN, R.S. (1940a) A revision of the classification of the Terebratelloid Brachiopoda. Record of the Canterbury Museum, v. 4, p. 267-275.

ALLAN, R.S. (1940b) Studies on the Recent and tertiary Brachiopoda of Australia and New Zealand. Part ii. Records of the Canterbury Museum, v. 4, p. 277-298.

ALLAN, R.S. (1960) The succession of Tertiary brachiopod faunas in New Zealand. Records of the Canterbury Museum, v. 7, p. $233-268$

AlLMON, W.D. (1988) Ecology of Recent turritelline gastropods (Prosobranchia, Turritellidae): curren knowledge and paleontological implications. Palaios, v. 3, p. 259-284

AlLLMON, W.D. (1992) Role of temperature and nutrients in extinctions of turritelline gastropods: Cenozoic of the northwestern Atlantic and northeastern Pacific. Palaeogeography, Palaeoclimatology, Palaeoecology. v. 92, p. $41-54$

ALLMON, W.D. (1993) Age, environment, and mode of deposition of the densely fossiliferous Pinecrest Sand (Pliocene of Florida): implications for the role of biological productivity in shell bed formation. Palaios, $v$. 8, p. 183-201.

ALtivon, W.D. (2001) Nutrients, Temperature, disturbance, and evolution: a model for the late Cenozoic marine record of the western Atlantic. Palaeogeography, Palaeoclimatology, Palaeoecology, v. 166, p. 9-26.

Altimon, W.D.; Rosemberg, G.; PORTELL, R.G.; Schindler, K. (1993) Diversity of Pliocene to Recent Atlantic coastal plain mollusks. Science, v. 260, p. 1626-1628.

ALIMON, W.D.; MORRis, P.J.; MCKinneY, M.L. (1996a) An intermediate disturbance hypothesis of maximal speciation. In: MCKINNEY, M.L.; DRAKE, J.A. Biodiversity Dynamics: turnover of populations Taxä, and Cammunities. Columbia Universiły Press, New York, p. 349m376. 
ALLNON, W.D.; EMSLIE, S.D.; JONES, D.S.; MORGAN, G.S. (1996b) Late Neogene oceanographic change along Florida's west coast: evidence and mechanisms. Journal of Geology, v. 104, p. 143-162.

ALPoY, J. (2002) Stratigraphy in phylogeny reconstruction - reply to Smith (2002). Joumal of Paleontology, v. 76 , п. 4, p. $587-589$.

AMORIM, D.S. (1997) Elementos Basicos de Sistemática Filogenéłica. 2. ed. Ribeiräo Preto, Holos, Editora \& Sociedade Brasileira de Entomologia. 276p.

AMORIM, D.S. (1998) Before the matrix. In: MEETING OF THE WILLI HENNIG SOCIETY, 17., São Paulo, 1993. Programs and Abstracts. São Paulo, p. 4-5.

AMORIM, D.S. (2002) Fundamentos de Sistemática Filogenética. 1. ed. Ribeiräo Preto, Holos, Editora. 155p. ANDEl., T.; LABOREL, J. (1964) Recent high relative sea level stand near Recife, Brazil. Science, v. 145, n. 3632 , p. $580 m 581$.

ANDERSON, L.C. (2000) Temporal and geographic size trends in Neogene Corbulidae (Bivalvia) of tropical America: using environmental sensitivity to decipher causes of morphological trends. Palaeogeography, Palaeoclimatology, Palaeoecology, v. 166, p. 9-26.

ANDERSON, J.B.; SHipp, S.S. (2001) Evolution of the West Antarctic ice-sheet. In: ALLEY, R.Q.; BiNDSCHADLER, R.A. The West Antarctic Ice Sheet: Behavior and Environment. AGU Antarctic Research Series, $v$. 77 , p. $45-58$

ANELLl, L.E. (1999) Invertebrados Neocarboníferos das formações Piauí (Bacia do Parnaíba) e Itaituba (Bacia do Amazonas): Taxonomia, Análise cladística das subfamílias Oriocrassatellinae (Crassatellacea, Bivalvia) e Neospiriferinae (Spiriferoidea, Brachiopoda). São Paulo, 184p. (Tese de Doutorado) - Instituto de Geociências, Universidade de São Paulo.

ANGlolini, L.; Balini, M.; Garzanti, E.; Nicora, A.; Tintori, A.; Crasquin, S.; Mutroni, G. (2003) Permian climatic and paleogeographic changes in Northern Gondwana: the Khui Formation of Interior Omar?. Palaeogeography, Paiaeoclimatology, Palaeoecology, v. 191, p. 269 300.

ARCHANGELSKY: S:; ROMERO, E. (1974) Pólen de gimnospermas (Coniferas) del Cretácico superior y Paleoceno de Patagonia. Ameghiniana, v. 11, n. 3, p. 217-236.

ARCHIE, J. (1985) Methods for coding variable morphological features for numerical taxonomic anaiysis. Systematic Zoology, v. 34, p. 326-345.

ARONSON, R.B.; BLAKE, D.B. (2001) Global cimate change and the origin of modem benthio communities in Antarctica. American Zoologist, v. 41, p. 27 39.

AsmUS, H.E.; PONTE, F.C. (1973) The Brazilian marginal basins. In: NAiRn, A.E.M.; StEhu, F.G. The ocean basins and margins. The South Atlantic. Plenum Press, New York, v. 1, p. 87-133.

Asmus, H.E; PORTo, R. (1972) Classificação das bacias sedimentares brasileiras segundo a tectônica de placas. In: CONGRESSO BRASILEIRO DE GEOLOGIA, 26., Belém, 1972. Anais. Belém, SBG, v. 2, p. $67 \times 90$.

Arkivs, D. (1959a) The growth stages of the lophophore and loop of the brachiopod Terebratalia transversa (Sowerby). Journal of Morphology, v. 105, n. 3, p. 401-426.

ATKins, D. (19596) The early growth stages and adult structure of the lophophore of Macandrevia cranium (Muller) (Brachiopoda, Dallinidae). Journal of the Marine Biological Association of the United Kingdom, v. 38, p. 335-350.

Ax, P. (1987) The Phylogenetic System: the systematization of organisms on the basis of their phylogenesis. Wiley, New York. 
AXELROO, D.; BAILEY, H. (1969) Palaeotemperature analysis of Tertary floras. Palaeogeography, Palaeoclimatology, Palaeoecology, v. 6, p. 163-195.

BÁEZ, A.M.; GASPARINI, Z. (1977) Origenes y evolución de los anfibios y reptiles del Cenozoico de América del Sur. Acta Geológica Lilloanensis, v. 14, p. 149-232.

Barbour WOOD, S.L.; KRAUSE, R.A.; KOWALEWSK, M.; WehmLler, J.F; SiMões, M.G.; GOOdFrIEND, G.A. (2003) A comparison of rates of time averaging between the bivalve Macoma cleryana and brachiopod Bouchardia rosea on a shallow subtropical shelf. In: THE GEOLOGICAL SOCIETY OF AMERICA ANNUAL MEETINS, 2003. Abstracts with Programs. GSA, v.35. p.273.

BARKER, P.F.; BurRelL, J. (1977) The opening of the Drake Passage. Marine Geology, v. 25, p. 15m34.

BARRON, J.; LARSEN, B.; BALDAUF, J.G. (1991) Evidence for late Eocene to early Oligocene Antarctic glaciation and observations on late Neogene glacial history of Antarctica: results from Leg 119. Proceedings ODP Scientific Results, v. 119, p. 869-891.

BASSET, M.G.; HOLMER, L.E.; POPOV, L.E.; LAURIE, J. (1994) Phylogenetic analysis and classification of the Brachiopoda - reply and comments. Lethaia, v. 26, p. 385-386

BEEcHER, C.․ (1891) Development of the Brachiopoda, Part!, Introduction. American Journal of Science (series 3), v. 41, p. 343-357.

BEECHER, C.E. (1895) Revision of the families of loop-bearing Brachiopoda. The development of Terebratalia obsoleta Dall. Transactions of the Connecticut Academy of Arts and Science, v. 9, p. 376 399.

BEECHER, C.E. (1897) Morphology of the brachia. Bulletin of the United States Geological Survey, v. $87, p$. $105-112$

BENEdetro, J.L. (2001) An early Ordovician (Arenig) brachiopod fauna from volcaniclastic rocks of western Puna, Argentina; paleoclimatic and paleogeographic implications. Ameghiniana, v. 38, n. 2, p. $131-146$.

BENEDETTO, J.L.; VACCAR!, N.E; CARRERA, M.G.; SANCHEz, T.M. (1995) The evolution of faunal provincialism in the Argentine Precordilera during the Ordovician: New evidence and paleogeographic implications. In: CoOper, J.D.; Drosser, M.K.; FInNEY, S.C. Ordovician Odyssey. Society of Economic Paleontologists and Mineralogists, Book, 77, p. 181-184.

BenedetTo, J.L.; SANChez, T.M.; CARRera, M.G.; Brussa, E.D.; SalAs, M.J. (1999) Paleontological constraints on successive paleogeographic positions of Precordillera terrane during the early Paleozoic. In: RAmos, $V$; Keppie, D. Gondwana-Laurentia commections before Pangea. USA, Geological Society of America, Special Paper. n. 336, p. 21-42

BENTLEY, M.J. (1999) Volume of Antarctic ice at the Last Glacial Maximum, and its impact on global sea level change. Quaternary Science Reviews, v. 18, n. 14, 1569-1595.

BERGREEN, W.A; KENT, D.V.; SWISHER, C.C.; AUBRY, M.P. (1995) A revised Cenozolc geochronology and ehronostratigraphy. In: BERGREEN, W.A.; KENT, D.V.; AUBRY, M.P.; HAROENBOL, J. Geochronology, Time scales and global stratigraphic Correlation. SEPM, Tulsa, p. 129-212.

Bertels, A. (1973) Bioestratigrafia del Cerro Bororó, Provincia del Chubut, República Argentina. In: CONGRESO GEOLÓGICO ARGENTINO, 5., 1973. Actas. v. 3, p. 71.90.

BERTELS, A. (1975) Ostracode ecology during the Upper Cretaceous and Cenozoic in Argentina. Bulletins of American Paleontology, v. 65, p. 317-351.

BERTELS, A. (1979) Paleogeografía de los foraminiferos del Cretácico superior y Cenozóico de América del Sur. Ameghiniana, v. 16, n. 3-4, p. 273-356 
Bertels, A. (1984a) Ciclos de disolución de foraminfferos planctónicos en el océano Atiantico Sudoccidentai Austral: significancia paleoceanográfica durante el Mioceno SLperior-Plioceno Inferior. In: CONGRESO LATINOAMERICANO DE PALEONTOLOGIA, 3., México, 1984. Actas. México, p. 524-546.

BERTELs, A. (1984b) Foraminiferos bentónicos del Neógeno del Océano Atlántico Sudoccidental Austral. Inferencias paleoctimáticas y paleoceanográficas. In: CONGRESO GEOLÓGICO ARGENTINO, 9., Bariloche, 1984. Actas. Bariloche, p. 455-474.

BERTEls, A.; Madeira-FalcetTA, M. (1977) Neogene Foraminifera-South Atlantic. In: Swain, F. Stratigraphic Micropaleontology of Allantic Basin and Bordarland. S. 1., 5. ed., p. 441.466.

BEU, A.G. (1974) Molluscan evidence of warm sea temperatures in New Zealand during Kapitean (late Miocene) and Waipipian (middle Pliocene) time. New Zealand Joumal of Geology and Geophysics, Letters to the Editor, v. 17, n. 2, p. 465-479.

BEU, A.G. (1975) Reply (to VELLA \& KENNETT, 1975). New Zealand Journal of Geology and Geophysics, Letters to the Editor, v. 18, n. 1, p. 198-202

BEU, A.G.; GRIFFIN, M.; MAXWELL, P.A. (1997) Opening of the Drake Passage gateway and Late Miocene to Pleistocene cooling reflected in Southem Ocean molluscan dispersal: evidence from New Zealand and Argentina. Tectonophysics, v. 281, p. 83-97.

BIANCH, L.A. (1969) Bancos de Ostreídeos pleistocênicos da Planície Costeira do Rio Grande do Sul. Iheringia, Geologia, v. 2, p. 3-40.

BIERnAT, G.; BIRKEnMAJER, K.; POPIEl-BARCzYK, E. (1985) Tertiary brachiopods from the Moby Dick Group of King George Island (South Shetland Islands, Antarctica). Studia Geologica Polonica, v. 81, p. 109-153.

BITNER, M.A. (1996) Brachiopods from the Eocene La Meseta Formation of Seymour Island, Antarctic Peninsula. In: GA'ZDZICKI, A. Paleontological Results of the Polish Antarctic Expeditions. Part H. Paleontographica Polonica, v. 55, p. 65-100.

BITNER, M.A.; CRAME, J.A. (2002) Brachiopods from the Lower Miocene of King George Island, West Antarctica. Polish Polar Research, v. 23, n. 1, p. 75-84.

BOHATY, S.M.; HARWOOD, D.M. (1998) Southern Ocean Pliocene paleotemperature variation from highresolution silicoflagellate biostratigraphy. Marine Micropaleontology, v. 33, p. 241-272.

BÖHME, M. (2003) The Miocene Climatic Optimum: evidence from ectothermic vertebrates of central Europe. Palaeogeography, Palaeoclimatology, Palaeoecology, v. 195, p. 389-401.

Boltovskoy, E. (1979) Paleooceanografia del Atlantico Sudoccidental desde el Mioceno, según estudios roraminiferologicos. Ameghiniana, v. 16, n. 3-4, p. 357-389.

Bol.tovskoY, E. (1980) The age of the Drake Passage. Alcheringa, v. 4, p. 289-297.

Bol.tovskoy, E. (1990) Late Pleistocene Holocene planktic foraminifera of the western equatorial Pacific. Boreas, v. 19 , p. $119-125$.

BONNER, W.N.; WALTON, D.W.H. (1985) Marine Habitats - Introduction. In: CRAME, J.A. Origins and Evolution of the Antarctic Biota. London, Geological Society Special Publication, n. 47 . p. $133-134$

Boulton, G.S. (1979) A model of Weichselian glacier fluctuations in the North Atiantic region. Boreas, v. $8, p$. 373-395

BOWEN, R. (1963) $0^{18} / 0^{16}$ paleotemperature measurements on Mesozoic Belemnoidea from Neuquén and Santa Cruz Provinces, Argentine. Journal of Paleontology, vol. 37, n. 3, p. 714-718.

BOWEN, Z.P. (1968) A guide to New Zealand recent brachiopods. Tuatara, v. 16, n. 2, p. 127-150. 
BRAND, U.; LOGAN, A.; HILLER, N.; RICHARDSON, J. (2003) Geochemistry of modem brachiopods: applications and implications for oceanography and paleoceanography. Chemical Geology, v. 198, p. 305-334.

BRENCHIEY, P. J; HARPER, D.A.T. (1998) Palaeoecology: Ecosystems, environments and evolution. 1 ed. New York, Chapman \& Hall. 402p.

Brochu, C.A.; SumRALL, C.D. (2001) Phylogenetic nomenclature and Paleontology. Joumal of Paleontology, v. 75, ก. 4, p. $754-757$.

BROOKS, D.R.; CAIRA, J.N.; PLATT, T.R.; PRITCHARD, M.H. (1984) Principles and methods of cladistic analysis: a workbook. University of Kansas, Museum of Natural History Speciai Publication 12.

BrownING, J.V.; MiLieR, K.G.; PAK, D.K. (1996) Global implications of lower to middle Eocene sequence boundary on the New Jersey coastal plain: The icehouse cometh. Geology, v. 24, p. 639-642.

BRUNTON, C.H.C. (1996) The functional Morphology of the Recent brachiopod Bouchardia rosea. Acta Eoologica (Stockholm), v. 77, n. 3, p. 233-240.

BRUNTON, C.H.C.; LAZAREV, S.S.; GRANT, R.E. (1995) A review and new classification of the brachiopod Order Productida. Palaeontology, v. 38, n. 4, p. 915 933

Brunton, C.it.C.; Alvarez, F: MACKinnon, D.l. (1996) Morphological tems used to describe the cardinalia of articulate brachiopods: homologies and recommendations. Historical Biology, v. 11, p. 9-41.

BRYANT, H.N. (2001) Character polarity and the rooting of cladograms. In: WAGNER, G.P. The character concept in evolutionary biology. San Diego, Academic Press. p. 315 338

BuckMAN, S.S. (1910) Antarctic Fossil Brachiopoda collected by the Swedish South Polar Expedition. Wissenschaftliche Ergebnisse der Schwedischen Suedpolar Expedition 1901-1903, Stockolm, v. 3, ก. 7, p. $1-40$.

BUDD, A.F.; JOHNSON, K.G. (1999) Origination preceding extinction during late Cenozoic tumover of Caribbean reefs. Paleobiology, v. 25 , p. $188-200$.

Buod, A.F.; JOHNSON, K.G.; STEMANN, T.A. (1996) Plio-Pleistocene turnover and extinctions in the Caribbean reef-coral fauna. In: JACKSON, J.B.C.; BUDD, A.F.; COATES, A.G. Evolution and Environment in tropical America. University of Chicago Press, Chicago, p. $188-204$.

BUENiNg, N.; CARLSON, S.J.; SPERO, H.J.; LEE, D.E. (1998) Evidence for the Early Oligocene formation of a proto-subtropical Convergence from oxygen isotope records of New Zealand paleogene brachiopods. Palaeogeography, Palaeochimatology, Palaeoecology, v. 138, p. 43-68.

BURCKLE, L.H.; MORTLOCK, R.; RUDOLPH, S. (1996) No evidence for extreme, long term warming in early Pliocene sediments of the Southern Oean. Marine Micropaleontology, v. 27, p. 1-4.

CAMACHO, H.H. (1966) Invertebrados. In: BORRELlo, A.V. Paleontografia Bonaerense. Comisión de Investigación Cientifica, Fasciculo ll, p. 1-160.

CAMACHO, H.H. (1967) Las transgressiones del Cretacico superior y Terciärio de la Argentina. Ameghiniana, v. 22, n. 4, p. 253-280.

CAmacho, H. H. (1969) La paleogeografia patagonica y la historia del Oceano Atantico. Ameghiniana, v. $24, n$. 4, p. $357-360$

CAMACHO, H.H.; CHIESA, J.O.; PARMA, S.G.; REICHzER, V. (2000) Invertebrados marinos de la Formación Man Aike (Eoceno Medio), Provincia de Santa Cruz, Argentina. Boletín de la Academia Nacional de Ciencias, Córdoba, v. 64, p. 187-208.

CAMPBELL, D.C. (2002) Paleontological and molecular evidence on bivalve phylogeny. In: THE GEOLOGICAL SOCIETY OF AMERICA ANNUAL MEETING, 2002. Abstracts with Programs. GSA, 2002, v.34. 
CAMPOS, E.J.D.; GONÇALVES, J.E.; IKEDA, Y. (1995) Water mass characteristics and geostrophic circulation in the South Brazil Bight: Summer of 1991. Journal of Geophysical Research, v. 100, p. 18537-18550.

CAMPOS, E.J.D.; VELHOT, D.; DA SILVEIRA, I.C.A. (2000) Sheif break upwelling driven by Brazil Current cyclonic meanders. Geophysical Research Letter, v. 27, p. 751-754.

CANTINo, P.D.; DE Queiroz, K. (2000) PhyloCode: a Phylogenetic Code of Biological Nomenclature. WWWhhome page, http://www.ohiou.edu/phylocode/.

CANTRIL, D.J. (2001) Early Oligocene nothofagus from CRP.3, Antarctica: implications for the vegetation history. Terra Antartica, v. 8, p. 401-406.

CARLSON, S.J. (1990) Phylogenetic relationships among brachiopod higher taxa. In: MACKINNON, D.I.; LEE, D.E.; CAMPBELL, J.D. Brachiopod Through Time. Rotterdam, A.A. Balkema. p. 3 10.

CAR!SON, S.J. (1992) Evolutionary trends in the articulate brachiopod hinge mechanism. Paleobiology, $v .18, n$. 3, p. $344-366$.

CARLSON, S.J. (1994) Investigating brachiopod phylogeny and classification - response to Popov et al. (1993). Lethaia, v. 26, p. 383-384.

CARLSON, S.J. (1995) Phylogenetic relationships among extant brachiopods. Cladistics, v. 11, p. $131-197$.

CARMO, D.A.; SANGUINETYI, Y.T. (1999) Taxonomy and palaeoceanographical significance of the genus Krithe (Ostracoda) in the Brazilian margin. Journal of Micropalaeontology, $v .18, \mathrm{p} .111-125$.

CARrEno, A.L.; COIMBra, J.C.; CARMO, D.A. (1999) Late Cenozoic sea level changes evidenced by ostracodes in the Pelotas basin, southermost Brazil. Marine Micropaleontology, v. 37, n. 2, p. 117-129.

CARROLL, M.; KOWALEWSK, M.; SIMÖEs, M.G.; RODLAND, D. (2003) Quantitative estimates of time-averaging in brachiopod shell accumulations. Paleobiology, v. 29, n. 3, p. 382-403.

CHANG, H.K.; KOWSMANN, R.O.; FIGUEIREDO, A.M.F. (1988) New concepts on the development of east Brazilian marginal basins. Episodes, v. 11, n. 3, p. 194-202.

ChAng, H.K.; Kowsmann, R.O.; Figueiredo, A.M.F.; Bender, A.A. (1992) Tectonics and stratigraphy of the East Brazil Rift system: an overview. Tectonophysics, v. 213, p. 97-138.

CHAPPIL, J. (1989) Quantilative characters in phylogenetic analysis. Cladistics, v. 5, p. 217-234.

CHEN, W.-J.; BONLLO, C.; LEOINTRE, G. (2003) Repeatability of clades as a criterion of reliability: a case study for molecular phylogeny of Acanthomorpha (Teleostei) with large number of taxa. Molecular Phylogenetics and Evolution, v. 26, p. 262-288.

CHOW, J.M.; BART, P.J. (2003) West Antarctic lce sheet grounding events on the Ross Sea outer continental shelf during the middie Miocene. Palaeogeography, Palaeocimatology, Palaeoecology, v. $198,0$. $169-186$.

CIESIELSKI, P.F.; SLITER, W.V.; WIND, F.H.; WISE JR., S.W. (1977) Paleoenvironmental analysis and correlation of a Cretaceous Islas Orcadas core from the Falkland Plateau, Southwest Atlantic. Marine Micropaleontology, v. 2, p. 27-34.

CIONE, A.L. (1978) Aportes paleoictiologicos al conocimiento de la evolution de las paleotemperaturas em el area austral de América del Sur durante el Cenozóico. Aspectos zoogeograficos y ecologicos conexos. Ameghiniana, v. 15, n. 1-2, p. 183-208.

ClaRK, C.; CURRAN, D.J. (1986) Outgroup analysis, homoplasy and global parsimony: a response to Maddison, Donoghue, and Maddison. Systematic Zoology, v. 35, p. 422-426.

GLARK, J.A.; FARREL, W.E.; PELTER, W.R. (1978) Global changes in postglacial sea level: a numerical calculation. Quatemary Researsh, v. 9, p. 265-287. 
CLARKE, A. (1993) Temperature and extinction in the sea: a physiologist's view. Paleobiology, v. 19, n. $4, p$. $499-518$.

CLARKE, A.; CRAME, J.A. (1989) The origin of the Southern Ocean marine fauna. In: CFAME, J.A. Origins and evolution of the Antarctic biota. Geological Society, Special Publication, v. 47, p. 1.322.

CLOSS, D. (1966) Cenozoic stratigraphy of Southern Brazil. Im: MICROPALEONTOLOGICAL COLLOQUUM OF WESTERN AFRICA, 2., Leiden. Proceedings. Leiden, 1966. p. 34-43.

CLoss, D. (1967) Miocene planktonic Foraminofera from Southern Brazil. Micropaleontology, v. 13, n. 3, p. 337-344.

Closs, D. (1970) Estratigrafia da Bacia de Pelotas. Meringia, n. 3, p. 3-76.

Closs, D. (1971) Fósseis cenozóicos da Bacia de Pelotas, RS. Arquivos do Museu Nacional, v. 54, p. 25-26.

COCOZZA, D.; CLARKE, C.M. (1992) Eocene micromplankton from La Meseta Formation, northern Seymour Island. Antarctic Sciences, v. 4, p. 355-362.

CODIGNOTTO, J.O.; AGUIRRE, M.L. (1993) Coastal evolution, changes in sea level and molluscan fauna in northeastern Argentina during the Late Quaternary. Marine Geology, v. 110, p. 163-175.

COHEN, B.L. (1992) Utitity of molecular phylogenetic methods: a critique of immuno taxonomy. Lethaia, v. $24, p$. 441-442.

COHEN, B.L. (1994) Immunomtaxonomy and the reconstruction of brachiopod phylogeny. Palaeontology, $v .37$, n. 4, p. $907-911$.

COHEN, B.L. (2000a) Monophyly of brachiopods and phoronids: reconciliation of molecular evidence with Linnaean classification (the Subphylum Phoroniformea nov.). Proceedings of the Royal Society of London, Series B Biology, v. 267, n. 1440, p. 225-231.

COHEN, B.L. (2000b) Brachiopod molecular phylogeny advances. In: THE MILLENIUM 8RACHIOPOD CONGRESS, London, 1999. Abstracts. London, s/p.

COHEN, B.L.; GAWTHFOP, A.; CAVALIERSMITH, T. (1998a) Molecular phylogeny of brachiopods and phoronids based on nuclear. encoded small subunit ribosomal RNA gene sequences. Philosophical Transactions Of The Royai Society Of London Series B-Biological Sciences, v. 353, n. 1378, p. 2039m2061.

COHEN, B.L.; STARK, S.; GAWTHROP, A.B.; BuRKE, M.E.; THAYER, C.W. (1998b) Comparison of articulate brachiopod nuclear and mitochondrial gene trees leads to a clade-based redefinition of protostomes (Protostomozoa) and deuterostomes (Deuterostomozoa). Proceedings of The Royal Society Of London Series B-Biological Sciences, v. 265, n. 1395, p. 475.482.

COLLINS, L.S.; COATES, A.G. (1999) A paleobiotic survey of Caribbean faunas from the Neogene of the Isthmus of Panama. Bulletins of American Paleontology, v. 357, p. 1-351.

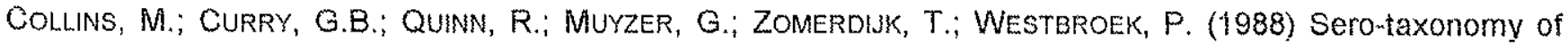
skeletal macromolecules in living terebratulid brachiopods. Historical Biology, v. 1, p. 207-224.

COLlins, M.; CURRY, G.B.; MUYZER, G.; QUIN, R.; XU, S.; WEstbroEk, P.; EWING, S. (1991) Immunological investigations of relationships within the Terebratulid brachiopods. Palaeontology, v. 34, n. 4, p. 785796.

Concherro, A. (†991) Nanofósiles eocenos de la Formación Man Aike (SE del lago Cardiel), Provincia de Santa Cruz, Argentina. Ameghiniana, v. 22, n. 3m. p. 385.390 .

COOPER, G.A. (1954) Recent brachiopods in Bikini and nearby atolls, Marshall Islands. United States Seological Survey Professional Papers, v. 260G, p. 315.318.

COOPER, G.A. (1970) Japanithyris is Campages. Journal of Paleontology, v. 44, p. 898-904. 
COOPER, G.A. (1973) Vema's Brachiopoda (Recent). Smithsonian Contributions to Biology, v. 17, p. 1-50.

COOPER, G.A. (1975) Brachiopods from West African waters with examples of collateral evolution. Journal of Paieontology, v. 49, n. 5, p. 911.927.

COOPER, G.A. (1977) Brachiopods from the Caribbean Sea, Gulf of México and adiacent waters. Studies of Tropical Oceanography, $v .14,0,1-211$.

COOPER, G.A. (1981) Brachiopoda from the southern Indian Ocean (Recent). Smithsonian Contributions to Biology, v. 43, p. 1.91.

COOPER, G.A. (1982) New brachiopods from the Southern Hemisphere and Cryptopora from Oregon (Recent). Smithsonian Contributions to Biology, v. 44, p. $1-42$.

COOPER, G.A.; DOHERTY, P.J. (1993) Calloria variegata, a new Recent species of brachiopod (Articulata: Terebratulida) from the northern New Zealand. Journal of the Royal Society of New Zealand, v. $23, n$. 3, p. 271-181.

COOPER, P.; JIN, J. (1996) Brachiopods. Rotterdan, A.A. Balkema. 373p.

COPPER, P. (1986) Filter-feeding and evolution in early spire-bearing brachiopods. In: RACHEBOEUF, P.R.; EMIG, C.C. Les Brachiopodes fossiles et actuels. Biostratigraphie du Paléozoique. Brest, v. 4, p. $219-230$. CORRÊA, I.C.S. (1979) Paleolinhas de costa na plataforma continental entre São Paulo e Santa Catarina. In: SIMPÓSIO REGIONAL DE GEOLOGIA, 2., Rio Claro, 1979. Atas. Rio Claro, v. 1, p. 269-278.

CORREA, I.C.S. (1990) Analyse morphostructurale et evolution palégeographique de la platemforme continentale Atlantique Sud Brésilienne (Rio Grande do Sul, Brésil). Bordeaux, 314p. (Tese de Doutorado) $=$ Universidade de Bordeaux, v. 1.

CORRÊA, I.C.S. (1996) Les variations du niveau de la mer durante les derniers 17.500 ans BP: l'exemple de la plate-forme continentale du Rio Grande do Sul, Brésil. Marine Geology, v. 130, p. 163-178.

CORREAA: I.C.S.; TOLDO JÚNIOR, E.E. (1996) The sea level stabilization in the Rio Grande do Sul continental shelf, Brazil. Anais da Academia Brasileira de Ciencias, v. 70, p. 213-219.

CRAIG, R.S. (1999a) Late Cretaceous brachiopods of the Perth and Carnarvon Basins, Western Australia. Records of the Westem Australian Museum, v. 19, p. 413-442.

CRAlG, R.S. (1999b) The brachiopod fauna of the Plio-Pleistocene Ascot Formation, Perth Basin, Western Australia. Records of the Western Australian Museum, v. 19, p. 451-464.

CRAIG, R.S. (2000) The Cenozoic brachiopods of the Carnarvon Basin, Western Australia. Palaeontology, $V$. 43, n. 1, p. $111-152$.

CrAiG, R.S. (2001) The Cenozoic Brachiopoda of the Bremer and Eucla Basins, southwest Western Australia. Records of the Western Australian Museum, v. 20, p. 199-236.

CRAME, J.A. (1992) Evolutionary history of the polar regions. Historical Biology, v. 6, p. 37 60.

CRAME, J.A. (1999) An evolutionary perspective on marine faunal connections between southernmost South America and Antarctica. Scientific Marine, v. 63, p. 1-14.

CRANE, P. (1985) Phylogenetic analysis of seed plants and the origin of angiosperms. Annals of the Missouri Botanical Garden, v. 72, p. $716 m 793$.

CRANSTON, P.; Humphries, C. (1988) Cladistics and computers: a chironomid conundrum? Cladistics, v. 4 , p. $72-92$.

CREER, K.M. (1973) A discussion of paleomagnetic poles on the map of Pangea for epochs in the Phanerozoic. In: CREER, K.M. Implications of Continental Drift to the Earth Sciences. v. 1, p. 47-76.

CROLAT, L. (1964) Space, time and form: The biological synthesis. Publicado pelo Autor, Caracas. 
CRONIN, T.M. (1985) Speciation and stasis in marine Ostracoda: climatic modulation of evolution. Science, $v$. 227, p. 60-63.

CRONIN, T.M.; DOWSET, H.J. (1993) Prism: warm climates of the Pliocene. Geotimes, v. 38, p. 17-19.

CRONIN, T.M.; IKEDA, N. (1990) Tectonic events and climatic change: opportunities for speciation in Cenozoic marine Ostracoda. In; Ross, R.M.; ALLMON, W.D. Causes of Evolution. A Paleontological Perspective. University of Chicago Press, Chicago, p. 210-248.

CRONIN, T.M.; SCHNEIDER, C.E. (1990) Climatic influences on species: evidence from the fóssil Record. Trends in Ecology and Evolution, v. 5, n. 9, p. 275-279.

CROWLEY, T.J. (1996) Pliocene climates: the nature of the problem. Marine Micropaleontology, v. 27, n. 1-4, p. $3-12$.

CURRY, G.B. (1982) Ecology and population structure of the recent brachiopod Terebratulina retusa from Scotland. Palaeontology, v. 25, n. 2, p. 227-246.

CURRY, G.B.; ENDO, K. (1991) Migration of brachiopod species in the North Atlantic in response to Holocene climatic change. Geology, v. 19, p. 1101-1103.

CURRY, G.B.; QUNN, R.; COLLINS, M.J.; ENDO, K.; EWING, S.; MUYZER, G.; WeSTBROEK, P. (1991) Immunological responses from brachiopod skeletal macromolecules; a new technique for assessing taxonomic relationships using shells. Lethaia, v. 24, p. 399-407.

DAEMON, R.F. (1969) Estudo bioestratigráfico preliminar efetuado em sedimentos neog enicos dos poços 2OS-1-RS (Palmares do Sul, RS), 2-MO-1-1RS (Mostardas, RS) e 2-Cl-1-RS (Cassino, RS) da Bacia de Pelolas, Rio Crande do Sul. Relatório n. 390, Petrobrás, Distrito de Exploração do Sul, 17p.

DALZIEL, W.D.; DE WIT, M.J.; PALMER, K.E. (1974) Fóssil marginal basin in the southern Andes. Nature, v. 250 , n. 5464, p. 291.294.

DAMBORENEA, S.E. (1993) Early Jurassic South American pectinaceans and circum-Pacific palaeobiogeography. Palaeogeography, Palaeoclimatology, Palaeoecology, v. 100, p. 109-123.

DAvidson, T. (1850) Description of a few recent species of Brachiopoda. Proceeding of the Zoological Society of London, v. 20, p. 75-82.

DAVIDSON, T. (1888) A monograph of recent Brachiopoda. Transactions of the Linnean Society of London, ser. 2, Zoology, v. 4, p. 1-230.

DAWSON, E.W. (1990) The systematics and biogeography of the living Brachiopoda of New Zealand. In: MACKInNon, D.I.; LEE, D.E.; CAMPBELL, J.D. Brachiopod Through Time. Rotterdam, A.A. Balkema. p.431-436.

DE QUeIROZ, K.; GAUTHIER, J. (1990) Phylogeny as a central principle in taxonomy: phylogenetic definitions of taxon names. Systematic Zoology, v. 39, p. 307-322.

DE QUeiroz, K.; GAUTHER, J. (1992) Phylogenetic taxonomy. Annual review of Ecology and Systematics, $v$. 23, p. $449-480$.

DE QUEIROZ, K.; GAUTHIER, J. (1994) Toward a phylogenetic system of biological nomenclature. Trends in Ecology and Evolution, v, 9, p. 27.31.

de santa Ana, H.; Veroslavsky, G.; Martínez, S.; Perea, D.; Ubilla, M. (1988) Estudio estratigráfico pretiminar de la Secuencia Mio-Pliocena del SW del Uruguay. In: PANEL DE GEOLOGÍA DEL LITORAL, 6.; REUNIÓN DE GEOLOGIA DEL URUGUAY, 1., Salto Uruguay, 1988. Anales. Salto Uruguay, p. 62. 67. 
DECONTO, R.M.; POLLARD, D. (2003) A coupled climate-ice sheet modeling approach to the Early Cenozoic history of the Antarctic ice sheet. Palaeogeography, Palaeoclimatology, Palaeoecology, v. 198, p. 3952.

DEl Rio, C.J. (1988) Bioestratigrafia y Cronoestratigrafía de la Formación Puerto Madryn (Mioceno medio), Provincia des Chubut - Argentina. Annales de la Academia Nacional de Ciencias Exactas, Físicas e Naturales de Buenos Aires, v. 40, p. 231-254.

DEL RiO, C.J. (1990) Composición, origen y significado paleoclimático de la malacofauna "Entrerriense" (Mioceno medio) de la Argentina. Annales de la Academia Nacional de Ciencias Exactas, Físicas e Naturales de Buenos Aires, v. 42, p. 205-224.

DEL RIO, C.J.; MARTinez, S.A.; SCASSO, R.A. (2001) Nature and origin of spectacular marine Miocene shell beds of northeastern Patagonia (Argentina): paleoceological and bathymetric significance. Palaios, v. 16, p. 3. 25.

Delaney, P.G.V. (1965) Fisiografia e Geologia da superficie da Planicie Costeira do Rio Grande do Sul. Publicação Especial da Escola de Geologia (UFRGS), v. 6, p. 1-105.

DELIBRAS, G.; LABOREL, J. (1971) Recent variations of sea-fevel along the Brazilian coast. Quatemaria, v. 10, p. $45-49$.

DEVEREUX, I. (1967) Oxygen isotope paleotemperature measurements on New Zealand Tertiary fossils. New Zealand Journal of Science, $v$. 10, p. 988-1011.

DEVEREUX, I. (1968) Oxygen isotope paleotemperatures from the Tertiary of New Zealand. Tuatara, v. 16, n. 1 , p. $41-45$.

Devereux, I.; Hendy, C.M.; Vella, P. (1970) Pliocene and Early Pleistocene sea temperature fluctuations, Magaopari Stream, New Zealand. Earth and Planetary Science Letters, v. 8, p. 163-168.

Diaz Martinez, E.; Mamet, B.; IsaAcson, P.E.; Grader, G.W. (2000) Permian marine sedimentation in northern Chile: new paleontological evidence from the Juan de Morales Formation, and regional paleogeographic implications. Journal of South American Earth Sciences, v. 13, n. 6, p. 511-525.

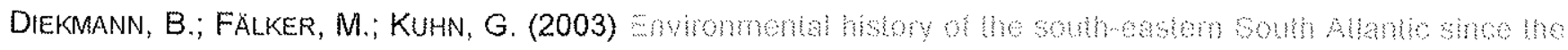

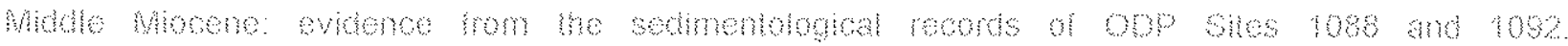

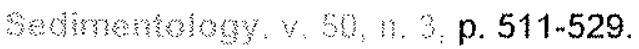

DINGLE, R.V.; MARENSSI, S.A.; LAVELLE, M. (1998) High latitude Eocene climate deterioration; evidence from the northern Antarctic Peninsula. Journal of the South America Earth Science, v. 11, p. 571-579.

DIVENERE, V.J.; KENT, D.V.; DALZIEL, I.W.D. (1994) Mid-Cretaceous paleomagnetic results from Marie Byrd Land, West Antarctica: a test of post-100 Ma relative motion between East and West Antarctica. Journal of Geophysical Research, v. 99, p. 15115-15139.

DIVENERE, V.J.; KENT, D.V.; DALZIEL, I.W.D. (1995a) Early Cretaceous paleomagnetic results from Marie Byrd Land, West Antarctica: implications for the Weddellia collage of crustal blocks. Journal of Geophysical Research, n. 100, p. 8133-8152.

DIVENERE, V.J.; KENT, D.V.; DALZIEL, I.W.D. (1995b) Tectonic implications of paleomagnetic results from Marie Byrd Land, West Antarctica. Antarctic Journal of the United States, n. 30.

DIVENERE, V.J.; KENT, D.V.; DALZIEL., I.W.D. (1996) Summary of paleomagnetic results from West Antarctica: implications for the tectonic evolution of the Pacific margin of Gondwana during the Mesozoic. In: STOREY, B.C.; KING, E.C.; LIVERMORE, R.A. Weddell Sea Tectonics and Gondwana Breakup. Geological Society of London Special Publication, n. 108, p. 31.43. 
DOEllo-JuRADO, M. (1922) Nota preliminar sobre braquiópodos fósiles de la Argentina referidos al género Bouchardia y sobre la posición del horizonte Salamanquense. Anales de la Sociedad Científica Argentina, v. 94, p. 197-204

DOHERTY, P.J. (1979) A demographic study of a subtidal population of the New Zealand articulate brachiopod Terebratella inconspicua. Marine Biology, y. 52, p. 331-342.

Donoghue, M.J.; CANTINO, P.D. 1984. The logic and limitations of the outgroup substitution approach to cladistic analysis. Systematic Botany, V. 9, p. 192\%202.

Donoghue, M.J.; DOYLE, J.; GAuThIER, J.; KLUge, A.; Rowe, T. (1989) The importance of fossils in phylogeny reconstruction. Annual Review of Ecology and Systematics, v. 20, p. 431-460.

DOUGL.AS, R.G.; SAVIN, S.M. (1975) Oxygen and carbon isotope analyses of Tertiary and Cretadeous microfossils from Shatsky Rise and other sites in the Northern Pacific Ocean. initial Reports of DSDP, $v$. 32. p. 509-520,

DOWSETT, H.; BARRON, J.; POORE, R. (1996) Middle Pliocene sea surface temperatures: a global reconstruction. Marine Micropaleontology, v. 27, n. 1-4, p. 13-25.

Dovle, J.A.; Donoghue, M.J. (1987) The importance of fossils in elucidating seed plant phylogeny and macroevolution. Reviews in Palaeobotany and Palynology, v. 50, p. 63-95.

DUTRA, T.L. (1997) Nothofagus leaf architeture, an old design to a new Gondwana: the use of the modern subtropical and temperate foliar character of the genus in paleoecology. In: CONGRESO GEOLOGICO CHILENO, 2., Valdivia, Chile, 1997. Programs and abstract. Valdivia, Chile, p. 189.

Dutra, T.L. (2000) Nothofagus no norte da Peninsula Antártica (ltha Rei George, llhas Shetland do Sul). II. Paleoceno superior-Eoceno inferior. Revista da Universidade de Guarulhos, Geociencias $\vee\left(n^{\circ}\right.$ especial), p. 131-136.

DUTRA, T.L.; BATTEN, D.J. (2000) Upper Cretaceous floras of King George Island, West Antarctica, and their palaeoenvironmental and phytogeographic implications. Cretaceous Research, v. 21, p. 181-209.

DUTRO JR., J.T.; BOARDMAN, R.S. (1981) Lophophorates: Notes for a Short Course. In: BROADHEAD, T.W. Studies in Geology. University of Tennessee, Department of Geological Sciences. v. $5,189 \mathrm{p}$.

ElDREDGE, N.; CRACRAFT, J. (1980) Phylogenetic patterns and the evolutionary process: method and theory in comparative Biology. Columbia University Press, New York.

Eluot, D.H. (1985) Physical Geography - Geologogical Evolution. In: CRAME, J.A. Origins and Evolution of the Antarctic Biota. London, Geological Society Special Publication, n. 47. p. 39-61.

ELLIOT, D.H. (1992) Jurassic magmatism and tectonism associated with Gondwanaland breakup: An Antarctic perspective. In: STOREY, B.C. Magmatism and the Causes of Continental Breakup. Geological Society of London Special Publication, n. 68, p. 165-184.

Elliort, G.F. (1947) The development of a British Aptian Brachiopod. Proceedings of the Geologist Association, v. 57, p. 144-159.

ELLIOTT, G.F. (1948) The evolutionary significance of brachial development in Terebratelloid brachiopods. Annals and Magazine of Natural History, v. 12, p. 297.317.

ELLIOTT, G.F. (1952) The internal structure of some Western Australian Cretaceous brachiopods. Journal of the Royal Society of Westem Australia, v. 36, p. 1-21.

ELLIOTT, G.F. (1953) Brachial development and evolution in Terebratelloid Brachiopods. Biological Review, v. 28, n. 3, p. $261-279$. 
ELLIOTT, G.F. (1960) A new Mesozoic Terebratellid brachiopod. Proceedings of the Geologist Association, $v$. 17, p. 25-30.

ELLIOT, G.F. (1965) Subfamilia Trigonoseminae Elliott, n. subfam. In: MOORE, R.C. Treatise on invertebrate Paleontology. Part H, Brachiopoda. The Geological Society of America and The University of Kansas Press. v. 2, p. 851-854.

ELLIOTT, G.F. (1976) Comments on the loop-development and the classification of terebratellacean brachiopods. Palaeontology, v. 19, n. 2, p. 413-414,

EL-SAYED, S.Z. (1985) Plankton of the Antarctic seas. In: CRAME, J.A. Origins and Evolution of the Antarctic Biota. London, Geological Society Special Publication, n. 47. p. 135-153.

EMIG, C.C. (1976) Le lophophore-structure significative des Lophophorates (Brachiopoda, Bryozoa, Phoronida). Zoologica Scripta, v. 5, p. 133-137.

EMIG, C.C. (1992) Functional disposition of the lophophore in living Brachiopoda. Lethaia, v. 25, p. 291-302.

ENDO, K. (2001) The phylogenetic position of brachiopods inferred from mitochondrial gene orders. In: BRUnTON, C.H.C.; COCKS, L.R.M.; LONG, S. Brachiopods, Past and Present. The Systematics Association, Special Volume Series, p. 63

ETHERIDGE, R. (1913) The Cretaceous fossils of Gingin 'Chalk'. Bulletin of the Geological Survey of Western Australia, v. 55, p. 9.34

EXoN, N. F.; KENNETT, J. P.; MALONE, M. J. (2000) Evolutionary and climatic consequences of opening the Tasmanian Seaway; results from ocean drilling. Geological Society of Australia, v. 59, p. 146.

FAIRBRIDGE, R.W. (1961) Eustatic changes in sea level. Physics and chemistry of the Earth, v. 4, p. 99-185. FAIRBRIDGE, R. (1967) Carbonate Rocks and Paleoclimatology in the biochemical history of the Planet. In: CHILINGER, V. Development in Sedimentology 9A: Carbonate Rocks, Origin, Ocurrence and Classification. Elsevier Publication Company, Amsterdam.

FARRIS, J.S. (1982) Outgroups and parsimony. Systematic Zoology, v. 31, p. 328-334.

FAsAno, J.; IsLA, F.; MOOK, W.; VANDE Plasche, O. (1987) Máximo transgressivo postglacial de 7000 años em Quequén, Província de Buenos Aires. Revista Asociación Geológica Argentina, v. 42, n. 3-4, p. 475. 477.

Feary, D.A.; Davies, P.J.; PIgran, C.J.; Symonds, P.A. (1991) Climatic evolution and control on carbonate deposition in northeast Australia. Palaeogeography, Palaeoclimatology, Palaeoecology, v. 89, p. 341 361.

FELdMAnn, R.M.; ChapMan, R.E.; HANNBAL, J.T. (1989) Paleotechniques. The Paleontological Society, Special Publications. v. 4, 358p.

FERNANDES, J.M.G. (1975) O gênero Uvigerina (Foraminiferida) do Cenozóico Superior da Eacia de Pelotas, Rio Grande do Sul, Brasil. Porto Alegra, 122p. (Dissertação de Mestrado) - Universidade Feredal do Rio Grande do Sul.

FerRARezZI, H.; MARQUes, A.C. (1997) Análise cladística numérica e recursos computacionais. In: AmORIM, D.S. Elementos Básicos de Sistemática Filogenética. 2. ed. Holos, Editora \& Sociedade Brasileira de Entomologia. p. 163-180.

Feruguo, E. (1935) Relaciones estratigráficas y faunisticas entre los estratos cretácicos y terciarios em la region del lago Argentino y em la del Golfo San Jorge (Patagonia). Boletín de Informaciones Petroleras (Buenos Aires), v. 128, p. 69-93.

Feruglio, E. (1949) Descripción geológica de la Patagonia. Buenos Aires, Dir. Gen. Y.P.F.(I). 334p. 
Field, B.D.; CRUNowell, M.P.; KENNETT, J.P.; KING, P.R.; JONES, C.M.; SCOTT, G.H. (2002) The early middle Miocene paleoenvironmental setting of New Zealand. Revista Mexicana de Ciencias Geológicas, v. 19, n. 3, p. $242-251$.

Figueiras, A.; BrogGl, J. (1972) Estado actual de nuestros conocimientos sobre los moluscos fosiles del Uruguay. Parte Ill (Continuación), Comunicaciones de la Sociedad Malacológica del Uruguay, v. $3, n$. 21, p. 131-154.

Figueiras, A.; Martinez, S.A. (1995) Nueva especie de Glottidia (Braquiopoda, Lingulidae) del Mioceno (Formación Camacho) del Uruguay. Ameghiniana, v. 32, p. 385-390.

FINK, W.L. (1982) The conceptual relationship between ontogeny and phylogeny. Paleobiology, $v, 8, p .25$ A.. 264.

Fisher, A.; ARTHUR, M. (1977) Secular variations in the pelagic realm. In: Cook, H. et al. Deep-water carbonate environments. Society of Economic Paleontologists and Mineralogists, v. 25.

FISHER, D.C.; FOOTE, M.; FOX, D.L.; LEIGHTON, L.R. (2002) Stratigraphy in phylogeny reconstruction - comment on Smith (2002). Journal of Paleontology, v. 76, n. 4, p. 585-586.

FLOWER, B.P.; KENNETT, J.P. (1994) The middle Miocene climatic transition: East Antarctic ice sheot development, deep ocean circulation and global carbon cycling. Palaeogeography, Palaeoclimatology, Palaeoecology, v. 108, p. 537-555.

FLOWER, B.P.; KENNETT, J.P. (1995) Middle Miocene deepwater paleoceanography in the southwest Pacific: relations with East Antarctic Ice Sheet development. Paleoceanography, v. 10, p. 1095-1112.

FONSECA, V.M.M. (2000) Braquiópodes. In: CARVALHO, I.S. Paleontologia. Rio de Janeiro, Editora Interciência. 1. ed, p. 365-386.

FONTANA, R.L. (1987) Desenvolvimento termomecânico da Bacia de Pelotas e parte sul da plataforma de Florianópolis. Ouro Preto, 128p. (Dissertação de Mestrado) - Universidade Federal de Ouro Preto.

FONTANA, R.L. (1990) Investigações geofísicas preliminares sobre o cone do rio Grande - Bacia de Pelotas Brasil. Acta Geológica Leopoldensia, São Leopoldo, v. 13, p. 161-170.

FOREY, P.L.; HUMPHRIES, C.J.; KITCHING, I.L.; SCOTLAND, R.W.; SIEBERT, D.J.; WILLIAMS, D.M. (1992) Cladistics. A practical course in systematics. Clarendon Press, Oxford.

FORTEY, R.A. (1990) Analysis of taxonomy and phylogeny. In: BRIGGS, D.E.G.; CROWTHER, P.R. Palaeobiology, a synthesis. Blackwell Science. p. 425-430.

FORTI-ESTEVES, I.R. (1968) Moluscos quaternários da Bacia de Pelotas (RS). Ciência a Cultura, v. 20, p. 155.

FORTiESTEVES, I.R. (1974) Bioestratigrafia e Paleoecologia (Mollusca) do Quaternário da planicie costeira do Rio Grande do SUl (Brasil). In: CONGRESSO BRASILEIRO DE GEOLOGIA, 28., Porto Alegre. Anais. Porto Alegre, SBG, v. 3, p. 133-149.

FOSTER, M.W. (1969a) Antarctic and Subantarctic brachiopods. Antarctic Journal of the United States, v. 4, h. 5, p. $1-191$.

FOSTER, M.W. (1969b) Brachiopoda. In: HEDGPETH, J.W.; BUSHNELL, V.C. Distribution of selected groups of marine invertebrates in waters south of $35^{\circ}$ S latitude. New, York, American Geographical Society. Antarctic Map Folio Series. folio 11, p. 21-22.

FosTER, M.W. (1974) Recent Antarctic and Subantarctic brachiopods. Antarctic Research Series, v. 21, p. 1. 189.

Foster, M.W. (1989) Brachiopods from the extreme South Pacific and Adjacent waters. Joumal of Paleontology, v. 63, n. 3, p. 268-301. 
FRAKES, L.A. (1979) Climate throughout Geologic Time. Elsevier, Amsterdam, 310p.

FRANCIS, J.E.; POOLE, I. (2002) Cretaceous and early Tertiary climates of Antarctica: evidence from fossil wood. Palaeogeography, Palaeoclimatology, Palaeoecology, v. 182, p. 47-64.

FURQUE, G.; CAMACHO, H.H. (1949) El Cretácico superior de la costa Atlántica de Tierra del Fuego. Revista de la Asociación Geológica Argentina, v. 4, n. 4, p. 263-289.

Gallagher, S.J.; Smith, A.J.; Jonasson, K.; Wallace, M.W.; Holdgate, G.R.; Daniels, J.; Taylor, D. (2001)

The Miocene palaeoenvironmental and palaeoceanographic evolution of the Gippsland Basin, Southeast Australia; a record of Southern Ocean change. Palaeogeography, Palaeoclimatology, Palaeoecology, V. 172, p. $53-80$.

Gallagher, S.J.; GreenWood, D.R.; Taylor, D.; Smith, A.J.; Wallace, M.W.; Holdgate, G.R. (2003) The Pliocene climatic and environmental evolution of southeastern Australia: evidence from the marine and terrestrial realm. Palaeogeography, Palaeoclimatology, Palaeoecology, v. 193, p. 349-382.

GARCIA-ALCALDE, J.L. (1998) Paleogeographical dispersion of Spanish Lower Devonian rhynchonellids. In: INTERNATIONAL CONODONT SYMPOSIUM, ECOS Vil, $7 .$, Bologna, 1998. Abstracts. Bologna, p. 3941.

GASPARINI, Z.B.; BÁEZ, A.M. (1975) Aportes al conocimiento de la herpetofauna Terciária de la Argentina. In: CONGRESO ARGENTINO DE PALEONTOLOGIA Y BIOESTRATIGRAFIA, 1. Actas. v. 2, p. 377-416.

GAUTHEER, J.; KLUGE, A.; ROWE, T. (1988) Amniote phylogeny and the importance of fossils. Cladistics, v. 4, p. 105-209.

Gazdzicki A.; Gruszczynski, M.; Hoffman, A.; Malkowski, K.; Marenssi, S.A.; Hal.as, S.; Tatur, A. (1992) Stable carbon and oxigen isotope record in the Paleogene La Meseta Formation, Seymour Island, Antarctica. Antarctic Science, v. 4, n. 4, p. 461-468.

GILL, A.E.; BRYAN, K. (1971) Effects of geometry on the circulation of a three-dimensional southern hemisphere ocean model. Deep-sea Research, v. 18, p. 685-691.

GILMOUR, T.H.J. (1978) Ciliation and function of the food-collecting and waste-rejecting organs of lophophorates. Canadian Journal of Zoology, v. 56, p. 2142-2155.

GIRIBET, G.; WHEELER, W.C. (2002) On bivalve phylogeny: a high-level analysis of the Bivalvia (Mollusca) based on combined morphology and DNA sequence data. Invertebrate Biology, v. 121, p. 271-324.

GovignotTo, J.O.; AguiRRE, M.L. (1993) Coastal evolution, changes in sea level and molluscan fauna in northeastern Argentina during the Late Quatemary. Marine Geology, v. 110, p. 163-175.

GodolpHM, M.F. (1976) Geologia do Holoceno costeiro do municipio de Rio Grande, RS. Porto Alegre, 146p. (Dissentação de Mestrado) - Curso de Pós-graduação em Geociências, Universidade Federal do Rịo Grande do Sul.

Godol.pHIM, M.F. (1983) Geomorfologia dos cordões litorâneos regressivos de Rio Grande, RS. Pesquisas, Série Mapa, n. 12, sem número.

GodolPhim, M.F. (1985) Paleogeografia da região do Cassino no município de Rio Grande, Brasil. Pesquisas, V. 17, p. $233-254$

GOdOLPHIM, M.F.; ARTUSI, L.; DEHNHARDT, B.A.; VILLWOcK, J.A.; EsTEVES, I.R.F. (1989) Novas evidências da transgressão holocênica na porção média da planicie costeira do Rio Grande do Sul. Acta Geológica Leopoldensia, v. 12 , n. 29, p. 23-36.

GOMIDE, J. (1989) Bacia de Pelotas. Biocronoestratigrafia baseada em nanofósseis calcários. In: CONGRESSO BRASILEIRO DE PALEONTOLOGIA, 11., Curitiba, 1989. Anais. Curitiba, SBP, v. 1, p. 339.351. 


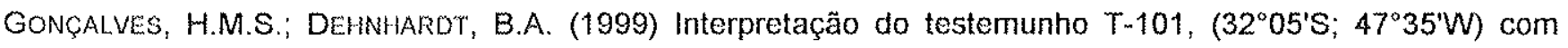
base em nanofósseis calcários - cone do Rio Grande, Rio Grande do Sul, Brasil. Revista Brasileira de Geociências, v. 29, n. 4, p. $527-532$.

GONZÁLEZ, M.A.; WELER, N.E. (1988) Late Pleistocene and Holocene coastal behaviour from $33^{\circ}$ to $40^{\circ}$ South, Argentine Republic. Joumal of Coastal Research, v. 4, n. 1, p. 59-68.

GoODWIN, 1. D. (1998). Did changes in Antarctic ice volume influence Late Holocene sea-level lowering? Quaternary Science Reviews, v. 17, p. 319.332

GORDILLo, S. (1998) Distribución biogeográfica de los moluscos Holocenos del litoral argentino-uruguayo. Ameghiniana, v. 35, p. $163-180$.

GORJANSKY, W.J.; POPOV, L.Y. (1986) On the origin and systematic position of the clacareous-shelled inarticulate brachiopods. Lethaia, v. 19, p. 233-240.

Goso, H.; Bossi, J.C. (1966) Cenozoico. In: Bossı, J.C. Geologia del Uruguay. Departamiento de Publicaciones, Universidade de la Republica, Montevideo, p. 259-305.

GRANDE, L.; BEMIS, W.E. (1998) A comprehensive phylogenetic study of amiid fishes (Amidae) based on comparative skeletal anatomy. An empirical search for interconnected patterns of natural history. woumal of Vertebrate Palaeontology, v. 18, n. 1-4, p. 1-69.

GRAYBEAL, A. (1998) is it better to add taxa or characters to a difficult phylogenetic problem? Systematic Biology, v. 47, p. $9-17$

GRUNOW, A.; KENT, D.; DALZIEL, I. (1991) New paleomagnetic data from Thurston Island: Implications for the tectonics of West Antarctica and Weddell Sea opening. Journal of Geophysical Research, v. $96, n$. B11, p. $17935-17954$.

GUNJI, Y. (1987) Metamorphosis of the loop in Cenozoic dallinacean brachiopods and is developmental constraint. Lethaia, v. 20, p. 239-255.

GUNJ, Y. (1990) The geometry of the loop and its morphogenetic field. In: MACKINNON, D.I; LEE, D.E.; CAMPBELL, J.D. Brachiopod Through Time. Rotterdam, A.A. Balkema. p.123-130.

HALh, S.A. (1977) Cretaceous and Tertiary dinoflagellates from Seymour Island, Antarctica. Nature, v. $267, n$. 5608 , p. 239-241.

HALLAM, A. (1988) The coniribution of palaeoniology to sysiematics and evolution. M: MAWKSWORTH, D.L. Prospects in Systematics. Systematics Association, Claredon Press, Oxford, p. 128-147.

Hallam, A. (1994) An outline of Phanerozoic Biogeography. In: HALLAM, A.; ROSEN, B.R.; WHITEMORE, T.C. Oxford Biogeography Series n. 10. Oxford University Press, Oxford.

HALLER, M.J. (1978) Estratigrafia de la región al poniente de Puerto Madryn, Provincia del Chubut, Republica Argentina. In: CONGRESO GEOLOGICO ARGENTINO, 7., Buenos Aires. Actas. Buenos Aires, 1978, p. 285-297.

HAMBREY, M.J.; LARSEN, B.; EHRMANiN, W.U. (1991) The glacial record from the Prydz Bay continental shelt, East Antarctic. In: BARRON, J.; LARSEN, B. Ocean Drilling Program Scientific Results 119, College Station, TX, p. 77.132.

HANGER, R.A. (1995) Geological area cladograms derived from parsimony analysis of endemism (PAE) for Permian brachiopods of Japan: significance for circum-Pacific paleogeography. In: ANNUAL MEETING OF THE GEOLOGICAL SOCIETY OF AMERICA, 27., Boulder, 1995. Abstracts with Programs. Boulder, n. 6, p. 53 
HANKEN, J. (1993) Model systems versus outgroups: alternative approaches to the study of head development and evolution. American Zoologist, v. 33, p. 448-456.

HANNAH, M.J.; WRENN, J.H.; WILSON, G.J. (2001) Preliminary report on Early Oligocene and ?Latest Eocene marine palynomorphs from CRP-3 drillhole, Victoria Land Basin, Antarctica. Terra Antartica, v. 8, p. 383388.

Harada, M.L;; Schneider, H.; Scheneider, M.P.C.; Sampalo, I.; Czelusniak, J.; Goodman, M. (1995) DNA evidence on the phylogenetic systematics of New World monkeys: support for the sistergroup of Cebus and Saimiri from two inlinked nucleas genes. Molecular Phylogenetics and Evolution, v. 22, p. 160. 174.

HATAI, K. (1940) The Cenozoic Brachiopoda of Japan. Tohoku Imperial University, Science Reports, ser. 2, Geology, v. 20, p. 1.413.

HEANEY, M.J. (1995) Phylogenetic analysis of pristinely preserved pennsylvanian pelecypods. In: CANADIAN PALEONTOLOGY CONFERENCE AND INTERNATIONAL SYMPOSIUM ON THE PALEOBIOLOGY AND EVOLUTION OF THE BIVALVIA, 15., Drumheller, 1995. Program and Abstracts. Drumheller, $p$. 14.

HENNIG, W. (1950) Grundzüge einer Theorie der phylogenestichen Systematik. Deutscher zentralverlag, Berlin. 370p.

HenNig, W. (1966) Phylogenetic systematics. Urbana, University of illinois Press, 263p.

HERBST, R.; ZABERT, L.L. (1987) Microfauna de la Formación Paraná (Mioceno superior) de la Cuenca ChacoParanense (Argentina). FACENA, v. 7, p. 165-206.

HERTEEIN, L.; GRANT, U.S. (1944) The Cenozoic Brachiopoda of western North America. California University at Los Angeles Publications, Mathematical-Physical Sciences, v. 3, p. 1-40.

Heydorn, A.E.F.; Bang, N.D.; Pearce, A.F.; Flemming, B.W.; Carter, R.A.; Schleyer, M.H.; Berry, F.P.; Hughes, G.R.; Bass, A.J.; Wallace, J.H.; VAN DER Elst, R.P.; CRAWFord, R.J.M.; SHELTON, P.A. (1978) Ecology of the Agulhas Current region: an assessment of biological responses to environmental parameters in the southwest Indian Ocean. Transactions of the Royal Society of South Africa, v. 43, p. 151-190.

HILdebrand-HABEL, T.; StRENG, M. (2003) Calcareous dinoflagellate associations and Maastrichtian-Tertiary climatic change in a high-latitude core (ODP Hole 689B, Maud Rise, Weddell Sea). Palaeogeography, Palaeoclimatology, Palaeoecology, v. 197, p. 293-321.

HILLER, N. (1988) The development of growth lines on articulate brachiopods. Lethaia, v. 21, p. 177-188.

HILLER, N. (1991) The southern African recent brachiopod fauna. In: MACKINNON, D.I.; LEE, D.E.; CAMPBELL, J.D. Brachiopods Through Time. Bakema, Rotterdam, p. 439-445.

HILLER, N. (1994a) The environment, biogeography, and origin of the Southern African Recent brachiopod fauna. Journal of Paleontology, v. 68, n. 4, p. 776-786.

HiLler, N. (1994b) The biogeographic relationships of the brachiopod fauna from Marion and Prince Edward Islands. South African Journal of Antarctic Pesearch, v. 24, n. 1-2, p. 67-74.

HILLIS, D.M. (1998) Taxonomic sampling, phylogenetic accuracy, and investigator bias. Systematic Biology, $V$. $47, p, 3-3$.

HhLIS, D.M.; BULL, J.J. (1993) An empirical test of bootstrapping as a method for assesing confidence in phylogenetic analysis. Systematic Biology, v. 42, p. 182-192. 
HILLIS, D.M.; HUELSENBECK, J.P.; CUNNINGHAM, C.W. (1994) Application and accuracy of molecular phylogenies. Science, v. 264, p. $671-677$.

HiNZ, K. (1981) A hypothesis on terrestrial catastrophes - wedges of very thick oceanward dipping layers beneath passive margins. Geol. Jahrb. Reine E, v. 22, p. 3-28.

HJORT, C.; BENTLEY, M.J.; INGOLFSSON, O. (2001) Holocene and premHolocene Temporary disappearance of the George VI Ice Shelf, Antarctic Peninsula. Antarctic Science, v. 13, n. 3, 296301.

HOLMER, L.E. (1991) Phylogenetic relationships within the Brachiopoda. Geologiska Föreningens i Stockolm Förhandlingar, v. 113, p. 84-86.

HOLMER, L.E. (2001) Phylogeny and classification: Linguliformea and Craniformea. The paleontological Society Papers, v. 7, p. 11-26.

HOLMER, L.E.; POPOV, L.E. (1997) Class Lingulata. In: KAESLER, R.L. Treatise on invertebrate Paleontology. Part H, Brachiopoda. Kansas, The Geological Society of America and The University of Kansas Press. V. 2, p. 30-146.

HOLMer, L.E.; POPOV, L.E.; BASSET, M.G.; LAURIE, J. (1995) Phylogenetic analysis and ordinal classification of the Brachiopoda. Palaeontology, v. 38, n. 4, p. 713.741

HUELSENBECK, J.P. (1991) When are fossits better than extant taxa in phylogenetic analysis? Systematic Zoology, v. 40, p. 458-469.

HUELSENBECK, J.P. (1995) The performance of phylogenetic methods in simulation. Systematic Biology, v. 44 , p. $17-48$.

HUELSENBECK, J.P.; HILLIS, D.M. (1993) Success of phylogenetic methods in the fourutaxon case. Systematic Biology, v. 42, p. 247-264.

HUTtON, F.W. (1873) Catalogue of the Tertiary Mollusca and Echinodermata of New Zealand, in the collection of the Colonial Museum. Wellington, Government Printer. 48p.

HUTTON, F.W. (1905) Revision of the Tertiary Brachiopoda of New Zealand. Transactions and Proceedings of the New Zealand Institute, v. 37, p. 474-481.

IMERING, H. VON (1897) Os molluscos dos terrenos Terciários da Patagonia. Revista do Museu Paulista, v. 2 , p. $217-382$.

IHERING, H. VON (1903) Les brachiopods Tentares de Patagonia. Annales del Museo Nacional de Buenos Aires, ser. 3A, v. 2, n. 321-349.

Hering, H. VON (1907) Les mollusques fossiles du tertiaire et du Crétacé supérieur de l'Argentina. Annales del Museo Nacional de Buenos Aires, ser. 3A, v. 7, p. 469-481.

IRIONDO, M.; Garcia, N. (1993) Climatic variations in the Argentine plains during the last 18,000 years. Palaeogeography, Palaeoclimatology, Palaeoecology, v. 101, p. 209-220.

JAANUSSON, V. (1971) Evolution of the brachiopod hinge. Smithsonian Contributions to Paleobiology, v. 3, p. 33-67.

JACKSON, J.B.C.; JUNG, P.; COATES, A.G.; COLLINS, L.S. (1993) Diversity and extinction of tropical American mollusks and emergence of the Isthmus of Panama. Science, v. 260, p. 1624-1626.

JACKSON, J.B.C.; BUDD, A.F.; COATES, A.G. (1996a) Evolution and environment in Tropical America. University of Chicago Press, Chicago, $425 p$.

JACKSON, J.B.C.; JUNG, P.; FORTUNATO, H. (1996b) Paciphilia revisited: tranisthmian evolution of the Strombina group (Gastropoda: Columbellidae). In: JACKSON, J.B.C.; BUDD, A.F.; COATES, A.G. Evolution and Environment in Tropical America. University of Chicago Pres, Chicago, p. 234-260. 
JACKSON, J.B.C.; TODD, J.A.; FORTUNATO, H.; JUNG, P. (1999) Diversity and assemblages of Neogene Caribbean Mollusca of lower Central America. A Paleobiotic Survey of Caribbean faunas from the Neogene of the isthmus of Panama. Builetins of Americam Paieontology, v. 357, p. 193-230.

JAECKS, G.S.; CARLSON, S.J. (2001) How phylogenetic inference can shape our view of heterochrony: examples from thecideide brachiopods. Paleobiology, v. 27, n. 2, p. 205-225.

James, M.A.; Ansell., A.D.; Collins, M.J.; CurRY, G.B.; POECK, L.S.; RHOdes, M.C. (1992) Biology of living brachiopods. Advances in Marine Biology, v. 28, p. 175-387.

JENKINS, D.G. (1968) Planktonic Foraminiferida as evidence of New Zealand Tertiary Paleotemperatures. Tuatara, v. 18, n. 1, 32-37.

JIN, J.S.; COOPER, P. (1997) Parastrophinella (brachiopoda): Its paleogeographic significance at the Ordovician/Silurian boundary. Joumal of Paleontology, v. 71 , n. 3, p. 369-380.

JOHNSON, J.G.; WESTBROEK, P. (1971) Cardinalia terminology of rhynchonellid brachiopods. The Geological Society of America Bulletin, v. 82, p. 1699-1702.

JOHNSON, K.G.; BUDD, A.F.; STEMANN, T.A. (1995) Extinction selectivity and ecology of Neogene Caribbean reef corals. Paleobiology, v. 21, n. 1, p. 1247-1268.

JONES, D.S.; ALLMON, W.D. (1995) Records of the upwelling, seasonaiity and growth in stable-isotope profiles of Pliocene mollusks shells from Florida. Lethaia, v. 28, p. 61-74.

JONKERS, H.A. (1998) Stratigraphy of Antarctic late Cenozoic pectinid-bearing deposits. Antarctic Sciences, $v$. 10, p. 161-170.

JONKERS, H.A. (2003) Late Cenozolc Recent Pectinidae (Mollusca: Bivalvia) of the southern Ocean and neighbouring regions. Monographies on Marine Mollusca, v. 5, p. 1-124.

JONKERS, H.A.; TAVANI, M. (1998) Lower Miocene macrofossils from CRP-1 drillhole, Cape Roberts (Victoria Land Basin, Antarctica). Terra Antartica, v. 5, p. 493-498.

JOPE, H.M. (1965) Composition of brachiopod shell. In: MOORE, R.C. Treatise on Invertebrate Paleontology. Part H, Brachiopoda. Kansas, The Geological Society of America and The University of Kansas Press. V. 1, p.156-164

Jost, H. (1971) O Quaternário da região norte da planicie costeira do Rio Grande do Sul, Brasil. Porto Alegre, 80p. (Dissertação de Mestrado) - Curso de Pós-graduação em Geociências, Universidade Federal do Rio Grande do Sul.

KEARNEY, M.; ClARK, J.M. (2003) Problems due to missing data in phylogenetic analyses including fossils: a critical review. Joumal of Vertebrate Paleontology, v. 23, n. 2, p. 263-274.

KELLLGG, K.S.; REYNoldS, R.L. (1978) Paleomagnetic results from the Lassiter Coast, Antarctica, and a test for oroclinal bending of the Antarctica Peninsula. Joumal of Geophysical Research, v. 83, n. B5, p. 22932299.

KELIY, D.C.; BRALONER, T.J.; ZAGHOS, J.C.; PREMOLI-SILVA, 1.; THOMAS, E. (1996) Rapid diversification of planktonic foraminifera in the tropical Pacific (ODP Site 865) during the late Paleocene Thermal Maximum. Geology, v. 24, N. 5, p. $423-426$.

KENNETT, J.P. (1967) Recognition and correlation of the Kapitean Stage (Upper Miocene, New Zealand). New Zeatand Joumal of Geology and Geophysics, v. 10, p. 1051-1063.

KENNETT, J.P. (1968) Paleo-oceanographic aspects of the foraminiferal zonation in the Upper Miocene-Lower Pliocene of New Zealand. Giomale di Geologia, Serie 2, v, 35, n. 2, p. 143-156. 
KENNETT, J.P. (1977) Cenozoic evolution and Antarctic glaciation, the Circum-Antarctic Ocean and their impact on global paleoceanography. Journal of Geophysics, v. 82, p. 3843-3860.

KENNETT, J.P. (1978) The development of planktonic biogeography in the Southern Ocean during the Cenozoic. Marine Micropaleontology, v. 3, n, 4, p. 301-345.

KENNETT, J.P. (1980) Paleoceanographic and biogeographic evolution of the southem ocean during the Cenozoic, and Cenozolc microfosil datums. Palaeogeography, Palaeoclimatology, Palaeoecology, v. 31, p. $123-152$.

KEnNETT, J.P. (1982) Marine Geology. Prentice-Hall, Englewood Cliffs, $813 p$.

KENNETT, J.P.; BARKER, P.F. (1990) Latest Cretaceous to Cenozoic climate and oceanographic developments in the Weddell Sea, Antarctica: an ocean drilling perspective. Proceedings of the ODP Scientific Results, v. 113, p. $937-960$.

KENNETT, J.P.; STOTT, L.D. (1991) Abrupt deep-sea warming, palaeoceanographic changes and benthic extinctions at the end of the Palaeocene. Nature, v. 353, p. 225-229,

KenNeTt, J.P.; WARNKE, D.A. (1992) The Antarctic Paleoenvironment, Pt. 2: A Perspective on Global Change (Antarctic Research Series, v. 60). American Geophysical Union, Washington, D.C.

Kennett, J.P.; Houtz, R.; Andrews, P.; Gostin, V.; Hajos, M.; Hampton, M.; Jenkins, D.; Margolis, S.; OVenshine, A.; Perch-Nielsen, K. (1974) Developmento of the Circun-Antarctic Current. Science, $v$. 186, p. 144-147.

Kennett, J.; Houtz, R.; Andrews, P.; Edwards, A.R.; Gostin, V.; Ha.jos, M.; Hampton, M.; Jenkins, D.; Margolis, S.; OVenshine, A.; PerchnNielsen, K. (1975) Cenozoic paleoceanography in the Southwest Pacific Ocean, Antarctic glaciation, and the development of the Circum-Antarctic Current. Initial Report of the DSDP, p. 1155-1169.

KLUGE, A.G. (1989) A concern for evidence and a phylogenetic hypothesis of relationships among Epicrates (Boidae, Serpentes). Systematic Zoology, v. 38, p. 7-25.

KOWALEWSKI, M.; SIMOEES, M.G.; FLESSA, K.W. (2000a) High-resolution records preserved in time-averaged shell assemblages: Holocene macrofauna as a toof for reconstructing recent history of coastal geosystems. Eos, Transactions, American Geophysical Union, v. 81, n. 19, p. 589.

Kowalewsk, M.; SIMŌEs, M.Q.; FLESSA, K.W. (2000b) Time-averaged bioclastic accumulations from modern coasts: multidisciplinary insights into ecological, environmental and climatic trends over recent millennia. In: ANNUAL MEETING OF THE GEOLOGICAL SOCIETY OF AMERICA, 32., Reno, 2000. Abstracts with Programs. Reno, v. 32, n. 2, p. A31.

KOWALEWSKI, M.; SIMÕES, M.G.; CARROL, M.; RODLAND, D.L. (2000c) Distribution of articulate brachiopods across a modern low-latitude shelf from the westem South Atlantic. In: ANNUAL MEETING OF THE GEOLOGICAL SOCIETY OF AMERICA, 32., Reno, 2000. Abstracts with Programs. Reno, v. 32, p. A96

KOWALEWSKI, M.; SIMÖES, M.G.; CARROLL, M.; RODLAND, D.L. (2002) Abundant brachiopod on a tropical upwellingunfluenced shelf (Southeast Brazilian Bight, South Alantic). Palaios, v. 17, p. 277-286.

KoWssmann, R.O.; Costa, M.P.A.; VicalVI, M.A.; Coutinho, M.G.N.; Gamboa, L.A.P. (1977) Modelo da sedimentaçäo holocênica na plataforma continental stu-brasileira. Projeto REMAC - Evolução sedimentar holocênica na plataforma continental continental e o talude do sul do Brasil. Petrobrás/CENPES, $v, 2$, p. $7-26$. 
LABARBERA, M. (1986) Brachiopod lophophores: functional diversity and scalling. In: RACHEBOEUF, P.R.; EMIG, C.C. Les Brachiopodes fossiles et actuels. Biostratigraphie du Palèozoique. Brest, v. 4, p. 313-322. LaWVer, L.A.; GaHAGan, L.M. (1998) Opening of the Drake Passage and its impact on Cenozoic ocean circulation. In: CROWLEY, T.J.; BURKE; K.C. Tectonic boundary conditions for climate and Geophysics. Oxford University Press, Oxford, p. 212-223.

LAWVER, L.A.; Gahagan, L.M. (2003) Evolution of Cenozoic seaways in the circum-Antarctic region. Palaeogeography, Palaeoclimatology, Palaeoecology, v. 198, p. 11.37.

LAYERLE, C.; SCARABINO, V. (1984) Moluscos def frente marítimo Uruguayo entre 9 y $78 \mathrm{~m}$ de profundidad: Análisis biocenologico. Contribuciones Del Departamiento de oceanografia fFacutad de Mumanidades y Ciencias), v. 1, p. 1-17.

LEAR, C.H.; ELderfielo, H.; WILSON, P.A. (2000) Cenozoic deep sea temperatures and global ice volumes frm $\mathrm{Mg} / \mathrm{Ca}$ in benthic foraminiferal ice model. Science, v. 287 , p. 269-272.

LFE, D.E. (1986) Paleoecology and Biogeography of the New Zealand Paleogene brachiopod fauna. In: RACHEBOEUF, P.R.; EMIG, C.C. Les Brachiopodes fossiles et actuels. Biostratigraphie du Paléozoique, n.4, p. 477 483 .

LEE, D.E. (1990) Aspects of the ecology and distribution of the living brachiopoda of New Zealand. In: MACKInNon, D.I.; LeE, D.E.; CAMPBELL, J.D. Brachiopods Through Time. Balkema, Rotterdam, p. 273279.

LEES, D.C.; FORTEY, R.A.; COCKS, L.R.M. (2002) Quantifying paleogeography using biogeography: a test case for the Ordovician and Silurian of Avalonia based on brachiopods and trilobites. Paleobiology, v. 28, n. 3 , p. 343-363.

LEIGHTON, L.R.; MAPLES, C.G. (2002) Evatuating internal versus external characters: phylogenetic analyses of the Echinoconchidae, Buxtoniinae, and Juresaniinae (Phylum Brachiopoda). Journal of Paleontology, $v$. 76, n. 4, p. 659-671.

LEV, R. (1961) Sobre algunos Terebratellidae de Patagonia (Argentina). Ameghiniana, v. 2, n. 5, p. $79 m 92$.

LEVY, R. (1964) Acerca de los gêneros Bouchardiella y Bouchardia (Braquiópodos) en el Terciario de Patagonia (Argentina). Ameghiniana, v. 3, n. 7, p. 212-220.

LEWIS, K.B.; JeNkins, C. (1969) Geographical variation of Nonionellina flemingi. Micropaleontology, $v .15, p .1$. 12.

L., W.-H. (1997) Molecular evolution. Sinauer Associates, Inc. Sunderland, MA.

LIVERMORE, R.; REEVES, C. (1999) Tectonic history of Antarctic seafloor in the South Atlantic-Weddeil SeaSouthwest Indian Sectors: Implications for Gondwana Breakup. In: INTERNATIONAL SYMPOSIUM ON ANTARCTIC EARTH SCIENCES, 8., Wellington, N.Z., 1999. Abstracts. 1999. Wellington, N.Z.

LIVERMORE, R.; WOOLLET, R. (1993) Seafloor spreading in the Weddell Sea and Southwest Atlantic since the Late Cretaceous. Earth and Planetary Science Letters, v. 117, p. 475.495.

LOgan, A.; Mackinnon, D.l; PHORSON, J.E. (1997) Morphology, distribution, life habits and phylogenetic affinities of the Recent brachiopod Gwynia capstja (Jeffreys). Pubblicazioni della Stazione Zoologica di Napoli, Marine Ecology, v. 18, n. 3, p. 239-252.

LoRus, C.; DUpLeSsY, J. (1977) Lês grands changements climatiques. La Recherche, v. 83, p. 947.955.

LOWE, J.J.; WALKER, M.J.C. (1997) Reconstructing Quaternary Environments. Longman Group Ltd., London, 4460. 
LUdBrook, N.H. (1978) Australia. In: MOULAdE, M.; NAIRN, A.E.M. The Phanerozoic Geology of the World II, The Mesozoic, A. Elsevier, p. 209-249.

LÜTER, C.; BARTOLOMAEUS, T. (1997) The phylogenetic position of Brachiopoda - a comparison of morphological and molecular data. Zoologica Scripta, v. 26, n. 3, p. 245-253.

MACKAY, S.; HEWITT, R.A. (1978) Ultrastructural studies on the brachiopod pedicle. Lethaia, v. 11, $0.331-339$.

MACKINNON, D.I. (1987) The influence of Australasian-Antarctic plate tectonics and palaeoceanographic development on the morphology and inferred life habils of New Zealand Neogene brachiopods.

Palaeogeography, Palaeoclimatology, Palaeoecology, v. 58, p. 63-73.

MACKINNON, D.I. (1993) LoOp ontogeny and ultrastructure in brachiopods of the family Terebratellidae. In: KOBAYASHI, I.; MUTVEI, H.; SAHNI, A. Structure, formation and evolution of fossil hard tissues. Tokyo, Tokai University Press. p. $31-40$.

MACKINNON, D.I.; LEE, D.E. (no prelo) Superfamilia Bouchardioidea. In: KAESLER, R.L. Treatise on Invertebrate Paleontology. Part H, Brachiopoda. Kansas, The Geological Society of America and The University of Kansas Press. v. 7.

MACKINNON, D.I; LEE, D.E; CAMPBELL, J.D. (1991) Brachiopod Through Time. Rotterdan, A.A. Batkema. $447 p$.

MACKInNON, D.I.; BEUS, S.S.; LEE, D.E. (1993) Brachiopod fauna of the Kokoamu Greensand (Oligocene), New Zealand. New Zealand Journal of Geology and Geophysics, v. 36, p. 327-347.

MACNIOCAILL, C; RANDALL, D.; CURTIS, M. (2003) New Cambrian paleomagnetic data reafirm a natal embayment position for the Ellsworth-Whitmore mountains in Gondwana reconstructions. Geophysical Research Abstracts, $v .5$ (sem número de página).

MADDISON, D.R.; MADDISON, W.P. (1998) MacClade 4.01. Analysis of Phylogeny and Character Evolution.

MAdDison, W.P., DONOGHuE, M.J.; MAdDison, D.R. (1984) Outgroup analysis and parsimony. Systematic Zoology, v. 33, p. 83-103.

MALLATT, J.; WINCHELL, C.J. (2002) Testing the new animal phylogeny: First use of combined large-subunit and small-subunit rRNA gene sequences to classify the protostomes. Molecular Biology and Evolution, $v$. 19, n. 3, p. $289-301$.

MaLumí́N, N. (1970) Bioestratigrafia del Terciário marino del subsuelo de la província de Buenos Aires (Argentina). Ameghiniana, v. 7, n. 2, p. 173-204.

MaLUMIÁN, N. (1990) Foraminíferos de la Formación Man Aike (Eoceno sureste Lago Cardiel), Provincia de Santa Cruz. Revista de la Asociación Geológica Argentina, v. 45, n. 3*4, p. 346-385.

MALUMMÁN. N.; MASIUK, V. (1973) Asociaciones foraminiferológicas fósiles de la República Argentina. In: CONGRESO GEOLOGICO ARGENTINO, 5. Actas. V. 3, p. 433-453.

MANCENIDO, M.O.; GRIFFIN, M. (1988) Distribution and paleoenvironmental significance of the genus Bouchardia (Brachiopoda, Terebratellidina): Its bearing on the Cenozoic evolution of the south Allantic. Revista Brasileira de Geociências, v. 18, p. $201 * 211$.

MANTELATTO, F.L.IM; Fransozo, A. (1999) Characterization of the physical and chemical parameters of Ubatuba Bay, northern coast of São Paulo State, Brazil. Revista Brasileira de Biologia, v. 59, n. 1, p. 23-31

MARENSSi, S.A; SANTILLANA, S.N.; RINALDI, C.A. (1998) Stratigraphy of the La Meseta Formation (Eocene), Marambio (Seymour) Island Antartica. Asociación Paleontológica Argentina, Publicación Especial "Paieógeno de América dei Sur y die la Peninsuia Antáríica", n. 5, p. 137-146. 
MARGOLIS, S.; KENNETT, J. (1970) Antarctic glaciation during the Tertiary recorded in sub Antarctic deep sea core. Science, v. 170, n. 3962, p. 1085-1087.

MARTIN, L.; SUguio, K. (1986) Excursion route along the coastal plains of the State of Parana and Santa Catarina. In: INTERNATIONAL SYMPOSIUM ON SEA LEVEL CHANGES AND QUATERNARY SHORELINES, Säo Paulo. Special Publication 1. São Paulo, 124p.

MARTIN, L.; SUgulo, K.; FLEXOR, J.M. (1988) Hauts niveaux Marins pléistocènes du littoral brésilien. Palaeogeography, Palao ochmatology, Palaeoecology, v. 68, p. 231-238.

MARTIN, L.; Suguio, K.; FleXoR, J.M.; DomingueZ, J.M.L.; BITTEnCOURT, C.S.P. (1996) Quaternary sea-level history and variation in dynamics along the central Brazilian coast: consequences on a coastal plain construction. Anais da Academia Brasileira de Ciências, v. 68, p. 303-354.

MARTínez, S.A. (1988) Los depositos de la "Transgresion Entrerriana" (Mioceno de Argentina, Brasil y Uruguay), comparacion de sus principales áreas fosiliferas a traves de los bivalvos y gastropodos. Ameghiniana, v. $25, n .1$, p. $23-29$.

MARTINEz, S.A. (1989) Los depósitos de la "transgresión entrerriana" (Mioceno de Argentina, Brasil y Uruguay). Comparación de sus principales áreas fosiliferas a través de los bivalvos y los gastrópodos. Ameghiniana, v. 25, p. 23-29.

MARTinez, S.A. (1990) Taphonomy and Paleoecology of Holocene mollusks from the western margin of the Merin Lagoon (Villa Soriano Fm., Uruguay). Quaternary of South America and Antarctic Peninsuia, v. 7, p. 121-135.

MARTINEZ, S.A. (1994) Bioestratigrafía (invertebrados) de la Formación Camacho (Mioceno, Uruguay). Buenos Aires, 340p. (Tese de Doutorado) - Faculdad de Ciencias Exactas y Naturales, Departamento de Clencias Geológicas, Universidad de Buenos Aires.

MARTINEZ, S.A.; DEL. RíO, C.J. (2000) Marine Miocene molluscs from southern South América: a biogeographic analysis. in: INTERNATIONAL GEOLOGICAL CONGRESS, 31., Rio de Janeiro, 2000. Abstracts. Rio de Janeiro, versão em $C D$, sem número de página.

MARTINEz, S.A.; Del Rio, C.J. (2002) Late Miocene molluscs from the southwestem Allantic Ocean (Argentina and Uruguay): a palaeobiogeographic analysis. Palaeogeography, Palaeoclimatology, Palaeoecology, v. 188, p. $167-187$.

MARTINEZ, S.A.; VERDE, M. (1992) Comparacion del registro de mortalidad masiva en una especie reciente (Bouchardia rosea) y una fosil (B. transplatina) (Brachiopoda: Terebratulida). Boletín de la Sociedad Zooiógica dei ưruguay, v. 7, p. 45 46.

Martinez, S.A.; Ubllla, M.; Verde, M.; Perea, D.; Rojas, A.; Guérèquiz, R.; Piñeiro, G. (2001) Paleoecology and Geochronology of Uruguayan coastal marine Pleistocene deposits. Quaternary Research, v, 55, p. 246-254

MARTinez Chacón, M.L.; PRINS, C.F.W. (1999) Distribución paleogeográfica de Aseptella (Productida): conexión entre los braquiópodos carboníferos de España y Argentina. Trabajos de Geología, Universidad de Oviedo, v. 21, p. 221-227.

MARTins, E.A. (1952) Fósseis da sondagem de 1862 em Pelotas, Estado do Rio Grande do Sul. Boletim do Museu Nacional, v. 17, p. 1-8.

MARTINS, L.R.S.; URIEN, C.M.; CORREA, I.C.S. (1996) Late Quaternary processes along the Rio Grande do Sul continental sheff (southem Brazi). Notas Técricas (CECOMFRGS), v. 9, p. 62.68. 
MASSAD, F.; SUGUiO, K.; PÉREZ, F.S. (1996) Propriedades geotécnicas de sedimentos argilosos como evidência de variações do nivel relativo do mar em Santos. In: CONGRESSO BRASILEIRO DE GEOLOGIA DE ENGENHARIA, 8. Rio de Janeiro. Anais. Rio de Janeiro, 1996, v. 1, p. 163-176.

MATSUSHIMA, Y. (1979) Reconstrução da assembléia de malacofauna que acompanhou a Transgressão Jômon na região sul de Canto. Daiionquiquenquiu, v. 17, p. 243-259. (em japonês)

MCCAMMON, H.M. (1973) The ecology of Magellania venosa, an articulate brachiopod. Journal of Paleontology, v. 47, n. 4, p. 266-278.

MCCUlloch, R.D.; Bentley, M.J.; PuRves, R.S.; Sugden, D.E.; Clapperton, C.M. (2000) Climatic inferences from glacial and palaeoecological evidence at the last glacial termination, southern south America. Journal of Quaternary Science, v. 15, n. 4, 409-417.

MCKinneY, ML.; MCNAMARA, K.J. (1991) Heterochrony: the Evolution of Ontogeny. New York, Plenum Press. 437p.

MELLO, L.H.C. (1999) Análise cladistica dos bivalves do Grupo Passa Dois (Neopermiano), Bacia do Paraná, Brasil: implicações taxonômicas, evolutivas e paleobiogeográficas. São Paulo, 160p. (Dissertação de Mestrado) - Instituto de Geociências, Universidade de São Paulo.

MíLlo, L.H.C.; SIMÖES, M.G. (2000) Comments on the nature and scope of the genus Bouchardia (Brachiopoda, Terebratellidae). In: PALEO-2000, REUNIÅO ANUAL DA SOCIEDADE BRASILEIRA DE PALEONTOLOGIA, NÚCLEO SP. Botucatu, 2000. Botetim de Resumos. Botucatu, p. 13.

Mello, L.H.C.; MARQUes, A.C.; GHILARDI, R.P.; SIMÕES, M.G. (1998) Taxonomic position of the bizarre Permian genera Anhembia and Leinzia and the phylogenelic consistency of the extinct family Megadesmidae (Bivalvia, Anomalodesmata). In: MEETING OF THE WILLI HENNIG SOCIETY, 17., São Paulo, 1993. Programs and Abstracts. São Paulo, p. 53-54.

Mello, L.H.C.; SIMÕEs, M.G.; MARQUes, A.C.; GHILARDi, R.P. (1999) Taphonomy, paleoecology and cladistics: a case study in Permian bivalves. In: ANNUAL MEETING OF THE GEOLOGICAL SOCIETY OF AMERICA, 31., Denver, 1999. Program and Abstracts. Denver, v. 31, p. A468.

MEndes, J.C. (1988) Paleontologia Básica, São Paulo, Edirora da Universidade de São Paulo, 347p.

MENÉNDEZ, C. (1971) Floras terciárias de la Argentina. Ameghiniana, v. 8, n. 3-4, p. 357-371.

Mesoutta, A.R. (1994) Variações no nível do mar nas costas brasileiras. Afro-Amarican GlossNews, v. 1, p. $3-4$.

Mil.DENHALL, D.C.; HARRIS, W.F. (1970) A cool climate pollen assemblage from the type Waipipian (middle Pliocene) of New Zealand. New Zealand Journal of Geology and Geophysics, v. 13, p. 586-591.

Milinkovitch, M.C; LeDuc, R.g.; Adachi, J.; Farnir, F.; Georges, M.; Hasegawa, M. (1996) Effects of character weighting and species sampling on phylogeny reconstruction: A case study based on DNA sequence data in cetaceans. Genetics, v. 144, n. 4, p. 1817-1833.

Mhler, K.G.; FaIRBanks, R.G.; MOUntaIN, G.S. (1987) Tertiary oxigen isotope synthesis, sea level history, and continental margin erosion. Paleoceanography, $v$. 2, p. 1-19.

MINEUR, R.1.; RIGHARDSON, J.R. (1984) Free and mobile brachiopods from New Zealand Oligocene deposits and Australian waters. Alcheringa, v. 8:327-334.

Moof R. (1989) The outgroup criterion revisited via naked zones and alleles. Systematic Zoology, v. $38, p$. 283-290.

MORNER, N.A. (1976) Euslasy and geoid changes. Joumal of Geology, v. 84, p. 123-152. 
MORNER, N.A. (1980) Eustasy and geoid changes as a function of core/mantle changes. In: MORNER, N.A. Earth Rheology, Isostasy ans Eustasy. Chichester, John Wile and Sons, p. 535-553.

MÖRNER, N.A. (1986) The concept of eustasy. A redefinition. Journal of Coastal Research, Special issue, $v$. 1, p. 49-52.

MORTON, A.C.; TAYLOR, P.N. (1987) Lead isotope evidence for the structure of the Rockall dipping-reflector passive margin. Nature, v. 326, p. 361-363.

MUR WOOD, H.M. (1965) Mesozoic and Cenozoic Terebratulidina. In: MOORE, R.C. Treatise on Invertebrate Paleontology. Part H, Brachiopoda. The Geological Society of America and The University of Kansas Press. v. 2, p. 762-816.

MUtTER, J.; TALWANI, M.; STOFFA, P.L. (1982) Origin of seaward dipping reflectors in oceanic crust off the Norwegian margin by "subaerial seafloor spreading". Geology, v. 10, p. 353-357.

NAKAMURA, K.; SHIMIZU, D.; ZHUO-TING, L. (1985) Permian palaeobiogeography of brachiopods based on the faunal provinces. In: NAKAZAWA, K,; DICKINS, J.M. The tethys, her Paleogeography and Paleobiogeography from Paleozoic to Mesozoic. Tokai University Press, Tokyo, p. 185-198.

NELSON, G. (1978) Ontogeny, phylogeny, paleontology, and the biogenetic law. Systematic Biology, v. $27, p$. 324-345.

NELSON, G.; PLATNICK, N.I. (1981) Systematics and biogeography: cladistics and vicariance. New York, Columbia University Press. $567 \mathrm{p}$.

Nelson, G.; PlatNiCK, N.I. (1984) Biogeography. Carol. Biol. Reader 119.

NiELSEN, C. (1991) The development of the brachiopod Crania (Neocrania) anomala (O.F. Müller) and its phylogenetic significance. Acta Zoologica, v. 72, p. 7-28.

NIELSEN, C. (2002) The phylogenetic position of Entoprocta, Ectoprocta, Phoronida, and Brachiopoda. Integrative and Comparative Biology, v. 42, n. 3, p. 685-691.

NiXON, K.C.; CARPENTER, J.M. (1993) On Outgroups. Cladistics, v. 9, p. 413-426.

NIXON, K.C.; CARPENTER, J.M. (1996a) On simultaneous analysis. Cladistics, v. 12, p. 221-242,

NiXON, K.C.; CARPENTER, J.M. (1990b) On consensus, collapsibility, and clade concordance. Cladistics, v. 12 , p. 305-322.

NOBLE, J.P.A.; LOGAN, A.; WEBB, G.R. (1976) The recent Terebratulina community in the rocky subtidal zone of the Bay of Fundy, Canada. Lethaia, v. 9, p. 1-17.

Nonato, E.F. (1999) Filo Brachiopoda. In: MIGOTTO, A.E.; TIAGO; C.G. Invertebrados Marinhos. Biodiversidade do Estado de São Paulo, Brasil: sintese do conhecimento ao final do século $x \chi x$. Såo Paulo. FAPESP. v. 3, p. 255-257.

NONATO, E.F.; PETT, M.A.V. (1996) Macrofauna bentonica das enseadas de Picinguaba e Ubatumirim: ocorrência de espécies raras e descrição de novas espécies. In: SIMPÓSIO SOBRE OCEANOGRAFIA, 3., São Pauto, 1996. Resumos. São Paulo, Instituto Oceanográfico/USP, p. 219.

NORELL, M.A.; WHEELER, W.C. (2003) Missing Entry Replacement Data Analysis: a replacement approach to deating with missing data in paleontological and total evidence data sets. Journal of Vertebrate Paleontology, v. 23, n. 2, p. 275-283,

NOVACEK, M.J. (1992a) Fossils, lopologies, missing data, and the higher level phylogeny of eutherian mammals. Systematic Biology, v. 41, p. 58-73.

NOVACEK, M.J. (1992b) Fossils as critical data for phylogeny. In: NOVACEK, M.J.; WHEELER, Q.D. Extinction and Phylogeny. New York, Columbia University Press. p. 46-88. 
O'BRIEN, P.; EXON, N. (2000) The core of global climate change; Australia-Antarctica. Australian Geological News, v. 58, p. 3-7.

OBERHÄNSL, H.; MULLER-MERz, E.; OBERHÄNSLI, R. (1991) Eocene paleoceanographic evolution at $20-30^{\circ} \mathrm{S}$ in the Atlantic Ocean. Palaeogeography, Palaeoclimatology, Palaeoecology, v. 83, p. 173-215.

OHra, S.; Kaiho, K.; Takei, T. (2003) Relationship between surface-water temperature and ice-sheet expansion during the middle Miocene. Palaeogeography, Palaeoclimatology, Palaeoecology, v. 201, n. 3-4, p. 307.320 .

OWEN, E.F. (1980) Tertiary and Cretaceous brachiopods from Seymour, Cockbum and James Ross Islands, Antartica. Bullotin of the Brish Museum (Natural History), Goology, v. 33, n. 20, p. 123-145.

PALACIO, F.J. (1982) Revisión zoogeográfica marina del sur del Brasil. Boletim do Instituto Oceanográfico, Sâo Paulo, v. 31, p. 69-92.

PATTERSON, C. (1981) Significance of fossils in determining evolutionary relationships. Annual Review of Ecology and Systematics, v. 12, 0. 195-223.

PATTERSON, C. (1982) Morphological characters and homology. In: JOYSEY, K.A.; FRIDAY, A.E. Problems of Phylogenetic Reconstruction. London, Systematics Association Special Volume, Academic Press. $n$. 21, p. $21-74$.

PECK, L.S.; MORRIS, D.J.; CLARKE, A. (1986) The caeca of punctate brachiopods: a respiring tissue not a respiratory organ. Lethaia, v. 19, p. 232.

Petriella, B.; ARChangelsky, S. (1975) Vegetación y Ambiente em el Paleoceno de Chubut. In: CONGRESO ARGENTINO DE PALEONTOLOGIA Y BIOESTRATIGRAFIA, 1. Actas. V.2, p. 257.268.

PHLLPOT, H.R. (1985) Physical geography - Climate. In: CRAME, J.A. Origins and Evolution of the Antarctic Biota. London, Geological Society Special Publication, n, 47. p. 23-38.

PICKEN, G.B. (1985) Marine habitats - Benthos. In: CRAME, J.A. Origins and Evolution of the Antarctic Biota. London, Geological Society Special Publication, n. 47. p. 154-172.

Pimentel, R.; Riggins, R. (1987) The nature of cladistic data. Cladistics, v. 3, p. 201-209.

PIOla, A.R.; CAMPOS, E.J.D.; MÖller, O.O.; Charo JR., M.; MARTINEz, C. (2000) Subtropical Shelf Front off eastern South America. Journal of Geophysical Research, v. 105, p. 6565-6578.

PIRAZZOU, P.A. (1993) Global sealevel changes and their measurement. Clobal Planetary Changas, $v$. 8 , p. $135-148$.

POL, D.; NORELL, M.A. (2001) Comments on the Manhattan Stratigraphic Measure. Cladistics, v. 17, p. 285289.

POORE, R.Z.; MATTHEWS, R.K. (1984) Oxygen isotope ranking of Late Eocene and Oligocene planktonic forminifera: implications for Oligocene sea-surface temperatures and global ice-volume. Marine Micropaleontology, v. 9, p. 111-134.

POPOV, L.E.; BASSET, M.G.; HOLMER, L.E.; LAURiE, J. (1993) Phylogenetic analysis of higher laxa of Brachiopoda. Lethaia, v. 26, p. 1-5.

PROTHERO, DR. (1989) Stepwise extinctions and climate decline during the later Eocene and Oligocene. In: DONOVAN, S.K. Mass extinctions: processes and evidence. Bethaven Press, London, p. 217-234.

PROTHERO, D.R. (1994) The late Eocene-Olgocene extinctions. Anmual Reviews of Earth and Planetary Sciences, v. 22, p. 145-165.

PROTHERO, D.R.; BERGgREN, W.A. (1992) Eocene-Oligocene chmatic and biotic evolution. Princeton University Press, Princeton. 
Prud'HOMme, B.; LARTILlot, N.; BALAVOINE, G.; AdOUTte, A.; VerVOORT, M. (2002) Phylogenetic analysis of the Wht gene farmily - Insights from Lophotrochozoan members. Current Biology, v, 12, p. 1395-1400.

RACHEBOEUF, P.R.; COPPER, P. (1990) The mesolophe, a new lophophore type for chonetacean brachiopods. Lethaia, v. 23, p. 341-346.

RACHEBOEUF, P.R.; GARCIA, J.P. (1996) Spine asymmetry in chonetoidean brachiopods: an example of reiterated heterochronies linked to intra-Devonian events. Palaeogeography, Palaeoclimatology, Palaeoecology, v. 123, p. 323-342.

RAE, T.C. (1998) The logical basis for the use of continuous characters in phylogenetic systematics. Cladistics, v. 14, p. 221-228.

RAINE, J.I.; AskIN, R.A. (2001) Terrestrial palynology of Cape Roberts Project drilthole CRP-3, Victoria Land Basin, Antarctica. Terra Antartica, v. 8, p. 389-400.

RAMSKÖLD, L.; WERDELIN, L. (1991) The phylogeny and evolution of some phacopid trilobites. Cladistics, v. 7 , p. 29-74.

Rannala, B.; Huelsenbeck, J.P.; YANG, Z.; NIELSEn, R. (1998) Taxon sampling and the accuracy of large phylogenies. Systematic Biology, V. A7, p. 702710.

RAVEN, P.H.; AXELROD, D.I. (1974) Angiosperm biogeography and past continental movements. Annual Mo. of Botanical Garden, v. 61 , p. 539-673.

REEVE, L.A. (1861) Monograph of the genus Terebratula. In: REEVE, L.A. Conchoiogia iconica. L. Reeve $\&$ Co., London, v. 13, pp., 7-11.

Reguero, M.A.; Marenssi, S.A.; Santill.ana, S.N. (2002) Antarctic Peninsula and South America (Patagonia) Paleogene terrestrial faunas and environments: biogeographic relationships. Palaeogeography, Palaeoclimatology, Palaecology, v. 179, p. 189-210.

RICCARDI, A.C. (1988) The Cretaceous system of southern South America. Geological Society of America, Memoir 168, p. 1-73.

RICHARDSON, J.R. (1973a) Studies on Australian Cainozoic brachiopods. 1. The loop development of Fremulina sanguinolenta (Gmelin, 1790). Proceedings of the Foyai Society of Victoria, v. 86, p. $111-116$.

RICHARDSON, J.R. (1973b) Studies on Australian Cainozoic brachiopods. 3. The Subfamily Bouchardiinae (Terebratellinae). Procedings of the Royal Society of Victoria, v. 86, $p .127-132$.

RICHARDSON, J.R. (1975a) Loop development and the classification of terebratellacean brachiopods. Palaeontology, v. 18, n. 2, n. 285 31 A.

RICHARDSON, J.R. (1975b) Growth pattern of the loop and cardinalia of five Recent terebratellid species. Proceedings of the Royal Society of Victoria, v. 87, p. 197-206.

Richardson, J.R. (1979) Pedicle structure of articulate brachiopods. Journal of the Royal Society of New Zealand, v. 9, p. 415-436.

RICHARDSON, J.R. (1980) Studies on Australian Cainozoic brachiopods. 5. The genera Victorithyris Allan, and Diedrothyris nov. Memoir of the National Museum of Victoria, v. 41, p. 43-52.

RICHARDSON, J.R. (1981a) Brachiopods in mud: resolution of the dilemma. Science, v. 211, p. 1161 1163.

RICHARDSON, J.R. (1981b) Brachiopods and pedicles. Paleobiology, v. 7, p. 87-95.

RICHARDSON, J.R. (1981c) Distribution and orientation of six anticulate brachiopod species from New Zealand.

New Zealand Journal of Zoology, v. 8, p. 189-196.

RICHAROSON: J.R. (1984) Evolution of brachiopods. National Geographic Society Research Reports.

Projects for 1976. p. 751-760. 
RICHAROSON, J.R. (1987) Brachiopods from carbonate sands of the Australian shelf. Proceedings of the Royal Society of Victoria, v. 99 , n. 2, p. 37-50.

RICHARDSON, J.R. (1991) Australasian Tertiary Brachiopoda. The Subfamily Anakineticinae nov. Proceedings of the Royal Society of Victoria, v. 103, n. 1, p. 29-45.

RICHARDSON, J.R. (1994) Origins and dispersal of a brachiopod family - the systematics, biogeography and evolution of the Family Terebratellidae. Proceedings of the Royal Society of Victoria, v. 106, p. 17-29.

RICHARDSON, J.R. (1997a) Ecology of articulate brachiopods. In: R.L. KAESLER (ed.), Treatise on invertebrate Paleontology. Part H, Brachiopoda. Kansas, The Geological Society of America and The University of Kansas Press. v. 1, p. 441.462.

RICHARDSON, J.R. (1997b) Biogeography of the articulated brachiopods. In: R.L. KAESLER (ed,), Treatise on Invertebrate Paleontology. Part $H$, Brachiopoda. Kansas, The Geological Society of America and The University of Kansas Press. v. 1, p. 463-472.

RICHARDSON, J.R.; WATSON, J.E. (1975a) Locomotory adaptations in a free-lying brachiopod. Science, $v, 189, p$. $381-382$.

RICHARDSON, J.R.; WATSON, J.E. (1975b) Form and function in Recent free living brachiopod Magadina cumingi. Paleobiology, v. 1, p. 379.387.

Ringuelet, R.A. (1978) Dinamismo histórico de la fauna brasílica en la Argentina. Ameghiniana, v. 15, n. 1-2, p. $255-262$

Robardet, M.; PARIS, F.; Plusquellec, Y.; TAIT, J. (2001) Comment on "New Early Devonian paleomagnetic data from NW France: Paleogeography and implications for the Armorican microplate hypothesis" by $\mathrm{J}$. Tait. Author's reply. Journal of Geophysical Research, v. 106, n. B7, p. 13307-13313.

Robert, C.M.; EXon, N.F.; Kennett, J.P.; Malone, M.J.; Brinkhuis, H.; Chaproniere, G.C.H.; Ennyu, A.; Fotherglll, P.; Fuller, M.D.; Grauert, M.; Hill, P.J.; JaneCek, T.R.; Kell.y, D.C.; Latimer, J.C.; Roessig, K.M.; NeEs, S.; Ninnemann, U.S.; Nuernberg, D.; Pekar, S.F.; Plelaton, C.C.; Pruehl. H.A.; Roehl, U.; Schellenberg, S.A.; Shevenel., A.E.; Stickley, C.E.; Suzukı, N.; Touchard, Y.; Wel, W.; WHITE, T.S. (2001) Paleogene ocean opening south of Tasmania, and its paleo-oceanographic implications; preliminary results from clay mineral analyses; ODP Leg 189. Comptes Rendus de l'Academie des Sciences, Serie II. Sciences de la Terre et des Planetes, v. 332, n. 5, p. 323-329.

RODLAND, D.; KOWALEWSKI, M.; CARROL, M.; SIMÖES, M.G. (2002) Colonists of a "lost world": quantitative analysis of brachiopod encrustation on the subtropical shelf of the Southeast Brazilian Bight. In: ANNUAL MEETING OF THE GEOLOGICAL SOCIETY OF AMERICA, 34., Denver, 2002. Abstracts with Program. Denver, v. 34, p. A34.

RODland, D.; KoWAlEWSK!, M.; CARROL, M.; SIMÕES, M.G. (2003) Home on the half-shell: encrustation of brachiopods and bivalves from the subtropical shelf of the Southeast Brazilian Bight. In: ANNUAL MEETING OF THE GEOLOGICAL SOCIETY OF AMERICA, 35., Memphis. Abstracts with Program. Memphis, v. $35, \mathrm{~s} / \mathrm{p}$.

ROOPNARINE, P. (1996) Systematics, biogeography and extinction of Chionine bivalves (Bivaivia: Veneridae) in Tropical America: Early Oligocene-Recent. Malacology, v. 38, p. 103-142.

ROOPNARINE, P.D. (1997) Endemism and extinction of a new genus of Chionine (Bivalvia: Veneridae) bivalve from the late Neogene of Venezuela. Journal of Paleontology, v. 71, n. 6, p. 1039-1046.

RoOpNaRine: P.D.; BEUSSINk, A. (1999) Extinction and naticid predation of the Chione von Muhlfeld in the Neogene of Florida. Palaeontologia Electronica, v. 2, n. 1 . 
ROSEN, D.E. (1976) A vicariance model of Caribbean biogeography. Systematic Zoology, v. 24, p. 431-464.

ROSEN, D.E. (1978) Vicariant patterns and historical explanation in biogeography. Systematic Zoology, v. 27, p. $159-188$.

ROSEN, D.E. (1994) Neobiogeography versus palaeobiogeography. In: R. MATTEUCCl (ed.), Studies on ecology and Paleoecology of benthic communities. Bulletin de la Société paléontologique italienne, special volume 2, p. 291-303.

RoweLL, A.J. (1961) Inhaiant and exhalant feeding current systems in Recent brachiopods. Geological Magazine, v. 98, p. 261-263.

ROWELL, A.J. (1981a) The Cambrian radiation: monophyletic or polyphyletic origins? In: TAYLOR, M.E. Short papers for the Second International Symposium on the Cambrian System. U.S. Geological Survey, p. 184-187.

ROWELL, A.J. (1981b) The origin of the brachiopods. In: Lophophorates, Notes for a short course. Tenessee, University of Tenessee. p.97-109

RoweLL, A.J. (1982) The monophyletic origin of the Brachiopoda. Lethaia, v. 15, p. 299-307.

RuDWIC, M.J.S. (1962) Notes on the ecology of brachiopods in New Zealand. Transactions of the Roya! Society of New Zealand, Zoology, v. 1, p. 327-335.

RuDWICK, M.J.S. (1970) Living and fossil brachiopods. London, Hutchinson. 199p.

SAITO, M.; ENDO, K. (2001) Molecular phylogeny and morphological evolution of laqueoid brachiopods. Paleontological Research, v. 5, n. 2, p. 87-100.

SANDY, M.R. (1990) A new early cretaceous articulated brachiopod from the northwest territories, Canada, and its Paleobiogeographic significance. Journal of Paleontology, v. 64, n. 3, p. 367-372.

SANDY, M.R. (1991) Cretaceous brachiopods from James Ross island, Antarctic Peninsula, and their paleobiogeographic affinities. Journal of Paleontology, v. 65, n. 3, p. 396-411.

SANDY, M.R.; BLoDGETT, R.B. (2000) Early Jurassic spiriferid brachiopods from Alaska and their paleogeographic significance. Geobios, v. 33, n. 3, p. 319-328.

SANGUinetTI, Y.T. (1979) Miocene ostracodes of the Pelotas Basin, State of Rio Grande do Sul. Pesquisas, $v$. 12, p. 119-187.

SANGUINETT, Y.T. (1980) Bioestratigrafia (Ostracodes) do Mioceno da Bacia de Pelotas, Rio Grande do Sul. Pesquisas, v. 13, p. 7-34.

SANGUinetm, Y.T.; ORnellas, L.P.; Coimbra, J.C. (1991) Post-Miocene ostracodes from the Pelotas Basin, southern Brazil. Taxonopmy - Part I. Pesquisas, v. 18, p. 138-155.

SANGUINETT, Y.T.; ORNeLlas, L.P.; COIMBRA, J.C.; Ramos, M.I.F. (1992) Postmiocene ostracodes from Pelotas Basin, southern Brasil. Taxonomy - Part ii. Pesquisas, v. 19, p. 155-156.

SARYTCHEVA, T.G.; LICHAREW, B.K.; SOKOLSKAJA, A.N. (1960) Otriad Productida. In: ORLOV, Y.A. Osnovy Paleontologii. Mshanki Brakhiopody. Moscow, izdatelstvo Akademii Nauk SSSR, p. 221-238.

SAVAZZ, E. (1999) Functional morphology of the invertebrate skeleton. London, John Wiley \& Sons. 687p.

SAViN, S.; DOUGLAS, R.; STEHHL, F. (1975) Tertiary marine paleotemperatures. Geological Society of America Bulletin, v. 86, p. 1499-1510.

Scarabino, V. (1977) Moluscos Del Golfo de San Matias (Província de Rio Negro, República Argenina) Inventario y claves para su identificación. Comunicaciones de la Sociedad Malacológica del Uruguay, y. 4, p. $177-285$. 
SCASSO, R.; DEL RIO, C.J. (1987) Ambientes de sedimentación y proveniência de la secuencia marina del Terciário Superior de la región de Península Valdés. Revista de la Asociación Geológica Argentina, v. 42 , p. 291-321.

SCHELLENBERG, S.A. (2001) Deep-ocean ostracode response to the Paleocene-Eocene thermal maximum. In: The Geological Society of America Annual Meeting, Geological Society of America Abstracts with Programs. GSA, 2001, v.33.

SCHNEIDER, J.A. (1992) Preliminary cladistic analysis of the bivalve family Cardiidae. Bulletin of American Malacologists, v. 9, p. 145-155,

SCHNeIder, J.A. (1995) Phylogeny of the Cardidae (Mollusca, Bivalvia): Protocardinae, Laevicardinae, Lahilliinae, Tulogocardiinae subfam.n. and Pleuriocardiinae subfam.n. Scripta Zoologica, v. 24, p. 321. 346.

SCHNEIDER, J.A. (1998a) Phylogeny of stem-group Eucardiids (Bivalvia: Cardidae) and the significance of the transitional fossil Perucardia. Malacologia, v. 40, n. 1-2, p. 37-62.

SCHNEIDER, J.A. (1998b) Phylogeny of the Cardiidae (Bivalvia): phylogenetic relationships and morphological evolution within the subfamilies Clinocardinae, Lymnocardinae, Fraginae and Tridacninae. Malacologia, v. 40, n. 1-2, p. 321-373.

SCHNEider, H. (2003) Métodos de Anélise Filogenética. Um guia prático. Holos, Editora \& Sociedade Brasileira de Genética, Ribeirão Preto, $114 \mathrm{p}$.

SCHNEIOER, J.A.; FOIGHIL, D.O. (1998) Phylogeny of the cardiid bivalves (Triassic- Recent): fossils, anatomy and molecules. In: The Geological Society of America Annual Meeting, 1988. Geological Society of America Abstracts with Programs. GSA, 1988, v. 30, N. 7, p. 93

SCHNITKER, D. (1974) West Allantic abyssal circulation during the past 120,000 years. Nature, v. 248, p. 385 387.

SEPKOSKl, J.J. (1981) A factor analytic description of the Phanerozoic marine fossil record. Paleobiology, v. 7 p. $36-53$

SHACKLETON, N.J.; KENNETT, J.P. (1975a) Paleotemperatures history of the Cenozoic and the initiation of Antarctic glaciation: oxygen and carbon isotopic analysis in DSDP 277, 279 and 281. Internal Report DSDP, v. 29, p. 743.

SHACKLETON, N.J.; KENNETT, J.P. (1975b) Late Cenozoic oxygen and carbon isotopic changes. DSDP Site 284: implication for glacial history of Northern Hemisphere and Antarctica. Internal Report DSDP, v. 29, p. 801.

SHEPARD, F.P. (1963) Thinty five thousand years of sea level. In: CLEMENTS, T. Essays in marine geology in honor of K.O. Emery. University of Caltomia Press, p. 1-10.

SHEPARD, F.P.; SUESS, H.E. (1956) Rate of postglacial rise of sea level. Science, v. 123, p. 1082-1083.

SH, G.R.; ARCHBOLD, N.W. (1995) Permian brachiopod faunal sequence of the Shan-Thai terrane: biostratigraphy, palaeobiogeographical affinities and plate tectonic/palaeoclimatic implications. Journal of Southeast Asian Earth Sciences, v. 11, n. 3, p. 177-187.

SH, G.R.; GRUNT, T.A. (2000) Permian Gondwana-Boreal antitropocality with special reference to brachiopod faunas. Palaeogeography, Palaeoclimatology, Palaecology, v. 155, p. 239-263.

SHI, G.R.; WATERHOUSE, J.B. (1990a) Sakmarian (Early Permian) brachiopod biogeography and major associations as related to terrane drift. In: MACKINNON, D.I.; LEE, D.E.; CAMPBELL, J.D. Brachiopod Through Time. Rotterdam, A.A. Balkema. p. 355-365. 
SHi, G.R.; WATERHOUSE, J.B. (1990b) Sakmarian (Early Permian) brachiopod biogeography and constraints on the timing of terrane rifting, drift, and amalgamation in SE Ásia, with reference to the nature of Permian "Tethys". In: PACIFIC RIM CONGRESS, 90., Melbourne. Proceedings, Meibourne, 1990, The Australasian Institute of Mining \& Metallurgy, v. 2, p. 271-276

SIDDALL, M.E. (1998) Stratigraphic fit to phylogenies: a proposed solution. Cladistics, v. 14, p. 201-208.

SIMÕES, M.G.; FitriPALDI, F.C. (1992) Fósseis da região de Rio Claro. Rio Claro, Arquivo do município de Rio Claro. 93p.

SIMÖES, M.G.; KOWALEWSKI, M. (2003) Modern accumulations of brachiopod shells in unconsolidated surfecial beach deposits, northern coast of Säo Paulo state, Brazil: taphonomic implications for the genesis of skeletal concentrations. In: LATINAMERICAN CONGRESS OF SEDIMENTOLOGY, 3., Belém, 2003. Abstracts. Belém, p. 220-221.

SIMÖES, M.G.; KOWALEWSK!, M. (2002) Taphonomy of recent articulate brachiopods from subtropical siliciclastic-carbonate environments of southem Brazil. In: GEOLOGICAL SOCIETY OF AMERICA ANNUAL MEETING, 34., Denver, 2002. Abstracts with Programs, p.357.

SIMOEES, M.G.; KOWALEWSKI, M. (2000) Recent brachiopods from the Brazilian continental shelf (South Atlantic) A preliminary report. In: THE MilLLENIUM BRACHIOPOD CONGRESS, London, 2000. Abstracts. London, p. 80.

Simões, M.G.; MARques, A.C.; Mello, L.H.C.; ANELL., L.E. (1997) Phylogenetic analysis of the genera of the extinct family Megadesmidae (Bivalvia, Anomalodesmata), with remarks on its paleoecology and taxonomy. Journal of Comparative Biology, v. 2, n. 2, p. 75-90.

SiMÖES, M.G.; MARques, A.C.; MELLo, L.H.C.; GHIL.ARDI, R.P. (2000a) The role of taphonomy in cladistic analysis: a case study in Permian bivalves. Revista Española de Paleontologia, v. 15, n. 2, p. 153-164.

SIMÖEs, M.G.; Mello, L.H.C.; KowaleWSKI, M.; Fransozo, A. (2000b) Drill holes in shells of the living fossil Bouchardia rosea (Nawe), 1823 (Brachiopoda, Terebratulida) from the southem Brasilian shelf. In: THE MILLENIUM BRACHIOPOD CONGRESS, London, 2000. Abstracts. London, p. 81

Simóes, M.G.; Kowalewski, M.; Mello, L.H.C.; Rodland, D.L.; CARROL, M. (2000c) Present-day terebratulid brachiopods from the southern Brazilian shelf: Paleontological and biogeographic implications. In: ANNUAL MEETING OF THE GEOLOGICAL SOCIETY OF AMERICA, 32., Reno, 2000. Abstracts with Programs. Reno, v. 32, p. A14

Simöes, M.G.; Kowalewski, M.; MeLlo, L.H.C.; RoDland, D.L.; CARROLL, M. (2001) Taphonomy of Boucharida rosea (Brachiopoda, Rhynchonelliformea) from sandy beachs and bays of nortwest coast of the northwest coast of SãoPaulo Stare. Reunião Anual da Sociedade Brasileira de Paleontologia, Paleo-2001, Rio Claro, SP, Boletim de Resumos, p.15

Simöes, M.G.; Kowalewski, M.; MELlo, L.H.C.; Rodland, D.L.; Carroll, M. (2004) Present-day terebratulid brachiopods from the Southern Brazilian Shelf: paleontological and biogeographic implications. Palaeontology, v. 47, n. 3, p. 1-19.

SKELTON, P.W.; BENTON, M.J. (1993) Mollusca: Rostroconchia, Scaphopoda and Bivalvia. In: BENTON, M.J. The Fossil Record. London, Chapman and Hall. p. 237-263.

SkElToN, P.W.; Crame, J.A.; MorRts, N.J.; HARPER, E.M. (1990) Adaptive divergence and taxonomic radiation in post-paleozoic bivalves. In: TAYLOR, P.D.; LARWOOD, G.P. Major evolutionary radiations. Oxford Systematics Association Special Volume, Clarendon Press. v. 42, p. 91-117. 
SMITH, A.B. (1992) Rooting molecular trees: problems and strategies. Biological Journal of the Linnean Society, v. 51 , p. 279-292.

SMITH, A.B. (2000) Stratigraphy in phylogeny reconstruction. Journal of Paieontology, v. 74, p. 763-766.

SMITH, A.B. (2002) Stratigraphy in phylogeny reconstruction - response. Journal of Paleontology, v. 76, n. 4, p. 594-595.

SMITH, G.R. (1984) Echinoid Palaeobiology. London, George Allen \& Unwin.

SMITH, G.R. (1994) Systematics and the fossil record documenting evolutionary patterns. Oxford, Blackwell Scientific Publications. 233p.

SOLIANI, Ë. (1973) Geologia da regiäo de Santa Vitóna do Pamar, RS, a posiçâo estratigráfica dos fósseis mamiferos pleistocênicos. Porto Alegre, 88p. (Dissertação de Mestrado) - Curso de Pósgraduação em Geociências, Universidade Federal do Rio Grande do Sul.

SOLIANI, E.; JOST, H. (1975) Mamíferos pleistocênicos e a sua posição estratigráfica na planicie costeira do Rio Grande do Sul, SE do Brasil. In: CONGRESSO BRASILEIRO DE GEOLOGIA, 28., Porto Alegre. Resumos das Comunicações. Porto Alegre, SBG, p. 791-792.

SORENSON, M.D. (1999) Trearot, version 2. Boston University, Boston, MA.

SPEZZAFERRI, S. (1995) Planktonic foraminiferal paleoclimate implications across the Oligocene-Miocene transition in the oceanic record (Atlantic, Indian, and South Pacific) Palaeogeography, Palaeoclimatology, palaeoecology, v. 114, p. 43-74.

SPRECHMANN, P. (1978) The paleoecology and paleogeography of the Uruguayuan coastal área during the Neogene and Quatemary. Zitteliana, v. 4, p. 3-72.

STANLEY, S.M. (1970) Relation of shell form to life of the Bivalvia (Mollusca). The Geological Society of America, Memoir, v. 125, p. 1-296.

STANLEY, S.M. (1986) Anatomy of a regional mass extinction: Plio-Pleistocene decimation of the western Atlantic bivalve fauna. Palaios, v. 1, p. 17-36.

STANLEY, S.M. (1990) The general correlation between rate of speciation and rate of extinction: fortuitous causal linkages. In: Ross, R.M.; ALLMon, W.D. Causes of Evolution. A Paleontological Perspective. University of Chicago Press, Chicago, p. 103-127.

STEVENS, P.F. (1980) Evolution of polarity of character states. Anmual Review of Ecology of Systematics, $v$. 11, p. 333-358.

STILWELL, J.D.; ZNSMEISTER, W. (1992) Molluscan systematics and biostratigraphy. Lower Tertiary La Meseta Formation, Seymour island, Antarctic Peninsula. American Geophysical Union, Antarctic Research Series 55, p. 1-191.

STOLARSK, J. (1996) Paleogene corals from Seymour Island, Antarctic Peninsula. In: GAzDzickl, A. Palaeontological results of the Polish Antarctic expeditions, Part II, v. 55, p. 51-63.

STOREY, B.C.; ALABASTER, T. (1991). Tectonomagmatic controls on Gondwana break-up models: Evidence from the proto-Pacific margin of Antarctica. Tectonics, v. 10, p. 1274-1288.

STOREY, B.C.; KYLE, P.R. (1997) An active mantle mechanism for Gondwana break-up. South African Journal of Geology, v. 100 , n. 4, p. 283-290.

STOT, L.D.; KENNETT, J.P.; SHACKLETON, N.J.; CORFELL, R.M. (1990) The evolution of Antarctic surface waters during the Paleogene: inferences from the stable isotopic compositions of planktonic foraminifers, ODP Leg 113. Proceedings of the ODP Scientific Research, v. 113, 849m863. 
Suguio, K. (1999) Geologia do Quaternário e mudanças ambientais; Passađo + Presente = Futuro? São Paulo, Paulo's Editora. $366 \mathrm{p}$.

SUGUIO, K.; MARTIN, L. (1978) Quaternary marine formations of the states of São Paulo and southern Rio de Janeiro, In: INTERNATIONAL SYMPOSIUM ON COASTAL EVOLUTION IN THE QUATERNARY, São Paulo. Special Publication. São Paulo, 1978, n. 1.1978, 55p.

Suguio, K.; Martin, L.; Bittencourt, A.C.S.P.; Dominguez, J.M.L.; Flexor, J.M.; Azevedo, A.E.G. (1985) Flutuaçס̃es do nível relativo do mar durante o Quaternário superior ao longo do litoral brasileiro e suas implicações na sedimentação costeira. Revista Brasileira de Geociências, v. 15, n. 4, p. 273-286.

SUGUIO, K.; MARTIN, L.; FLEXOR, J.M.; AzEVEDO, E.G. (1986) The Quaternary sedimentary deposits in the States of Paraná and Santa Catarina coastal plain. Quaternary of South America and Antarctic Peninsula, $v$ 4, p. 3-26.

SUGUIO, K.; MARTIN, L.; FLEXOR, J. (1988) Quaternary sea levels of the Brazilian Coast: recent progress. Episodes, v. 11, n. 3, p. 203-203

SWOFFORD, D.L. (1998) PAUP: Phylogenetic Analysis Using Parsimony (and other methods), 4.0.

TAVIANI, M.; BEU, A.G. (2003) The palaeoclimatic significance of Cenozoic marine macroffossil assembiages from Cape Roberts Project drillholes, McMurdo Sound, Victoria Land Basin, East Antarctica. Palaeogeography, Palaeoclimatology, Palaeoecology, v. 198, p. 131-143.

TAVIANI, M; ZAHN, R. (1998) The stable oxygen isotope Record of Pleistocene and Miocene bivalves in the CRP-1 Drillhole, Victoria Land Basin, Antarctica. Terra Antartica, v. 5, p. 419-243

TAVIAN, M.; BeU, A.G.; Lombardo, C. (1998) Pleistocene macrofossils from CRP-1 Drillhole, Victoria Land Basin, Antarctica. Terra Antartica, v. 5, p. 485-491.

TAVIANI, M.; BEU, A.G.; JONKERS, H.A. (2000) Macrofossils from CRP $2 / 2 A$ Victoria Land Basin, Antarctica. Terra Antartica, v. 7, p. 513-526.

ThAYER, C.W. (1975) Diductor muscles of brachiopods: active or passive? Paleobiology, v. 1, p. 44-47.

THAYER, C.W. (1986) Respiration and the function of brachiopod punctae. Lethaia, v. 19, p. 23-31.

THELE, K. (1993) The Holy Grail of the perfect character: the cladistic treatment of morphometric data. Cladistic, v. 9, 275-304.

THESEN, Z,V. (1977) Bolivitidae e Caucasinidae (Foraminiferida) do Cenozóico superior da Bacia de Pelotas, Rio Grande do Sul. Acta Geológica Leopoldensia, v. 2, n. 3, p. 3-82

THOMPSON, R.S.; FLEMING, R.F. (1996) Middle Pliocene vegetation: reconstructions, paleoclimatic inferences, and boundary conditions for climate modeling. Marine Micropaleontology, v. 27, n. 144, p. 27 49

THOMSON, J.A. (1915) Brachiopoda genera: the position of shells with magaselliform loops, and of shells with bouchardifom beak characters. Transactions and Proceedings of the New Zealand institute, v. 47, p. 392-403.

THOMSON, J.A. (1918) The genus Bouchardia (Brachiopoda) and the age of the Younger Beds of Seymour Island, West Antarctic. Geological Magazine, v. 5, 258-263.

THOMSON, J.A. (1927) Brachiopod morphology and genera (Recent and Tertiary). New Zealand Board of Science and Art, Wellington, Manual, v. 7, p. 1-338.

THOMSON, M.R.A. (1991) Antarctic invertebrate fossil: the Miesozoic-Cainozoic Record. in: TINGEY, R.J. The Geology of Antarctica, Claredon Press, Oxford, p. 487-498.

TOMAzelu, L.J.; VILlwock, J.A. (1989) Processos erosivos atuais na cosia do Rio Grande do Sui, Brasit: Evidências de uma provável tendência contemporânea da elevação do nível relativo do mar. In: 
CONGRESSO BRASILEIRO DE GEOLOGIA DO QUATERNÁRIO, 7., Rio de Janeiro. Anais. Rio de Janeiro, ABEQUA. sem número de páginas.

TOMmAS!, L.R. (1969) Observações preliminares sobre a fauna bêntica de sedimentos moles da Baia de Santos e regiões vizinhas. Boletim do Instituto Oceanográfico, v. 16, n. 1, p. 43n65.

TOMimasi, L.R. (1970a) Sobre o braquiópode Bouchardia rosea (Mawe), 1823. Boletim do instituto Oceanográfico de São Paulo, v. 19, p. 33-42.

TOMMAst, L.R. (1970b) Observações sobre a fauna bêntica do complexo estuarino-lagunar de Cananéia Boletim do Instituto Oceanográfico, v. 19, p. 43-56.

TONNI, E.P.; FIDALGO, F. (1978) Consideraciones sobre los cämbios climálicos durante el Pleistoceno tardioreciente em la província de Buenos Aires. Aspectos ecológicos y zoogeograficos relacionados. Ameghiniana, v. 15, n. 1-2, p. 235-253.

TORELLO, F.F.; SIMÖES, M.G. (2003) Tafonomia experimental do fóssit-vivo Bouchardia rosea (Brachiopoda, Terebratellidae) e suas implicações paleontológicas. In: WORKSHOP CIENTÍFICO DE PÓSGRADUAÇÃO DO IGc-USP, 3., São Paulo, 2003. Boletim de Resumos. São Paulo, p. 15.

TORELlo, F.F.; SIMÓES, M.G.; PASSOS, J.R.S. (2003a) Dorsal and ventral brachiopod shell resistance to abrasion tested under laboratory conditions: what is causing their bias in the fossil record? In: LATINAMERICAN CONGRESS OF SEDIMENTOLOGY, 3., Belém, 2003. Abstracts. Belém, p. 222-223.

TORELLO, F.F.; SIMÖES, M.G.; PASSOS, J.R.S. (2003b) Comparative bivalve and brachiopod shell resistance to abrasion tested in a taphonomic tumbling barrel. In: LATINAMERICAN CONGRESS OF SEDIMENTOLOGY, 3., Belém, 2003. Abstracts. Belém, p. 223-224.

TORELLO, F.F.; SIMỎES, M.G.; PASSOS, J.R.S. (2002a) The taphonomic tumbling barrel- a methodological review to understand preservational biases in the fossil record. In: FIRST INTERNATIONAL PALEONTOLOGICAL CONGRESS, Sydney, 1., 2002. Abstracts. Sydney, p.285-286.

TORELLO, F.F.; SIMÖES, M.G.; PASSOS, J.R.S. (2002b) Bivalve shell resistance to abrasion tested in a taphonomic tumbling barrel. In: REUNIÃO ANUAL DA SOCIEDADE BRASILEIRA DE PALEONTOLOGIA, PALEO2002, São Paulo, 2002. Boletim de Resumos. Såo Paulo, p.21.

TORELLO, F.F.; SIMOEES, M.G.; PASSOS, J.R.S. (2001) The taphonomic tumbling barrel: design, construction and applications. In: CONGRESSO BRASLEIRO DE PALEONTOLOGIA, 17., Rio Branco, 2001. Boletim de Resumos. Rio Branco, p. 32.

TORELLO, F.F.; SIMÕES, M.G.; PASSOS, J.R.S. (2000) Taphonomic tumbling: destroying shells to understand the nature of fossil record. In: REUNIÄO ANUAL DA SOCIEDADE BRASILEIRA DE PALEONTOLOGIA, PALEO2000, Botucatu, 2000. Boletim de Resumos. Botucatu, p.23.

TRAUTINAAN, T.A.; ELLIOTT, D.H. (1976) Sedimentology and petrology of Lower Tentiary deltaic sediments of Seymour Island, Antarctic Peninsula. Geological Society of America, Abstracts and Programs, v. $8, n$. 6, p. 1144-1145.

TRUEMAN, J. (1996) Permutations tests and outgroups. Cladistics, v. 12, n. 3, p. 253-261.

TURCQ, B.; COE, R.; FROIDECOND, J.M. (1986) Variability of beach ridges on the coast of Marica (Rio de Janeiro Brazil). Quaternary of South America and Antarctic Peninsula, v. 14, p. 45-57.

UliANA, M.A.; BIDOLE, K.T. (1988) Mesozoic-Cenozoic paleogeographic and geodynemic evolution of southern South America. Revista Brasileira de Geociências, v. 18, n. 2, p. 172-190. 
VALENTINE, J.W.; JABLONSKi, D. (1983) Speciation in the shallow sea: general patterns and biogeographic controls. In: SIMS, R.W.; PRICE, J.H.; WHALLEY, P.E.S. Evolution, Time, and Space: the emergence of the Biosphere. Academic Press, London, p. 201-226.

VELLA, P.; KENNETT, J.P. (1975) Molluscan fossils and late Neogene paleotemperatures. New Zealand Journal of Geology and Geophysics, Letters to the Editor, v. 18, n. 1, p. 197-198.

VERMEIJ, G.J. (1978) Biogeography and adaptation. Harvard University Press, Cambridge, p. 1-331.

VERMEIJ, G.J. (1987) Evolution and Escalation. Princeton University Press, Princeton, p. 1.526.

VERMEIJ, G.J. (1989) Interoceanic differences in adaptation: effects of history and productivity. Marine Ecology Prograss Series, 57, p. 293-305.

VERMEIJ, G.J. (1990) Tropical Pacific pelecypods and productivity: a hypothesis. Bulletin of Marine Science, $v$. 47, p. 62.67.

VERMEIJ, G.J. (1993) The biological history of a seaway. Science, v. 260, p. 1603-1604.

VERMEIJ, G.J. (1996) Marine biological diversity: muricid gastropods as a case study. In: JABLONSKI, D.; ERWIN, D.H.; LIPPS, J.H. Evolutionary Paleobiology. University of Chicago Press, Chicago, p.355-375.

Vulwock, JA. (1984) Geology of the coastal province of Rio Grande do Sul, Southern Brazil. A synthesis, Pesquisas, n. 16, p. 5-49.

VILLWock, J.A.; MARTINS, L.R. (1972) Depósitos lamíticos de pós-praia, Cassino, RS. Pesquisas, v. 1, p. 68-85. VILLWOCK, J.A.; TOMAZELL, J.L. (1995) Geologia costeira do Rio Grande do Sul. Notas Técnicas, v. 8, p. 1-45. VILLWOCK, J.A.; TOMAZELLI, L.J.; LOSS, E.L.; DEHNHARDT, E.A.; HORN FILHO, N.O.; BACHI, F.A.; DEHNHARDT, B.A. (1986) Geology of the Rio Grande do Sul coastal province. In: RABASSA, J. Quaternary of South America and Antarctic Peninsula, v. 4, p. 79-97.

VOLKHEIMER, W. (1971) Aspectos pateoclimatológicos del Terciário Argentino. Revista del Museo Argentino de Ciencias Naturales "Bernardino Rivadavia", Paleontologia, v. 1, n. 8, p. 243-262.

VöRös, A. (1977) Provinciality of the Mediterranean lower Jurassic brachiopod fauna: causes and plate-tectonic implications. Palaeogeography, Palaeoclimatology, Palaeoecology, v. 21, p. 1-16.

VÖRÖS, A. (1997) Jurassic brachiopods of Hungary. Faunal changes and paleogeography on the western Tethys (in Hungarian). Studia Naturalia, v. 11, p. 1-110.

WAGNER, G.P. (2001) The Character Concept in Evolutionary Biology. San Diego: Academic Press.

WAGNER, P.J. (2002) Testing phylogenetic hypotheses with stratigraphy and morphology - a comment on Smith (2002). Joumal of Paloontology, v. 76, n. 4, p. 590.593.

WALLER, T.R. (1978) Morphology, morphoclines and a new classification of the Pteriomorphia (Mollusca: Bivalvia). Philosophical Transactions of the Royal Society of London, v. B284, p. 345-365.

WALLER, T.R. (1998) Origin of the Molluscan Class Bivalvia and a phylogeny of major groups. In: JOHNSTON, P.A.; HAGGART, J.W. Bivalves - An Eon of evolution - paleobiological studies honoring Norman D. Newell. Calgary, University of Calgary Press. p. 1-46.

WARNKE, D.A.; ALLEN, C.P.; MULLeR, D.W.; HODELL, D.A.; Bruner, C.A. (1992) Miocene-Pliocene Antarctic glacial evolution: a synthesis of icerrafted debris, stable isotope, and planktonic foraminiferal indicators. In: KENNETT, J.P.; WARNKE, D.A. The Antarctic Paleoenvironment: A perspective on global change. AGU Antarctic Research Series, p. 311-325.

WATROUS, L.E.; Wheeler, Q.D. (1981) The out-group comparison method of character analysis. Systematic Zoology, v. 30, p. 1-11. 
WEBB, P..N. (1991) A review of the Cenozoic stratigraphy and paleontology of Antarctica. In: THOMSON, M.R.A.; CRAME, J.A.; THOMSON, J.W. Geological Evolution of Antarctica. Cambridge University Press, Cambridge, p. 599-607.

WEBB, P.-N. (1993) Evolution of Cenozoic palaeoenvironments. A review of the Cenozoic stratigraphy and paleontology of Antarctica. In: THOMSON, M.R.A.; CRAME, J.A.; THOMSON, J.W. Geological Evolution of Antarctica. Cambridge University Press, Cambridge, p. 599-607.

WEBB, G.R.; LOGAN, A.; NOBLE, J.P.A. (1976) Occurrence and significance of brooded larva in a recent brachiopod, Bay of Fundy, Canada. Journal of Paleontology, v. 50, n. 5, p. 869-871.

WEl, W. (2002) Opening of the Australia-Antarctica Gateway, as dated by nannofossils. Journal of Nannoplankton Research, v.24, n.2, p. 179

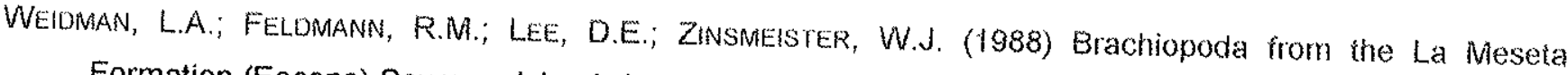
Formation (Eocene) Seymour Island, Antarctica. Memoir of the Geological Society of America, v. 169 $449-457$

WEISSEl, J.K.; HAYES, D.E. (1972) Magnetic anomalies in the southeast Indian Ocean. Antarctic Research Series, v. 19, p. 165-196.

WHEELER, Q.D. (1981a) The out-group comparison method of character analysis. Systematic Zoology, v. 30, p. $1-11$.

WHEELER, Q.D. (1981b) The ins and outs of character analysis: a response to Crisci and Stuessy. Systematic Botany, v. 6, p. 297-306.

WHEELER, W.C. (1990) Nucleic acid sequences phylogeny and random outgroups. Cladistics, v. 6, p. $363=368$

WIENS, J.J. (1998) Does adding characters with missing data increase or decrease phylogenetic accuracy?

Systematic Biology, v. 47, n. 4, p. 625-640.

WIENS, J.J. (2003) Does adding characters with missing data increase or decrease phylogenetic accuracy Systematic Biology, v. 47, n. 4, p. 625-640.

WIENS, J.J.; REEDER, T.W. (1995) Combining data sets with different numbers of taxa for phylogenetic analysis.

Systematic Biology, v. 44, p. 548-558.

WIENS, J.J.; SERVEDIO, M.R. (1998) Phylogenetic analysis and intraspecific variation: performance of parsimony, likelihood, and distance methods. Systematic Biology, v. 47, p. 228-253,

WILEY, E.O. (1981) Phylogenetics. The theory and practice of phylogenetic systematics. New York, John Wiley \& Sons.

WuLIAMS, A. (1956) The calcareous shell of the Brachiopoda and its importance to their classification. Biological Reviews, v. 31 , p. $243-287$.

WhLlAMS, A. (1960) Feeding mechanisms of spire-bearing brachiopods. Geological Magazine, v. 97, p. 514. 516.

WLLLAMS, A.; HARPER, D.A.T. (2000) Order Orthida. In: KAESLER, R.L. Treatise on invertebrate Paleontology.

Part H, Brachiopoda. Kansas, The Geological Society of America and The University of Kansas Press. v. 3, p. 714-846.

WILLIAMS, A.; ROWELL, A.J. (1965) Classification. In: MOORE, R.C. Treatise on Invertebrate Paleontology. Part

$\mathrm{H}$, Brachiopoda. Kansas, The Geological Society of America and The University of Kansas Press. $p$. 214-237.

WILLIAMS, A.; WRIGHT, A.D. (1961) The origin of the loop in articulate brachiopods. Palaeoecology, v. 4, n. 2, p. $149 m 176$ 
Williams, A.; RoWell, A.J.; Muir-Wood, H.M.; Pitrat, C.W.; SChmidt, H.; Stehli, F.G.; Ager, D.V.; Wrigth, A.D.; EllIOTT, G.F.; AMSDEN, T.W.; RUDWICK, M.J.S.; HATAl, K.; BIERNAT, G.; MCLAREN, D.J.; BOUCOT, A.J.; JOHNSON, J.G.; STATON, R.D.; GRANT, R.E.; JOPE, H.M. (1965) Treatise on Invertebrate Paleontology. Part H, Brachiopoda. Kansas, The Geological Society of America and The University of Kansas Press. $927 \mathrm{p}$.

WILliams, A.; CARLSON, S.J.; Brunton, C.H.C.; HOlmer, L.E.; Popov, L.E. (1996) A supra-ordinal classification of the Brachiopoda. Philosophical Transactions of the Royal Society of London, V. B351, p. 1171 . 1193.

WILLIAMS, A.; CARLSON, S.J.; BRUNTON, C.H.C. (1997a) Subphylum Linguliformea. In: KAEStER, R.L. Treatise on invertebrate Paleontology. Part H, Brachiopoda. Kansas, The Geological Society of America and The University of Kansas Press. v. 3, p. 30-157.

WILLIAMS, A.; HARPER, D.A.T.; GRANT, R.E. (1997b) Suborder Lyttoniidena. In: KAESLER, R.L. Treatise on Irvertebrate Paleontology. Part $H$, Brachiopoda. Kansas, The Geological Society of America and The University of Kansas Press. v. 3, p. 619-641.

Williams, A.; James, M.A.; Emig, C.C.; Mackay, S.; RHOdes, M.C.; COHEN, B.L.; GaWthrop, A.B.; PeCK, L.S.; CURRY, G.B.; ANSElL, A.D.; CUSACK, M. WALTON, D.; BRUNTON, C.H.C.; MACKINNON, D.l; RICHARDSON, J.R. (1997C) Treatise on Invertebrate Paleontology. Part H, Brachiopoda. Kansas, The Geological Society of America and The University of Kansas Press. v.1, 539p.

WILLIAMS, A.; CARLSON, S.J.; BRUNTON, C.H.C. (2000a) Brachiopod Classification. In: KAESLER, R.L. Treatise on Invertebrate Paleontology. Part $H$, Brachiopoda. Kansas, The Geological Society of America and The University of Kansas Press. v. 2, p. 1-27.

Williams, A.; Carlson, S.J.; Brunton, C.H.C.; Holmer, L.e; Popov. L.E.; Mergl, M.; Laurie, J.R.; Basset, M.G.; COCKS, L.R.M.; JIA-YU, R.; LAZAREV, S.S.; GRANT, R.E.; RACHEBOEUF, P.R.; YU-GaN, J.; WARDLAW, B.R.; HARPER, D.A.T.; WRIGHT, A.D.; RUBEL, M. (2000b) Treatise on inveriebrate Paleontology. Pari H, Brachiopoda. Kansas, The Geological Society of America and The University of Kansas Press. V.2, 423p.

WiLLS, M.A. (1998) Congruence between phylogeny and stratigraphy: randomization testes and the gap excess ratio. Systematic Bjology, v. 48, n. 3, p. 559-580.

WILSON, M.V.H. (1992) importance for phylogeny of single and multiple stem-group fossil species with example from freshwater fishes. Systematic Biology, v. 41, p. 462-470.

WING, S.L.; GINGERICH, P.D.; SCHMITZ, B.; THOMAS, E. (2003) Causes and consequences of globally warm climates in the early Paleogene. The Geological Society of America Special Paper, p. 1-9.

WOLFE, J. (1971) Tertiary climatic fluctuations and methods of analysis of Tertiary floras. Palaeogeography, Palaeoclimatology, Palaeoecology, v. 9, p. 27-57

WOOD, A.M.; RAMOS, M.I.F.; WHATLEY, R.C. (1999) The palaeozoogeography of Oligocene to Recent marine Ostracoda from the Neotropics (mid- and South America) and Antarctica. Marine Micropaleontology, $v$. 37, p. 345-364.

WRENN, J.H.; HART, G.F. (1988) Paleogene dinoflagellate cyst biostratigraphy of Seymour island, Antarctica. Geological Society of America, Memoir, v. 169, p. 321444.

YOUNG, G.C. (1995) Application of cladistics to terrane history - parsimony analysis of qualitative geological data. Journal of Southeast Asian Earth Sciences, v. 11, n. 3, p. 167-176.

YRIGOYEN, M. (1969) Problemas estratigráficos Del Terciário de Argentina. Ameghiniana, v. 6, p. 315-329. 
ZABERT, L.L.; HERBST, R. (1977) Revision de la microfauna Miocenica de la Formacion Parana (entre Victoria y Villa Urquiza - Provincia de Entre Rios - Argentina), com algunas consideraciones estratigraficas FACENA Corrientes Argentina, v. 1, p. 131-174.

ZACHOS, J.C.; BERGREEN, W.A.; AUBRY, M.P.; MACKENSEN, A. (1992) Isotope and trace element geochemistry of Eocene and Oligocene foraminifers from site 748. Kerguelen Plateau. Proceedings of the ODP, Scientific Results, p. 839-854

ZACHOS, J.C.; STOTT, L.D.; LOHMANN, K.C. (1994) Evolution of early Cenozoic marine kemperatures. Paleoceanography, v. 9, p. 353-387.

ZACHOS, J.C.; QUINN, T.M.; SALAMY, K.A. (1996) High-resolution (104 years) deep-sea foraminiferal stable isotope records of the Eocene-Oligocene climate transition. Paleoceanography, $v .11, p .251-266$.

ZACHOS, J.C.; PAGAN, M.; SLOAN, L.; THOMAS, E.; BILLuPS, K. (2001) Trends, mythms, and aberrations in global climate $65 \mathrm{Ma}$ to present. Science, v. 292, p. 686-693.

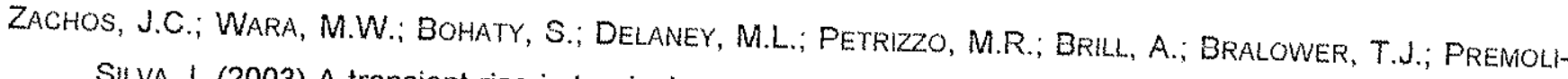
SiLVA, I. (2003) A transient rise in tropical sea surface temperature during the Paleocene-Eocene thermal maximum. Science, $v$. 302, n. 5650, p. 1551-1554

ZELTZER, F. (1976) Geologia e Paleogeografia da restinga da Laguna dos Patos, RS. Porto Alegre, 117p. (Dissertação de Mestrado) - Curso de Pós-graduação em Geociências, Universidade Federal do Rio Grande do Sul.

ZEZINA, O.N. (1970) Brachiopod distribution in the Recent ocean with Reference to problems of Zoogeographic zoning. Paleontological Journal, v. 2, p. 147-158.

ZEZINA, O.N. (1975) Deep-sea brachiopods from the southeast Pacific and Scotia. Trudy Instituta Okeanologii, v. 103, p. 247-258.

ZEZINA, O.N. (1979) On the formation of recent brachiopod fauna on the shelves and slopes of the World Ocean. Byulteten Moskovskogo Obshchestva Ispytateiey Prirody, Novaya Seriya, Otdel Biologicheskiy, v. 84, p. 52-59.

ZEZINA, O.N. (1980) On the composition, distribution, and some biological features of cold water brachiopods in the Southern Hemisphere. In: KUZNETSOV, A.P. Ekologicheskiye issledovaniya shel'fa. P.P. Shirshov Institute of Oceanology. p. 9-35.

ZEZINA, O.N. (1985) Recent brachiopods and some problems of the bathyal oceans. Moscow, Nauka. 247p. ZEZINA, O.N. (2003) On the Ecological, Morphological, and Evolutionary Features of Brachiopods living in Marginal and Extreme Environments. Paleontological Journal, v. 37, n. 3, p. 263-269.

ZINSMEISTER, W.J. (1977) Note on a new occurrence of the southern hemisphere aporrhaid gastropod Struthioptera Finlay and Marwick on Seymour island, Antarctica. Journal of Paleontology, v. $51, n, 2, p$. 399-404.

ZINSMEISTER, W.J. (1982) Late Cretaceous-Early Tertiary molluscan biogeography of the southern circumPacific. Journal of Paleontology, v. 56, n. 1, p. 84-102.

ZINMEISTER, W.; CAMACHO, H.H. (1978) La fauna de moluscos de la Formación La Mieseta (Eoceno superior hasta posiblemente Oligoceno inferior) Isla Vicecomodoro Marambío, Península Antártica. In: CONGRESO ARGENTINO DE PALEONTOLOGIA $\gamma$ BIOESTRATIGRAFIA, 2, $Y$ CONGRESO LATINOAMERICANO DE PALEONTOLOGIA, 1. Resumenes.

ZUCOL, A.F.; BREA, M. (2000) Análisis fitolítico de la Formación Paraná em la Província de Entre Rios. INSUGEO, Serie Correlacion Geológica, v. 14, p. 67-76. 


\section{ESTAMPAS}




\section{ESTAMPAS}

\section{Explicacão para as estampas:}

- indicação entre parênteses, após nome do táxon, refere-se à fonte original das ilustrações, seja ela coleção científica ou artigo científico (e.g., HLLLER \& MACKINNON, 2000);

- DZP-IBB/UNESP = Coleção Científica de Braquiópodes Cenozóicos do Instituto de Biociências, UNESP - Botucatu;

- MACN= Coleção Científica do Museo Argentino de Ciências Naturales, Buenos Aires, Argentina;

- $\mathrm{OU}=$ Coleção Científica da Ontago University, Nova Zelândia;

- SAM= Coleção Cientifica do Southern Australian Museum

- a escala gráfica utilizada (barras) corresponde a 0,5 cm; 


\section{ESTAMPA 1}

\section{A-F: Bouchardia rosea}

Detalhes da morfologia interna de conchas de Bouchardia rosea em diferentes estágios de desenvolvimento ontogenético, com especial interesse nas estruturas da cardinália, através de microscopia eletrônica de varredura. Importante notar a completa ausência de crura ou bases crurais ao longo do desenvolvimento. A- estágio inicial de desenvolvimento da cardinália, com vestígios dos sulcos característicos; B- detalhe do mesmo espécime de A, com destaque para o surgimento do sulco em forma de ' $V$ ' (seta); $C$ - estágio um pouco mais avançado de desenvolvimento evidenciando melhor o sulco e a cardinália livre de crura (seta); D- detalhe da cardinália de $\mathrm{C}$, com destaque para o desenvolvimento do sulco; $\mathrm{E}$ - estágio ontogenético mais avançado, onde as setas apontam o septo mediano, braquídio, do sulco na cardinália já desenvolvidos e a ausência de crura; F- detalhe do septo mediano, braquídio e região anterior de individuo adulto de Bouchardia rosea. 


\section{ESTAMPA 1}
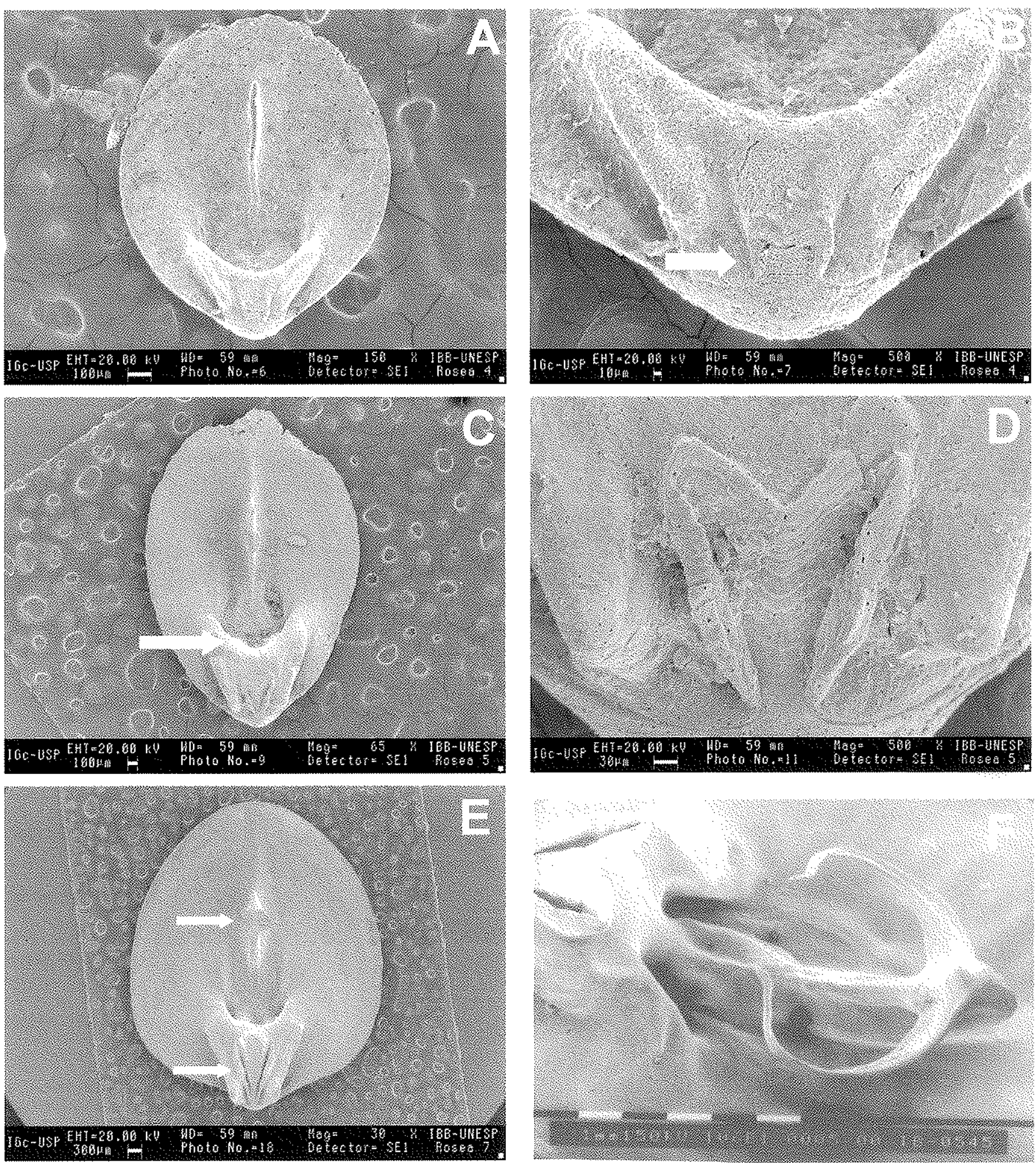


\section{ESTAMPA 2}

\section{A.F: Bouchardia rosea}

$A$ : vista externa da valva ventral (DZP-IBB/UNESP); $B$ : vista interna da valva ventral (DZP-IBB/UNESP); $C$ : vista interna da valva dorsal com destaque para cardinália e braquidio (DZP-IBB/UNESP); D: detalhe da região posterior da valva ventral, com destaque para a posição do pedículo (DZP-IBB/UNESP); $E$ : detalhe do processo cardinal com sulco em forma de " $V$ " invertido (DZP-IBB/UNESP); F; detalhe do processo cardinal com os músculos didutores, ressecados, ainda posicionados nos sulcos em forma de " $V$ " (DZP. IBB/UNESP).

G-J: Bouchardia antarctica

G: vista externa da valva ventral (MANCEÑIDO \& GRIFFIN, 1988); H: vista interna da valva ventral (MANCENIDO \& GRIFFIN, 1988); I: vistá externa da valva dorsal; J: vista interna da valva dorsal (MANCEÑIDO \& GRIFFIN, 1988).

L-P: Bouchardia transplatina

L: vista anterior de espécime articulado fechado (MACN 45); $\mathrm{M}$ : vista externa da valva ventral (MACN 4949); $\mathrm{N}$ : vista interna da valva ventral (MACN 45); O: vista externa da valva dorsal (MACN 4949); P: vista interna da valva dorsal (MACN 45). 


\section{ESTAMPA 2}
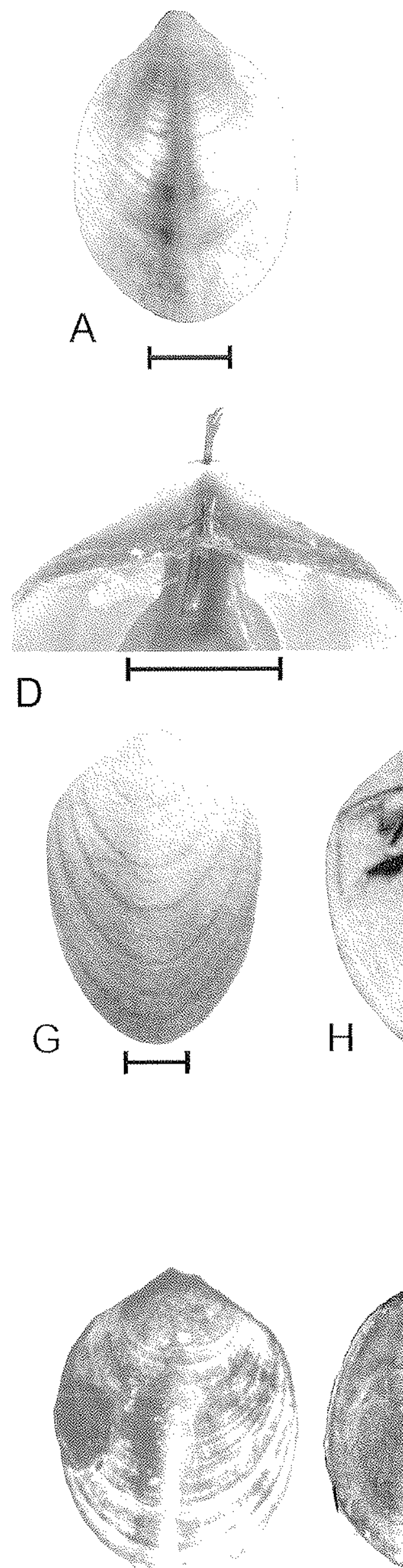

$M \longmapsto$
B
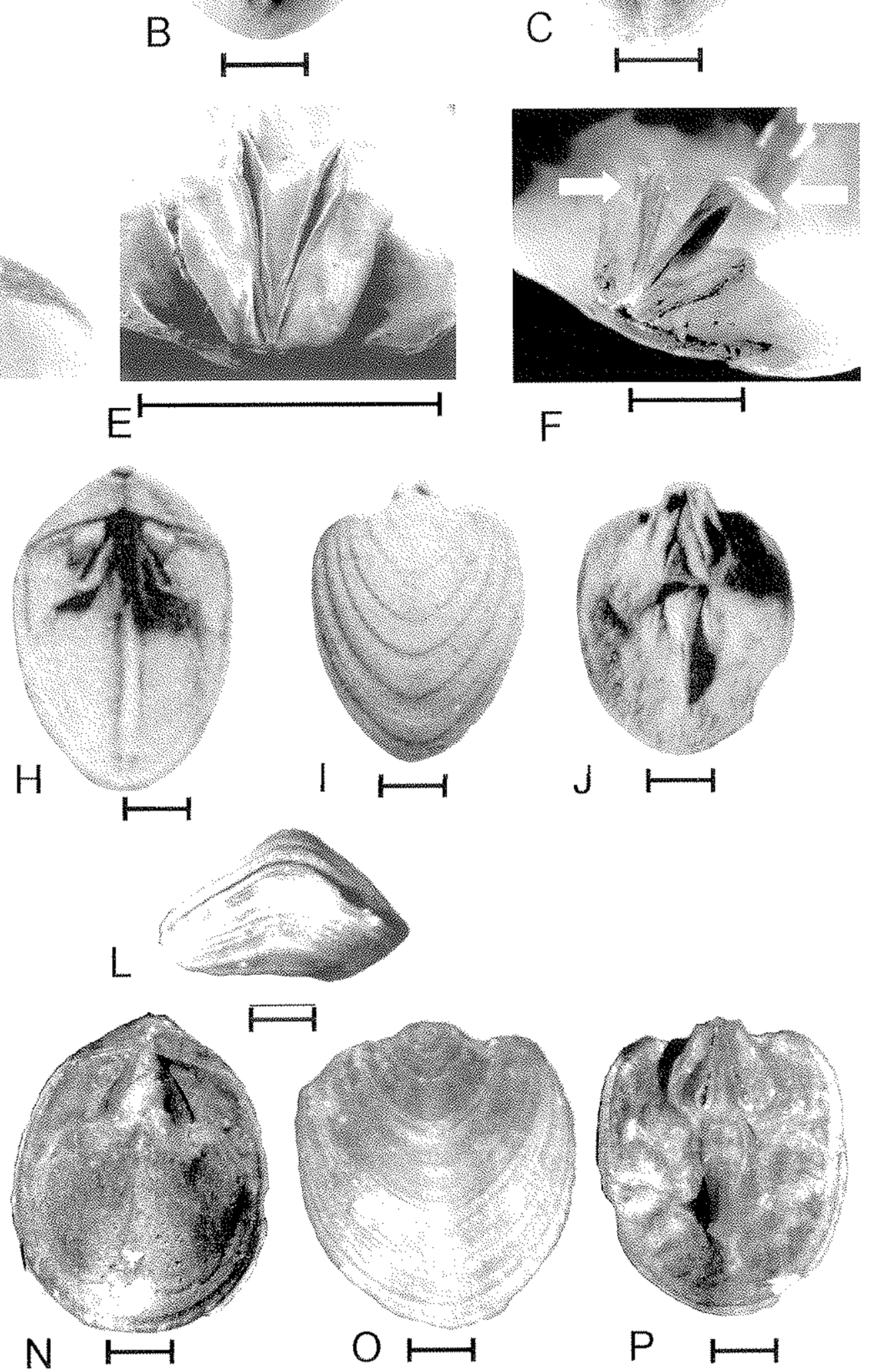


\section{EsTAMPA 3}

A.F: Bouchardia zitteli

A: vista externa da valva ventral (MANCEÑIDO \& GRIFFIN, 1988); B: vista interna da valva ventral (MACN 44); C: vista externa da valva dorsal (MANCEÑIDO \& GRIFFIN, 1988); D: vista interna da valva dorsal (MACN 42); $E$ : detalhe do braquídio incompleto preservado em espécime articulado fechado (MACN 44); F: vista frontal de espécime articulado fechado (MACN 44).

G-H: Bouchardia conspicua

G: vista dorsal de espécime articulado fechado (MANCEÑIDO \& GRIFFIN, 1988); H: vista interna da valva dorsal fragmentada com destaque para elementos da charneira e septo mediano (MACN 2658).

I-J: Bouchardiella patagonica

$L$ : vista externa da valva dorsal (MACN sem numeração) ; $M$ : vista externa da valva ventral (MACN sem numeração).

L-M: Bouchardiella jorgensis

I: vista externa da valva ventral (MACN 4948); J: vista externa da valva dorsal (MACN 4948).

$\mathrm{N}-\mathrm{O}$ : Malleia portlandica

$\mathrm{N}$ : vista interna da valva dorsal (RICHARDSON, 1994); O: vista frontal de espécime articulado fechado (RICHARDSON, 1973). 


\section{ESTAMPA 3}
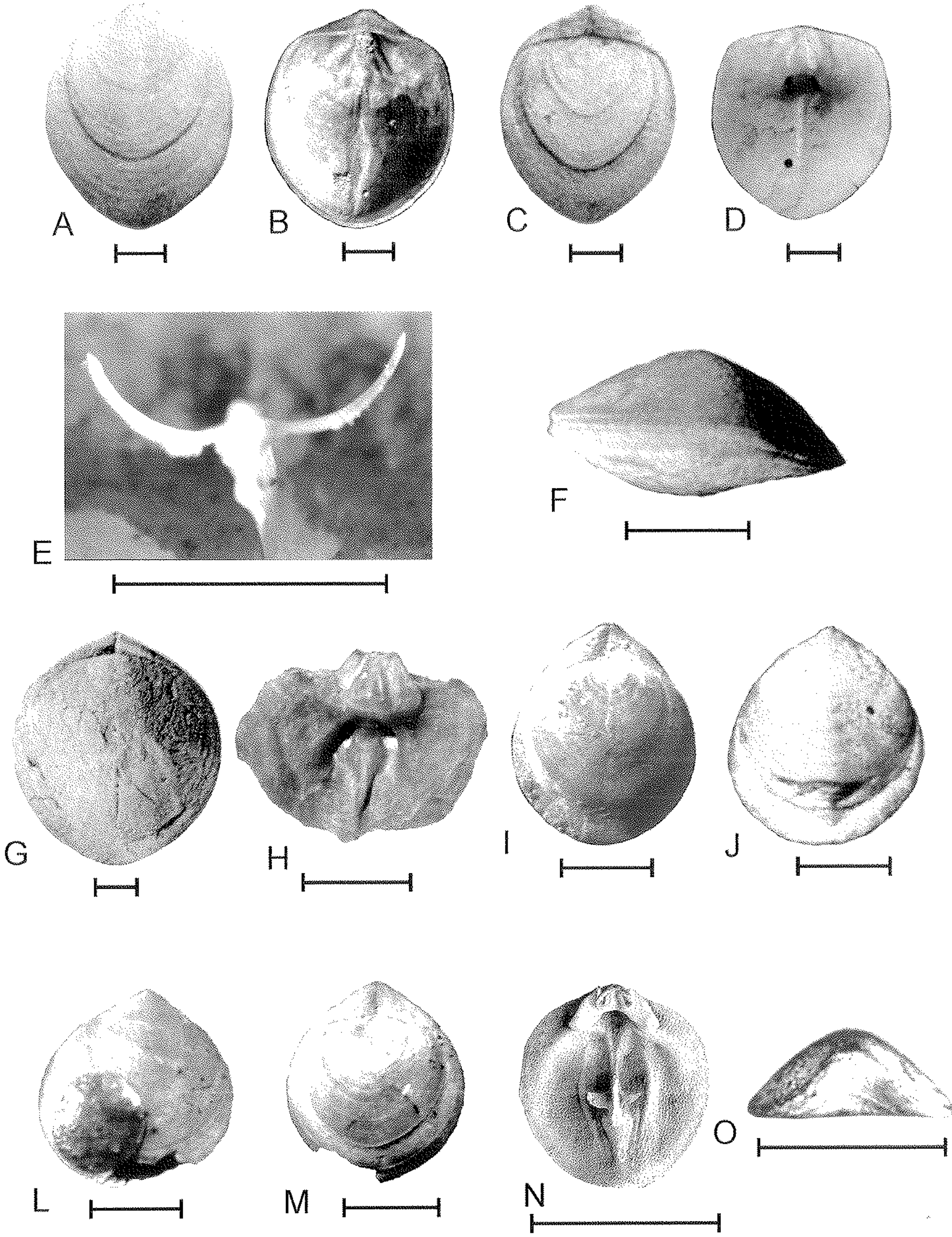


\section{ESTAMPA 4}

A-E: Neobouchardia minima

A: vista externa da valva dorsal (OU-DL98); B: vista externa da valva ventral (OU-DL98); C: vista interna da valva dorsal (MACKINNON, 1987); D: vista interna da valva ventral (MACKINNON, 1987); E: vista externa, lateral, de um espécime articulado fechado (OU-DL98).

F-N: Anakinetica cumingi

F: vista externa, lateral, de um espécime articulado fechado (SAMPL0136); G: vista dorsal de espécime articulado fechado (RICHARDSON, 1987); $\mathrm{H}$ : vista externa da valva ventral (RICHARDSON, 1987); I: vista interna da valva dorsal (RICHARDSON, 1987); J: vista interna da valva ventral (RICHARDSON, 1987); L: vista externa, frontal, de um espécime articulado fechado (SAM-PL0136); M: região posterior da valva ventral com a musculatura e pediculos rebatidos, e destaque para a posição dos dentes, na porção espessada da concha (SAM-PL0136); $\mathrm{N}$ : detalhe da região posterior da valva ventral, com destaque para a posição do pedículo (SAM-PL0136). 


\section{ESTAMPA 4}
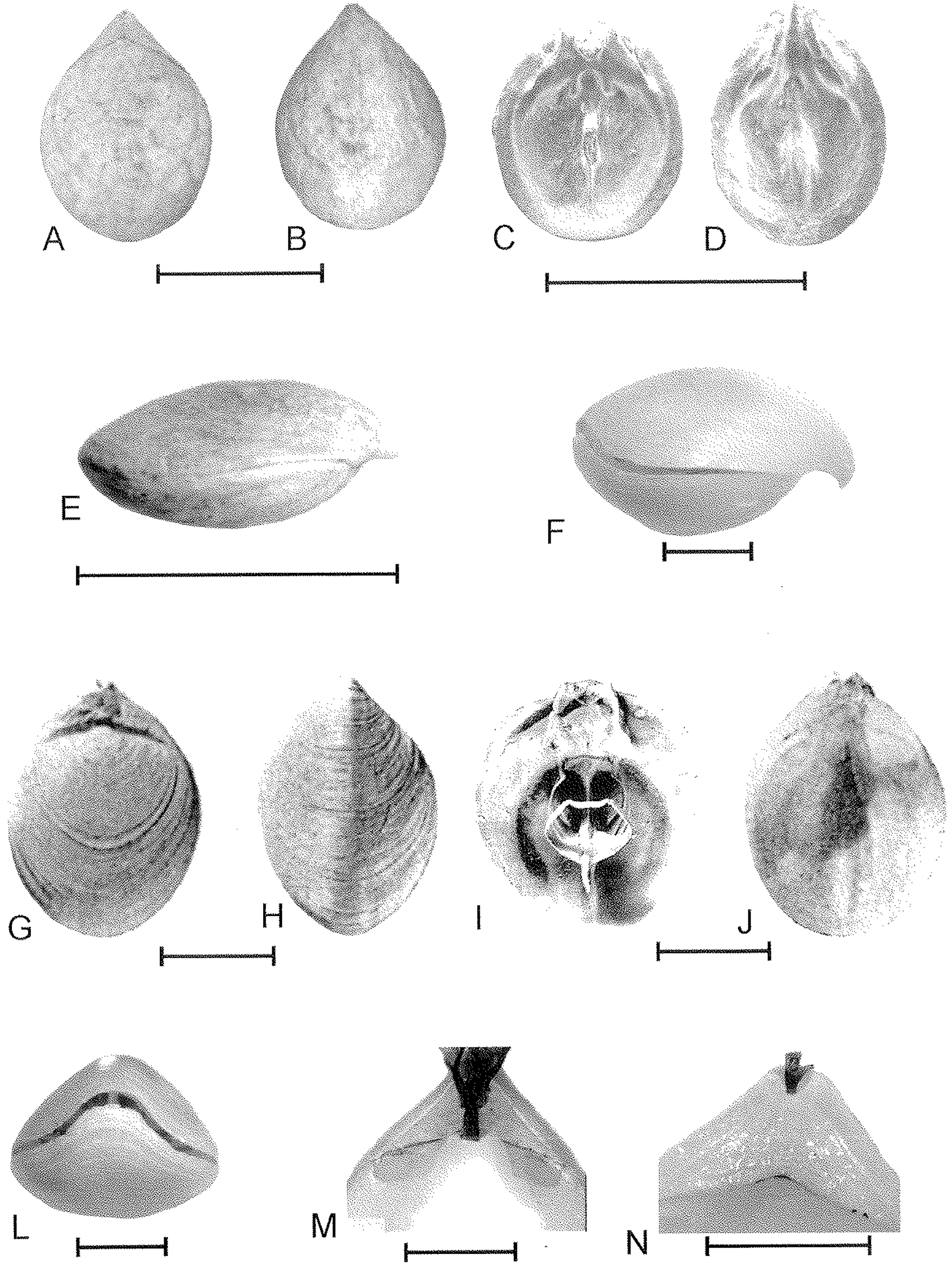


\section{ESTAMPA 5}

\section{A-C: Anakinetica cumingi}

A: vista interna da valva dorsal, com porções das partes moles ainda preservadas, como os músculos didutores (setas) (SAMPL0136); B: vista parcial, interna, da valva dorsal, com destaque para o lofóforo (setas finas) e parte anterior do septo mediano (seta larga) (SAM-PL0136); C: vista parcial, interna, da valva dorsal, com destaque para a união do braquídio com a crura (seta) (SAMPL0136).

D-N: Australiarcula artesiana

D: vista externa da valva ventral (ELLIOTT, 1959); E: vista dorsal de espécime articulado fechado (ELLIOTT, 1959); F: vista externa, lateral, de espécime articulado fechado, parcialmente preservado (SAM-F15280); G: vista externa, frontal de espécime articulado fechado (ELLIOTT, 1959); H: vista externa, posterior, de espécime articulado fechado (SAM-F15280); I: vista dorsal, interna, da valva dorsal, com destaque para a extremidade do septo mediano com parte do braquidio ainda preservado (SAM-F15276); J: vista interna, parcial, da valva dorsal, com destaque para as cavidades (setas) na base da plataforma cardinal (SAM-F15276); L: vista interna, parcial, da valva dorsal, com destaque para o processo cardinal (setas) (SAM-F15276); M: vista interna, parcial, da valva dorsal, com destaque para os vestígios da crura (setas) (SAMF15276); N: vista interna, parcial, da valva dorsal, com destaque para a extremidade anteriormente estendida (seta) do septo mediano (SAM-F15276). 


\section{ESTAMPA 5}

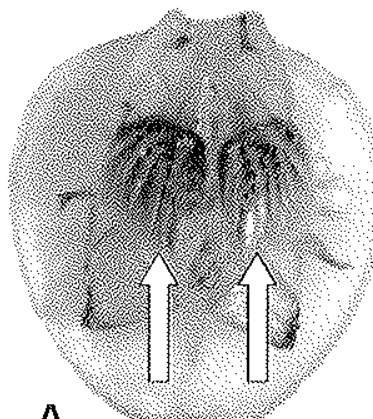

A

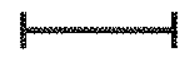

B

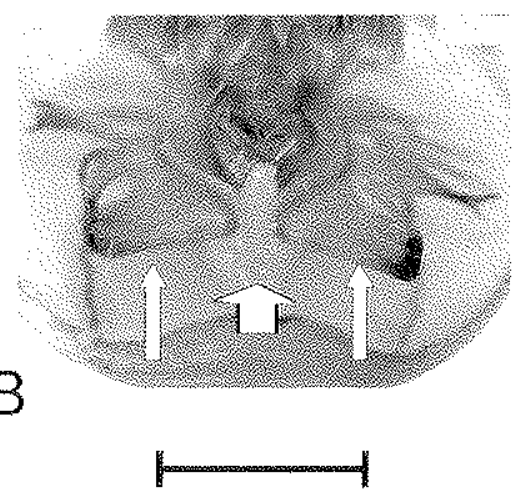

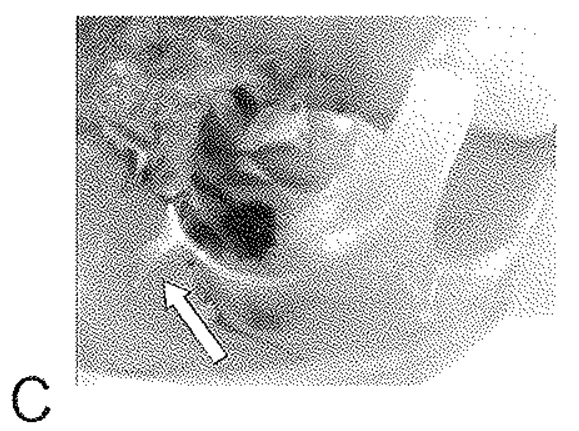

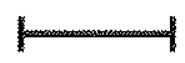

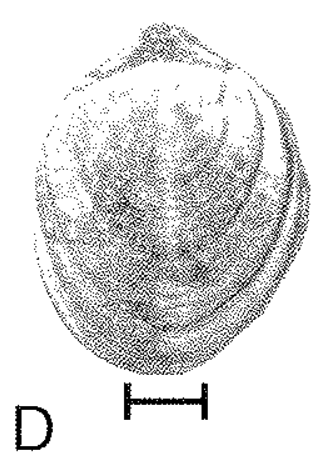
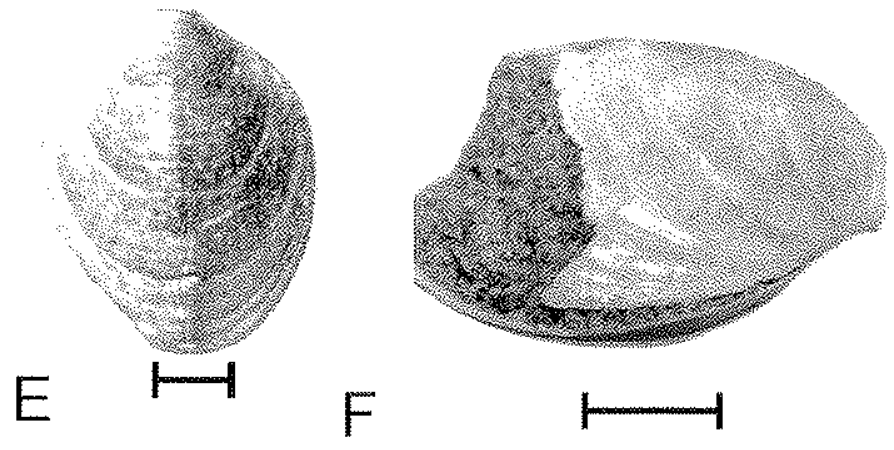

$\mathrm{F}$

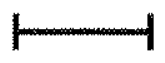

G
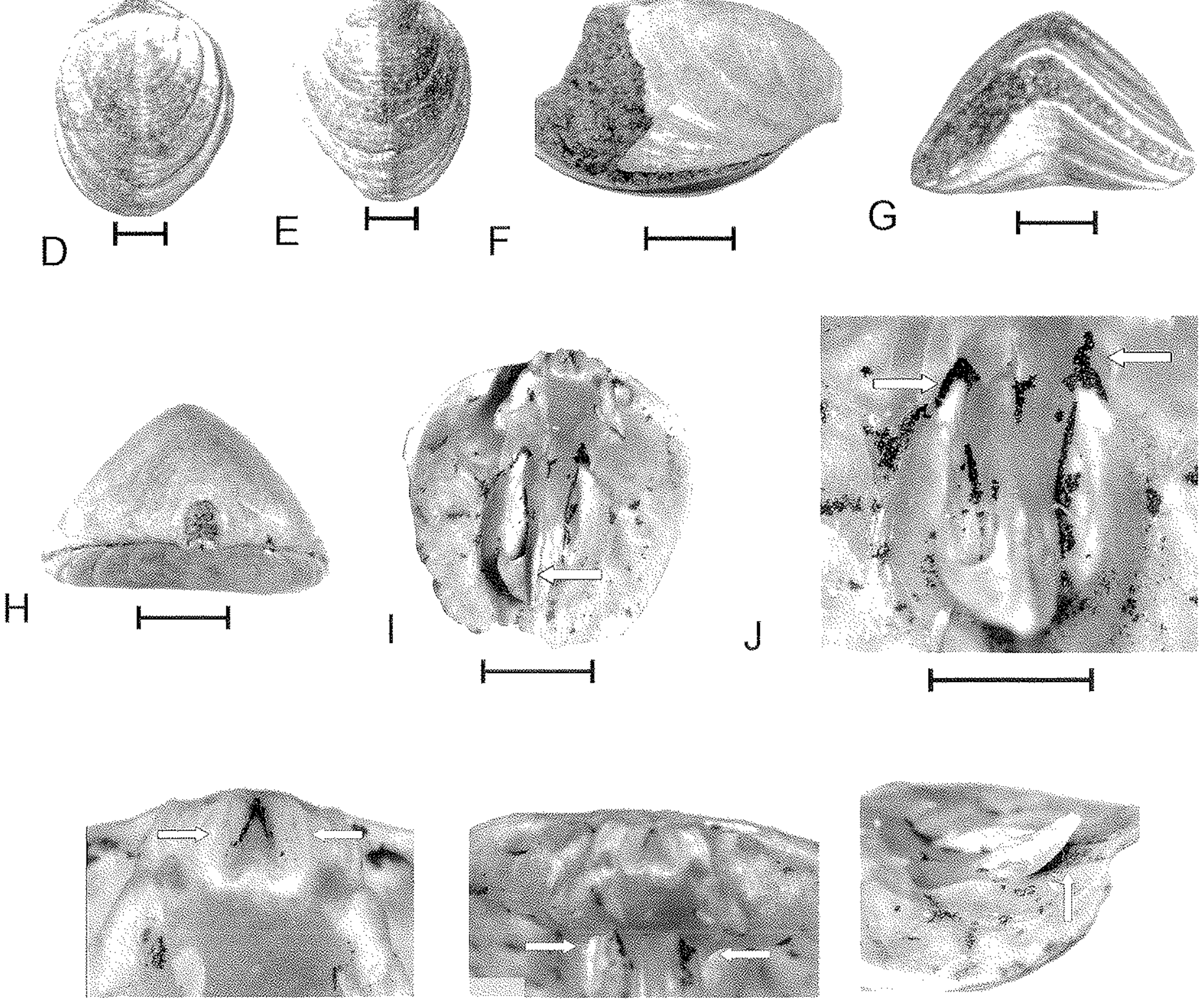

L

M

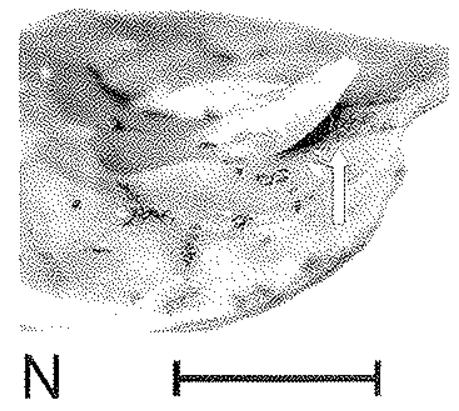




\section{ESTAMPA 6}

\section{A-E: Adnatida deformis}

A: vista frontal de espécime articulado fechado, com destaque para a comissura anterior (RICHARDSON, 1991); B: vista dorsal de espécime articulado fechado (RICHARDSON, 1991); C: vista ventral de espécime articulado fechado (RICHARDSON, 1991); D: vista lateral de espécime articulado fechado deixando ver o comportamento do bico (RICHARDSON, 1991); E: vista interna da valva dorsal em espécime que, apesar do estado de preservação precário, deixa ver aspectos da charneira e do septo mediano (RICHARDSON, 1991).

F-J: Aliquantula insolita

F: Vista da valva dorsal parcialmente preservada deixando ver aspectos da charneira, septo mediano e cicatrizes musculares (RICHARDSON, 1991); G: vista frontal de espécime articulado fechado, com concha parcialmente destruída na região anterior (RICHARDSON, 1991); $\mathrm{H}$ : vista dorsal de espécime articulado fechado (RICHARDSON, 1991); I: vista lateral de espécime articulado fechado, com valva ventral parcialmente quebrada em sua porção anterior, deixando ver o comportamento do bico (RICHARDSON, 1991); J: vista interna da valva ventral parcialmente quebrada, deixando ver aspectos do bico, placas deltidiais, dentição e cicatrizes musculares (RICHARDSON, 1991).

\section{L-P: Elderra toorlooensis}

$L$ : vista interna da valva dorsal, parcialmente fragmentada na região anterior, deixando ver aspectos da charneira, septo mediano e cicatrizes musculares (RICHARDSON, 1991); $M$ : vista ventral de espécime articulado fechado (RICHARDSON, 1991); N: vista dorsal de espécime articulado fechado (RICHARDSON, 1991); O: vista frontal de espécime articulado fechado com especial atenção para a comissura anterior (RICHARDSON, 1991); P: vista lateral de espécime articulado fechado deixando ver o comportamento do bico (RICHARDSON, 1991).

\section{Q-T: Magadina lunata}

Q: vista dorsal de espécime articulado fechado (RICHARDSON, 1991); R: vista ventral de espécime articulado fechado (RICHARDSON, 1991); S: vista lateral de espécime articulado fechado deixando ver o comportamento do bico (RICHARDSON, 1991); T: vista interna da valva dorsal, parciaimente fragmentada na região anterior, deixando ver, apesar do estado de preservação precário, aspectos da charneira e septo mediano (RICHARDSON, 1991). 


\section{ESTAMPA 6}
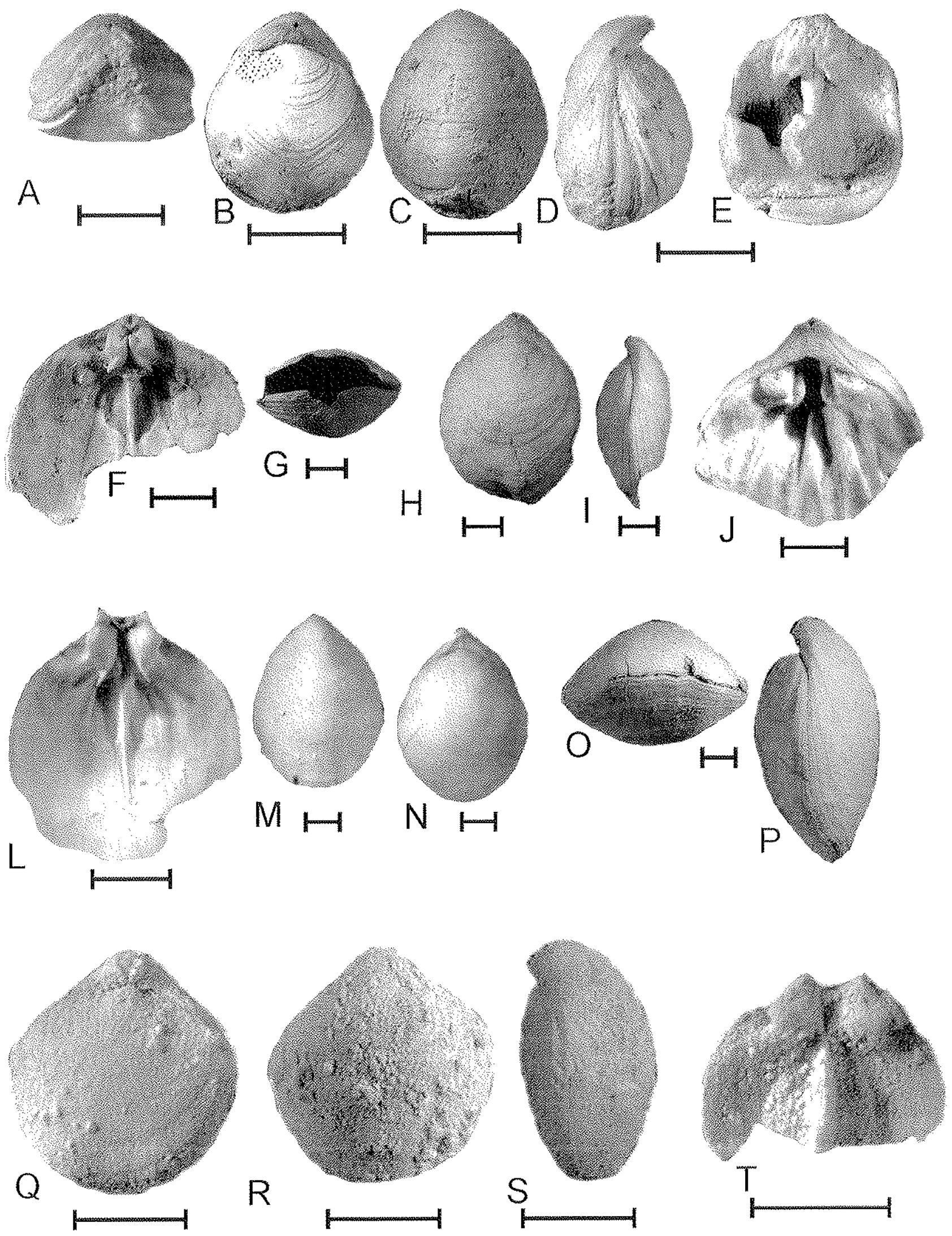


\section{ESTAMPA 7}

A-E: Magadinella woodsiana

A: vista interna da valva dorsal deixando ver aspectos da charneira, septo mediano e cicatrizes musculares (RICHARDSON, 1991); B: vista dorsal de espécime articulado fechado (RICHARDSON, 1991); C: vista lateral de espécime articulado fechado deixando ver o comportamento do bico (RICHARDSON, 1991); D: vista frontal de espécime articulado fechado com destaque para a comissura anterior (RICHARDSON, 1991); E: vista interna de valva ventral deixando ver aspectos das placas deltidiais, dentição e assoalho da valva (RICHARDSON, 1991);

F-l: Pilkena compressa

F: vista parcial interna da região posterior de uma valva ventral deixando ver as placas deltidiais e a dentição (HILLER \& MACKINNON, 2000); G: vista interna de uma valva dorsal parcialmente fragmentada, deixando ver aspectos da charneira $e$ do septo mediano (RICHARDSON, 1991); H: vista dorsal de espécime articulado fechado (RICHARDSON, 1991); l: vista lateral de espécime articulado fechado deixando ver o comportamento do bico (RICHARDSON, 1991).

$\mathrm{J}$ : Rhizothyris kokoamuensis

$\mathrm{J}$ : vista parcial interna de valva dorsal fragmentada, deixando ver aspectos da charneira e do septo mediano (HILLER \& MACKINNON, 2000).

L-M: Rhizothyris labiata

L: vista dorsal de espécime articulado fechado (HILLER \& MACKINNON, 2000); M: vista lateral de espécime articulado fechado deixando ver o comportamento do bico (HILLER \& MACKINNON, 2000). 


\section{ESTAMPA 7}
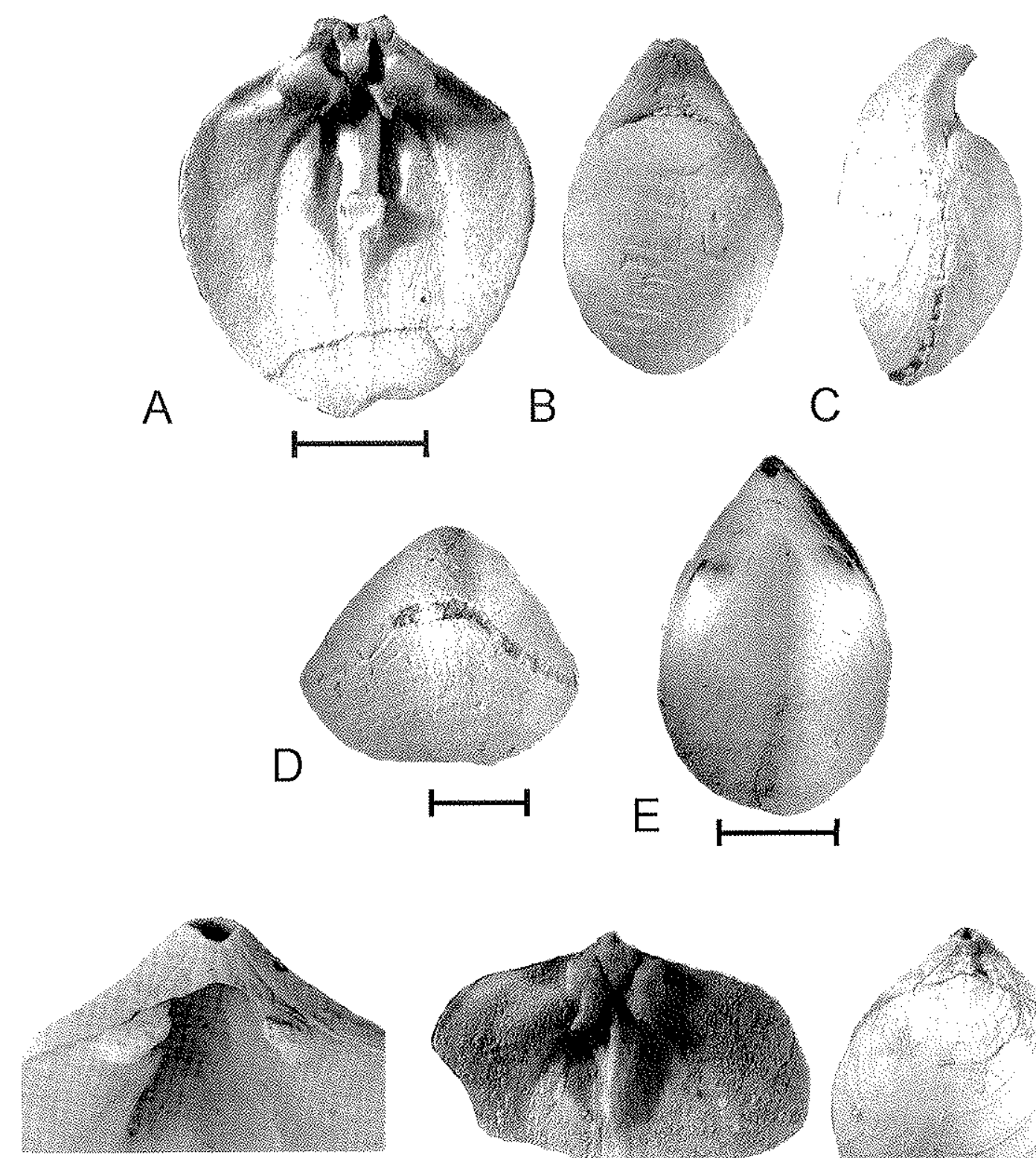

$\mathrm{F}$
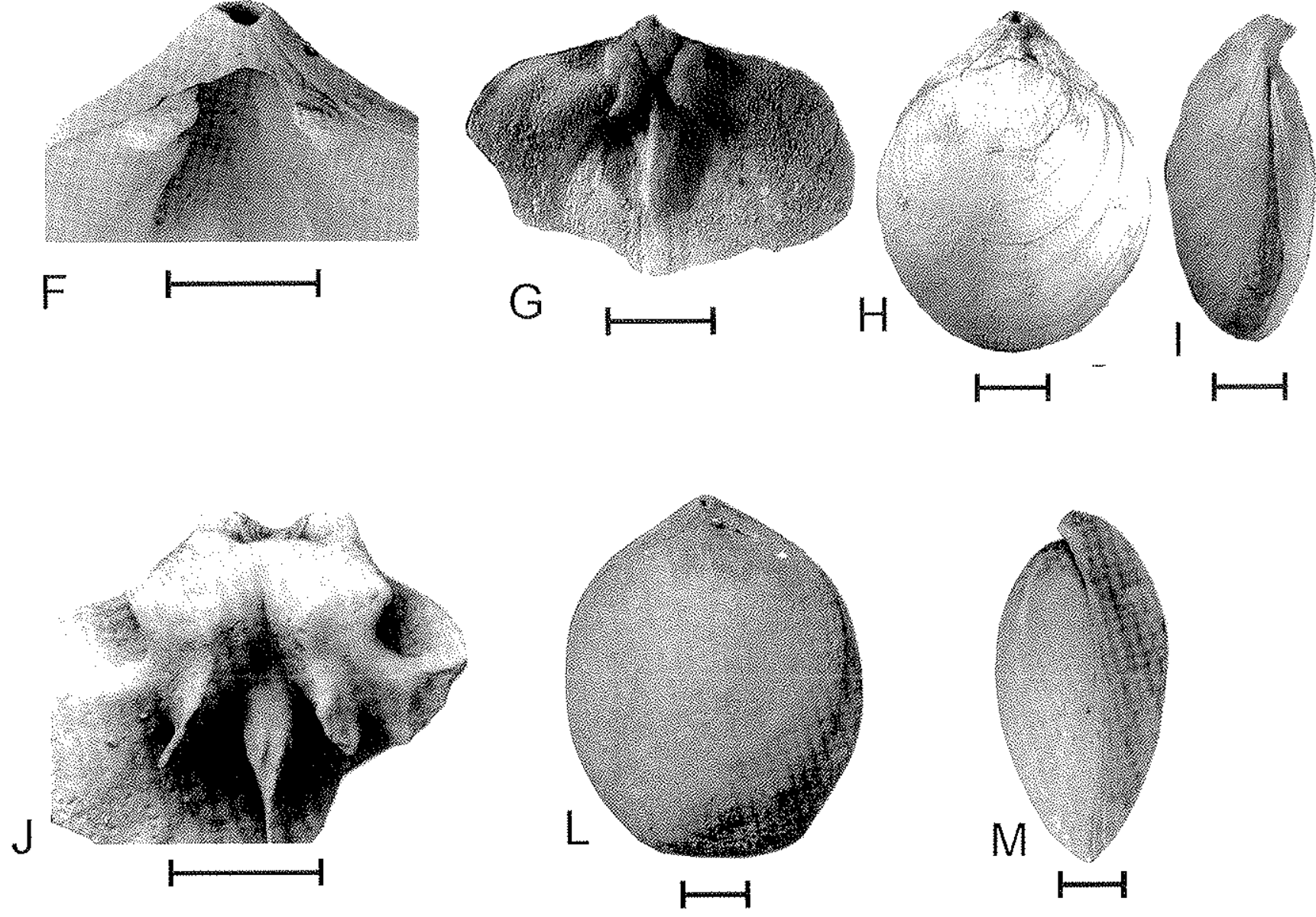